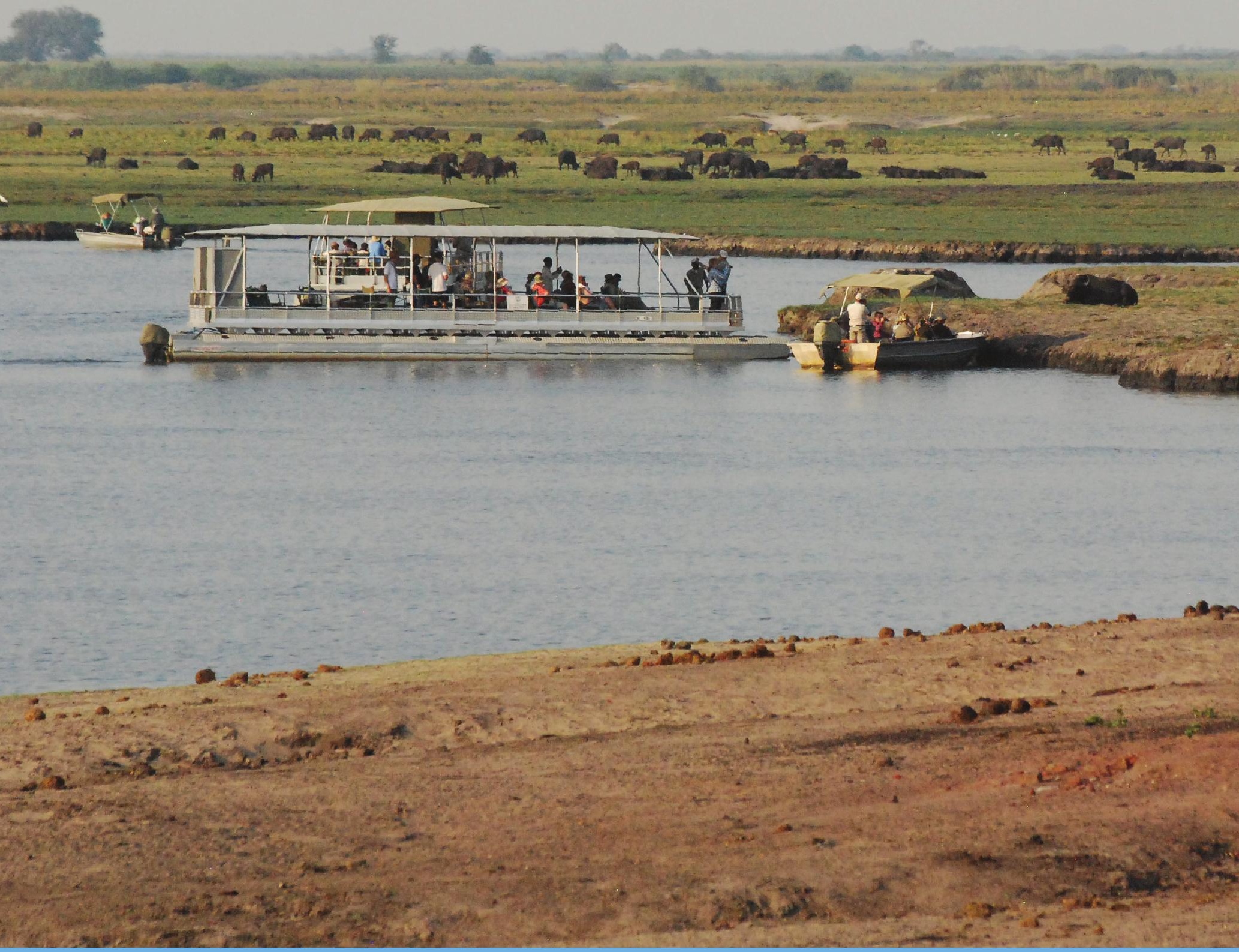

\title{
Chobe District Integrated Land Use Plan
}

Theo van der Sluis, Lin Cassidy, Chris Brooks, Piotr Wolski, Cornelis VanderPost, Piet Wit, Rene Henkens, Michiel van Eupen, Keta Mosepele, Oggie Maruapula, Elmar Veenendaal 



\section{Chobe District Integrated Land Use Plan}

Theo van der Sluis ${ }^{1}$, Lin Cassidy ${ }^{2}$, Chris Brooks ${ }^{2}$, Piotr Wolski ${ }^{2}$, Cornelis VanderPost ${ }^{2}$, Piet Wit ${ }^{2}$, Rene Henkens ${ }^{1}$, Michiel van Eupen ${ }^{1}$, Keta Mosepele ${ }^{4}$, Oggie Maruapula ${ }^{2}$, Elmar Veenendaal ${ }^{3}$

${ }^{1}$ Wageningen Environmental Research (Alterra)

${ }^{2}$ Independent consultant

${ }^{3}$ Wageningen University \& Research

${ }^{4} \mathrm{ORI}$

This research is funded by UNDP, Contract nr. PR005/2016.

Wageningen Environmental Research

Wageningen, July 2017

Report 2813

ISSN 1566-7197 
Theo van der Sluis, Lin Cassidy, Chris Brooks, Piotr Wolski, Cornelis VanderPost, Piet Wit, Rene Henkens, Michiel van Eupen, Keta Mosepele, Oggie Maruapula, Elmar Veenendaal, 2017. Chobe District Integrated Land Use Plan. Wageningen, Wageningen Environmental Research, Report 2813. 182 pp.; 70 fig.; 22 tab.; 275 ref.

Keywords: Sustainable Land Use, Planning, CBNRM, Human-Wildlife Conflict, Tourism, Savanna Ecosystems, Sociology, Zambezi

The pdf file is free of charge and can be downloaded at https://doi.org/10.18174/419817 or via the website www.wur.nl/environmental-research (scroll down to Publications - Wageningen Environmental Research reports). Wageningen Environmental Research does not deliver printed versions of the Wageningen Environmental Research reports.

All maps prepared by WEnR are digitally available in High Resolution at the following site: https: //doi.org/10.18174/420002

Most literature sources ('grey' literature') are accessible at the library website:

https: //library.wur.nl/ojs/index.php/Botswana_documents/index

(C) 2017 Wageningen Environmental Research (an institute under the auspices of the Stichting Wageningen Research), P.O. Box 47, 6700 AA Wageningen, The Netherlands,

T +31 (0) 3174807 00, E info.alterra@wur.nl, www.wur.nl/environmental-research. Wageningen Environmental Research is part of Wageningen University \& Research.

- Acquisition, duplication and transmission of this publication is permitted with clear acknowledgement of the source.

- Acquisition, duplication and transmission is not permitted for commercial purposes and/or monetary gain.

- Acquisition, duplication and transmission is not permitted of any parts of this publication for which the copyrights clearly rest with other parties and/or are reserved.

Wageningen Environmental Research assumes no liability for any losses resulting from the use of the research results or recommendations in this report.

Wageningen Environmental Research Report 2813 | ISSN 1566-7197

Photo cover: Theo van der Sluis;

Other pictures Elmar Veenendaal, Theo van der Sluis, Rene Henkens etc. 


\section{Contents}

$\begin{array}{ll}\text { List of abbreviations } & 7\end{array}$

$\begin{array}{ll}\text { Executive summary } & 9\end{array}$

$\begin{array}{llr}1 & \text { Introduction } & 17\end{array}$

$\begin{array}{lll}1.1 & \text { Aims for ILUP } & 18\end{array}$

1.2 General expectations 18

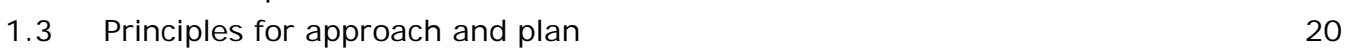

$\begin{array}{lll}1.4 & \text { Approach and methodology } & 22\end{array}$

$\begin{array}{lll}1.5 & \text { Stakeholder Engagement } & 22\end{array}$

1.6 Framework plan, relations with sub-district-plans 23

$\begin{array}{lll}1.7 & \text { Relevant legislation } & 23\end{array}$

$\begin{array}{lll}1.8 & \text { Outline Integrated Land Use Plan } & 24\end{array}$

$\begin{array}{lll}1.9 & \text { Acknowledgements } & 24\end{array}$

$2 \quad$ Land use types and Land Suitability $\quad 25$

$\begin{array}{lll}2.1 & \text { Definition of land use types } & 25\end{array}$

$\begin{array}{lll}2.2 & \text { Suitability for Agriculture } & 27\end{array}$

2.2.1 Arable farming $\quad 27$

2.2.2 Livestock grazing $\quad 29$

$\begin{array}{lll}2.3 & \text { Suitability for Tourism } & 30\end{array}$

2.4 Suitability for Forestry $\quad 32$

$\begin{array}{lll}2.5 & \text { Overall land suitability assessment } & 32\end{array}$

$\begin{array}{lll}2.6 & \text { Key findings } & 33\end{array}$

$3 \quad$ Integrated Land Use Plan $\quad 34$

3.1 Introduction $\quad 34$

3.2 Key findings $\quad 53$

$4 \quad$ Implementation Framework $\quad 54$

4.1 Institutional set-up $\quad 54$

$\begin{array}{lll}4.2 & \text { Review period } & 56\end{array}$

$\begin{array}{lll}4.3 & \text { Community consultations } & 56\end{array}$

$5 \quad$ Chobe District, environment $\quad 57$

$\begin{array}{lll}5.1 & \text { Administrative boundaries Chobe District } & 57\end{array}$

$\begin{array}{lll}5.2 & \text { Soils } & 58\end{array}$

5.3 Climate $\quad 59$

$\begin{array}{lll}5.4 & \text { Water } & 64\end{array}$

$\begin{array}{lll}5.5 & \text { Land Tenure } & 69\end{array}$

$\begin{array}{lll}5.6 & \text { Current plan development in Chobe } & 71\end{array}$

$\begin{array}{lll}5.7 & \text { Key findings } & 72\end{array}$

$6 \quad$ Biodiversity and Conservation $\quad 74$

$\begin{array}{lll}6.1 & \text { Protected areas } & 74\end{array}$

6.2 International context, KAZA region $\quad 75$

6.2.1 The Kavango-Zambezi Transfrontier Conservation Area $\quad 75$

6.2.2 KAZA TFCA Governance $\quad 77$

$\begin{array}{lll}6.3 & \text { International conventions and agreements } & 77\end{array}$

6.3.1 UN conventions $\quad 77$

6.3.2 Non-UN multilateral agreements of special relevance to Chobe District 78 
6.3.3 Agreements on international waters covering Chobe District 79

$\begin{array}{lll}6.4 & \text { Regional Cooperation } & 79\end{array}$

6.5 Ecoregions $\quad 80$

6.6 Forests and vegetation cover $\quad 81$

6.6.1 Historical vegetation cover trends $\quad 81$

6.6.2 Current vegetation types and tree cover $\quad 82$

6.7 Wildlife $\quad 83$

6.7.1 Connected wildlife populations

6.7.2 Diversity and Status of Wildlife in Chobe District 83

$\begin{array}{lll}6.8 & \text { Key findings } & 87\end{array}$

$7 \quad$ Socio-economic conditions $\quad 88$

7.1 Socio-economic conditions and societal needs $\quad 88$

7.1.1 Demographics 88

$\begin{array}{ll}7.1 .2 \text { Education } & 89\end{array}$

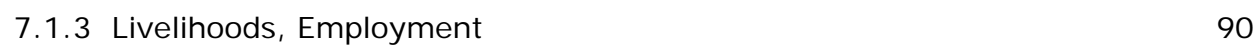

$\begin{array}{ll}7.1 .4 \text { Societal needs } & 93\end{array}$

$\begin{array}{lll}7.2 & \text { Tribal situation } & 94\end{array}$

$\begin{array}{lll}7.3 & \text { Settlements } & 95\end{array}$

$\begin{array}{lll}7.4 & \text { Kasane and Kazungula Township } & 97\end{array}$

$\begin{array}{lll}7.5 & \text { Traditional natural resource use } & 97\end{array}$

$\begin{array}{llr}7.6 & \text { CBOs and CBNRM } & 99\end{array}$

$\begin{array}{llr}7.7 & \text { Poverty } & 100\end{array}$

$\begin{array}{lll}7.8 & \text { Key findings } & 101\end{array}$

8

Land use $\quad 102$

8.1 Agriculture $\quad 102$

8.1.1 Smallholder arable farming $\quad 102$

$\begin{array}{ll}8.1 .2 \text { Livestock } & 103\end{array}$

$\begin{array}{ll}8.1 .3 \text { Irrigated farming } & 104\end{array}$

8.1.4 Commercial farming 104

8.1.5 Horticulture $\quad 104$

$\begin{array}{ll}\text { 8.1.6 Fish farming } & 105\end{array}$

$\begin{array}{lll}8.2 & \text { Forestry } & 105\end{array}$

$\begin{array}{lll}8.3 \text { Wildlife } & 106\end{array}$

8.3.1 Distribution of Wildlife across Chobe District 106

8.3.2 Corridors 110

8.3.3 Hunting 111

8.3.4 Illegal wildlife off-take 111

8.3.5 Elephant Impact on Vegetation 113

$\begin{array}{lll}8.4 & \text { Fisheries } & 113\end{array}$

8.5 Tourism $\quad 115$

8.5.1 Tourism-use depending the season and time of day 115

$\begin{array}{ll}\text { 8.5.2 Tourism-use depending spatial factors } & 115\end{array}$

$\begin{array}{lll}8.6 & \text { Infrastructure } & 118\end{array}$

$\begin{array}{lll}8.7 & \text { Mining } & 118\end{array}$

$\begin{array}{lll}8.8 & \text { Key findings } & 119\end{array}$

$\begin{array}{llr}9 & \text { Environmental pressures and risks } & 120\end{array}$

$\begin{array}{lll}9.1 & \text { Key pressures } & 120\end{array}$

9.2 Changing environment $\quad 122$

9.2.1 Changes and risks arising due to human activities within the District $\quad 122$

9.2.2 Climate or hydrology-related changes 123

$\begin{array}{ll}9.2 .3 \text { Overgrazing } & 125\end{array}$

$\begin{array}{ll}9.2 .4 \text { Wild Fires } & 125\end{array}$

9.3 Urban sprawl $\quad 126$

$\begin{array}{llr}9.4 & \text { Environmental pollution } & 129\end{array}$ 
9.5 Human-wildlife conflict $\quad 130$

$\begin{array}{ll}\text { 9.5.1 Livestock predation } & 130\end{array}$

9.5.2 Crop damage due to wildlife 130

9.5.3 Approaches to deal with human-wildlife conflict $\quad 132$

$\begin{array}{lll}9.6 & \text { Key findings } & 133\end{array}$

10 Development aspects $\quad 134$

$\begin{array}{lll}10.1 & \text { Agriculture } & 134\end{array}$

10.1.1Intensification and increased value of produce $\quad 134$

$\begin{array}{ll}\text { 10.1.2Agricultural support and integration } & 134\end{array}$

$\begin{array}{ll}\text { 10.1.3Commercial farms development } & 135\end{array}$

10.1.4Agricultural Co-existence $\quad 136$

10.1.5Cluster fencing $\quad 136$

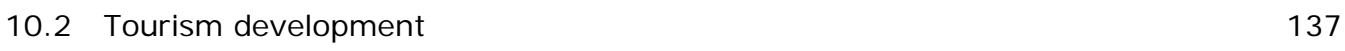

$\begin{array}{ll}\text { 10.2.1Tourism target groups } & 137\end{array}$

10.2.2Sustainable tourism development principles $\quad 139$

$\begin{array}{ll}10.2 .3 \text { Visitor management } & 140\end{array}$

10.2.4Training, education, awareness raising 140

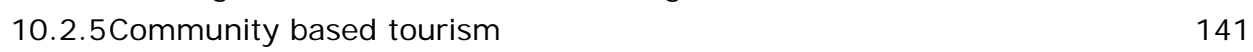

$\begin{array}{lll}10.3 & \text { Forestry development } & 141\end{array}$

10.3.1Collecting firewood and veld products $\quad 141$

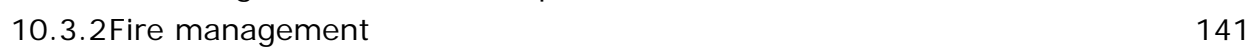

10.4 Wildlife Management 142

10.4.1National Park Zoning $\quad 142$

10.4.2 National Park rates and revenues $\quad 142$

10.4.3Human-Wildlife Conflict $\quad 143$

10.4.4Illegal wildlife off-take $\quad 145$

$\begin{array}{ll}10.4 .5 \text { Corridors } & 145\end{array}$

$\begin{array}{ll}\text { 10.4.6Fisheries } & 145\end{array}$

10.5 Water Resources 146

10.5.1Water resources availability 146

10.5.2Water supply infrastructure and institutional context $\quad 147$

10.5.3Large scale water transfers and the broader context of water demand

$\begin{array}{ll}\text { (Botswana and Zambezi basin) } & 147\end{array}$

$\begin{array}{ll}\text { 10.5.4Boreholes for wildlife } & 148\end{array}$

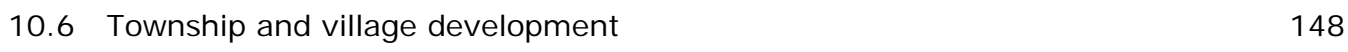

10.6.1Green development of Kasane-Kazungula Township 148

10.6.2Township expansion and degazettement of Forest Reserve $\quad 149$

10.6.3Development of villages and rural settlements $\quad 149$

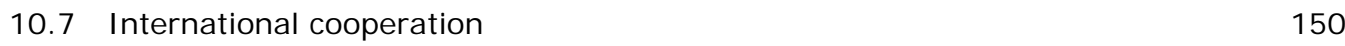

$\begin{array}{lll}10.8 & \text { CBNRM } & 151\end{array}$

$\begin{array}{ll}\text { 10.8.1CBOs } & 151\end{array}$

10.8.2 J oint Venture Partnerships 152

10.9 Poverty alleviation and economic development $\quad 152$

$\begin{array}{ll}10.10 \text { Key findings } & 153\end{array}$

11 Information gaps \& research $\quad 155$

$\begin{array}{ll}\text { References } & 156\end{array}$

$\begin{array}{lll}\text { Annex } 1 & \text { Community Consultations } & 167\end{array}$

Annex 2 Consulted people and Organisations 170

$\begin{array}{lll}\text { Annex } 3 & \text { Wildlife Distribution Maps } & 171\end{array}$

$\begin{array}{lll}\text { Annex } 4 & \text { Wildlife Corridors } & 175\end{array}$ 



\section{List of abbreviations}

\begin{tabular}{|c|c|}
\hline BMC & Botswana Meat Corporation \\
\hline BOGA & Botswana Guides Association \\
\hline ВTO & Botswana Tourism Organisation \\
\hline CBNRM & Community Based Natural Resources Management \\
\hline CBD & Convention on Biodiversity \\
\hline CBO & Community Based Organisation \\
\hline CDC & Chobe District Council \\
\hline CECT & Chobe Enclave Community Trust \\
\hline $\mathrm{CHA}$ & Controlled Hunting Area \\
\hline CKL & Chobe-Kwando-Linyanti (matrix of areas) \\
\hline CLB & Chobe Land Board \\
\hline CNP & Chobe National Park \\
\hline DCP & Department of Crop Production \\
\hline DLUPU & District Land Use Planning Unit \\
\hline DTRP & Department of Town and Regional Planning \\
\hline DWNP & Department of Wildlife and National Parks (under MEWP) \\
\hline EWB & Elephants Without Boarders \\
\hline FMD & Foot and Mouth Disease \\
\hline FPA & Fish Protection Area \\
\hline $\mathrm{FR}$ & Forest Reserve \\
\hline GIS & Geographical Information System \\
\hline GoB & Government of Botswana \\
\hline HATAB & Hospitality and Tourism Association of Botswana \\
\hline HWC & Human-Wildlife Conflict \\
\hline IBA & Important Bird Areas \\
\hline ILUP & Integrated Land Use Plan \\
\hline ITCZ & Inter Tropical Convergence Zone \\
\hline JVP & J oint Venture Partnership \\
\hline KALEPA & Kazungula, Lesoma and Pandamatenga Management Trust \\
\hline KAZA & Kavango - Zambezi Transfrontier Conservation Area \\
\hline KCS & Kalahari Conservation Society \\
\hline LAC & Limits of Acceptable Change \\
\hline LSU & Livestock Unit \\
\hline MEWT & Ministry of Environment, Wildlife and Tourism \\
\hline MoA & Ministry of Agriculture \\
\hline NAMPAADD & National Master Plan for the Arable Agriculture and Dairy Development \\
\hline NCS & National Conservation Strategy \\
\hline ORI & Okavango Research Institute \\
\hline PAC & Problem Animal Control \\
\hline RS & Remote Sensing \\
\hline SAREP & Southern Africa Regional Environmental Program \\
\hline SADC & Southern African Development Community \\
\hline TFCA & TransFrontier Conservation Area \\
\hline ToR & Terms of Reference \\
\hline TFP & TransFrontier Park \\
\hline UB & University of Botswana \\
\hline UN & United Nations \\
\hline UNDP & United Nations Development Program \\
\hline WMA & Wildlife Management Area \\
\hline WUR & Wageningen University and Research (umbrella org. of ALTERRA and University) \\
\hline WWF & World Wide Fund for nature \\
\hline
\end{tabular}




\section{Executive summary}

The Chobe District Integrated Land Use Plan is a framework plan: it sets the boundary conditions for more detailed plans, such as the tourism management plans. The land use is defined for each zone and the management plans to be developed for these zones should be in line with this zoning.

This Integrated Land Use Plan provides the larger framework for development. The plan evaluates the different claims for development, and the need for land, water and other natural resources. The plan addresses current conflicting land uses, in particular human-wildlife conflicts (which is basically conflicting functions: agricultural and residential functions versus conservation and tourism functions). The plan proposes a zoning for the Chobe District. It addresses the possibilities for multifunctional use of areas, but also provides recommendations for developmental issues related to the conflicts, such as recommendations for crop protection or implementation of compensation schemes.

This executive summary presents part of the Integrated Land Use Plan, Chapter 3 and 4. More detail as well as detailed maps are presented in the respective chapters.

The Table below (Table 5 in the report) presents the recommended land use designation for each zone

Planning zones and proposed Land Use

\begin{tabular}{|c|c|c|}
\hline Code & Planning zone & Land use designation \\
\hline $\mathrm{CH} 1-\mathrm{N}$ & Chobe Enclave-North & Mixed land use \\
\hline $\mathrm{CH} 1-\mathrm{S}$ & Chobe Enclave-South & Community tourism \\
\hline $\mathrm{CH} 2-\mathrm{CFR}$ & Chobe Forest Reserve & Forest Reserve with community non-timber subsistence use \\
\hline $\mathrm{CH} 3-\mathrm{R}$ & CNP River Front & Conservation/Tourism - intensive \\
\hline $\mathrm{CH} 3-\mathrm{M}$ & CNP Maku Pan & Conservation/Tourism - low \\
\hline CH3-NG & CNP Ngwezumba valley & Conservation/Tourism - intermediate \\
\hline CH3-SAV & Savuti Marsh and plains & Conservation/Tourism - intensive \\
\hline $\mathrm{CH} 3-\mathrm{CHAN}$ & CNP Savuti West \& Channel & Conservation/Tourism - intermediate \\
\hline $\mathrm{CH} 3-\mathrm{SE}$ & NP South-East & Conservation/Tourism - low \\
\hline $\mathrm{CH} 4-\mathrm{KK}$ & Kasane-Kazungula township & Urban \\
\hline $\mathrm{CH} 4-\mathrm{LES}$ & Lesoma & Settlement \\
\hline $\mathrm{CH} 4-\mathrm{KFR}$ & Kasane Forest Reserve \& Ext. & Forest conservation \\
\hline $\mathrm{CH} 5-\mathrm{KP}$ & Kakulwane Plains & Community tourism - intermediate / livestock grazing \\
\hline $\mathrm{CH} 6-\mathrm{KAZ}$ & Kazuma Forest Reserve & Forest conservation / Community tourism \\
\hline $\mathrm{CH} 7-\mathrm{MAl}$ & Maikaelelo Forest Reserve & Forest Reserve \\
\hline CH8-PW & Pandamatenga-West & Commercial farming / Community tourism \\
\hline $\mathrm{CH} 9-\mathrm{PN}$ & Pandamatenga & Commercial farming \\
\hline $\mathrm{CH} 10-\mathrm{PE}$ & Pandamatenga & Commercial farming \\
\hline $\mathrm{CH} 11 \& 12-\mathrm{NU}$ & Nunga WMA & Commercial wildlife utilisation \\
\hline $\mathrm{CH} 13-\mathrm{SIB}$ & Sibuyu Forest Reserve & Forest conservation / Tourism - intermediate \\
\hline
\end{tabular}

\section{Land use zoning}

\section{CH1-N: Chobe Enclave-North}

Recommended Land-Use Designation: Mixed land use

Key issues: Settlement and agricultural expansion, combined with increased wildlife populations, have led to high levels of Human-wildlife conflict, especially with Elephant. The 2014 ban on hunting has led to a reduction in CECT revenue, potentially undermining community support for the presence of wildlife in the area. Cluster fencing has potential for addressing Human-wildlife conflict, but if alignment and geometry is not correctly set up, conflict could be exacerbated. 
Zoning: The Northern part of the Chobe Enclave, where the settlements are located, is currently used for mixed farming. The area is zoned for mixed land use, which is in line with the wishes of the residents.

Since the human population is expanding, sufficient land must be reserved to meet future demand for farmland. $\mathrm{CH} 1-\mathrm{N}$ needs to be zoned for optimal agricultural development. We recommend the Land Board to implement LUCIS as per Tawana Land board for allocation of fields. The issues of wildlife corridors and key biodiversity hotspots must be considered to ensure that viable tourism development can still occur and to help reduce the Human-Wildlife Conflict. Fields should be clustered and where possible electrically fenced (see $\S 10.1 .5$ ). Corridors should be conserved with no future allocation in them (§ 10.4.4).

Livestock grazing and development of cattleposts can be permitted in the boundary area with $\mathrm{CH}-1$ South, where less arable farming occurs. Also in the West along the river and near Lake Liambezi there is livestock grazing. Expansion of livestock can be permitted where this does not conflict with arable farming or molapo farming. Around the villages along the escarpment conflict with predators is higher, and expansion of cattleposts should not be allowed here.

The area has good potential for tourism due to access to the park and floodplains of the Kwando and Chobe.

\section{CH1-S: Chobe Enclave-South}

Recommended Land-Use Designation: Community tourism

Key issues: Environmental constraints limit livestock and crop production in this area. The area is important for several migratory wildlife species (including Buffalo and Zebra) and includes several known cross-border corridors into Zambezi region. Tourism use along the Linyanti needs to take into consideration Namibian activities, as these appear fairly numerous already.

Zoning: The Southern part of the Chobe Enclave has limited suitability for farming, as a result of marginal and variable soils, lack of water for livestock or human habitation, and presence of mogau. It appears that there are no plans for formal agricultural expansion into this southern portion, primarily because of the lack of surface water or potable groundwater. The lower half of $\mathrm{CH} 1$ is a really important migration route for wildlife (see $\S 8.3 .2$ ). Consequently allocation of farm land here must be limited, and kept for wildlife-based tourism activities. The south-western portion of $\mathrm{CH} 1$ must remain unfenced, with limited settlement, to avoid disruption of wildlife migration and increased humanwildlife conflict. The area has potential for tourism, in particular the floodplains along the river and Lake Liambezi. A tourism management plan is currently (2016-2017) being prepared for $\mathrm{CH} 1$. More community based operations (joint ventures) should be stimulated, and tourism infrastructure can be developed near the villages. Support from KAZA and UNDP should be stimulated in the development of these ventures, in cooperation with e.g. mobile operators in $\mathrm{CH} 1$ and $\mathrm{CH} 2$.

\section{CH2-CFR: Chobe Forest Reserve}

Recommended Land-Use Designation: Forest Reserve with community non-timber subsistence use Key issues: Original purpose was for timber harvesting, but was not sustainable nor economically viable. Alternative uses that protect key ecosystems and support wildlife migration are needed. Illegal tourism activities are already occurring. Veld product extraction, especially firewood, is not being managed or monitored.

Zoning: The Chobe Forest should keep its role for the community as a resource base, in particular for NTFPs or veld products. The importance of the Reserve was stressed by the consulted communities in the Enclave. The Forest Reserve has conservation as primary land use, and sustainable collection of veld products or other resources, as secondary use. To ensure that the benefits devolve to the appropriate community, the Natural Resource Permits should be managed and monitored by the Trust. In the past hunting operations took place, with the income generated from trophy hunting going to the CECT. If in due time the hunting ban may be lifted, this area could fulfil its role again for hunting, reestablishing the revenue flow back to the communities. Without this change in the hunting law the District and Botswana Government should look to promote community based ecotourism opportunities that ensure that the CECT communities derive direct economic benefit. It has potential for tourism, this zone has a reasonable road network, and good potential for bird watching and game viewing. 


\section{CH3: Chobe National Park}

Chobe National Park is bordered by three Forest Reserves, one community grazing area and one commercial tourism area within a WMA. Primary land use zoning is Conservation, secondary tourism. CNP is subdivided in six sub-zones, they serve only to propose specific land use, and the delineation of these zones is flexible. However, the broad principles regarding levels of usage should be taken into consideration during the development of the upcoming revision of the CNP management plan.

\section{CH3-R: CNP River Front}

Recommended Land-Use Designation: Conservation/Tourism-Intensive

Key issues: Crowding and overuse by tour operators. Degraded riparian vegetation by large numbers of Elephants. Pressure on habitats for protected species (e.g. African skimmers, Hippos).

Zoning: The Chobe National Park River Front and Floodplains are prime conservation area. Tourism is concentrated in this area and very intensive. Considering the importance of tourism for the national economy, it is important to improve the tourism experience, at the same time increase the sustainability of the activities. Therefore zoning measures are required to decrease the pressure on this area, and to create some areas with limited disturbance of wildlife, in particular birds. We recommend that the NP decongestion plan for this zone is implemented and further developed. Active visitor management is essential to maintain the tourism experience. Diversification of the tourism product would also release some pressure from this area. Such measures are proposed for $\mathrm{CH} 1, \mathrm{CH} 2$ or $\mathrm{CH} 3-\mathrm{NG}$ (Ngwezumba valley).

\section{CH3-M: CNP Maku Pan}

Recommended Land-Use Designation: Conservation/Tourism-Low

Key issues: Limited tourism potential. Important refuge area for wildlife.

Zoning: The Maku area in Chobe National Park is located south of the major road crossing the park (A33). Limited activities take place at the moment, the area has few outstanding features and the sandy roads and slightly monotonous sandveld vegetation result in limited potential for game viewing. It is a low tourism density zone, and the focus for land use is on maintaining ecological integrity and functioning.

\section{CH3-NG: CNP Ngwezumba Valley}

Recommended Land-Use Designation: Conservation/Tourism-Intermediate

Key issues: The "backbone" of CNP, with critical hydrological linkage from Kakulwane Plains through Ngwezumba Valley to Savuti Marsh and Mababe Depression. Important linkage between grasslands in the eastern plains to those around Savuti and Mababe Depression. Challenging driving conditions.

Zoning: Ngwezumba valley is $15 \mathrm{~km}$ wide, along the dry valley with clusters of pans, it is the core of the National Park during the rainy season and a large Elephant population and other game move here. Conservation of this area is crucial. The area is of immense importance for the wildlife populations which are the pillar of all economic activities in the district and important for all of Botswana.

Besides conservation the area is zoned for tourism (intermediate intensity): the area has in particular potential for visitors that seek solitude, isolation, the wilderness experience and adventure (see also $\S 2.3$ ). The road network and signage should be improved to facilitate tourism activity. The aim is to have mobile safari operators working in this area, rather than promoting self-drives, both for the ecological integrity of the area and safety reasons, with regard to the isolation of the area. Only one lodge is currently operational, and there are some bush camps. It is recommended that few (maximum five) more HATAB and BOGA sites are established along the valley system with an improved game drive network to attract mobile operators.

Further monitoring is required of the borehole pumping strategy and the impact of water provision on the biosphere.

\section{CH3-SAV: CNP Savuti Marsh and Plains}

Recommended Land-Use Designation: Conservation/Tourism-Intensive

Key issues: Tourism congestion is already a problem. The area appears to have reached its maximum development potential.

Zoning: The core of CNP is formed by Savuti, the Channel and adjoining marsh south of the area. The landscape is strongly connected with the Ngwezumba valley through to Kakulwane Plains, as well as the Mababe depression, and through the Savuti channel to the Kwando-Linyanti, and at larger 
distance with the Okavango Delta. Savuti is thus the central link for migratory species in northern Botswana. Savuti is a prime wildlife area and forms with the River Front the main tourist area of the National Park. Campsites are operated through private companies along the Savuti Channel. Several commercially operated camps run in this same area, some are located at larger distance, e.g. near Gcoha Hills. All tourism is based on the important wildlife resources in the area, the open plains which allow for good game viewing. The presence of large predators like Lion and leopard is an additional important attraction.

The current tourism activity around the marsh and near the channel is at maximum carrying capacity. It is therefore recommended that no new lodges be built here and no further campsites developed. Any further beds within the area will lead to a loss of wilderness experience for the tourists, while detrimental impact on wildlife behaviour could occur with any further increase of tourism numbers. Some game viewing hides and towers could be developed though to facilitate better game viewing.

\section{CH3-CHAN: CNP Savuti West $\&$ Channel}

Recommended Land-Use Designation: Conservation/Tourism-Intermediate

Key issues: Area is difficult to access due to sandy conditions. Important migration route between the marsh and Linyanti/Kwando system.

Zoning: This dry Sandveld zone is an important wet season grazing area for wildlife species (and their predators) moving out of Savuti, in particular when the channel flows. The area is not easily accessible due to the sandy soils and the presence of the Magikwe sand ridge. Tracks are crossing towards Linyanti, Gcoha Hills, Khwai or Mababe.

Primary land use is Conservation with tourism (intermediate intensity). Tourism here is mainly based on game drives from the campsite or the safari camps located in Savuti. It is recommended that no further development of infrastructure is permitted.

\section{CH3-SE: CNP South-East}

Recommended Land-Use Designation: Conservation/Tourism-Low

Key issues: Remote, difficult to access. Low tourism potential. Useful as a wildlife refuge area. Zoning: This zone is located east of the Savuti Marsh, south of Ngwezumba Valley. Few roads cross the area towards the north-east, some visitors pass here, sometimes for camping. Due to its remoteness and limited variability and distinct features, the tourism use potential is low.

\section{CH4-KK: Kasane-Kazungula Township}

Recommended Land-Use Designation: Urban

Key issues: Rapid urban and peri-urban development; commercial interest. Showcase for Chobe Tourism Destination.

Zoning: Kasane-Kazungula township is locked in by protected areas, notably the Chobe River, Kasane Forest Reserve and Chobe National Park. Kasane is very dynamic and rapidly developing (see § 7.4 and 9.3), primary function is urban area, with small-scale industries and service providers (tourism in particular), and localized farming and horticulture.

There is an urgent need for further expansion of the Kasane-Kazungula urban area. Considering regional development priorities and the need for income and employment generation we recommend therefore - under very strict conditions ( $\S$ 10.6.2)- to degazet part of the Kasane Forest reserve. The green aspect of the township should be engrained in the inception and development phase. Areas are being and should be designated where local entrepreneurs are stimulated to develop activities, like production and sale of crafts, artisanal products, local guided tours in and around town and boating trips on the river.

The demand for agricultural produce for visitors, combined with the presence of water and reasonable soils, would require more promotion of horticultural and agricultural production. This would require sub-zoning of agricultural land and reservation for farming, e.g. in the area of Chobe farms and Kazungula. A detailed soil survey is required to identify potentially suitable agricultural land in the floodplain area between Kasane and Kazungula (outside the wildlife corridors). Plots currently not put to use or land which has been undeveloped for more than 3 years in this hotspot for development should be re-claimed. A LUCIS based approach could be followed to define optimal land allocation, to identify land for agriculture and urban development, whilst also taking cognisance of stakeholder needs and desires, and the Kasane-Kazungula development plan. 


\section{CH4-LES: Lesoma Community}

Recommended Land-Use Designation: Settlement zone

Key issues: The area serves as a kind of 'overflow' area from Kasane-Kazungula. Companies establish lodges and camps here to cater for limited capacity in Kasane, resulting in at least 4 lodges.

Zoning: Lesoma was originally a San settlement, but the development of commercial farms nearby the growth of the tourism industry, and in-migration from elsewhere in the country has led to the expansion of the settlement and a change in land use.

It is recommended that this zone is taken out of the Forest Reserve. The proposed contour still leaves room for expansion and avoids wildlife migration corridors, such as just north of the Lesoma village. No further expansion of any kind (be it houses or lodges) should be permitted outside this contour.

\section{CH4-KFR: Kasane Forest Reserve and Extension} Recommended Land-Use Designation: Forest conservation

Key issues: Original purpose for timber harvesting was not sustainable nor economically viable. Pressure due to the close proximity of Kasane and Kazungula township is high. Illegal settlement, dumping of waste, and sand mining occurring. Veld product extraction, especially firewood, not being managed or monitored. This is an important cross-border corridor for wildlife moving between Zimbabwe and CNP.

Zoning: Kasane Forest Reserve is of importance as resource for the people (collection of veldproducts). Besides, the area is of great importance for wildlife migration, from the interior of the Chobe District towards the Chobe river and floodplains.

To a limited extent collection of firewood could be permitted, which provides income to households, but quota should be observed and monitoring is required to ensure sustainable off-take levels. Part of the Reserve has already been degazetted. It is recommended that the degazetted area be expanded, considering the urgent need for expansion of the township, with extent and location to be studied (see $\mathrm{CH} 4-\mathrm{KK}$ ). It is of importance that the remainder of the Forest Reserve remains intact.

\section{CH5-KP: Kakulwane Plains}

Recommended Land-Use Designation: Community tourism-intermediate and livestock grazing Key issues: Abuts directly on CNP, and the designated status of tribal grazing area suggests potential of conflict in the absence of a buffer area.

The northern part of the CHA falls on a vertisol plains area that is absolutely critical to the hydrological functioning of the Ngwezumba valley, through which it links to the Savuti marsh. These plains are very important corridors for movement of migratory species such as Zebra, and need to be kept open and unfenced. Agricultural development should be avoided here to minimise Human-wildlife conflict, and to support the overarching national goal of maintaining the wildlife-based focus of Chobe District. Zoning: Ch5 Kakulwane is currently not designated. This zone is a vital source area for the Ngwezumba valley, through infiltration of surface water the larger landscape system is maintained. I ts location between the core of CNP and Hwange means that this is essential for long-term sustainable wildlife populations, many studies have shown that the ecotone between the Miombo/Mukusi woodland and the grasslands on the vertisols are a critical corridor for wildlife movements (see $\S 8.3 .2$ ) and the importance for seasonal grazing. For these reasons it is strongly recommended not to change land use into farming, this would lead to a strong increase in conflict.

Proposed zoning is Community tourism. There should be a high level of government support to facilitate community based ecotourism. Communities - in a JVP with a safari company - can do wildlife viewing operations in this area. Also a commercial wildlife lodge or lodges from Lesoma can operate here.

There are currently cattleposts encroaching into the plains - whilst there is no direct conflict between cattle and the other herbivores, further expansion of cattle will lead to more conflict with predators. It is therefore proposed to gazette it as a WMA, with stricter controls on pastoral and arable development. Existing cattleposts will be allowed, but no further expansion or establishment of new cattleposts is permitted. In this area no compensation can be paid for livestock losses due to predators. 


\section{CH6-KAZ: Kazuma Forest Reserve}

Recommended Land-Use Designation: Forest conservation and Community tourism

Key issues: Original purpose for timber harvesting not sustainable nor economically viable. Pressure due to the illegal self-drive tourism, and potential cross-border access by poachers. Though small, the area has some attractive landscapes, and its proximity to the tar road offers an opportunity to relieve tourism pressure on CNP.

Zoning: Kazuma FR forms a buffer between the commercial farming area and the more open Plains in the North. It is proposed to zone the area for Community based tourism, whereby the communities in a JVP with a commercial company- can develop tourism. The denser forest would allow for a commercial wildlife lodge to be developed in the area, but also tourism from the lodges located near Pandamatenga could conduct wildlife viewing activities here. Along the main road domestic (low-cost) tourism could be stimulated.

\section{CH7-MAI : Maikaelelo Forest Reserve}

Recommended Land-Use Designation: Forest Reserve

Key issues: Original purpose for timber harvesting not sustainable nor economically viable. Area is remote, and access is difficult. Its location in the centre of Chobe District, abutting CNP suggests an important refuge function for both plant resources and wildlife.

Zoning: Maikaelelo Forest Reserve still contains some important areas with gallery forests, which are quite untouched by man. It is proposed that this area is zoned as a strict reserve. No developments or activities should be allowed, and no-one should enter the area without a permit. The area is kept for scientific research, which would ensure preservation of valuable plant and genetic resources for future use.

\section{CH8-PW: Pandamatenga West}

Recommended Land-Use Designation: Commercial farming and community tourism

Key issues: In the recent past this area has been intended to serve as wildlife utilisation in a livestock grazing area. However, the arbitrary composition of the constituent communities in the CBNRM Trust, KALEPA, combined with its distance from any of these communities, has hampered the development of tourism. In addition, good soils in the east make it more attractive for crop production. Intensive agriculture would be a direct conflict with the "refuge" function of Maikaelelo forest reserve.

Zoning: Pandamatenga West is currently not designated for a particular land use, however it has been set aside for CBNRM activities for KALEPA Trust, with the potential of ecotourism activities through joint venture partnerships. As described in $\S 8.1$, there are plans for further development of commercial farming. Based on sustainable land use principles, it is recommended to develop commercial dryland farming. Irrigated farming is not sustainable here, groundwater resources are insufficient, water transport from the Zambezi would be very costly, it is vulnerable for climate change, and would require a lot of energy. It is recommended to expand commercial farming stepwise in smaller phases, and on the condition that also communities receive a share of land in each phase and that community tourism is not unduly affected. However, by granting permission for this area to be developed, long-term future development could see developments expand to the far west of the CHA onto the Forest Reserve. It is therefore essential to install a buffer zone of at least $15 \mathrm{~km}$ in the west of $\mathrm{CH} 8$ in which no commercial agriculture will occur. Also the wildlife corridor through Pandamatenga should be retained. The undeveloped area in the west, unsuitable for farming, would allow for low-density community tourism activities through the KALEPA Trust.

\section{CH9-PN: Pandamatenga North}

Recommended Land-Use Designation: Commercial farming

Key issues: The commercial farms fall across a critical wildlife corridor linking Hwange to CNP. Farming blocks should be realigned parallel to, instead of across, the corridor. There are undeveloped opportunities linking agriculture to tourism here, such as horticultural production to supply Chobe lodges with fresh produce.

Zoning: Pandamatenga-North has been developed over the past 30 years for commercial farming. The Pandamatenga settlement is also located in this zone. It is proposed that Commercial farming is maintained. In addition, land should be made available for intensified horticultural production by community members or groups that are assisted with support programs from MoA or KAZA. 
The current corridor between the two blocks should remain open, that is, no building and construction of infrastructure should take place. Some of the farmlands in the corridor must be vacated, whereby farmers will be compensated by allocation of farmland further south in this block, or in $\mathrm{CH} 8$. The number of buildings is limited and they should be removed.

The electric fence placed some years back (see $\S$ 8.3.1.5) has been poorly sited and needs to be relocated to re-establish the corridor and to release enclosed wildlife, in line with the recommendations from earlier assessments and studies done.

The newly proposed fence from the farmers' association needs to be carefully planned, and based on location, size and alignment it should be assessed whether it can adjoin the current fence (see $\S$ 10.1.5). Appropriate road signage and speed reductions north and south of the corridor should be put in place to warn motorists, especially truckers.

Environmental conditions must improve: further study is required into the long-term impact on soil carbon stocks, as well as leaching of agro-chemicals into groundwater and surface water (see also $\S 9.4)$.

\section{CH10-PE: Pandamatenga East}

Recommended Land-Use Designation: Commercial farming

Key issues: As with Pandamatenga North, the commercial farms fall across a critical wildlife corridor linking Hwange to CNP. Farming blocks should be realigned parallel to, instead of across, the corridor. More attention should be paid to the environmental aspects of commercial production, to ensure the long-term sustainability of the soils and consequently production levels.

Zoning: This area has been developed more recently as farming area. The Commercial farming is maintained. A relocation of the electrified fence is required to open the corridor. Some of the farmlands in the corridor may need to be vacated, whereby farmers might be allocated farmland further south in this block or in $\mathrm{CH} 8$. For some of the buildings in the corridors financial compensation may be required, but the number of buildings is limited. Appropriate road signage and speed reductions north and south of the corridor should be put in place to warn especially truckers. Also here environmental conditions must improve. Study is required into the long-term impact on soil carbon stocks, as well as more sustainable use of agro-chemicals to protect groundwater and surface water.

\section{CH11\&12-NU: Nunga WMA}

Recommended Land-Use Designation: Commercial wildlife utilisation

Key issues: The moratorium on hunting has left $\mathrm{CH} 11$ empty, as no suitable photographic tour operator has tendered for the area. This makes the wildlife in the area vulnerable to commercial poaching. The installation of permanent water points to attract wildlife may have negative consequences for wildlife populations in the mid- to long-term.

Zoning: $\mathrm{CH} 11$ was in the past a commercial photographic area and $\mathrm{CH} 12$ was a commercial hunting area. designation is maintained, but with a shift to photographic or adventure tourism in both CHAs. Commercial tourism operations can concentrate on photographic safaris, in particular around the pans that hold water in the area. Also game drives into Ngwezumba area (CH3-NG) would be possible. The objective would be to promote medium to low level adventure based tourism, as game densities are still not as high as the high density tourism zones in Chobe. Based on this the number of prescribed beds and standard of accommodation should be suited towards the middle tier of the safari industry. If the hunting ban, after evaluation, would be lifted, the area of $\mathrm{CH} 12$ which is outside the $25 \mathrm{~km}$ buffer zone of CNP, could be used for commercial hunting activities again. For $\mathrm{CH} 12$ a tourism management plan has been prepared, proposed development is in line with the management plan. The artificial water points policy should be revisited with a view to removing or rotating use.

\section{CH13-SI B: Sibuyu Forest Reserve}

Recommended Land-Use Designation: Forest conservation and Tourism-Intermediate Key issues: Original purpose for timber harvesting not sustainable nor economically viable. Pressure due to illegal self-drive tourism, and potential cross-border access by poachers. The area has some attractive landscapes, and its proximity to the tar road offers an opportunity to provide tourism activities to the domestic market.

Zoning: Sibuyu Forest Reserve is important for wildlife migration, it forms a corridor for animals migrating south and east-west. It is recommended that the Forest Reserve remains a Forest 
conservation area. Local communities will have access, they can collect veldproducts here, and to a limited extent firewood. There is some potential for photographic tourism in the area, along the river valley a lodge may be possible and allowed, provided that a commercial operator is willing to run this with involvement of people from Pandamatenga.

If the ILUP is to function as an integrated plan, it requires constant close sectoral cooperation and interaction. Current collaborative arrangements require considerable strengthening. DLUPU should be revitalised, and should have a more proactive role, and sector representatives such as Agriculture, DWNP, BTO etc. should commit to full participation, to ensure resource management across the whole landscape, and not just within sector zones. This is the only way to ensure proper adaptive management that is responsive to ecosystem variations.

Various institutions are responsible for land use planning (see Table 6). The key institutions are the Chobe Land Board, the Chobe District Council and the Department of Lands. The Chobe District ILUP used stratification, focused groups and one-on-one interactions as methods and approaches that guided community consultations. Land Board and DTRP should undertake a further comprehensive consultation/dissemination exercise to introduce and share the details of the plan with the district's communities and stakeholders.

It is recommended that a specific monitoring/evaluation team is appointed to guide the implementation of the ILUP. A review should take place within 2-3 years for purposes of guiding implementation for the remaining period of effect for the plan.

It is necessary that the Chobe District ILUP be immediately resourced after approval to effect implementation, thus enabling effective plan duration and review timeframes. 


\section{$1 \quad$ Introduction}

Chobe District is the northernmost district in Botswana, bordering Zimbabwe, Zambia and Namibia (Figure 1). The District is currently lacking an Integrated Land Use Plan (ILUP) ${ }^{1}$. This has resulted in uncontrolled development, occasionally haphazard land allocation, unsustainable land use, lack of guidance for developers or companies operating in the area without a long term perspective for development.

Currently different plans are under development, for the forest reserves, Chobe National Park, Wildlife Management Area, and the Kasane-Kazungula township. Without proper guidance, e.g. by an umbrella plan in which strategic choices are made for regional development, these plans will be impaired. The larger framework is required for the conservation sector, the forestry sector, the tourism sector, agricultural development, township development and infrastructure.

This ILUP provides the larger framework for development. The plan evaluates the different claims for development, and the need for land, water and other natural resources. The plan addresses current conflicting land uses, in particular human-wildlife conflicts (which is basically conflicting functions: agricultural and residential functions versus conservation and tourism functions).

The plan proposes a zoning for the Chobe District. It addresses the possibilities for multifunctional use of areas, but also provides recommendations for developmental issues related to the conflicts, such as recommendations for crop protection or implementation of compensation schemes.

The plan is submitted to the Chobe District Land Use Planning Unit (DLUPU), for their consideration and adoption. This plan should be guiding in the detailing of all other land use studies.

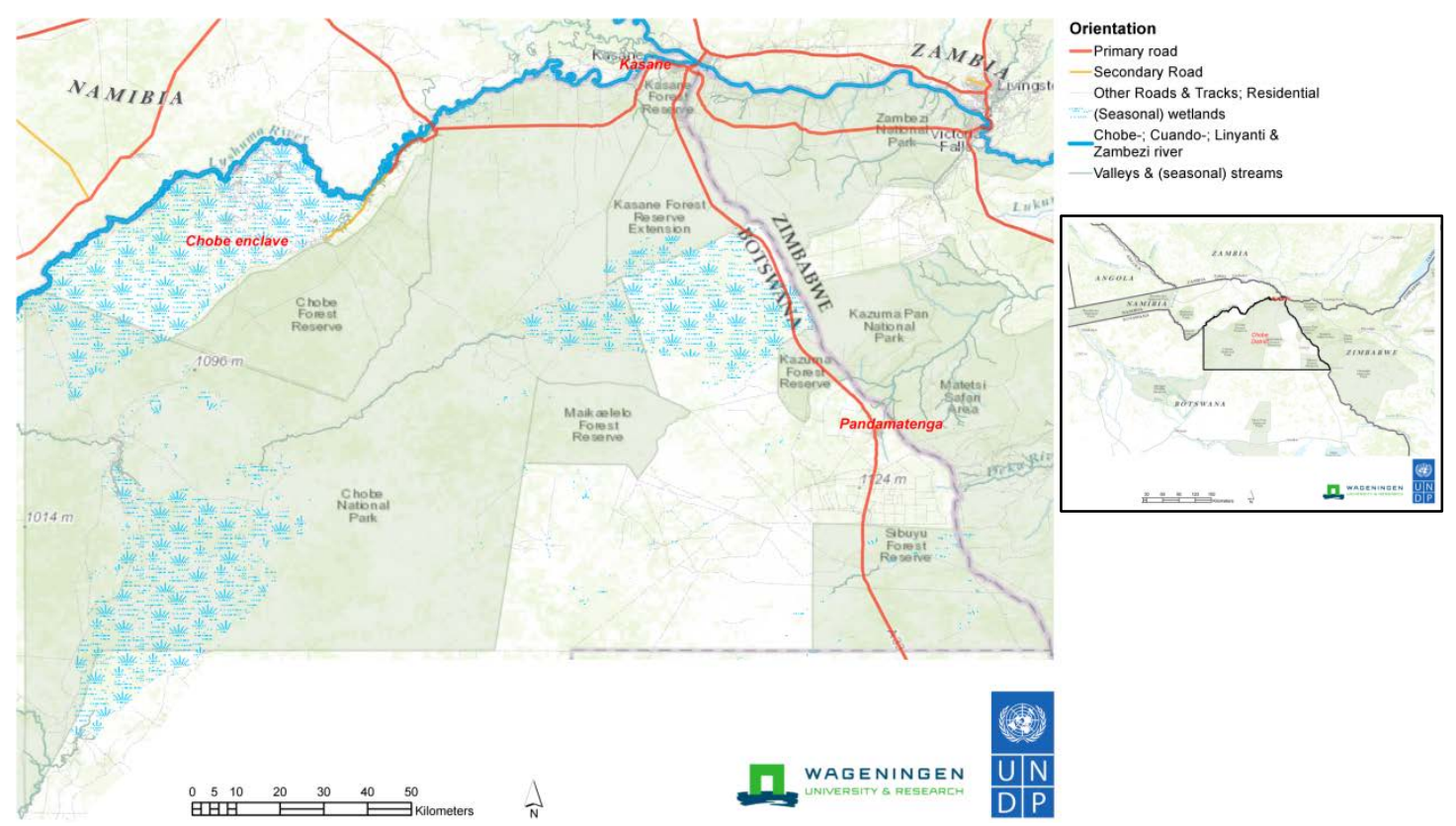

Figure 1 Chobe District, the area for which the land use plan is being prepared

\footnotetext{
${ }^{1}$ In this document "the plan" or ILUP refers to this Chobe District, unless otherwise specified.
} 


\subsection{Aims for ILUP}

The Chobe District ILUP has been developed based on:

I. Consultation of, and support by communities and other stakeholders, creating ownership of the plan;

II. Recognition of the importance of conservation of natural resources and in particular of biological diversity;

III. Promotion and improvement of sustainable rural livelihoods;

IV. Support of tourism as an important economic activity, with special reference to the promotion of the diversification of the tourism product;

V. Recognition of the economic potential of other uses of natural resources, such as (commercial) agriculture;

More specific objectives for this Chobe District ILUP are:

- To harmonize different land- and water uses with environmental conditions

- to decrease poverty among the communities, as one of the core problems related to resource degradation, amongst others by integrating communities in mainstream development in Botswana

- to ensure sustainable economic use of natural resources such as the sustainable harvesting of NTFPs

- to promote the protection of crucial areas for biodiversity conservation, as well as corridors for wildlife and people inside the Chobe District

- to strengthen protected areas management

- to reduce threats to biodiversity in the buffer zone

- to harmonize land use in Chobe with land use in areas adjacent to Chobe District, and ensure that it is compatible with biodiversity conservation goals

- to develop a plan shared by all authorities, which can form the basis for future land use activities and land allocation as well as future land use and development plans

- to develop a collaborative governance framework

\subsection{General expectations}

The Chobe District plays a central role in achieving the sustainable development goals for the Nation. Specifically, tourism development based on the sustainable use of natural resources puts large State land wildlife and forestry areas at the Centre of NDP 11 (GoB 2016c). The tourism sector also has a key role to play in the strategies for poverty eradication by providing employment and economic development for local communities (Vision 2036; GoB 2016d). Within the planning area, the Pandamatenga area has been designated as a special development area for arable agriculture and its associated industries (NDP 11). In addition to these economic foci, NDP 11 also notes the sustainable management of cultural values as a prerequisite for land use planning.

Given its position at the core of KAZA, and the central role of its wildlife-based tourism industry for the national sector, Chobe District's overarching land-use focus is therefore to secure the long term sustainable utilization and conservation of wildlife resources, and the management of the ecosystems that underpin this goal. At the same time, the land use plan must take into account the space needed for the sustained cultural and rural economic activities of local communities, and facilitate their increasing participation in tourism as the prime economic sector in the region. In addition, it must provide for the economic development in the specially designated arable development areas of Pandamatenga.

The UNDP Bio-Diversity Project recognizes that the district is threatened by uncoordinated / incompatible land uses, human wildlife conflict, impediments to ecological connectivity (e.g. of wildlife corridors across international borders), possible loss of bio-diversity, climate change and large numbers of Elephants. Other challenges include lack of land, an increasing human population, ineffective land management and institutional arrangements. 
The District Development Plan 7 (Chobe District Council 2010) mentions specifically the need for an ILUP, to realise environmental goals (par. 2.5.3) and to promote sound and sustainable environmental management of the Chobe ecosystems. This issue comes up from the DDP 6 already, and is also brought forward in the proposed projects (par. 5.6). Interestingly, it is mentioned here in conjunction with 'Repossession of undeveloped plots, Enforcement of Development Plans, Land Use Plans and Development Covenants' (Chobe District Council 2010).

The general expectation of the Chobe Integrated Land Use plan is to provide the Chobe District Land Board, District Land Use Planning Unit, Department of Lands Physical Planning Unit and other environmental and economic sectors with a product that will serve as a template for the allocation and distribution of land to different sectors. There is increased pressure for additional land to meet the varying needs of local level households, while still allowing for the development of economic activities that provide revenues to the national coffers. Importantly, State Land comprises much of the district. While the actual tenure of State Land may be difficult to change, the potential to diversify the activities that take place in the different types of State Land must be developed.

The Chobe Integrated Land Use Plan will therefore address integrated economic and land use planning objectives, not just static land allocation per se. It is a livelihood transformation strategy for Chobe District that is anchored on equitable land allocation, land distribution and land management. It is imperative to realize the role of the Land Board (under the Ministry of Land Management Water and Sanitation Services) and that of the renamed Ministry of Environment, Natural Resources Conservation and Tourism.

According to feedback from community consultations in Parakarungu, Lesoma, Pandamatenga and discussions with Government officials (mainly Heads of Departments) and other organizations, including private sector business persons, it was apparent that there is a general expectation that the Chobe Integrated Land Use Plan will unleash opportunities for new land allocations, strengthened land management systems and increased participation by the residents of the area in economic activities, including benefits from participation in tourism. The Department of Tourism would like to see increased activities in tourism including cultural preservation.

Some specific points and expectations

- There is general expectation that the Chobe ILUP will make available land for allocation, for increased and varied types of land uses by the Chobe Land Board and that the Plan would be authoritative and enforceable by relevant structures.

- The Plan would also rationalize the utilization of Forest Reserves. Augmentation of the planning areas through de-gazettement of the Forest Reserves will possibly take place.

- It is also expected that land serving will take place to enable developments.

- Cluster fencing will be extended to other areas of the district to minimize crop damage by wildlife and hence reduce human-wildlife conflicts.

- It is expected that the plan would be bold enough to withstand anticipated criticism and be appealing to various interested stakeholders, who may not necessarily agree on all set priorities.

- Expansion of the Pandamatenga commercial arable farms with additional 40,000 hectares will provide opportunity for residents (as opposed to foreign farmers) to engage in commercial farming by acquiring land of at least 500 hectares each as this would enable financing by commercial banks which are currently reluctant to consider any arable farming enterprise below the stated figure.

- Some of the expectations, especially from the general members of the public, might not be aligned to/with the aims and objectives of the ILUP, as required by the TOR. These differing views would have been re-aligned as part and parcel of the consultation process. Botswana espouses consultation as one of the cornerstones of the development process and Botswana's democracy.

\section{Plan Emphasis, Approval and I mplementation Requirements}

Chobe District Integrated Land Use Plan (ILUP) is a uniquely required guiding document that is critical for continued land allocation and utilization within the entire district. Intrinsically, this would be the first plan of its kind in Chobe District. 
The plan will be approved for implementation, effective mid-2017, and will span a period not exceeding ten (10) years - as this would enable effective implementation that should take into account monitoring and feedback (adaptive management).

An Integrated Land Use Plan requires conceptualization, rationalization and comprehensive understanding - that would facilitate and enable not only the plan preparation but especially also its smooth implementation. In this context, consultation becomes paramount.

Land is viewed as an economic resource that should be put to equitable and optimal use. In this regard, there are instances of undeveloped fields or plots or resting fields, some of which could be subject of inheritance and/or posterior use, unless the land allocating authority would suggest otherwise, (repossession and/or dezoning). The increased demand for additional portions of land that should be available for allocation by the Chobe Land Board is also apparent. Throughout the district, there is a general understanding that land should be accessible to the general members of the community and residents. They should have secure and permanent land rights on portions of land that they occupy, as it is generally felt that land is a finite resource.

The twenty (20) year planning horizon tradition adopted for physical plans and development plans will not suffice for this particular Chobe District ILUP, that has very specific aims and objectives that should be met within a short time span. Otherwise the sense of urgency (that the Chobe District ILUP must emphasize) will be lost and un-intended consequences (outcomes) might result. Furthermore, resourcing and coordination of integrated economic, ecological and social plans is always very difficult, so there has to be a compression of time to "force" effective plan implementation and therefore achievement of the intentions of the plan, within the set timeframe and possibly through the anticipated resources.

Conclusively, this Chobe District ILUP will have to be an acceptable, approved, implementable, timebound plan, that will address the critical land use issues currently affecting the entire Chobe District and all its stakeholders.

\subsection{Principles for approach and plan}

The following aspects are fundamental for the approach:

\section{Community-Based Natural Resource Management}

Community Based Natural Resources Management (CBNRM) aims at achieving conservation and rural economic development through local community participation in natural resource management and tourism development. CBNRM is a shift from the top down to a more bottom-up approach in natural resource management where communities take control of the management of the natural resources they depend on.

The CBNRM principles of conservation and rural livelihoods should also guide tourism development for rural areas in the Chobe District. From the communities living within and around the Chobe area, some can significantly benefit from tourism development. In line with the principles of sustainable tourism and sustainable development they can be capacitated to make informed decisions on natural resource conservation in their local environment.

CBNRM in tourism may be carried out through a J oint Venture Partnership between local communities and tourism operators. Local communities prefer J oint Venture Partnerships (JVPs) because tourism development is a relatively new economic activity for them; hence most communities lack the necessary entrepreneurial skills and experience in managing tourism enterprises. Joint venture partnerships with Safari companies are preferred under the assumption that there will be an effective transfer of entrepreneurship and managerial skills in tourism business from companies to local communities, and that there is an acceptable sharing of benefits for both communities and companies. 


\section{Adaptive management}

Adaptive management is an approach that acknowledges the lack of unequivocal and definitive knowledge of the ways in which ecosystems and societies work, and the uncertainty that dominates our interaction with them. In this perspective, there is a need for monitoring, evaluation and constant improvement of ecosystem management. This perspective requires horizontal (local to local) as well as vertical (local to regional to global) collaboration. In this regard, adaptive management allows managers to take action in the face of global change, to enhance and complement scientific knowledge in order to reduce uncertainties, and to craft policies that respond to, and even take advantage of unanticipated outcomes.

\section{Holistic, landscape-based approach}

We have adopted a holistic and integrated landscape approach. This approach gives ample attention to the multi-functionality of the landscape, the large spatial structures and interactions in the landscape, and the needs of consultation and involvement of local stakeholders (Sayer, 2013). The plan also incorporates conditions for resilience in future development.

\section{Sustainable Tourism}

Botswana has adopted sustainable development as an approach to guide development. Since the 1990s sustainable tourism has become the strategy that informs and guides the formulation of tourism policies, strategies and plans in Botswana, especially in environmentally sensitive areas like the Chobe. The sustainable tourism principles state that tourism development should address issues of economic development, environmental concerns, social factors, and the structure of the international tourism system. Sustainable tourism refers to all kinds of tourism development that meet the needs of host populations, tourists and operators. Similarly, this form of tourism is carried out without compromising the ability of future generations (hosts, tourists and operators) to satisfy their own needs and desires from the same resources. Tourism development is expected to observe the principles of Limits of Acceptable Change (LAC) which in general ensures that tourism activities and facilities are developed in such a way that tourism does not degrade the environmental and cultural resources it relies upon. The LAC has worldwide become one of the environmental guiding principles used to promote tourism and conservation.

\section{I ntegrated approaches to land- and water uses}

The Convention of Biological Diversity (CBD) has adopted the Ecosystem Approach (EA) to achieve its objective. The EA provides a framework for integrated management of ecosystems. The 12 principles endorsed by the Conference of Parties in Nairobi (COP 5, see ${ }^{2}$ ), provide guidance to integrate management in time and space, bridging gaps across sectors and disciplines, linking theory with practice, and field experiences with policy making. In line with principle 12, the plan will be 'state-ofthe-art', regarding scientific insights and it will refer to indigenous knowledge where appropriate. The plan will also be in line with sustainability principles as promoted by the National Conservation Strategy (NCS) and Natural Capital Accounting as adopted by the Botswana Government. It will be observant of the important international relations within the matrix of protected areas in the region, the transboundary Kwando-Zambezi protected area development.

We refer to the precautionary principle here, as adopted by the CBD to which Botswana is a signatory, which should be leading for planning. The legal experts of the World Commission on Environmental Law formulate it differently nowadays: In dubio, pro natura. Or: when there is doubt, nature comes first...

\footnotetext{
${ }^{2}$ https://www.cbd.int/doc/decisions/COP-05-dec-en. pdf.
} 


\subsection{Approach and methodology}

The Chobe District Integrated Land Use Plan needs to:

a. Balance the diverse range of stakeholders and community aspirations for the District;

b. Provide opportunities for socio-economic development and employment generation;

c. Be ecologically sustainable;

d. Be technically feasible;

e. Be cost-effective to establish and implement in the long-term, and;

f. Provide clearly defined roles and responsibilities for the management of land allocation in the District.

The general methodology outlined below integrates the approaches and the study process, to accomplish the project tasks. The method is aligned with the requirements and remits of the ToR.

\section{Data collection}

Relevant data, studies, reports and plans have been compiled in a literature database. The consultant has approached organisations for additional studies and papers. Internet searches were done to complement the existing literature.

Available maps have been compiled and are stored in a GIS system. Additional relevant map data have been compiled from organisations like FAO, IPCC, WWF and Trans-frontier Parks.

\section{Public consultation}

The consultants' approach has been aimed at developing a thorough understanding of stakeholder/ community aspirations, as well as environmental, socio-economic and physical developments, and the regulatory framework within Chobe-Kwando-Linyanti area. The consultation stage involved collection of information from interviews, focus groups meetings, and workshops with residents, government officials, and other stakeholders. The findings of this stage formed the foundation for the Chobe District ILUP. Consultation and focus group meetings were arranged in the study area, particularly in the Chobe Enclave, to elicit from them the critical issues and aspirations associated with the Chobe District development prospects and the development of the ILUP.

\section{Chobe District I ntegrated Land Use Plan}

The Consultants have combined the findings of the consultation phase with the bio-physical and planning data, to develop a common vision for the future development of Chobe District and based on that development strategies, and the Integrated Land Use Plan.

The Land use (Zoning) map and sketches have been prepared with the intention to conceptualize appropriate spatial framework(s) in and around Chobe District, that will guide and coordinate planning, conservation, tourism and development initiatives, as well as minimize conflicts between different activities/users of Chobe District.

The preferences identified by community and stakeholders, in combination with the feasibility analysis for different forms of land use have been used to formulate the Chobe District ILUP. The proposed zoning and development plan is translated into management/action strategies for implementation. All maps prepared by WEnR are digitally available in High Resolution at the following site: https: //doi.org/10.18174/420002

\subsection{Stakeholder Engagement}

The consultants' approach to stakeholder participation in this project has been functional, whereby stakeholders have elicited core ideas for Chobe District future development, which may also assist in building consensus. Basically, stakeholders are expected to act as vanguards in driving the plan preparation process.

In the development of the Chobe District ILUP, the Consultant has liaised with a broad range of stakeholders. They were identified during the preparation of the Inception Report and arranged 
according to the extent of their potential importance. As illustrated in Figure 2, this categorisation and prioritisation was based on a "stakeholder analysis model", used to rank each stakeholder vis-à-vis their level of influence and interest. This, in turn provided a basis for determination of the level of stakeholder's engagement in the process of the Chobe District Integrated Plan preparation.

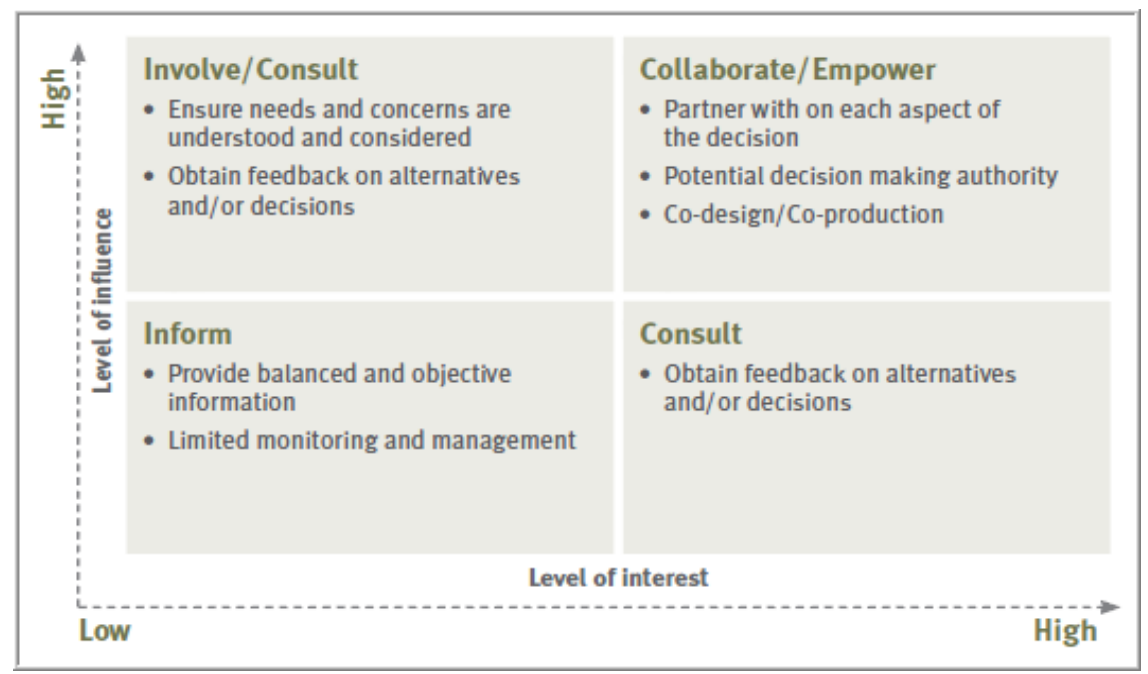

Figure 2 Stakeholder analysis model used in ranking of the stakeholders

\subsection{Framework plan, relations with sub-district-plans}

The Chobe District Integrated Land Use Plan is a framework plan: it sets the boundary conditions for more detailed plans, such as the tourism management plans.

The land use is defined for each zone. The management plans for these zones should be in line with this zoning, the outline should be embedded in the briefs (ToRs) for the consultants that prepare the plans. This means that in principle the zoning agreed in the ILUP will be followed in the detailed management or land use zoning plans, i.e. areas zoned for e.g. intermediate level tourism will not be changed by the initiative of the consultant into low or high level tourism. However, in some cases changes in zoning can be made if deemed necessary by the Land Board, following the review procedure as discussed in par. 4.2.

The ILUP will be guiding in the preparation and prioritisation of detailed plans. It will also be guiding for further district development planning.

\subsection{Relevant legislation}

The following regulations and laws are relevant for the Integrated Land Use Plan for Chobe District:

- Agricultural Resource Conservation chap. 35:06

- Anthropological Research Act chap. 59:02,

- Aquatic Weeds chap. 34:04

- Atmospheric Pollution (Prevention) chap. 56:03

- Civil Aviation chap. 71:01-03

- Custom and Excise chap. 50:01

- Diseases of Animals chap. 37:01

- Environmental Impact Assessment Act 2005, chap. 65: 07

- Fencing Act chap. 33:03

- Fish Protection chap. 38:04

- Forest chap. 38:03

- Herbage Preservation chap. 38:02

- Immigration Act chap. 25:02 
- Mines and Minerals chap. 66:01

- Mines, quarries Works and machinery chap. 44:02

- Monuments and Relics Act, chap. 59:03

- Mutual Assistance in Criminal Matters, chap. 08:04

- Plant protection chap. 35:02

- Tourism Act 2009, chap. 42:09

- Waste Management Act 1998, chap. 65:06

- Wildlife Conservation and National Parks Act (Act No. 28 of 1992).

\subsection{Outline Integrated Land Use Plan}

Chapter two to four form the Integrated Land Use Plan. These chapters form the core of the Integrated Land Use Plan, and for convenience they are presented in front. They cannot be fully appreciated without the contextual information, the resources, socio-economic description, land use and the spatial analysis of environmental pressures and changes and specific recommendations for implementation and management planning in the following chapter 5-10.

Chapter two describes land use types and land suitability. Chapter three is the central part of the plan, the description and the future land use for each zone. Chapter four presents the implementation framework.

Chapter five provides an overview of Chobe District and the environmental conditions. In chapter six aspects of biodiversity and conservation are presented. Chapter seven describes the socio-economic conditions that are fundamental for the Chobe District ILUP, chapter eight describes current land use. Chapter nine presents an analysis of the environmental pressures an risks. Chapter ten discusses the developmental issues relevant for the future of the district and provides leads and practical advice for implementation aspects for the different sectors. Chapter eleven finally describes the information gaps, with recommendations for further study.

All maps prepared by WEnR are digitally available in High Resolution at the following site: https: //doi.org/10.18174/420002

\subsection{Acknowledgements}

The ILUP Team wishes to thank the Chobe Land Board for the organisation of the community meetings, extensive logistical support and, their personal involvement in the planning process. The Reference Group is gratefully acknowledged for the guidance and many comments during the development of the Plan. Thanks also are due to the BioCHobe Project, UNDP for the funding of the Plan. Our gratitude goes to staff from ORI for their inputs. A number of organisations, in particular Elephants without Borders and Caracal, shared essential information for the understanding of ecological and conservation issues. The KAZA office in Kasane is gratefully acknowledged for assistance and data sharing and discussions regarding the plan. In particular the Peace Park Foundation and the department of Surveys and Maps are acknowledged for provision in digital format of map resources such as the KAZA land use map. The department of Wildlife and national Parks granted access to various park areas during the planning process. Finally, thanks go to all residents and resource persons in the Chobe who gave us their trust and time to meet us, discuss and guide the important Land use issues in the District. 


\section{Land use types and Land Suitability}

\subsection{Definition of land use types}

The major land use types identified for Chobe District are farming, forestry, fisheries, conservation and urban/build-up areas, as well as associated land use types.

These major land use types and sub-land use types, are described below. These land use types can also be used for possible future development of management plans and sub-zoning of areas.

- Farming

- Arable dryland farming

- Commercial arable farming

- Livestock farming and cattle posts

- Horticulture and irrigated farming

- Mixed farming

- Forestry

- Forest reserves with tourism activities

- Forest reserve without access, strict conservation / refuge area

- Community forestry

- Conservation

- Chobe National Park

- Wildlife Management Area

- Urban and sub-urban

- Residential

- Commercial

- Green development zone and corridor

- Tourism

- Tourism - high intensity

- Tourism - medium intensity

- Tourism - low intensity

- Infrastructure

- Hunting and gathering

- Veldproducts

- Hunting

Within the scope of this plan it is not intended to do a full land suitability assessment, nor are the data available to do a such an assessment. Based on the available literature, the suitability is discussed for the different types of land use.

The land suitability described in Chapter two should be read in conjunction with Chapter 5 (environment), 6 (biodiversity), 7 (socio-economic conditions) and 8 (land use).

\section{Farming}

Arable dryland farming

Main function: arable farming. The main activity here is ploughing and growing crops.

Grazing is regarded as conflicting land use, therefore no cattleposts or livestock watering points can be allocated in this zone or within a radius of $8 \mathrm{~km}$. from the ploughing area.

Existing water points will be tolerated (permitted) but no upgrading of the water points or redrilling will be allowed. Where the community would like to relocate some of the water points from the ploughing area to another zone, all possible assistance should be given.

Watering points can only be allocated for domestic purposes and for watering of draught animals (horses, oxen and donkeys). This entails a limitation of the number of livestock watered at one water point to a maximum of two span ( 20 head) of oxen. Any excess of cattle should be grazed in the grazing area. Gathering of veldproducts is not considered to be a conflicting land use in an arable farming area. 
Commercial arable farming

Main function: commercial dryland or commercial irrigated farming.

Within commercial arable farming areas no change of function is allowed (e.g. towards other commercial functions, industrial functions, tourism or recreational functions).

Watering points can only be allocated for domestic purposes. Irrigation is only allowed if water is provided from external water carriers, such as from the Zambezi (not from boreholes).

Livestock farming and cattle posts

Livestock development areas have as primary function grazing of domestic and game animals. No arable fields or residential plots can be allocated in these areas, since these are regarded as conflicting with the grazing function.

Gathering is permitted in the grazing areas since this does not form conflicting land use.

Horticulture and irrigated farming

Main function: horticultural production or small-scale irrigated farming.

Horticulture is not compatible with other forms of land use, since it involves small-scale, intensified production of e.g. vegetables. Water can be extracted from wells, boreholes or from rivers and dams.

Mixed farming

Mixed farming areas do not have a specified use. All land uses can occur in the same area. In principle areas were designated 'mixed farming' when residents in the specific area expressed the wish of not wanting specified zoning.

\section{Forestry}

The main function of the forest reserves will largely be outlined in the outcomes of the ongoing Chobe Forests SEA and subsequent management plans. However, it is believed the focus will be on ecosystem services, inter alia:

- Carbon sequestration;

- Regulation of fresh water;

- Forest landscape aesthetics;

- Biodiversity conservation

- Habitat functions (e.g. for wildlife populations)

- Low impact ecotourism.

In addition, ongoing harvesting of renewable plant resources, including wood, firewood, veld foods and medicinal plants will continue as main land use activities.

Forest reserve (strict)

Main function: Conservation of the area without any interference or management practices.

This zonation ensures the preservation of valuable plants and genetic resources and the supply of other ecosystem services (e.g. water) for future use. The genetic resources are very important in the light of climate change, and shifting ecotones. As a consequence, the area is closed for all, there is no infrastructure, no activities are developed and only (to a limited extent) scientific research is permitted. It is not allowed to enter the area without permit.

Community forestry

Main function: Protection of the forest as well as its supporting vegetation and resources, and sustainable use and offtake of veldproducts. In some cases it can also be planted woodlots for firewood. The resources are to benefit neighbouring local communities.

\section{Conservation}

Chobe National Park

Main function: conservation of the ecological integrity of the National Park and sustaining the wildlife resources of the area.

At the same time, the park has the aim to generate income, through tourism, for the wellbeing of the Botswana people. 


\section{Wildlife Management area}

Main function: to promote commercial utilization of wildlife while at the same time assisting the poorer rural dwellers to increase their incomes and hence improve their standard of living.

The Wildlife Management Area can be considered as a form of zoning of land for wildlife utilization within the Reserved Areas category as differentiated by the TGLP (Natural Resources and People 2009). There should be appropriate WMA Regulations; the area should have a draft management plan; a policy of sustained wildlife utilization should be implemented.

\section{Tourism}

The definition of high, medium and low tourism-use zones should be seen as way to characterize tourism development. All zones are quit large on itself and tourism management plans for each zone should identify locations for tourism infrastructure development. The tourism-use zones can be characterized as follows:

High intensity tourism

Tourism high-use zones: these are easily accessible zones with an abundant wildlife year-round and high landscape values. The zone has more permanent than non-permanent lodges. These are concentrated within certain sub-zones. The zone has a relative dense road-network for safari-drives. Sufficient rest for wildlife is safe-guarded by the implementation of core-areas (non-go areas for tourists) and a rest-period during the night (no night-safari's).

Intermediate intensity tourism

Medium-use zones: these zones are more remote than the high-use zones, but are still characterised by high landscape values and an abundant wildlife, though maybe only during certain periods of the year. The zone provides opportunities for wilderness camping and has more non-permanent than permanent lodges. All within certain sub-zones. The zone has a relative extensive road-network for safari-drives. Night-safaris are allowed.

Low intensity tourism

Low-use zones: these zones are less attractive for development of safari-tourism, but might have potential for development of specific niches, like hunting tourism. The zones have a low-density road network, to pass through mainly. The feasibility to run lodges in these zones is very limited, but wilderness camping in the proximity of the roads is an opportunity.

\subsection{Suitability for Agriculture}

\subsubsection{Arable farming}

There are few focal areas which are in principle suitable for arable farming:

- The Chobe Enclave

- Pandamatenga

- Kasane-Kazungula riverine area and floodplains

\section{The Chobe Enclave}

The Chobe Enclave has been extensively studied, in the so-called CFDA-study by Utrecht University (Barnhoorn et al. 1994, Beekma 1989). The area is a mosaic of areas, highly variable in loam and clay content, and with different elevations. The flooding from the river will affect largely how the suitability is for farmland. Some low lying areas may benefit in a dry year from water collecting here and the additional soil moisture that is available. In wet years however, these areas may be flooded, areas may be pounded, resulting in failing crops. Another aspect is the salinity of the soils in some localities, e.g. between Kavimba and Kachikau, which is a result of soil properties and fluctuating water tables. In previous studies (Beekma 1989) scenarios were defined for which land suitability was assessed for a variety of crops. Soils in the lower floodplain areas may be most suitable during the dry scenario, however, in wet years crop growth may be severely hampered here and higher elevated ridges may be more suitable. The system is therefore very variable from year to year. 
Land suitability is classified from S1 to S4, basically from 'optimal suitability' (S1) without any limitations for farming, 'marginally suitable' (S3), 'very marginally suitable' (S4), 'unsuitable' (N1) upto 'permanently unsuitable' (N2). Table 1 presents the suitability for the various scenarios. Most land can be cultivated under the dry scenario, whereby the majority of the soils is rated as 'marginally suitable. Sorghum, millet, groundnut and sunflower are most suited for farming in the enclave, maize in fact is not well suited for this area under dry conditions: only with a flood scenario it is performing as good as sorghum.

This reinforces the point that the area is highly dynamic, and under various conditions people adjust their choice of fields they are ploughing. This dynamic is important to sustain rural livelihoods.

Table 1 Area distribution for different crops per class in the Chobe CFDA (Beekma 1989)

\begin{tabular}{lllllllll}
\hline Crops & S2 & S2/S3 & S3 & S3/S4 & S3/N & S4 & S4/N & N1/N2
\end{tabular}

\begin{tabular}{|c|c|c|c|c|c|c|c|c|}
\hline dry scenario: & & & & & & & & \\
\hline maize & - & - & 3256 & 1186 & - & 50972 & 3408 & 623 \\
\hline sorghum & 2182 & 1186 & 52045 & 2476 & 932 & 356 & - & 268 \\
\hline millet & 2387 & 1186 & 46163 & 5797 & 932 & 2710 & - & 268 \\
\hline groundnut & 2364 & 1186 & 44375 & 5797 & 932 & 4498 & - & 268 \\
\hline sunflower & 2270 & 1186 & 51958 & 2476 & 932 & 356 & - & 268 \\
\hline cotton & - & - & 5630 & 11230 & - & 39771 & 2547 & 268 \\
\hline pumpkin & - & - & 15400 & 8429 & 1793 & 17853 & 7520 & 6267 \\
\hline beans & - & - & 15400 & 8429 & 1793 & 17853 & 7520 & 6267 \\
\hline \multicolumn{9}{|c|}{ intermediate scenario: } \\
\hline maize & - & - & 4 & - & - & 12363 & 10385 & 36693 \\
\hline sorghum & - & - & 12363 & 10314 & 932 & 10858 & 10538 & 14435 \\
\hline \multicolumn{9}{|l|}{ flood scenario: } \\
\hline maize & - & - & 5332 & - & - & 1282 & 2547 & 50284 \\
\hline sorghum & - & - & 6614 & 1610 & 932 & 942 & 9222 & 40121 \\
\hline
\end{tabular}

\section{Pandamatenga}

Pandamatenga plains consist mostly of very clayey vertisols ("Black Cotton Soils"). These vertisols have a very narrow management window during which they can be tilled. In the dry season the soils are too hard to be worked on and deep cracks develop. Once wet they become very plastic. In spite of these physical difficulties, they are the better spoils for agricultural development. Although this soil is productive, it does require specific management expertise and specialized equipment to plough and harvest within a short time frame.

The FAO soil survey from 1990 does not provide a land suitability classification (Moganane 1990). The land classification from the Kavango-Zambezi project shows however a mosaic of different land units for the mapped area (Table 2). 
Table 2 Land classification for the western Pandamatenga area (Kavango-Zambezi project 2015)

\begin{tabular}{|c|l|c|c|}
\hline $\begin{array}{c}\text { Mapping } \\
\text { Unit }\end{array}$ & \multicolumn{1}{c|}{ Soil/Land Unit Description } & \multicolumn{2}{|c|}{ Area } \\
\cline { 3 - 4 } ZA1/1 & $\begin{array}{l}\text { Flat almost flat, very deep, moderately well drained, very } \\
\text { dark gray to gray color, sandy clay loam, developed on } \\
\text { lacustrine 0-1.5\% slopes: Soil HypereutricVertisols } \\
\text { (Vreuh) }\end{array}$ & 5,512 & 12.13 \\
\hline $\begin{array}{c}\text { ZA1/2 } \\
\mathbf{2}\end{array}$ & $\begin{array}{l}\text { Flat, moderately deep, well drained, Very dark gray - } \\
\text { Dark grayish brown color, sandy loam texture, } \\
\text { developed on lacustrine, 0-1\% slopes: soils } \\
\text { HypocalcicVertisols (VRccw) }\end{array}$ & 6,656 & 14.56 \\
\hline $\begin{array}{l}\text { ZA2/3 } \\
\mathbf{3}\end{array}$ & $\begin{array}{l}\text { Flat almost flat, very deep, somewhat excessively } \\
\text { drained, dark reddish brown to light brownish gray } \\
\text { color, loamy sand texture, developed on sandveld, slopes } \\
\text { 0-1.5\%, Soils: HypoferalicArenosols (ARflw) }\end{array}$ & 1,903 & 4.19 \\
\hline $\begin{array}{l}\text { ZA2/4 } \\
\mathbf{4}\end{array}$ & $\begin{array}{l}\text { Flat almost flat, very deep, excessively drained, dark } \\
\text { grayish brown to yellowish brown color, developed on } \\
\text { sandveld, deposit, sand texture, slope o-2\% soils: }\end{array}$ & 21,300 & 47.0 \\
\hline ZA5 & $\begin{array}{l}\text { Flat almost flat, very deep, excessively drained, dark } \\
\text { grayish brown to yellowish brown color, developed on } \\
\text { sandveld, deposit, sand texture, slope o-2\% soils: }\end{array}$ & 10,000 & 22 \\
\hline ZA6 & Qettlement & 10.8 & 0.02 \\
\hline ZA7 & Quarry Site & 4.65 & 0.01 \\
\hline
\end{tabular}

\section{Kasane-Kazungula riverine area and floodplains}

East of Kasane along the Chobe River are suitable areas for farming. The local agro-climate is very suitable since this area has the highest rainfall in the country. This allows e.g. Chobe Farms to grow crops like Mangoes, Bananas or Strawberries. Moreover, the access to water from the river also allows for water extraction for irrigated farming.

No soil maps were found for the Kasane-Kazungula area, but the floodplains have mostly a high clayand loam content, are well-drained, and very well accessible. Moreover, markets are nearby, and in the future also exporting from the area would be facilitated with the development of the transport hub. At the same time, it seems the area is not well used, and good farmland is rapidly lost due to haphazard urban development in and around Kasane and Kazungula.

\subsubsection{Livestock grazing}

Chobe District never was a livestock rearing area. The presence of tsetse fly until the middle of last century resulted in an area void of livestock, and limited human habitation (see par. 6.6.1). The potential for livestock grazing is reasonable in parts of the Chobe District. Research done by Mendelsohn (Mendelsohn \& Roberts, 1997), shows that large parts of the region have moderate potential for livestock farming. Only small parts of the Chobe Enclave (mainly in floodplains) have reasonable potential, with a carrying capacity of appr. 3-4 LSU/ha, but during dry months the quality of grazing decreases. Here however many conflicts occur due to the presence of farmlands and fields.

The livestock sector is little developed in Chobe District: no marketing facilities exist, and there are no larger slaughter facilities such as from BMC. Currently meat products from the Zambezi Region may not be exported to the EU due to the region being a Foot and Mouth Disease (FMD) area. Since 1996, the Zambezi Region has suffered five outbreaks of FMD with four occurring in the periods of 2007, 2011 and 2012. Subsequently, the region was placed under FMD restriction for $44 \%$ of the 68 months (Barnes, 2013). Local and informal trade in meat and livestock is also hampered during FMD outbreaks, as no permits for moving livestock are issued during these outbreaks. These restriction of meat export is one of the biggest challenges faced by farmers in the region (Ministry of Lands and Resettlement 2015).

The main constraints in much of the district include: limited surface water, and unsuitable ground water; presence of mogau in sandier areas; conflict with wildlife - both competition for resources and predation. 


\subsection{Suitability for Tourism}

Appraisal of the suitability of zones for tourism development basically depends on two factors: the visibility of wildlife and the accessibility of the zone in terms of roads and proximity to urban areas and airports (like Maun and Kasane). Based on these factors, Table 3 and Figure 3 summarize the suitability of each zone for tourism development. However, this suitability can decrease as a result of high visitor pressure or 'overcrowding'.

The tourism pressure is not evenly distributed within the Chobe district. Even though ecological impact assessments are not available there are signs that the Chobe Riverfront is currently being overused especially in the tourism high-season (both on land and on the water), while most of the remaining Chobe district might be considered 'under-used'. This will be discussed further in $\S 8.5$ and $\S 10.2$. Nevertheless, tourism numbers are expected to increase $50 \%$ next ten years (see $\S 10.2$ ), and it's therefore vital to extend tourism development to other zones as well. Considering the size of these areas (Table 3 ) there is sufficient reason to trust that this can be achieved in a sustainable way (see $\S 10.2)$.

Table 3 Area, current tourism use and proposed use for the different zones

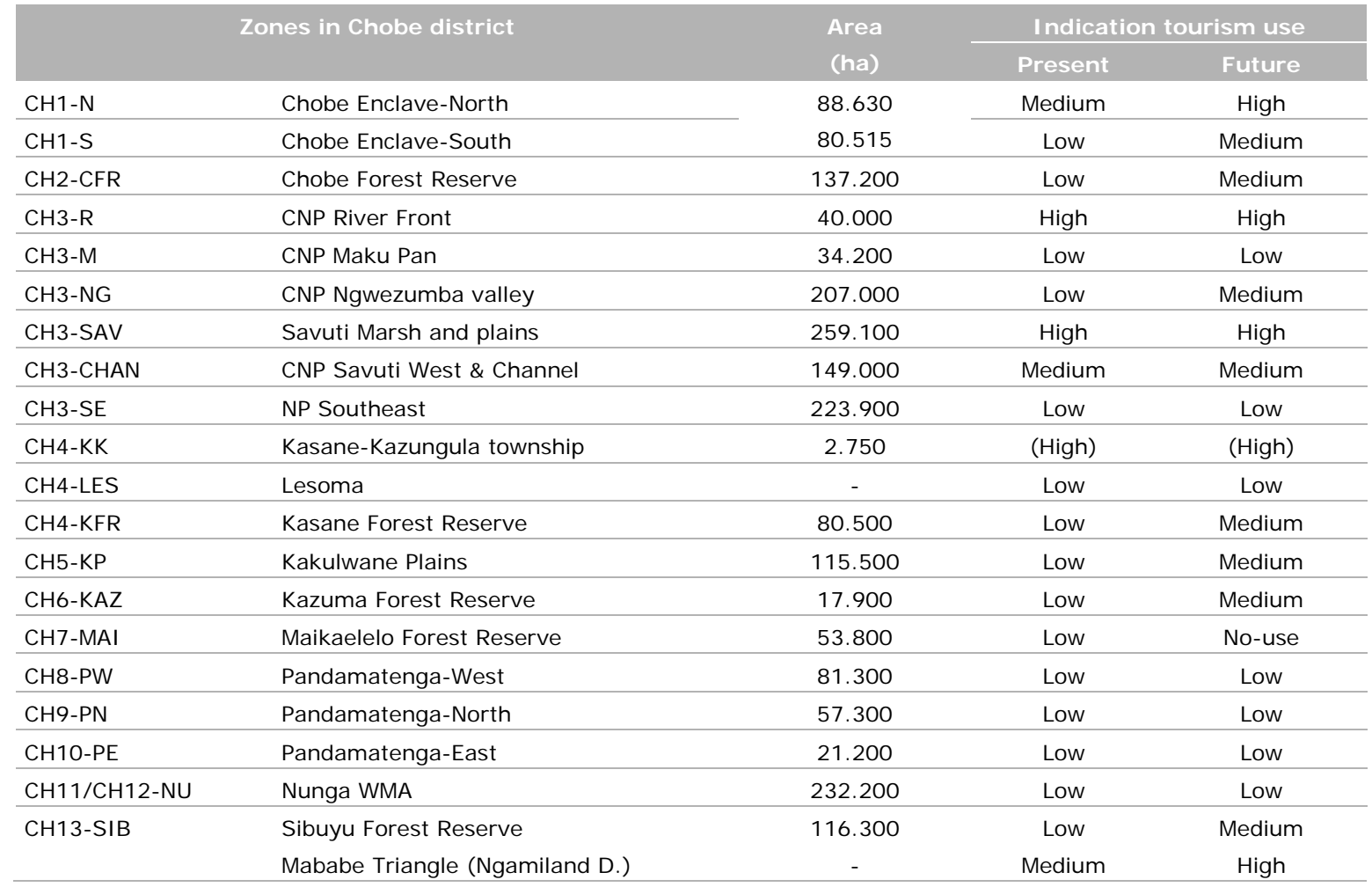




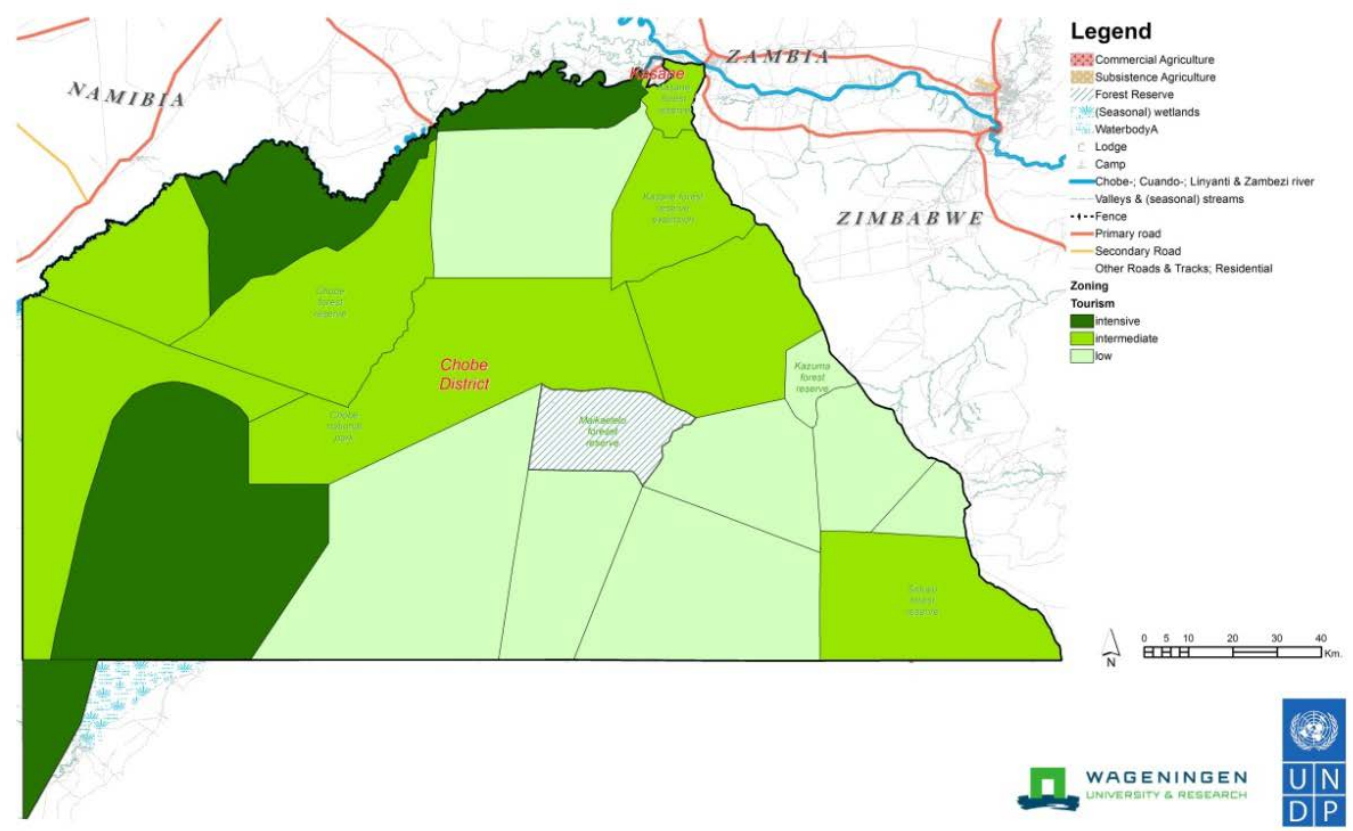

Figure 3 Possible future tourism intensity, based on tourism potential

\section{Potential future tourism high-use zones}

The Chobe Riverfront (CH3-R) will remain high-use zones in the future. Its capacity for further tourism development is limited, if its wilderness experience is to be preserved and improved. The zones most suitable to 'absorb' current visitor pressure from the Chobe Riverfront are the ones that provide similar spectacular wildlife experiences and are relatively close to Kasane Airport. This especially concerns Chobe Enclave North (CH1-N), which is within one-hour drive by tarmac road from Kasane. Other zones close to $\mathrm{CH} 3-\mathrm{R}$ do also have tourism development potential but lack the spectacular riverine wildlife and views. Development potential of $\mathrm{CH} 1-\mathrm{N}$ is mainly located near the floodplains along the river and Lake Liambezi. The zone is however also critical for wildlife access to the river and wildlife corridors to and along the river must therefore be respected. At least two camps are operating in this zone (Three Baobabs and Linyanti Bush Camp), which sub-lease from the local communities. More community based operations (joint ventures) and tourism infrastructure may be developed. A Tourism management plan is (2016-2017) being prepared for $\mathrm{CH} 1$.

The Savuti marsh and plains ( $\mathrm{CH} 3-\mathrm{Sav}$ ) will remain a high-use zone, especially near the marsh and channel. Tourism development is limited here, in order not to spoil the wilderness experience. The Khwai river in the adjacent annex of the Chobe National Park in the south western part of the District also qualifies for some more (community-based) tourism development. High intensity tourism occurs along the rest of the Khwai River, with the section of the Khwai River in Chobe containing no campsites of existing lodges.

\section{Potential future tourism medium-use zones}

Several zones or zone-clusters within the Chobe District are regarded suitable for tourism medium-use in the future:

- The Chobe ( $\mathrm{CH} 2-\mathrm{CFR})$ and Kasane Forest Reserves (CH4-FR) have potential to 'absorb' visitor pressure from the Chobe River Front (CH3-R). These zones are relatively easy accessible, have a reasonable road network and good potential for bird watching and game viewing. Permanent structures are not recommended due to its proximity to Kasane, Kazungula and Lesoma. In the past hunting operations took place in the Chobe FR, whereby the income generated from trophy hunting went to the community (CECT). Whether this is feasible again in the future is unclear.

- The Kakulwane and Pandamatenga plains are important migratory routes for wildlife between conservation areas in Zimbabwe and the Chobe National Park. The fringes of these plains offer good potential for tourism development, meaning the south of the Kasane Forest Extension (CH4-FR), Kakulwane Plains ( $\mathrm{CH} 5-\mathrm{KP})$, Kazuma Forest Reserve (CH6-Kaz) and Sibuyu Forest Reserve (CH13$\mathrm{Sib}$ ). All these zones are relatively easily accessible by the main tarmac road (A33) between Maun and Kasane. 
- The 149,000 ha Ngwezumba valley (CH3-NG) is a wildlife corridor between the Kakulwane plains and the Savuti marshes. It comprises a mixture of open grassland, mopane forest and mixed deciduous forests around clay-bottomed pans that hold water well into the dry winter. The good forage in this area attracts an abundant wildlife. The Ngwezumba River, which carved a gorge, only flows after heavy rainfall. The road network is limited and may be extended to facilitate game viewing. Present one operational camp and some bush camps may be extended with some HATAB and BOGA sites along the valley system to facilitate mobile operators. Tourism development however should remain limited, as this zone is remote and represents the core of the Chobe National Park.

- The Chobe-Enclave South ( $\mathrm{CH} 1-\mathrm{S}$ ) provides good potential for bird watching and game viewing, especially near the river. The road network is limited though and the zone is relatively far away from Kasane, which limits it's suitability as a tourism high-use zone.

\section{Potential future tourism low-use zones}

Zones less feasible for tourism development are the ones that are less accessible and/or offer less spectacular wildlife experiences. Limited accessibility can be due to a limited road network as well as flooding during the rainy season. These zones may however qualify for special target groups. Before the ban on trophy hunting in January 2014, for instance, many of the forest reserves were used for hunting tourism (Mbaiwa 2015), which provided substantial income for the poor local communities.

\section{$2.4 \quad$ Suitability for Forestry}

A number of historical studies reviewed in this land use plan have identified the forest reserves as areas where valuable timber resources were found. However, their distribution within the reserves has been found to be patchy and the important timber tree species are here on the limit of their climatic distribution, with the rest of Botswana being to dry. In terms of timber exploitation, the reserves are at best marginal, in particular as exploitation in the recent past has not been sustainable (with a history of Pterocarpus mining) and fire incidence being high in some areas. Under such conditions sustainable timber extraction is very difficult and not recommended. Timber resources are genetically of great importance for future sustainable forest use (drought resistant strains) and currently the reserves are not suitable for commercial forestry operations. Instead, studies suggest that their role in carbon sequestration could be most important, and that any conversion from intact forest to degraded forest or open savanna could significantly reduce the CO2 stocks of the forest reserves (GIZ 2013), However, the collection of firewood, thatching grass and other non-timber forest products for noncommercial subsistence use is possible as prescribed in existing agreements with neighbouring communities, and as likely to be supported in the up-coming Chobe Forests SEA and consequent forest-specific management plans.

\subsection{Overall land suitability assessment}

Based on the assessment above, as well as current land use and restrictions, we come to the following assessment of suitability for the different planning zones (Table 4). 
Table 4 Planning zones and land suitability (estimate by ILUP experts)

\begin{tabular}{|c|c|c|c|c|c|c|c|c|c|c|c|}
\hline Code & Planning zone & $\frac{8}{\frac{2}{10}}$ & 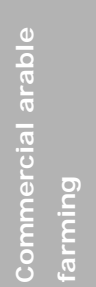 & 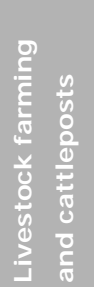 & 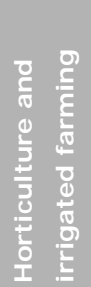 & $\begin{array}{l}\frac{0}{2} \\
\frac{5}{2} \\
\frac{2}{0} \\
\frac{0}{0} \\
\frac{x}{2} \\
\frac{x}{2}\end{array}$ & $\frac{2}{2}$ & $\frac{5}{\frac{5}{3}}$ & 틀 & 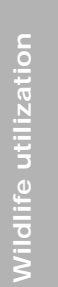 & 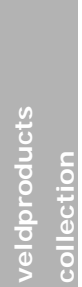 \\
\hline $\mathrm{CH} 1-\mathrm{N}$ & Chobe Enclave-North & $\bullet$ & & $\bullet$ & $\bullet$ & $\bullet$ & & $\bullet$ & - & $\bullet$ & $\bullet$ \\
\hline $\mathrm{CH} 1-\mathrm{S}$ & Chobe Enclave-South & & & $\bullet$ & $\bullet$ & • & & $\bullet$ & $\bullet$ & $\bullet$ & $\bullet$ \\
\hline $\mathrm{CH} 2-\mathrm{CFR}$ & Chobe Forest Reserve & & & & & & • & $\bullet$ & $\bullet$ & $\bullet$ & $\bullet$ \\
\hline $\mathrm{CH} 3-\mathrm{R}$ & CNP River Front & & & & & & $\bullet$ & $\bullet$ & - & & \\
\hline $\mathrm{CH} 3-\mathrm{M}$ & CNP Maku Pan & & & & & & $\bullet$ & & & & \\
\hline $\mathrm{CH} 3-\mathrm{NG}$ & CNP Ngwezumba valley & & & & & & $\bullet$ & $\bullet$ & $\bullet$ & & \\
\hline $\mathrm{CH} 3-\mathrm{SAV}$ & Savuti Marsh and plains & & & & & & & $\bullet$ & $\bullet$ & & \\
\hline $\mathrm{CH} 3-\mathrm{CHAN}$ & CNP Savuti West \& Channel & & & & & & & $\bullet$ & - & & \\
\hline $\mathrm{CH} 3-\mathrm{SE}$ & NP South-East & & & & & & & & & & \\
\hline $\mathrm{CH} 4-\mathrm{KK}$ & Kasane-Kazungula township & $\bullet$ & $\bullet$ & & $\bullet$ & $\bullet$ & & $\bullet$ & $(\bullet)$ & & \\
\hline CH4-LES & Lesoma & $\bullet$ & & & & $\bullet$ & & $\bullet$ & $\bullet$ & $\bullet$ & $\bullet$ \\
\hline $\mathrm{CH} 4-\mathrm{KFR}$ & Kasane Forest Reserve \& Ext. & & & & & & • & $\bullet$ & $\bullet$ & $\bullet$ & $\bullet$ \\
\hline $\mathrm{CH} 5-\mathrm{KP}$ & Kakulwane Plains & & & & & & & $\bullet$ & $\bullet$ & $\bullet$ & $\bullet$ \\
\hline $\mathrm{CH} 6-\mathrm{KAZ}$ & Kazuma Forest Reserve & & & & & & $\bullet$ & $\bullet$ & - & $\bullet$ & $\bullet$ \\
\hline $\mathrm{CH} 7-\mathrm{MAI}$ & Maikaelelo Forest Reserve & & & & & & $\bullet$ & $\bullet$ & & & \\
\hline CH8-PW & Pandamatenga-West & $\bullet$ & $\bullet$ & $\bullet$ & $\bullet$ & & & & & & \\
\hline $\mathrm{CH} 9-\mathrm{PN}$ & Pandamatenga-North & $\bullet$ & $\bullet$ & $\bullet$ & $\bullet$ & & & & & & \\
\hline $\mathrm{CH} 10-\mathrm{PE}$ & Pandamatenga-East & $\bullet$ & $\bullet$ & $\bullet$ & $\bullet$ & & & & & & \\
\hline $\mathrm{CH} 11 \& 12-\mathrm{NU}$ & Nunga WMA & & & & & & & & & $\bullet$ & \\
\hline $\mathrm{CH} 13-\mathrm{SIB}$ & Sibuyu Forest Reserve & & & & & & $\bullet$ & $\bullet$ & • & • & • \\
\hline
\end{tabular}

\section{$2.6 \quad$ Key findings}

- The Chobe District has a moderate to marginal suitability for most forms of land use;

- Arable farming is constrained by variable soils of moderate or poor suitability;

- Soils along the Chobe River between Kasane and Kazungula may be very suited for farming, but no detailed soil mapping data was found to underpin this. Detailed soil surveys would be required, to allocate here land for intensive horticultural production, and possibly irrigation;

- Despite the importance of Pandamatenga for commercial farming, the heavy vertisols require expert knowledge to manage it and specific weather events increase the risks of crop failure or limit harvest opportunities. The potential for commercial irrigated farming is currently being considered but also criticised (see chapter 10);

- Chobe is very marginally suited for livestock farming, due to lack of water and presence of mogau;

- The forestry potential is currently limited, due to climatic conditions, past harvesting practices and fires occurring;

- The forests are an important source for firewood, in particular for people with limited access to resources;

- Chobe District has a high tourism potential, and there is potential for growth of the tourism sector in about half of the planning zones;

- There is a lot of opportunity for tourism away from the congested areas of the Chobe Riverfront and Savuti. 


\section{Integrated Land Use Plan}

\subsection{Introduction}

This chapter describes the major land use type or combination of land use types in relation to the physical map units.

The map units (Figure 4) follows as much as possible existing boundaries, e.g. from WMAs or tribal and State land, but some areas have been subdivided for planning purposes. Table 5 presents all zones, showing the land use zone codes devised for this plan, and summarizes the proposed Land Use designation.

Each zone is described in the remainder of this chapter in terms of: recommended land use designation, land tenure constraints, key issues, primary implementing agencies, stakeholders for engagement, description of issues and reference to management issues detailed later in the plan.

Table 5 Planning zones and proposed Land use designation

\begin{tabular}{|c|c|c|}
\hline Code & Planning zone & Land use designation \\
\hline $\mathrm{CH} 1-\mathrm{N}$ & Chobe Enclave-North & Mixed land use \\
\hline $\mathrm{CH} 1-\mathrm{S}$ & Chobe Enclave-South & Community tourism \\
\hline $\mathrm{CH} 3-\mathrm{R}$ & CNP River Front & Conservation/Tourism - intensive \\
\hline $\mathrm{CH} 3-\mathrm{M}$ & CNP Maku Pan & Conservation/Tourism - low \\
\hline CH3-SAV & Savuti Marsh and plains & Conservation/Tourism - intensive \\
\hline $\mathrm{CH} 3-\mathrm{CHAN}$ & CNP Savuti West $\&$ Channel & Conservation/Tourism - intermediate \\
\hline $\mathrm{CH} 3-\mathrm{SE}$ & NP South-East & Conservation/Tourism - low \\
\hline $\mathrm{CH} 4-\mathrm{KK}$ & Kasane-Kazungula township & Urban \\
\hline CH4-LES & Lesoma & Settlement \\
\hline $\mathrm{CH} 7-\mathrm{MAI}$ & Maikaelelo Forest Reserve & Forest Reserve \\
\hline $\mathrm{CH} 8-\mathrm{PW}$ & Pandamatenga-West & Commercial farming / Community tourism \\
\hline $\mathrm{CH} 9-\mathrm{PN}$ & Pandamatenga & Commercial farming \\
\hline $\mathrm{CH} 10-\mathrm{PE}$ & Pandamatenga & Commercial farming \\
\hline $\mathrm{CH} 11 \& 12-\mathrm{NU}$ & Nunga WMA & Commercial wildlife utilisation \\
\hline $\mathrm{CH} 13-\mathrm{SIB}$ & Sibuyu Forest Reserve & Forest conservation / Tourism - intermediate \\
\hline
\end{tabular}




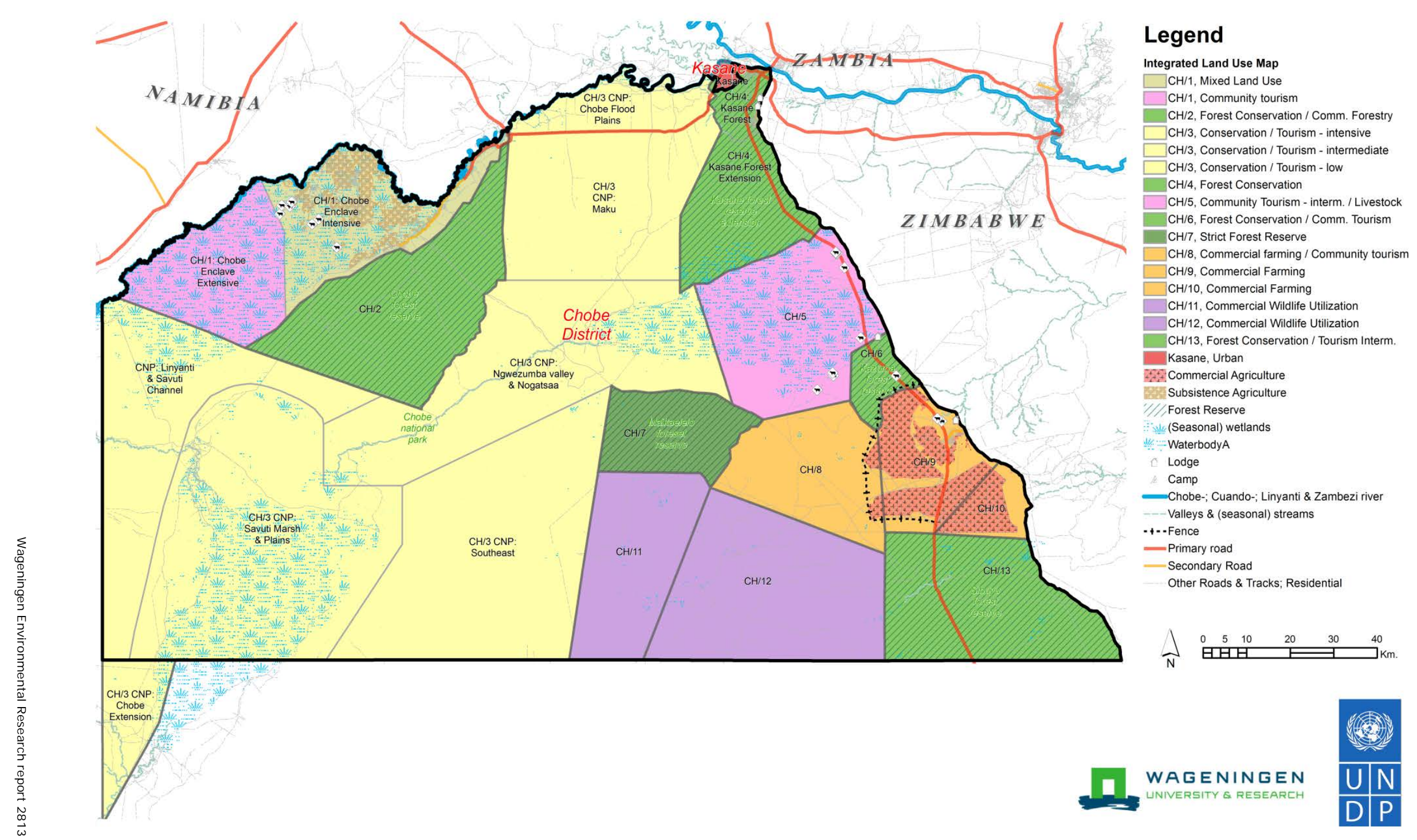

Figure 4 Proposed land use zoning for Chobe District 


\section{CH1-N: Chobe Enclave-North}

\section{Recommended Land-Use Designation:}

Mixed land use

\section{Land Tenure Constraints:}

None

\section{Key issues:}

Settlement and agricultural expansion, combined with increased wildlife populations, have led to high levels of Human-wildlife conflict, especially with Elephant. The 2014 ban on hunting has led to a reduction in CECT revenue, potentially undermining community support for the presence of wildlife in the area.

Cluster fencing has potential for addressing

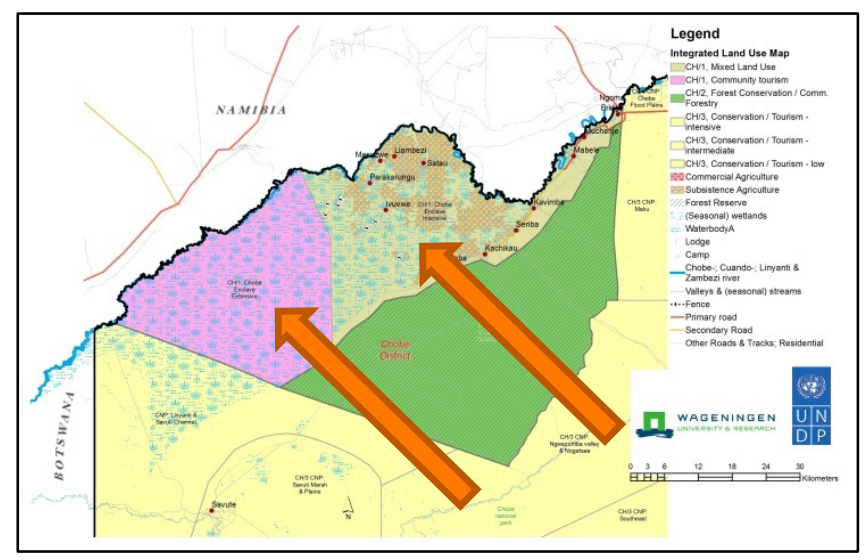

Figure 5 Detailed zoning for $\mathrm{CH} 1-\mathrm{N}$ and $\mathrm{CH} 1-\mathrm{S}$ Human-wildlife conflict, but if alignment and geometry is not correctly set up, conflict could be exacerbated.

Primary I mplementing Agencies:

Chobe Land Board

\section{Stakeholders for Engagement:}

CECT

Dikgosi and VDCs of the five villages

DCP

DAP

BTO

DWNP - PAC

EWB

\section{Description:}

The Chobe Enclave is situated between the Kwando-Linyanti River system, CNP and Chobe Forest Reserve. The Northern part of the Chobe Enclave where the settlements are located (Figure 6) is currently used for mixed farming. The area is zoned for mixed land use, which is in line with the wishes of the residents.

Since the human population is expanding, sufficient land must be reserved to meet future demand for farmland. CH1-N needs to be zoned for optimal agricultural development. Factors such as soil quality, proximity to existing villages and existing fields are key to identify best farmland. We recommend the Land Board to implement LUCIS as per Tawana Land board for allocation of fields. The issues of wildlife corridors and key biodiversity hotspots must be considered to ensure that viable tourism development can still occur and to help reduce the Human-Wildlife Conflict. Fields should be clustered and where possible electrically fenced (see $\S 10.1 .5$ ). Corridors should be conserved with no future allocation in them ( $\S 10.4 .4)$.

Diversification of farming is important, and in particular more intensive small scale farming and horticulture is needed to cater for visitors to the area as well as to Kasane.

Livestock grazing and development of cattleposts can be permitted in the boundary area with $\mathrm{CH}-1$ South, where less arable farming occurs (Figure 6). Also in the West along the river and near Lake Liambezi there is livestock grazing. Expansion of livestock can be permitted where this does not conflict with arable farming or molapo farming. This however should be assessed in discussion with the communities, as most land appears to have been tilled at some point in the recent past. Around the villages along the escarpment conflict with predators is higher, and expansion of cattleposts should not be allowed here.

The area has good potential for tourism due to access to the park and floodplains of the Kwando and Chobe. Two tourism camps are operating within the communities (Muchenje Campsite and Mwandi View) with three lodges / camps on the ridge above Ngoma, but there is more potential in this zone, and community based tourism can also be stimulated. Around Parakarungu there are already ideas for private initiatives, e.g. community camping, cultural activities etcetera. Lake Liambezi is currently little explored for tourism, more facilities could be developed here.

Management issues: Farming innovations $\S 10.1 .1$; wildlife corridors $\S$ 8.3.2, HWC $\S 10.4 .3$; Illegal wildlife off-take $\S 10.4 .4$; 1 10.4.5; Community based tourism $\S 10.2 .5$. 


\section{CH1-S: Chobe Enclave-South}

\section{Recommended Land-Use Designation:}

Community tourism

\section{Land Tenure Constraints:}

None

\section{Key issues:}

Environmental constraints limit livestock and crop production in this area. The area is important for several migratory wildlife species (including Buffalo and Zebra) and includes several known crossborder corridors into Zambezi region. Tourism use along the Linyanti needs to take into consideration Namibian activities, as these appear fairly numerous already.

\section{Primary I mplementing Agencies:}

Chobe Land Board

\section{Stakeholders for Engagement:}

\section{CECT}

Dikgosi and VDCs of the five villages

BTO

DWNP

EWB

\section{Description:}

The Southern part of the Chobe Enclave has limited suitability for farming, as a result of marginal and variable soils, lack of water for livestock or human habitation, and presence of Mogau. It appears that there are no plans for formal agricultural expansion into this southern portion, primarily because of the lack of surface water or potable groundwater. The lower half of $\mathrm{CH} 1$ is a really important migration route for wildlife (see § 8.3.2). Consequently, allocation of farm land here must be limited, kept for wildlife-based tourism activities. The south-western portion of $\mathrm{CH} 1$ must remain unfenced, and with limited settlement, to avoid disruption of wildlife migration and increased human-wildlife conflict. The area has potential for tourism, in particular the floodplains along the river and Lake Liambezi. This area is critical for wildlife access to the river front. A tourism management plan is currently (20162017) being prepared for $\mathrm{CH} 1$. At least two camps are currently operating (Three Baobabs and Linyanti Bush Camp), which in a joint venture arrangement sub-lease the tourism rights. More community based operations (joint ventures) should be stimulated, and tourism infrastructure can be developed near the villages. Support from KAZA and UNDP should be stimulated in the development of these ventures, in cooperation with e.g. mobile operators in $\mathrm{CH} 1$ and $\mathrm{CH} 2$.

Management issues: Farming innovations $\S 10.1 .1$; wildlife corridors $\S 8.3 .2$, 10.4 .5 ; tourism zoning § 10.2.2; Community based tourism § 10.2.5; HWC § 10.4.3; Illegal wildlife off-take $\S 10.4 .4$; Fisheries $\S 10.4 .6$.

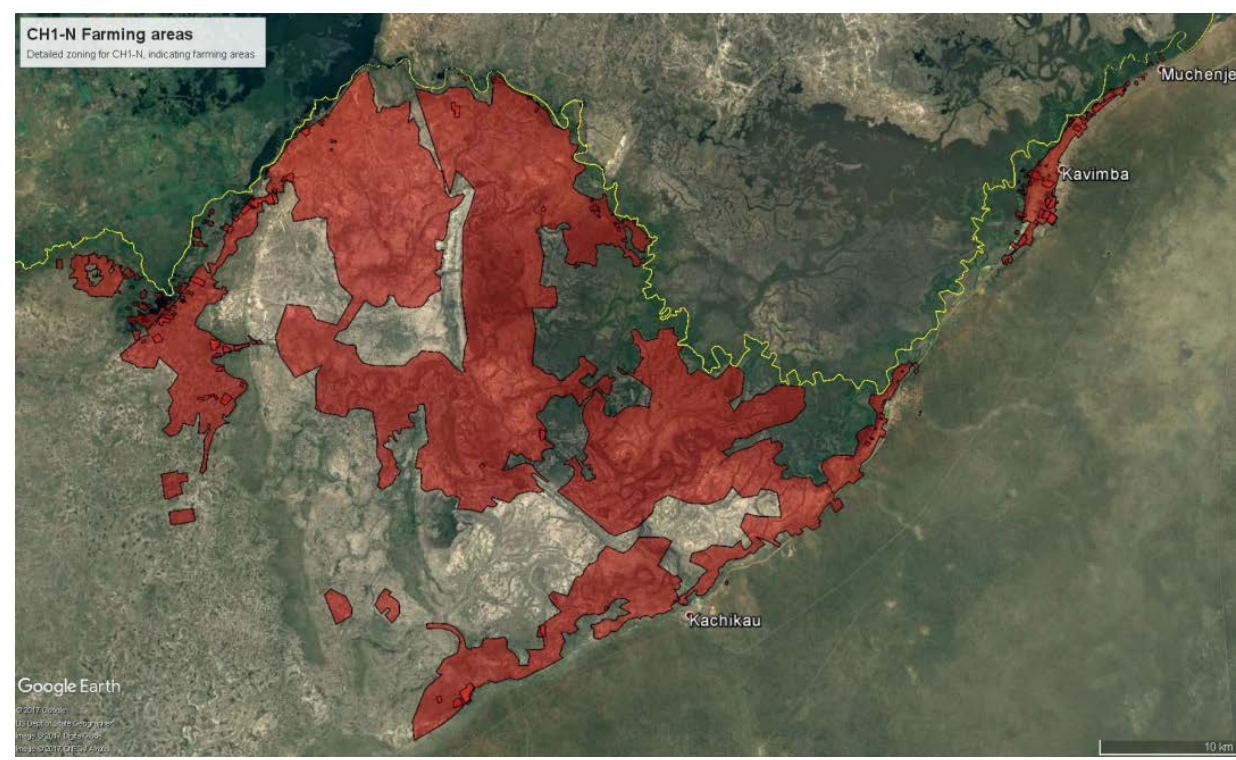

Figure 6 Detailed land use map for $\mathrm{CH} 1-\mathrm{N}$, indicating farming areas 


\section{CH2-CFR: Chobe Forest Reserve}

\section{Recommended Land-Use Designation:}

Forest Reserve with community non-timber subsistence use

\section{Land Tenure Constraints:}

State land, designated forest use. Any major changes in use would require degazettement.

\section{Key issues:}

Original purpose was for timber harvesting, but was not sustainable nor economically viable. Alternative uses that protect key ecosystems and support wildlife migration are needed. Illegal tourism activities are already occurring. Veld product extraction, especially firewood, is not being managed or monitored.

\section{Primary I mplementing Agencies:}

DFRR

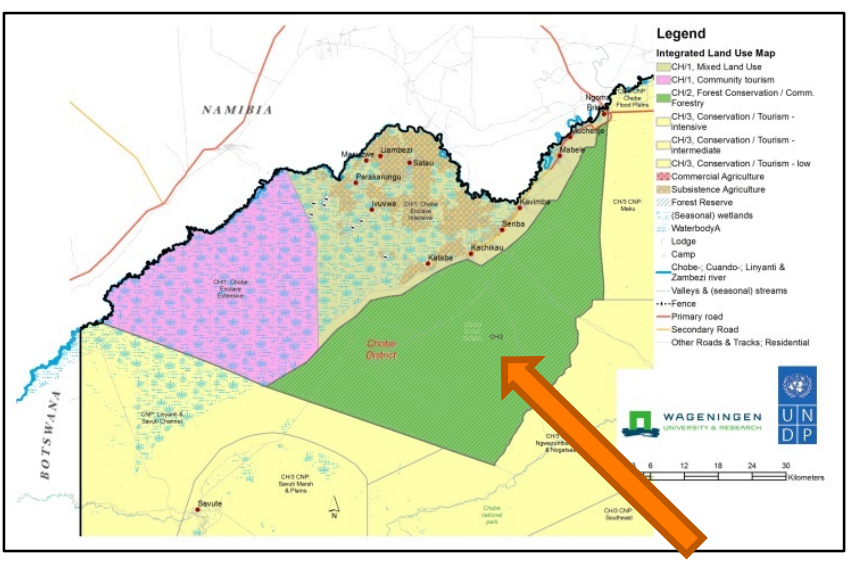

Figure 7 Detailed zoning for $\mathrm{CH} 2$

\section{Stakeholders for Engagement:}

BTO

DWNP

Chobe Enclave communities, and their CBNRM body, CECT

\section{Description:}

The Chobe Forest Reserve is situated between the Chobe Enclave and CNP. The forest reserve should keep its role for the community as a resource base, in particular for NTFPs or veld products. The importance of the Reserve was stressed by the consulted communities in the Enclave. The Forest Reserve has forest conservation as primary land use, and sustainable collection of veld products or other resources, as secondary use. To ensure that the benefits devolve to the appropriate community, the Natural Resource Permits should be managed and monitored by the Trust.

In the past hunting operations took place, with the income generated from trophy hunting going to the CECT. If in due time the hunting ban may be lifted, this area could fulfil its role again for hunting, reestablishing the revenue flow back to the communities. Without this change in the hunting law the District and Botswana Government should look to promote community based ecotourism opportunities that ensure that the CECT communities derive direct economic benefit. It has potential for tourism, which can also relieve pressure off the Chobe riverfront. This zone has a reasonable road network, and good potential for bird watching and game viewing.

Management issues: Firewood and veld products $\S 10.3 .1$; Community based tourism $\S 10.2 .5$; HWC § 10.4.3; Illegal wildlife off-take § 10.4.4. 


\section{CH3: Chobe National Park}

Chobe National Park is bordered by three Forest Reserves $(\mathrm{CH} 2, \mathrm{CH} 4, \mathrm{CH} 7)$, one community grazing area $(\mathrm{CH} 5)$ and one commercial tourism area within WMA ( $\mathrm{CH} 11)$. Primary land use zoning is Conservation, secondary is tourism.

CNP is subdivided in six sub-zones that are discussed below (Figure 8). The sub-zones serve only to propose specific land use, and the delineation of these zones is flexible. However, the broad principles regarding levels of usage should be taken into consideration during the development of the upcoming revision of the CNP management plan.

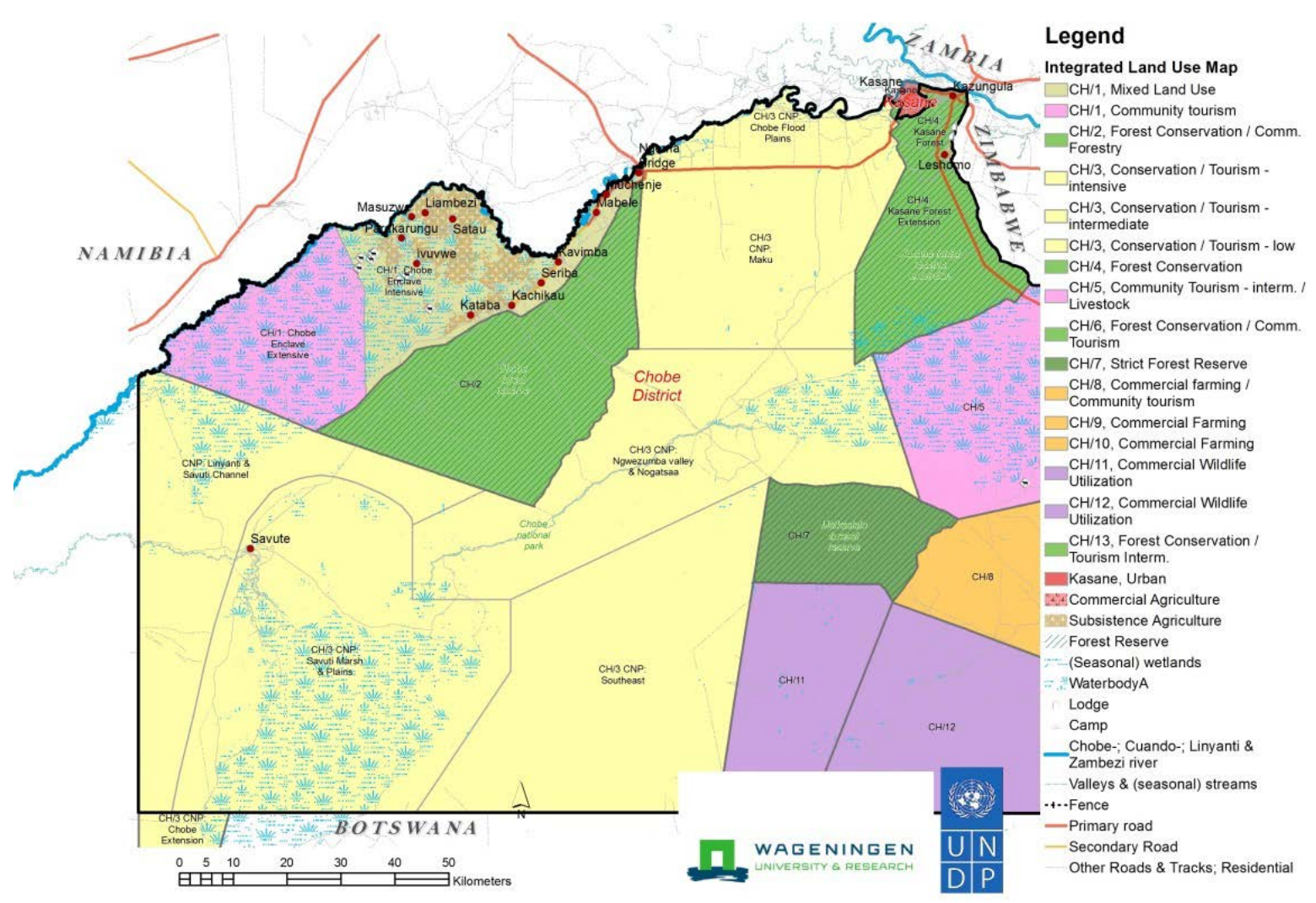

Figure 8 Overview of Chobe National Park CH3 sub-zones (zoning for planning purposes only) 


\section{CH3-R: CNP River Front}

\section{Recommended Land-Use Designation:}

Conservation/Tourism-Intensive

\section{Land Tenure Constraints:}

State land, designated wildlife conservation use.

\section{Key issues:}

Crowding and overuse by tour operators.

Degraded riparian vegetation (reduction in structure and composition) by large numbers of Elephants. Pressure on habitats for protected species (e.g. African skimmers, Hippos).

\section{Primary I mplementing Agencies:}

\section{DWNP}

\section{Stakeholders for Engagement:}

BTO

HATAB

\section{BOGA}

\section{Description:}

The Chobe National Park River Front is the northernmost part of the park, on the Chobe River, and adjoining Kasane township. The River Front and Floodplains are prime conservation area. Tourism is concentrated in this area and very intensive. Considering the importance of tourism for the national economy, it is important to improve the tourism experience, at the same time increase the sustainability of the activities. Therefore zoning measures are required to decrease the pressure on this area, and to create some areas with limited disturbance of wildlife, in particular birds. We recommend that the NP decongestion plan for this zone is implemented and further developed. Active visitor management is essential to maintain the tourism experience. Diversification of the tourism product would also release some pressure from this area. Such measures are proposed for $\mathrm{CH} 1, \mathrm{CH} 2$ or $\mathrm{CH} 3-\mathrm{NG}$ (Ngwezumba valley).

Management issues: Tourism zoning $\S 10.2$.2; wildlife boreholes $\S 10.5 .4$; Visitor management $\S 10.2 .3$.

\section{CH3-M: CNP Maku Pan}

\section{Recommended Land-Use Designation:}

Conservation/Tourism-Low

\section{Land Tenure Constraints:}

State land, designated wildlife conservation use.

\section{Key issues:}

Limited tourism potential. Important refuge area for wildlife.

\section{Primary I mplementing Agencies:}

DWNP

\section{Stakeholders for Engagement:}

BTO

HATAB

BOGA

\section{Description:}

The Maku area in Chobe National Park is located south of the major road crossing the park (A33) and is named after one of the pans in the area. Maku lies in between two forest reserves, $\mathrm{CH} 2$ and $\mathrm{CH} 4$. Limited activities take place at the moment, the area has few outstanding features and the sandy roads and slightly monotonous sandveld vegetation result in limited potential for game viewing. It is a low tourism density zone, and the focus for land use is to maintain ecological integrity and functioning. Management issues: borehole management $\S 10.5 .4$; Illegal wildlife off-take $\S 10.4 .4$. 


\section{CH3-NG: CNP Ngwezumba Valley}

\section{Recommended Land-Use Designation:}

Conservation/Tourism-Intermediate

\section{Land Tenure Constraints:}

State land, designated wildlife conservation use.

\section{Key issues:}

The "backbone" of CNP, with critical hydrological linkage from Kakulwane Plains through Ngwezumba Valley to Savuti Marsh and Mababe Depression. Important linkage between grasslands in the eastern plains to those around Savuti and Mababe Depression. Challenging driving conditions.

\section{Primary I mplementing Agencies:} DWNP

\section{Stakeholders for Engagement:}

BTO

HATAB

BOGA

\section{Description:}

Ngwezumba valley is located south of $\mathrm{CNP}-\mathrm{M}$, and is enclosed by $\mathrm{CH} 2, \mathrm{CH} 5$, and $\mathrm{CH} 7$. The zone is some $15 \mathrm{~km}$. wide along the dry valley with clusters of pans, the biggest being Nogatsaa Pan. The valley ends in the area of Zwei Zwei Pan. This valley is the core of the National Park during the rainy season, and a large Elephant population and other game move here. This area is thus of immense importance for the wildlife populations, which are the pillar of all economic activities in the district and important for all of Botswana. Conservation of this area is therefore crucial.

Besides conservation the area is zoned for tourism (intermediate intensity): the area has in particular potential for those that seek solitude, isolation, the wilderness experience and adventure (see also $\S$ 2.3). The road network and signage should be improved to facilitate tourism activity. The aim is to have mobile safari operators working in this area, rather than promoting self-drives, both for the ecological integrity of the area and safety reasons, with regard to the isolation of the area. Only one lodge is currently operational, and there are some bush camps. It is recommended that few (maximum five) more HATAB and BOGA sites are established along the valley system with an improved game drive network to attract mobile operators.

Further monitoring is required of the borehole pumping strategy and the impact of water provision on the biosphere.

Management issues: Tourism zoning $\S 10.2$.2; borehole management $\S 10.5 .4$. 


\section{CH3-SAV: CNP Savuti Marsh and Plains}

\section{Recommended Land-Use Designation:}

Conservation/Tourism-Intensive

\section{Land Tenure Constraints:}

State land, designated wildlife conservation use.

\section{Key issues:}

Tourism congestion is already a problem. The area appears to have reached its maximum development potential.

\section{Primary I mplementing Agencies:} DWNP

\section{Stakeholders for Engagement:}

BTO

HATAB

BOGA

\section{Description:}

The core of CNP is formed by Savuti, the Channel and adjoining marsh south of the area. The landscape is strongly connected with the Ngwezumba valley through to Kakulwane Plains, as well as the Mababe depression, and through the Savuti channel to the Kwando-Linyanti, and at larger distance with the Okavango Delta. Savuti is thus the central link for migratory species in northern Botswana. Savuti is a prime wildlife area and forms with the River Front the main tourist area of the National Park. A plea to conserve this area as a pristine landscape, without fences and boreholes, is made by Fynn (2014) in a policy document from ORI. Proposed primary land use is Conservation.

Campsites are operated through private companies along the Savuti Channel. Several commercially operated camps run in this same area, some are located at larger distance, e.g. near Gcoha Hills. All tourism is based on the important wildlife resources in the area, the open plains which allow for good game viewing. The presence of large predators like Lion and leopard is an additional important attraction.

The current tourism activity around the marsh and near the channel is at maximum carrying capacity. It is therefore recommended that no new lodges be built here and no further campsites developed. Any further beds within the area will lead to a loss of wilderness experience for the tourists, while detrimental impact on wildlife behaviour could occur with any further increase of tourism numbers. Some game viewing hides and towers could be developed though to facilitate better game viewing. The Mababe Triangle is technically outside Chobe District, but still part of CNP. Community tourism initiatives can be facilitated further south, near Mababe and along the Khwai River. There are possibilities here for another campsite/lodge. The Khwai River serves a purpose for low to middle level tourism. It is high density, there would be potential for one more tourism facilities in this area. DWNP should undertake a tourism carrying capacity assessment of all of these zones to assess the potential for further development.

Management issues: Tourism zoning $\S 10.2$.2; borehole management $\S$ 10.5.4. 


\section{CH3-CHAN: CNP Savuti West \& Channel}

\section{Recommended Land-Use Designation:}

Conservation/Tourism-Intermediate

\section{Land Tenure Constraints:}

State land, designated wildlife conservation use.

Key issues:

Area is difficult to access due to sandy conditions. I mportant migration route between the marsh and Linyanti/Kwando system.

\section{Primary I mplementing Agencies:}

DWNP

Stakeholders for Engagement:

\section{BTO}

HATAB

BOGA

\section{Description:}

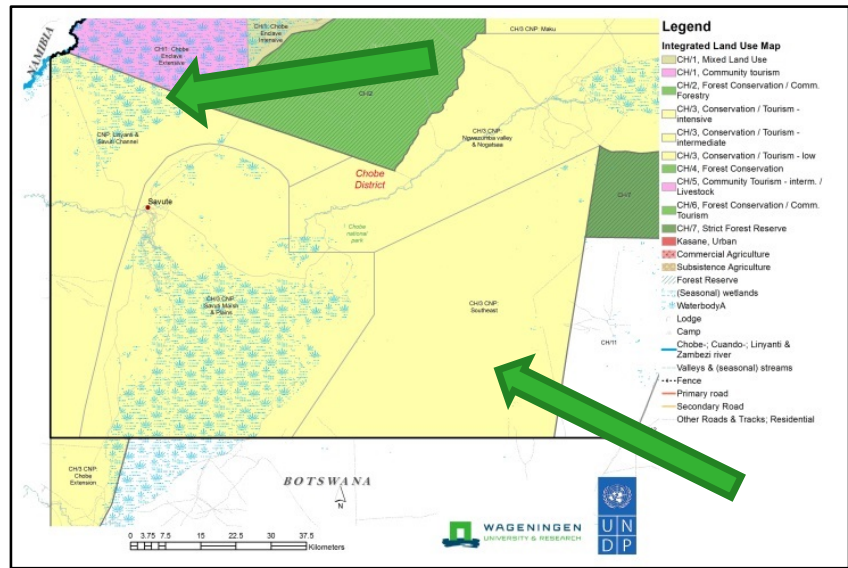

Figure 12 Detailed zoning for $\mathrm{CH} 3-\mathrm{CHAN} \& \mathrm{CH} 3-\mathrm{SE}$

This dry Sandveld zone is situated west of Savuti, bordering Ngamiland District, just south of $\mathrm{CH} 1$ and $\mathrm{CH} 2$. The area is an important wet season grazing area for wildlife species (and their predators) moving out of Savuti, in particular when the channel flows. The area is not easily accessible due to the sandy soils and the presence of the Magikwe sand ridge. Tracks are crossing towards Linyanti, Gcoha Hills, Khwai or Mababe.

Primary land use is Conservation with tourism (intermediate intensity). Tourism here is mainly based on game drives from the campsite or the safari camps located in Savuti. It is recommended that no further development of infrastructure is permitted.

Management issues: Tourism zoning $\S 10.2$.2; borehole management $\S$ 10.5.4.

\section{CH3-SE: CNP South-East}

\section{Recommended Land-Use Designation:}

Conservation/Tourism-Low

Land Tenure Constraints:

State land, designated wildlife conservation use.

\section{Key issues:}

Remote, difficult to access. Low tourism potential. Useful as a wildlife refuge area.

\section{Primary I mplementing Agencies:}

DWNP

\section{Stakeholders for Engagement:}

BTO

HATAB

BOGA

\section{Description:}

This zone is located east of the Savuti Marsh, south of Ngwezumba Valley. In the East it is bordered by Maikaelelo Forest Reserve $(\mathrm{CH} 7)$ and commercial wildlife utilisation area $\mathrm{CH} 11$. Few roads cross the area towards the north-east, some visitors pass here, sometimes for camping. Due to its remoteness and limited variability and distinct features, the tourism use potential is low.

Management issues: borehole management $\S 10.5 .4$. 


\section{CH4-KK: Kasane-Kazungula Township}

\section{Recommended Land-Use Designation:}

Urban

\section{Land Tenure Constraints:}

\section{Key issues:}

Rapid urban and peri-urban development; commercial interest. Showcase for Chobe Tourism Destination.

\section{Primary I mplementing Agencies:}

\section{DTRP and CLB}

Stakeholders for Engagement:

Dikgosi and VDC

\section{Description:}

Kasane-Kazungula township is locked in by protected areas, notably the Chobe River, Kasane

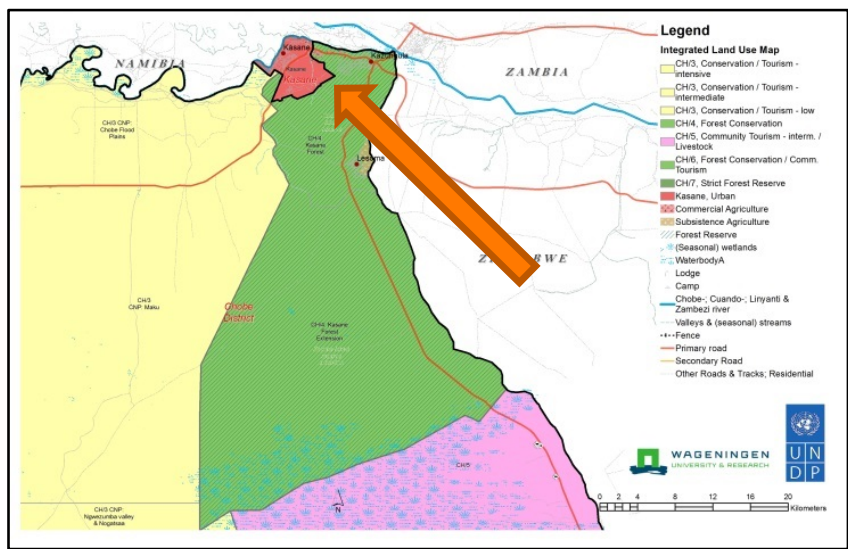

Figure 13 Detailed zoning for $\mathrm{CH} 4-\mathrm{KK}$

Forest Reserve and Chobe National Park. Kasane is very dynamic and rapidly developing (see $\S 7.4$ and 9.3), primary function is urban area, with small-scale industries and service providers (tourism in particular), and localized farming and horticulture.

There is an urgent need for further expansion of the Kasane-Kazungula urban area. Considering regional development priorities and the need for income and employment generation we recommend therefore - under very strict conditions (see § 10.6.2)- to degazet part of the Kasane Forest reserve. The green aspect of the township should be engrained in the inception and development phase. Areas are being and should be designated where local entrepreneurs are stimulated to develop activities, like production and sale of crafts, artisanal products, local guided tours in and around town and boating trips on the river.

The demand for agricultural produce for visitors, combined with the presence of water and reasonable soils, would require more promotion of horticultural and agricultural production. This would require sub-zoning of agricultural land and reservation for farming, e.g. in the area of Chobe farms and Kazungula. A detailed soil survey is required to identify potentially suitable agricultural land in the floodplain area between Kasane and Kazungula (outside the wildlife corridors). Plots currently not put to use or land which has been undeveloped for more than 3 years in this hotspot for development should be re-claimed. Agricultural land can be given out to commercial farmers with experience in (irrigated) farming or horticulture. No function change of this land should be allowed in future. A LUCIS based approach could be followed to define optimal land allocation, to identify land for agriculture and urban development, whilst also taking cognisance of stakeholder needs and desires, and the Kasane-Kazungula development plan, once adopted.

Management issues: wildlife corridors $\S 8.3 .2$, 10.4.5; Farming innovations $\S 10.1 .1$; Community based tourism § 10.2.5; HWC § 9.5.3, § 10.4.3; Fisheries § 10.4.6; urban sprawl § 10.6.3; green urban development $\S 10.6 .1$; Poverty alleviation $\S 10.9$. 


\section{CH4-LES: Lesoma Community}

\section{Recommended Land-Use Designation:}

Settlement zone

\section{Land Tenure Constraints:}

Technically within forest reserve on State land. Residential allocations should be on a densehousing basis to avoid the need for further encroachment into the forest reserve.

\section{Key issues:}

The area serves as a kind of 'overflow' area from Kasane-Kazungula. Companies establish lodges and camps here to cater for limited capacity in Kasane, resulting in at least 4 lodges.

\section{Primary I mplementing Agencies:}

Department of Lands

Chobe Land Board

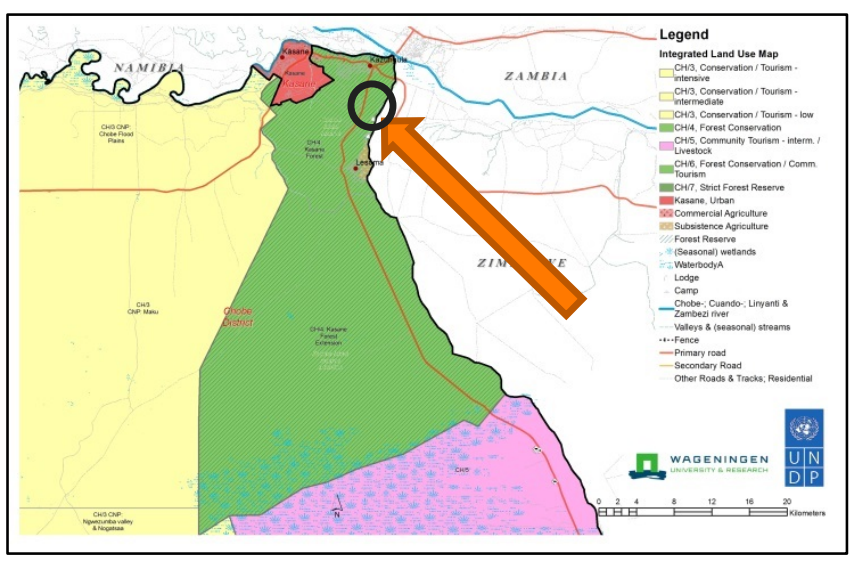

Figure 14 Detailed zoning for CH4-LES

\section{Stakeholders for Engagement:}

\section{Department of Crop Production}

\section{Description:}

Lesoma was originally a San settlement, but the development of commercial farms nearby, the growth of the tourism industry, and in-migration from elsewhere in the country has led to the expansion of the settlement and a change in land use.

It is recommended that this zone is taken out of the Forest Reserve. The proposed contour (Figure 15) still leaves room for expansion and avoids wildlife migration corridors, such as just north of the Lesoma village. No further expansion of any kind (be it houses or lodges) should be permitted outside this contour.

Management issues: Farming innovations § 10.1.1; HWC § 9.5.3, § 10.4.3; urban sprawl § 10.6.3; Poverty alleviation $\S 10.9$.

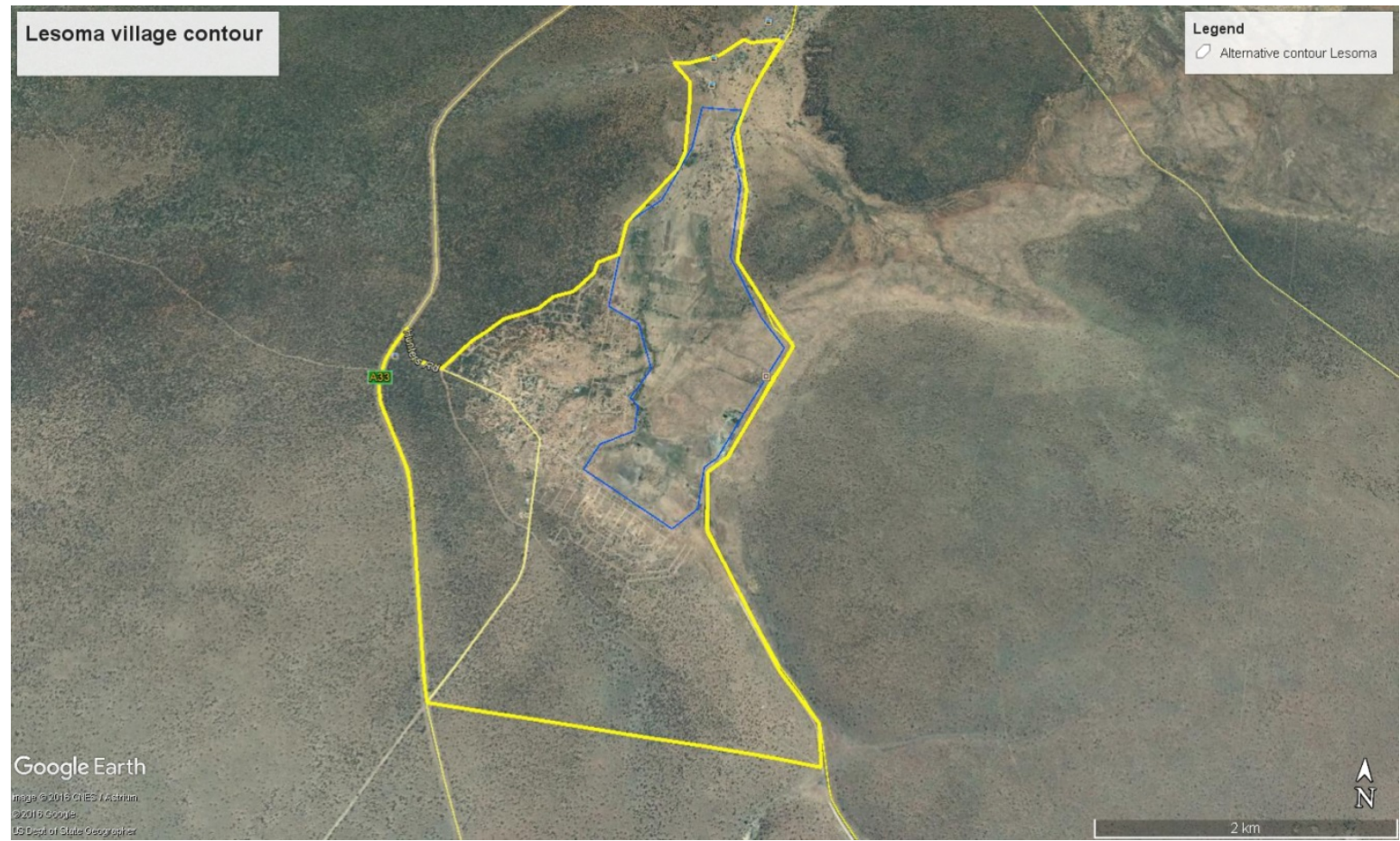

Figure 15 Detailed zoning for $\mathrm{CH} 4$-LES, proposed contour of Lesoma settlement zone 


\section{CH4-KFR: Kasane Forest Reserve and Extension}

\section{Recommended Land-Use Designation:}

Forest conservation

\section{Land Tenure Constraints:}

State land, designated forest use. Any major changes in use would require degazettement.

\section{Key issues:}

Original purpose for timber harvesting was not sustainable nor economically viable. Pressure due to the close proximity of Kasane and Kazungula township is high. Illegal settlement, dumping of waste, and sand mining occurring. Veld product extraction, especially firewood, not being managed or monitored. This is an important cross-border corridor for wildlife moving between Zimbabwe and CNP.

\section{Primary I mplementing Agencies:}

DFRR

\section{Stakeholders for Engagement:}

BTO

DWNP

Kasane, Kazungula and Lesoma communities

\section{Description:}

Kasane Forest Reserve is the smallest of the Forest Reserves, and is adjoining the Forest Extension. The area is located between the Kasane-Kazungula township, Chobe National Park, and Kakulwane Plains. The area is of importance as resource for the people (collection of veldproducts). Besides, the area is of great importance for wildlife migration, from the interior of the Chobe District towards the Chobe river and floodplains.

To a limited extent collection of firewood could be permitted, which provides income to households, but quota should be observed and monitoring is required to ensure sustainable off-take levels.

Part of the Reserve has already been degazetted. Considering the urgent need for expansion of the township it is recommended that the degazetted area be expanded (see $\mathrm{CH} 4-\mathrm{KK}$ ), with extent and location to be studied. It is of importance that the remainder of the Forest Reserve remains intact.

Management issues: wildlife corridors $\S$ 8.3.2, § 10.4.5; urban sprawl § 10.6.2; Firewood and veld products $\S 10.3 .1$; Illegal wildlife off-take $\S 10.4 .4$. 


\section{CH5-KP: Kakulwane Plains}

\section{Recommended Land-Use Designation:}

Community tourism-intermediate and livestock grazing

\section{Land Tenure Constraints: \\ None \\ Key issues:}

Abuts directly on CNP, and the designated status of tribal grazing area suggests potential of conflict in the absence of a buffer area.

The northern part of the CHA falls on a vertisol plains area that is absolutely critical to the hydrological functioning of the Ngwezumba valley, through which it links to the Savuti marsh. These plains are very important corridors for movement of migratory species such as Zebra, and need to

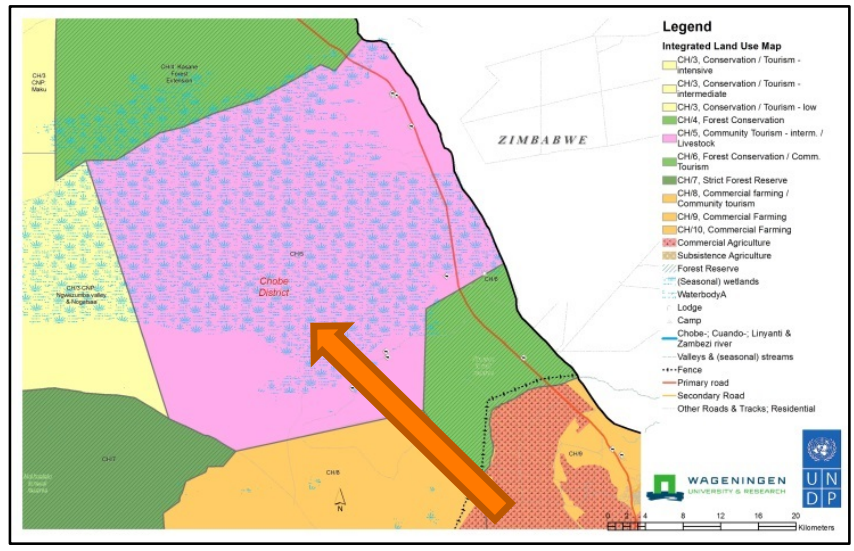

Figure 17 detailed zoning for $\mathrm{CH} 5-\mathrm{KP}$ be kept open and unfenced. Agricultural development should be avoided here to minimise Humanwildlife conflict, and to support the overarching national goal of maintaining the wildlife-based focus of Chobe District.

\section{Primary I mplementing Agencies:}

Chobe Land Board

\section{Stakeholders for Engagement:}

DWNP

Lesoma community

BTO

Department of Crop Production

\section{Description:}

Ch5 Kakulwane Plains is situated between CNP and the Zimbabwean border and Hwange NP, two forest reserves and Pandamatenga area. Currently it is not designated. This zone is a vital source area for the Ngwezumba valley, through infiltration of surface water the larger landscape system is maintained. Its location between the core of CNP and Hwange means that this is essential for longterm sustainable wildlife populations, many studies have shown that the ecotone between the Miombo/Mukusi woodland and the grasslands on the vertisols are a critical corridor for wildlife movements (see § 8.3.2) and the importance for seasonal grazing. For these reasons it is strongly recommended not to change land use into farming, this would lead to a strong increase in conflict. Proposed zoning is Community tourism. There should be a high level of government support to facilitate community based ecotourism. Communities - in a JVP with a safari company - can do wildlife viewing operations in this area. Also a commercial wildlife lodge or lodges from Lesoma can operate here.

There are currently cattleposts encroaching into the plains - whilst there is no direct conflict between cattle and the other herbivores, further expansion of cattle will lead to more conflict with predators. It is therefore proposed to gazette it as a WMA, with stricter controls on pastoral and arable development. Existing cattleposts will be allowed, but no further expansion or establishment of new cattleposts is permitted. In this area no compensation can be paid for livestock losses due to predators.

Management issues: wildlife corridors $\S$ 8.3.2, $\S 10.4 .5$; Firewood and veld products $\S 10.3 .1$; Fire management $\S 10.3 .2$; Illegal wildlife off-take $\S 10.4 .4$; Community based tourism $\S 10.2 .5$. 


\section{CH6-KAZ: Kazuma Forest Reserve}

\section{Recommended Land-Use Designation:}

Forest conservation and Community tourism

\section{Land Tenure Constraints:}

State land, designated forest use. Any major changes in use would require degazettement.

\section{Key issues:}

Original purpose for timber harvesting not sustainable nor economically viable. Pressure due to the illegal self-drive tourism, and potential cross-border access by poachers. Though small, the area has some attractive landscapes, and its proximity to the tar road offers an opportunity to relieve tourism pressure on CNP.

Primary I mplementing Agencies: DFRR

\section{Stakeholders for Engagement:}

BTO

DWNP

Pandamatenga community

\section{Description:}

Kazuma FR is situated between Kakulwane Plains, Pandamatenga and CH8. The area forms a buffer between the commercial farming area and the more open Plains in the North. It is proposed to zone the area for Community based tourism, whereby the communities - in a JVP with a commercial company- can develop tourism. The denser forest would allow for a commercial wildlife lodge to be developed in the area, but also tourism from the lodges located near Pandamatenga could conduct wildlife viewing activities here. Along the main road domestic (low-cost) tourism could be stimulated. Management issues: Firewood and veld products $\S 10.3 .1$; Fire management $\S 10.3 .2$; Illegal wildlife off-take $\S 10.4 .4$; Community based tourism $\S 10.2 .5$.

\section{CH7-MAI : Maikaelelo Forest Reserve}

\section{Recommended Land-Use Designation:}

Forest Reserve

\section{Land Tenure Constraints:}

State land, designated forest use. Any major changes in use would require degazettement.

\section{Key issues:}

Original purpose for timber harvesting not sustainable nor economically viable. Area is remote, and access is difficult. Its location in the centre of Chobe District, abutting CNP suggests an important refuge function for both plant resources and wildlife.

\section{Primary I mplementing Agencies:}

DFRR

\section{Stakeholders for Engagement:}

DWNP

\section{Description:}

Maikaelelo Forest Reserve is located in between CNP, Nunga WMA and CH8. It is remote, far from existing communities. The area still contains some important areas with gallery forests, which are quite untouched by man. It is proposed that this area is zoned as a strict reserve. No developments or activities should be allowed, and no-one should enter the area without a permit. The area is kept for scientific research, which would ensure preservation of valuable plant and genetic resources for future use.

Management issues: Fire management $\S 10.3 .2$; Illegal wildlife off-take $\S 10.4 .4$. 


\section{CH8-PW: Pandamatenga West}

\section{Recommended Land-Use Designation:}

Commercial farming and community tourism

\section{Land Tenure Constraints:}

\section{None}

\section{Key issues:}

In the recent past this area has been intended to serve as wildlife utilisation in a livestock grazing area. However, the arbitrary composition of the constituent communities in the CBNRM Trust, KALEPA, combined with its distance from any of these communities, has hampered the development of tourism. In addition, good soils in the east make it more attractive for crop production. Intensive agriculture would be a direct conflict with the "refuge" function of Maikaelelo forest reserve.

\section{Primary I mplementing Agencies:}

Chobe Land Board

\section{Department of Crop Production}

\section{Stakeholders for Engagement:}

KALEPA Trust and its constituent communities: Kazungula, Lesoma and Pandamatenga

\section{Description:}

Pandamatenga West is located west of the existing commercial farming area of Pandamatenga. The area is currently not designated for a particular land use, however it has been set aside for CBNRM activities for KALEPA Trust, with the potential of ecotourism activities through joint venture partnerships. As described in $\S 8.1$, there are plans for further development of commercial farming. Based on sustainable land use principles, it is recommended to develop commercial dryland farming. I rrigated farming is not sustainable here, groundwater resources are insufficient, water transport from the Zambezi would be very costly, it is vulnerable for climate change, and would require a lot of energy. The agro-consultants' plans for irrigated farming seem rather optimistic, considering the quality and variability of the soils, and is only feasible based on huge sunk investments by the Botswana Government.

It is recommended to expand commercial farming stepwise in smaller phases (e.g. 10,000 ha per phase), and on the condition that also communities receive a share of land in each phase and that community tourism is not unduly affected. However, by granting permission for this area to be developed, long-term future development could see developments expand to the far west of the CHA onto the Forest Reserve. It is therefore essential to install a buffer zone of at least $15 \mathrm{~km}$ in the west of $\mathrm{CH} 8$ in which no commercial agriculture will occur. Also the wildlife corridor through Pandamatenga should be retained (Figure 21). The undeveloped area in the west, unsuitable for farming, would allow for low-density community tourism activities through KALEPA Trust.

Management issues: Farming innovations $\S 10.1$.1; Commercial farming $\S 10.1 .3$; Wildlife corridors $\S$ 10.4.5; Community based tourism $\S 10.2 .5$; Fire management $\S 10.3 .2$. 


\section{CH9-PN: Pandamatenga North}

\section{Recommended Land-Use Designation:}

Commercial farming

\section{Land Tenure Constraints:}

None

\section{Key issues:}

The commercial farms fall across a critical wildlife corridor linking Hwange to CNP. Farming blocks should be realigned parallel to, instead of across, the corridor. There are undeveloped opportunities linking agriculture to tourism here, such as horticultural production to supply Chobe lodges with fresh produce.

\section{Primary I mplementing Agencies:}

Chobe Land Board

Department of Crop Production

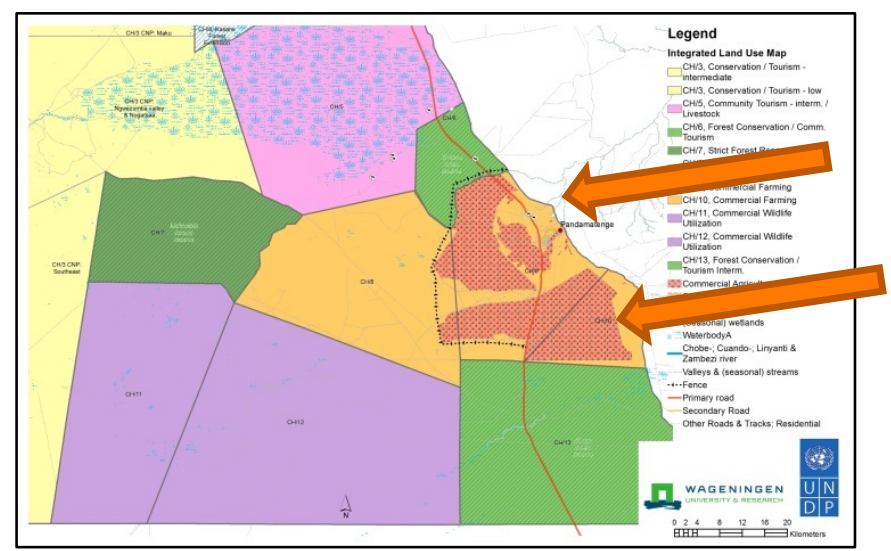

Figure 20 Detailed zoning for $\mathrm{CH} 8-\mathrm{P}$ and $\mathrm{CH} 8-\mathrm{PE}$

\section{Stakeholders for Engagement:}

Pandamatenga community

DWNP

\section{Description:}

Pandamatenga-North is located between the Kazuma Forest Reserve, Pandamatenga-West and Pandamatenga-East. The area has been developed over the past 30 years for commercial farming. The Pandamatenga settlement is also located in this zone. It is proposed that Commercial farming is maintained. In addition, land should be made available for intensified horticultural production by community members or groups that are assisted with support programs from MoA or KAZA.

The current corridor between the two blocks should remain open, that is, no building and construction of infrastructure should take place (see Figure 21). Some of the farmlands in the corridor must be vacated, whereby farmers will be compensated by allocation of farmland further south in this block, or in $\mathrm{CH} 8$ (Figure 19). Some of the buildings in the corridor seem to be temporary, for few others some financial compensation might be required; the buildings should be removed.

The electric fence placed some years back (see §. 8.3.1.5) has been poorly sited and needs to be relocated to re-establish the corridor and to release enclosed wildlife, in line with the recommendations from earlier assessments and studies done (ESA 2014). The newly proposed fence from the farmers' association needs to be carefully planned, and based on location, size and alignment it should be assessed whether it can adjoin the current fence (see § 10.1.5). Appropriate road signage and speed reductions north and south of the corridor should be put in place to warn motorists, especially truckers.

Environmental conditions must improve: further study is required into the long-term impact on soil carbon stocks, as well as leaching of agro-chemicals into groundwater and surface water (see also $\S 9.4)$.

Management issues: Farming innovations $\S 10.1 .1$; Commercial farming $\S 10.1 .3$; Wildlife corridors $\S$ 10.4.5; Community based tourism $\S 10.2 .5$; Fire management $\S 10.3 .2$. 


\section{CH10-PE: Pandamatenga East}

\section{Recommended Land-Use Designation:}

\section{Commercial farming}

\section{Land Tenure Constraints:}

None

\section{Key issues:}

As with Pandamatenga North, the commercial farms fall across a critical wildlife corridor linking Hwange to CNP. Farming blocks should be realigned parallel to, instead of across, the corridor. More attention should be paid to the environmental aspects of commercial production, to ensure the longterm sustainability of the soils and consequently production levels.

\section{Primary I mplementing Agencies:}

Chobe Land Board

Department of Crop Production

\section{Stakeholders for Engagement:}

Pandamatenga community

DWNP

\section{Description:}

This area has been developed more recently as farming area. The Commercial farming is maintained. A relocation of the electrified fence is required to open the corridor. Some of the farmlands in the corridor may need to be vacated, whereby farmers might be allocated farmland further south in this block or in $\mathrm{CH} 8$ (Figure 19, 21). For some of the buildings in the corridors financial compensation may be required, but the number of buildings is limited. Once realized, the corridor ultimately fulfils its objective. Appropriate road signage and speed reductions north and south of the corridor should be put in place to warn motorists, especially truckers.

Also here environmental conditions must improve. Study is required into the long-term impact on soil carbon stocks, as well as more sustainable use of agro-chemicals to protect groundwater and surface water.

Management issues: Farming innovations $\S 10.1 .1$; Commercial farming $\S 10.1 .3$; Wildlife corridors $\S$ 10.4.5; Community based tourism $\S 10.2$.5; Fire management $\S 10.3 .2$.

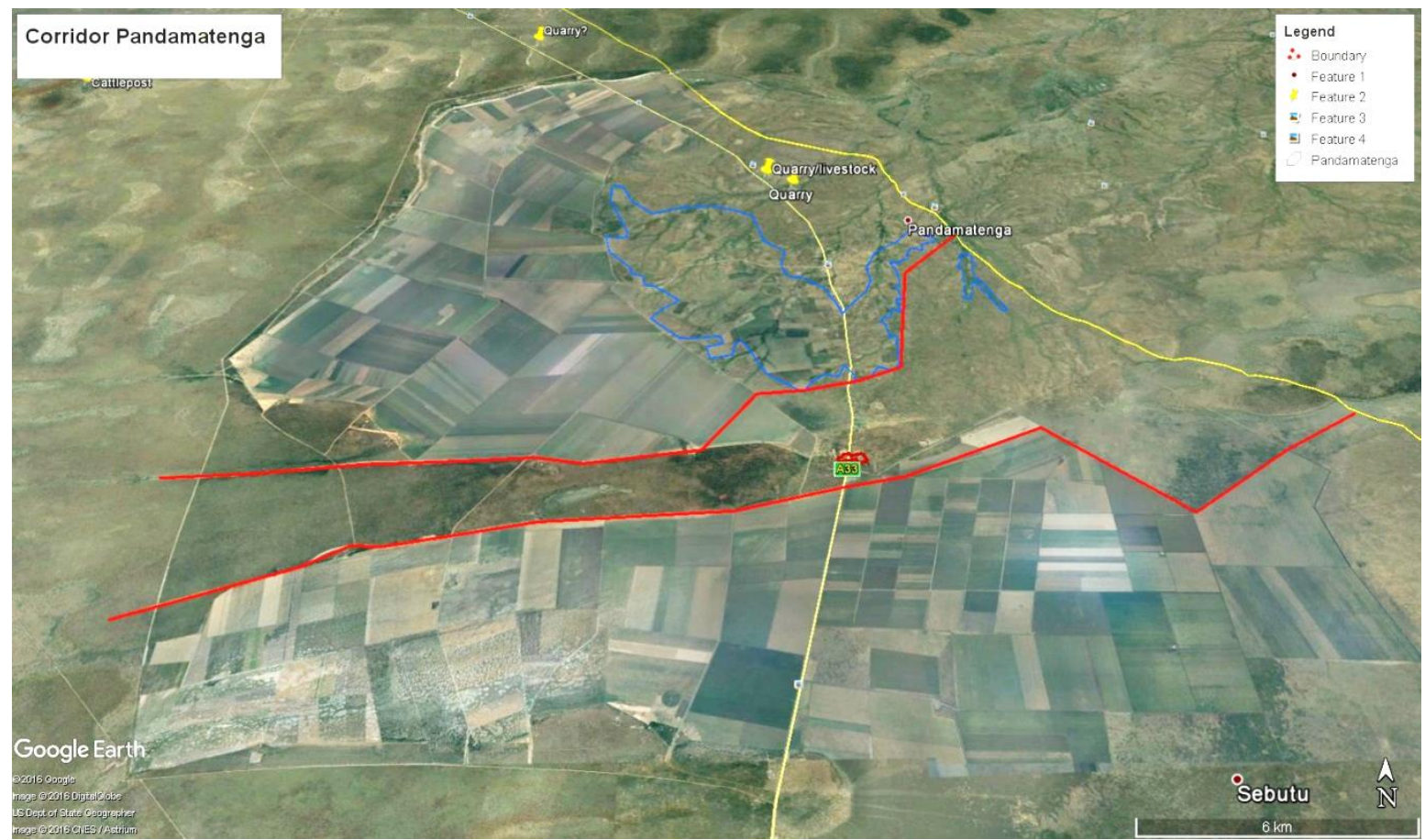

Figure 21 Corridor between farming blocks of Pandamatenga that needs to be vacated 


\section{CH11\&12-NU: Nunga WMA}

\section{Recommended Land-Use Designation:}

Commercial wildlife utilisation

\section{Land Tenure Constraints:}

None

\section{Key issues:}

The moratorium on hunting has left $\mathrm{CH} 11$ empty, as no suitable photographic tour operator has tendered for the area. This makes the wildlife in the area vulnerable to commercial poaching. The installation of permanent water points to attract wildlife may have negative consequences for wildlife populations in the mid- to long-term.

\section{Primary I mplementing Agencies:}

Chobe Land Board ${ }^{3}$ and BTO

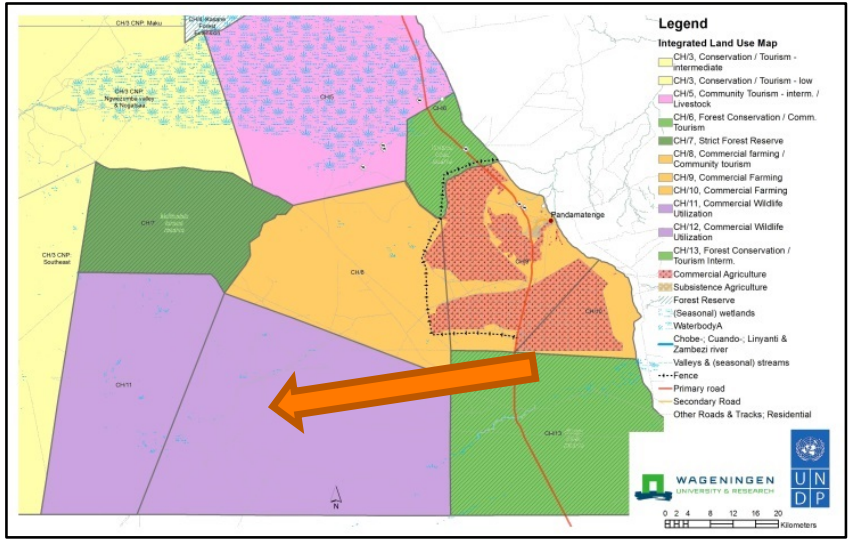

Figure 22 Detailed zoning for $\mathrm{CH} 11 \& 12-\mathrm{NU}$

Stakeholders for Engagement:

DWNP

\section{Description:}

$\mathrm{CH} 11$ was in the past a commercial photographic area and $\mathrm{CH} 12$ was a commercial hunting area. designation is maintained, but with a shift to photographic or adventure tourism in both $\mathrm{CHAs}$. Commercial tourism operations can concentrate on photographic safaris, in particular around the pans that hold water in the area. Also game drives into Ngwezumba area (CH3-NG) would be possible. The objective would be to promote medium to low level adventure based tourism, as game densities are still not as high as the high density tourism zones in Chobe. Based on this the number of prescribed beds and standard of accommodation should be suited towards the middle tier of the safari industry. If the hunting ban, after evaluation, would be lifted, the area of $\mathrm{CH} 12$ which is outside the $25 \mathrm{~km}$ buffer zone of CNP, could be used for commercial hunting activities again. For $\mathrm{CH} 12$ a tourism management plan has been prepared, proposed development is in line with the management plan. The practice of artificial water points should be revisited with a view to removing or rotating usage of the points.

Management issues: borehole management $\S 10.5 .4$; Illegal wildlife off-take $\S 10.4 .4$.

\footnotetext{
${ }^{3}$ It is the Chobe Land Board which is - legally- finally responsible for decision making.
} 


\section{CH13-SIB: Sibuyu Forest Reserve}

\section{Recommended Land-Use Designation:}

Forest conservation and Tourism-Intermediate

\section{Land Tenure Constraints:}

State land, designated forest use. Any major changes in use would require degazettement.

\section{Key issues:}

Original purpose for timber harvesting not sustainable nor economically viable. Pressure due to illegal self-drive tourism, and potential crossborder access by poachers. The area has some attractive landscapes, and its proximity to the tar road offers an opportunity to provide tourism activities to the domestic market.

Primary I mplementing Agencies: DFRR

\section{Stakeholders for Engagement:}

BTO

DWNP

Pandamatenga community

\section{Description:}

Sibuyu Forest Reserve is located between Nunga WMA, Pandamatenga, and Central District. The area is important for wildlife migration, it forms a corridor for animals migrating south and east-west. It is recommended that the Forest Reserve remains a Forest conservation area. Local communities will have access, they can collect veldproducts here, and to a limited extent firewood. There is some potential for photographic tourism in the area, along the river valley a lodge may be possible and allowed, provided that a commercial operator is willing to run this with involvement of people from Pandamatenga.

Management issues: Firewood and veld products $\S 10.3 .1$; Fire management $\S 10.3 .2$; Illegal wildlife off-take $\S 10.4 .4$; Community based tourism $\S 10.2 .5$.

\subsection{Key findings}

- The zoning map is largely based on: existing planning zones (in particular CHAs), environmental characteristics (vegetation, soils) and social characteristics (current land use, presence of villages or settlements;

- Some larger areas were sub-divided, such as the Chobe Enclave or Chobe National Park;

- This has resulted in 20 planning zones;

- For each zone the following elements have been described: recommended land use designation, land tenure constraints, key issues, primary implementing agencies, stakeholders for engagement, description and management issues;

- It is recommended to decrease tourism pressure from the River Front and Savuti towards other, currently less-used zones;

- There is little room for expansion of traditional subsistence farming, since the current system is very much integrated and of an adaptive nature;

- Kasane-Kazungula requires land for expansion, careful planning is required to identify which part of the forest could be degazetted;

- The area of Lesoma should be degazetted, and a proposal is presented for a new village contour;

- Expansion of commercial farming is proposed west of Pandamatenga. Dryland farming is proposed since irrigated farming is not considered sustainable here;

- Kakulwane Plains is vital for the landscape system, and thus for tourism and the economy, and should be zoned for community tourism and kept fence-free.

- Maikaelelo Forest Reserve is proposed as Forest Reserve with maximum protection. 


\section{$4 \quad$ Implementation Framework}

\subsection{Institutional set-up}

If the ILUP is to function as an integrated plan, it requires constant close sectoral cooperation and interaction. Current collaborative arrangements require considerable strengthening. DLUPU should be revitalised, and should have a more proactive role, and sector representatives such as Agriculture, DWNP, BTO etc. should commit to full participation to ensure resource management across the whole landscape, and not just within sector zones. This is the only way to ensure proper adaptive management that is responsive to ecosystem variations.

Various institutions are responsible for land use planning and provision of land for housing in the District. The key institutions are the Chobe Land Board, the Chobe District Council and the Department of Lands. Some of the functions of the Land Board are:

- To allocate and vary customary land rights. This includes, granting rights of use, hearing and approving applications for land for building residences or extensions of residences, ploughing lands, grazing areas and communal village land uses.

- Hearing appeals and placing restrictions or conditions on the use of tribal land.

- To describe grazing areas in consultation with the District Council.

- To set aside land for commonage in consultation with the District Council.

- To lease land for common law purposes. This includes: granting and cancelling leases and granting permission for transfer of rights or change of use.

- To grant land in consultation with the District Council for stated purposes.

- To hear and decide disputes regarding customary land rights in their areas.

According to the Department of Town and Regional Planning, which has professional expertise and custody for planning at the national level, the Chobe Land Board will "own" and "direct" implementation of the Chobe District ILUP. Land Use Officers/Planners have been seconded to Land Boards throughout the country to enhance their capacities in the planning and implementation of specific land use plans for respective districts/planning areas. The Chobe Land Board will therefore coordinate the implementation through the assistance of the District Land Use Planning (DLUPU), for which it is the Chair.

All tribal land issues are dealt with by the office of Chobe Land Board Secretary, while State land matters are handled by the Department of Lands in Francistown. Table 6 shows the responsibilities of the different institutions for the plan implementation in the different land use zones. It is expected that the plan implementation/coordination structures should be authoritative, robust, empowered, innovative and multi-disciplinary to recognize the different and integrated expectations of the varied stakeholders.

It is recommended that a specific monitoring/evaluation team is appointed to guide the implementation of the ILUP.

Because of the district's endowment in natural resources, there are some departments which are also a major stakeholder in land use issues and these include Wildlife and National Parks, Forestry and Range Resources, Tourism, Crop Production, Environmental Affairs and the Agricultural Resources Board.

The Ministry of Lands and Housing is responsible for the policy formulation and guidance when dealing with both state and tribal land matters. Since Chobe is a Tourism hub, the Ministry of Environment, Wildlife and Tourism also plays a very important role as some of these mining activities are located within the Forest Reserves. The mining permits are processed by the Mines Departments in Gaborone. 
Table 6 Responsibilities of institutions in planning in the different zones

\begin{tabular}{|c|c|c|c|}
\hline Planning Zone & Responsible organisations & $\begin{array}{l}\text { Organisations } \\
\text { involved }\end{array}$ & Consulted \\
\hline \multirow[t]{5}{*}{$\mathrm{CH} 1-\mathrm{N}$} & Chobe Land Board & CECT & Communities of the 5 Enclave villages \\
\hline & & DCP & EWB \\
\hline & & DAP & \\
\hline & & BTO & \\
\hline & & DWNP & \\
\hline \multirow[t]{3}{*}{$\mathrm{CH} 1-\mathrm{S}$} & Chobe Land Board & CECT & Communities of the 5 Enclave villages \\
\hline & & BTO & EWB \\
\hline & & DWNP & \\
\hline \multirow[t]{2}{*}{$\mathrm{CH} 2-\mathrm{CFR}$} & DFRR & BTO & CECT and Communities of the \\
\hline & & DWNP & 5 Enclave villages \\
\hline \multirow[t]{2}{*}{$\mathrm{CH} 3-\mathrm{R}$} & DWNP & BTO & HATAB \\
\hline & & & BOGA \\
\hline \multirow[t]{2}{*}{$\mathrm{CH} 3-\mathrm{M}$} & DWNP & BTO & HATAB \\
\hline & & & BOGA \\
\hline \multirow[t]{2}{*}{$\mathrm{CH} 3-\mathrm{NG}$} & DWNP & BTO & HATAB \\
\hline & & & BOGA \\
\hline \multirow[t]{2}{*}{ CH3-SAV } & DWNP & BTO & HATAB \\
\hline & & & BOGA \\
\hline \multirow[t]{2}{*}{$\mathrm{CH} 3-\mathrm{CHAN}$} & DWNP & ВTO & HATAB \\
\hline & & & BOGA \\
\hline \multirow[t]{2}{*}{$\mathrm{CH} 3-\mathrm{SE}$} & DWNP & BTO & HATAB \\
\hline & & & BOGA \\
\hline \multirow[t]{3}{*}{$\mathrm{CH} 4-\mathrm{KK}$} & DTRP & DLUPU & Communities of Kasane and \\
\hline & Chobe Land Board & & Kazungula \\
\hline & & & EWB \\
\hline \multirow[t]{2}{*}{$\mathrm{CH} 4-\mathrm{LES}$} & Department of Lands & DCP & Lesoma Community \\
\hline & Chobe Land Board & & \\
\hline \multirow[t]{2}{*}{$\mathrm{CH} 4-\mathrm{KFR}$} & DFRR & BTO & Kasane, Kazungula and Lesoma \\
\hline & & DWNP & communities \\
\hline \multirow[t]{3}{*}{$\mathrm{CH} 5-\mathrm{KP}$} & Chobe Land Board & DWNP & Lesoma Community \\
\hline & & BTO & \\
\hline & & DCP & \\
\hline \multirow[t]{2}{*}{$\mathrm{CH} 6-\mathrm{KAZ}$} & DFRR & BTO & Pandamatenga community \\
\hline & & DWNP & \\
\hline $\mathrm{CH} 7-\mathrm{MAI}$ & DFRR & DWNP & \\
\hline \multirow[t]{2}{*}{ CH8-PW } & Chobe Land Board & KALEPA & Communities of Kazungula, Lesoma \\
\hline & DCP & & and Pandamatenga \\
\hline \multirow[t]{2}{*}{ CH9-PN } & Chobe Land Board & DWNP & Pandamatenga community \\
\hline & $\mathrm{DCP}$ & & \\
\hline \multirow[t]{2}{*}{ CH10-PE } & Chobe Land Board & DWNP & Pandamatenga community \\
\hline & $\mathrm{DCP}$ & & \\
\hline \multirow[t]{2}{*}{$\mathrm{CH} 11 \& 12-\mathrm{NU}$} & Chobe Land Board/BTO ${ }^{4}$ & DWNP & \\
\hline & & BTO & \\
\hline \multirow[t]{2}{*}{$\mathrm{CH} 13-\mathrm{SIB}$} & DFRR & BTO & Pandamatenga community \\
\hline & & DWNP & \\
\hline
\end{tabular}

\footnotetext{
${ }^{4}$ Land Board is - legally- ultimately responsible for decision-making.
} 


\subsection{Review period}

It is suggested that unlike "other long term plans" that are being prepared for Government purposes, this Chobe District ILUP should have a somewhat shorter duration not exceeding 10 years.

A review should take place within 2-3 years for purposes of guiding implementation for the remaining period of effect for the plan. It is strongly emphasized that if not adequately monitored and reviewed, this Chobe District ILUP would be over-taken by events and therefore rendered useless and would not serve its intended purposes. A regular, 6-monthly review of implementation progress should be scheduled, again through a special DLUPU session.

It is necessary that the Chobe District ILUP be immediately resourced after approval to effect implementation, thus enabling effective plan duration and review timeframes.

\subsection{Community consultations}

Botswana greatly espouses and adheres to the principles and practice of public consultations and the Kgotla is taken as the neutral and appropriate place where consultation should take place as facilitated by diKgosi (traditional leaders). However, additional consultation and one-on-one interviews guided by selected questions were done with the Council Secretary, District Commissioner, Member of Parliament for the area, relevant Government Officers (Wildlife, Tourism etc) and some Independent/Community members and the Business Community.

Consultations took place in Parakarungu, Pandamatenga, Lesoma and Kasane, with representation from the entire district. The formal presentation of the Inception Report to the well-attended DLUPU meeting of November 18, 2016 gave feedback as there were representatives of the community (KALEPA. CECT, etc). The impression therefore is that the Chobe District ILUP will incorporate and reflect the views of the community and this was emphasized throughout all the Kgotla consultations (See Annex 1).

The Chobe District ILUP used stratification, focused groups and one-on-one interactions as methods and approaches that guided community consultations.

Land Board and DTRP should undertake a further comprehensive consultation/dissemination exercise to introduce and share the details of the plan with the district's communities and stakeholders.

After finalization of the plan and acceptance by the authorities, copies should be distributed to all communities involved.

The plan should be shared with other departments through a special session of the DLUPU, so that other departments can appreciate their expected role in it, and make any adjustments necessary to ensure their full commitment.

\section{Key findings}

- Central in the plan is the proper implementation of this plan

- The Land Board is the organisation that should oversee (and is in charge) of all development planning in the District.

- The plan should be shared with other departments through a special session of the DLUPU, so that other departments can appreciate their expected role in it, and make any adjustments necessary to ensure their full commitment.

- A regular, 6-monthly review of implementation progress should be scheduled, again through a special DLUPU session. 


\section{$5 \quad$ Chobe District, environment}

\subsection{Administrative boundaries Chobe District}

Chobe District, which covers approximately $22,500 \mathrm{~km}^{2}$, is the northernmost district of Botswana. The district shares international borders with the Caprivi Strip (Namibia), Zambia to the north and Zimbabwe to the east (Figure 1). Administratively, it is bordered by Ngamiland District in the southwest and Central District in the south. Kasane township, the only urban centre in the district, lies some $500 \mathrm{~km}$ north of the city of Francistown and $600 \mathrm{~km}$ by tarred road from Maun, the capital of Ngamiland District. Besides Kasane, the district has eight larger villages: Pandamatenga, Lesoma and Kazungula in the East, and Mabele/Muchenje, Kavimba, Kachikau, Satau, and Parakarungu in the West.

The agricultural and veterinary boundaries coincide with the district boundary (unlike in many other districts). The District Agricultural Officer and Veterinary Officers are based in Kasane. Also the Wildlife and National Parks Headquarters are based in Kasane.

The district includes the Chobe National Park, one semi-protected Wildlife Management Area, and six Forests reserves as well as (communal) areas reserved for residential, arable and pastoral uses (Figure 24).

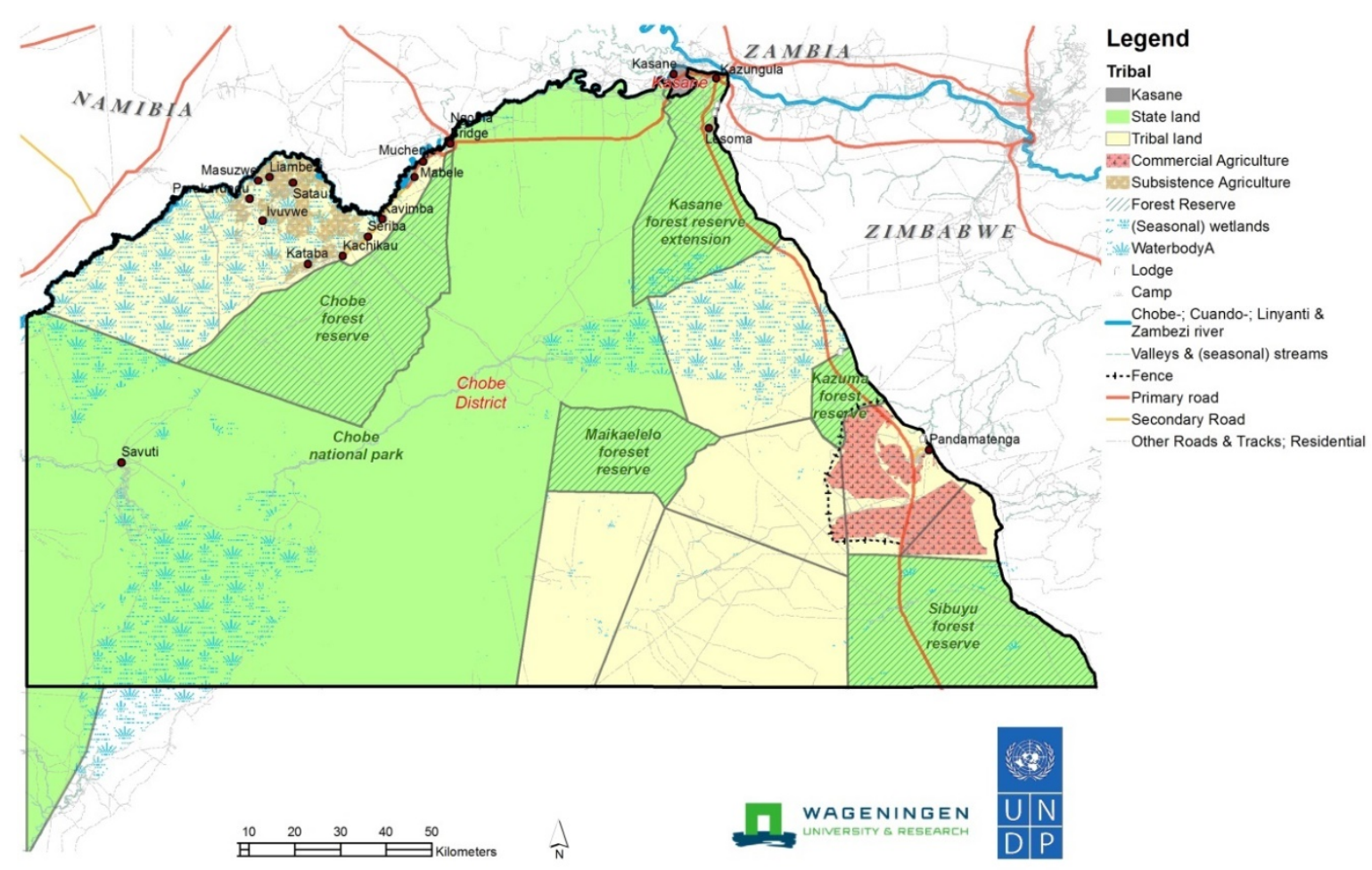

Figure 24 Chobe District, villages and dominant features 


\subsection{Soils}

Chobe District consists of flat woodlands on deep Kalahari Sands. It has low lying lacustrine deposits and alluvium soils along Chobe - Linyanti drainage system.

The Chobe District physiographic map in Figure 25 is based on the Soil map of the Government of Botswana. (FAO, 1990). Soils in Chobe District can be divided in two large complexes. The larger part of Chobe District is covered by deep, sandy soils developed from the Kalahari Sands (arenosols). In geological times of drier spells, longitudinal dune systems have developed in places. These soils have a very low fertility and their water retention capacity is very limited. The suitability is limited to conservation- or rangEland-purposes.

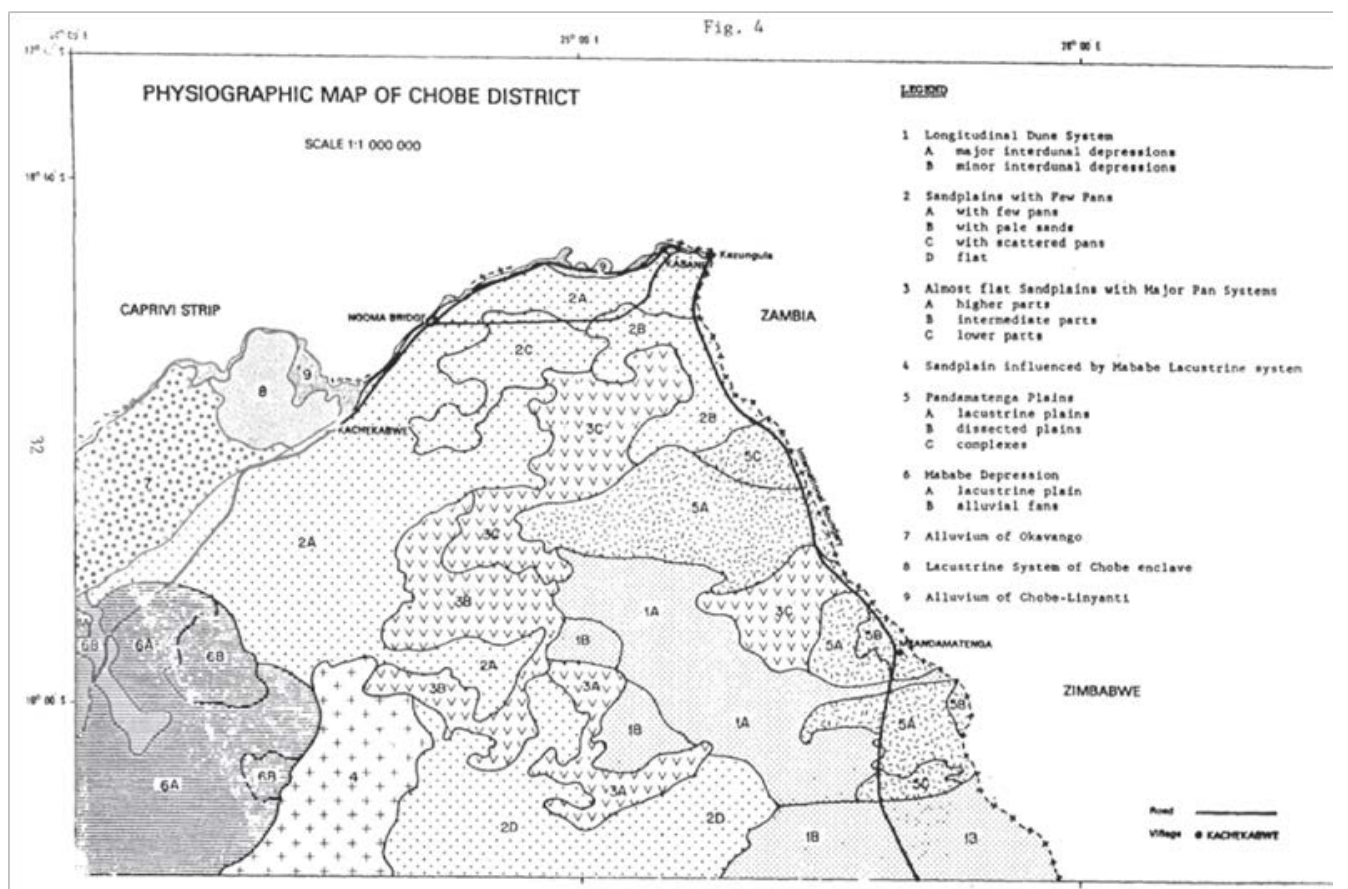

Figure 25 Physiographic map (Moganane et al. 1990, p. 32)

Lower areas are covered by alluvial soils and complexes of lacustrine origin. These soils have a better water retention capacity, with moderate fertility. Locally problems with salinity may limit land-use options. Important complexes include the Pandamatenga Plains in the East, along the Chobe River in the North and the Mababe Depression the South-West of the District (Figure 25).

At Pandamatenga vertisols ("Black Cotton Soils") are found (Figure 26). These plains have been uplifted by tectonic movements and the water they collect in the rainy season is gradually drained off towards the South-West of the District; the Northern plains into the Ngwezumba channel and eventually into the Savuti marsh. As these vertisols are composed of very fine clay, they have a very short window at the beginning of the rainy season during which they can be tilled. In the dry season they are too hard to be worked on and deep cracks develop. Once wet they become very plastic. In spite of these physical difficulties, they are the better spoils for agricultural development.

In the Chobe Enclave coarse loamy gleysols and calcisols occur. Such soils are high in organic matter and have a good water retention capacity. Depending on water availability some small scale farming, in particular recession farming (molapo), may take place in these areas. In some areas salinity may be a problem though, as a result of fluctuating water tables calcium salt may form even white crusts on the top of the soils. Also in irrigated farming this may occur, in particular when insufficient water is available to flush the salt out.

In the central area of Chobe National Park, course and loamy luvisols are present (Figure 26).

The Mababe Depression in the South-West of the park is covered by a stretch of luvisols and fine loamy and clayey Chernozems. According to the FAO these soils are relatively fertile with a good agricultural potential. 


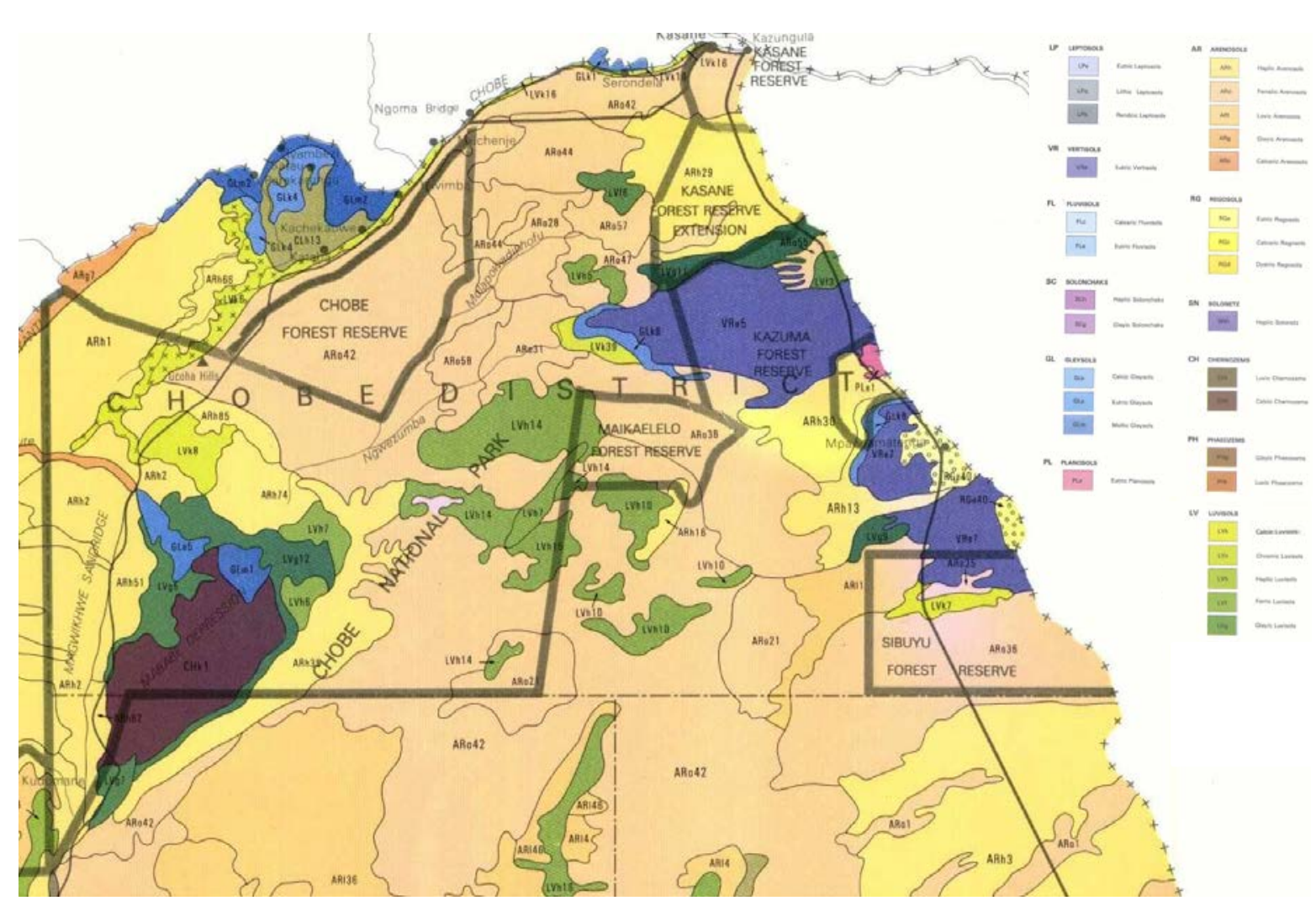

Figure 26 Chobe soils, UNDP-FAO soil classification system (FAO 1990)

\subsection{Climate}

\section{I ntroduction}

The description of climate of the Chobe District is conditional on the availability of appropriate longterm monitoring data. There is, however, only one long-term meteorological station located within the District, i.e. Kasane, while nearest stations (Maun and Shakawe) are as the crow flies, some $\sim 150 \mathrm{~km}$ to the south, and $\sim 200 \mathrm{~km}$ to the west of the District boundary. We have, therefore, relied on a number of surrogate datasets to describe Chobe District climate, namely:

- CRU 3.23, which is a gridded, ground observations-based (interpolated) rainfall and air temperature dataset, covering the period of 1901-2015, with a resolution of $0.5^{\circ}$ (approx. $50 \mathrm{~km}$ ), and temporal resolution of 1 month, used to assess long term behaviour of rainfall,

- CHIRPS 2.2, which is a gridded, blended satellite-observation-based data set, available for 19812016 , with a spatial resolution of $0.25^{\circ}$, and temporal resolution of 1 day, used to assess spatial heterogeneity of rainfall across the region.

\section{Drivers of climate variability}

There are no pronounced topographical differences in the Chobe region, and as a result the spatial pattern of climate mostly reflects the character of large scale circulation systems driving the interaction of three air masses - warm humid air redirected westwards from the equatorial Indian Ocean, cold dry air originating in the subtropical Indian Ocean, and warm humid air recurved from the tropical Atlantic (Tyson \& Preston-Whyte, 2000). The boundaries between these air masses form two large-scale convergence zones - the Inter Tropical Convergence Zone (ITCZ) and Congo Air Boundary $(C A B)$, which migrate northwards in austral winter and southwards in austral summer. The ITCZ/CAB system reaches the Chobe region while in its most-southerly position in J anuary-February, and its presence facilitates frequent development of convergence clusters, and thus rainfall. That migrating convergence system responds to the relative differences in sea surface temperatures in the three above mentioned sections of the Oceans, which drives the interannual rainfall variability and underlay the relationship between the region's rainfall and global modes of climate variability. 


\section{Seasonal variability of climate}

Rainfall in the Chobe district is characterized by a well-defined seasonality, with mono-modal rainy season occurring during austral summer, i.e. October-March (Figure 27), coinciding with the period of the highest seasonal temperatures (maximum daily temperatures reaching $34-36^{\circ} \mathrm{C}$, minimum daily temperatures reaching $20-22^{\circ} \mathrm{C}$, Figure 28 ).
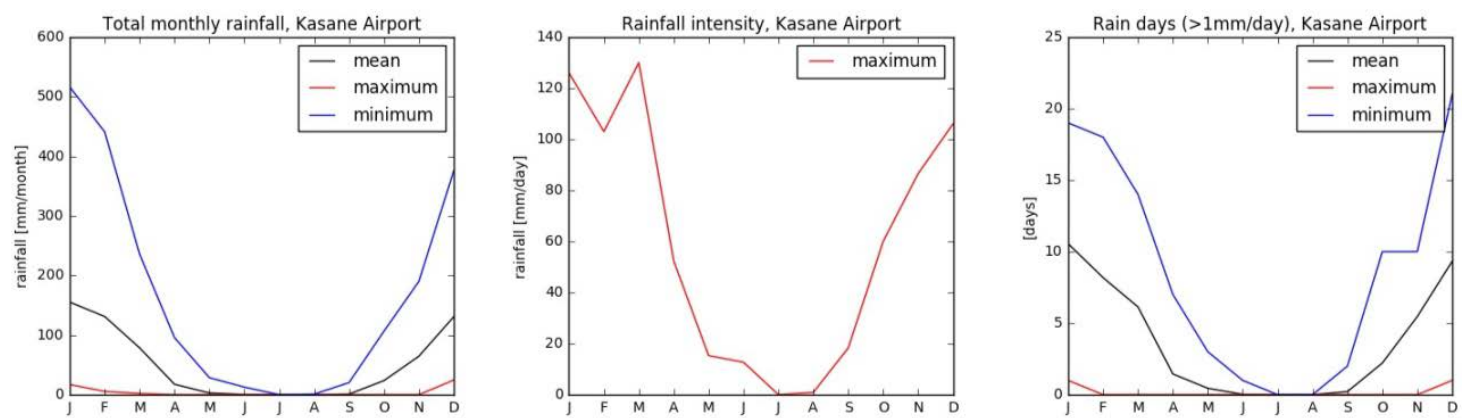

Figure 27 Rainfall climatology, based on 1970-2006 data, indices expressing totals, intensity and frequency on a month-to-month basis, Kasane Airport (Data source: Botswana DMS)

As mentioned earlier, rainy season's rainfall is convective in nature, and delivered mostly in the form of localized afternoon/night storms, $10-30 \mathrm{~km}$ in size, with daily totals reaching $120 \mathrm{~mm} /$ day (Figure 27). The distribution of these storms in space is essentially random.

The J une-J uly period (austral winter) has the lowest temperatures (minimum daily temperature falling as low as $6^{\circ} \mathrm{C}$, and maximum daily temperature falling only to the level of $20-22^{\circ} \mathrm{C}$, Figure 28 ), and is essentially devoid of rain events (Figure 27). Occasionally, however, large scale atmospheric circulation brings in humid air from the Indian ocean to the central part of the continent, and may create rainfall events reaching $>100 \mathrm{~mm}$ /day (an example occurred in June 2009, although it was located to the south of Chobe NP, $>20 \mathrm{~mm}$ / day recorded at Kasane).

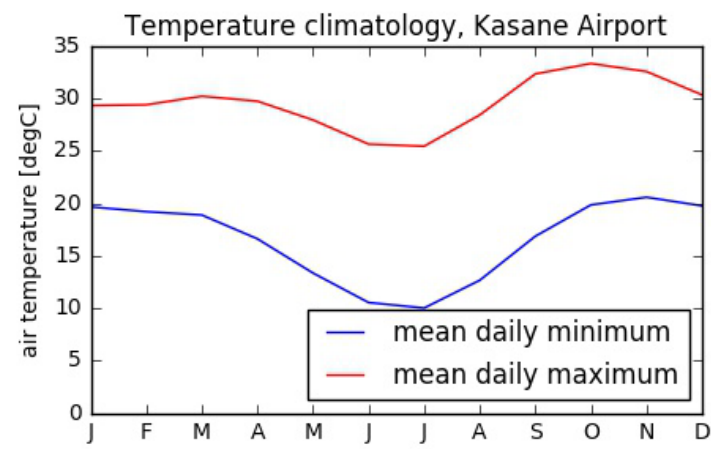

Figure 28 Air temperature climatology, based on 1980-2000 data, for minimum daily and maximum daily temperature, Kasane Airport (Data source: Botswana DMS) 


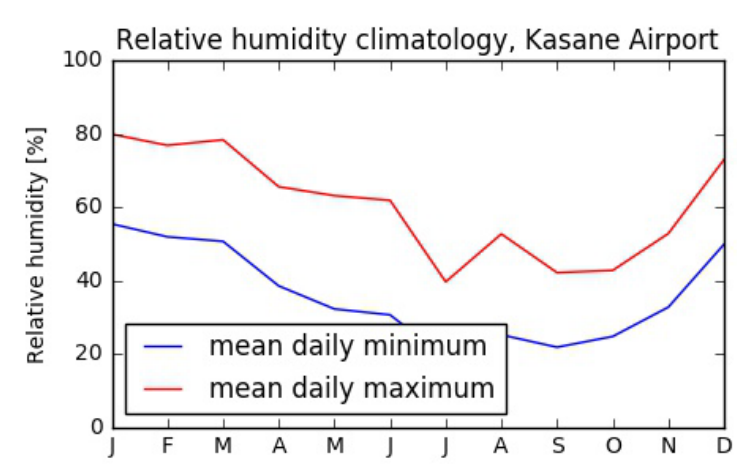

Figure 29 Relative humidity climatology, based on 1980-2000 data, Kasane Airport (Data source: Botswana DMS)

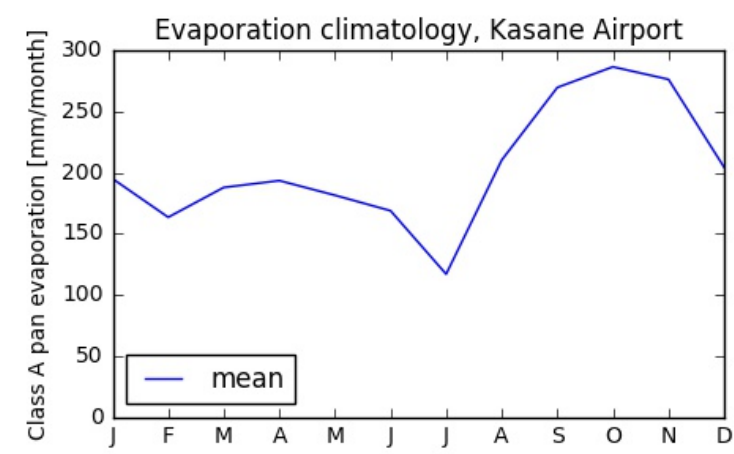

Figure 30 Evaporation (class A pan) climatology, based on data for 1980-2000, Kasane Airport (Data source: Botswana DMS)

Relative humidity follows a slightly different seasonal pattern, with the lowest values (20-25\%) recorded before the onset of the rains, and highest values (80\%, occasionally reaching $100 \%$ ) occurring during days/hours following rain events (Figure 29). Winds show yet another pattern, with maximum speed (typically 2-3 m/s) occurring at the end of the dry season (October), and lowest (typically $0.5-1.5 \mathrm{~m} / \mathrm{s}$ ) in February (Figure 30). Actual evaporation is at a maximum in October, reaching $300 \mathrm{~mm} /$ month, and reaches minimum in July (less than $150 \mathrm{~mm} / \mathrm{month}$ ). It is subdued during the rainy season, in spite of relatively high temperatures, perhaps due to cloudiness (Figure 31). Importantly, conditions where rainfall exceeds evaporation occur only in the mid-rainy season and only in above-average rainfall years.

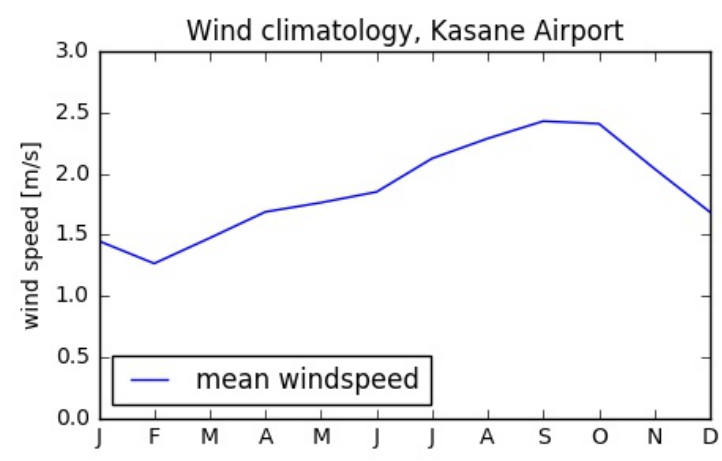

Figure 31 Wind climatology, based on data for 1980-2000, Kasane Airport (Data source: Botswana DMS) 
At the inter-annual time scale, rainfall variability is moderate, with Kasane receiving $\sim 900 \mathrm{~mm} /$ year in wettest years, and $\sim 300 \mathrm{~mm} /$ year in driest years, and a mean rainfall of $\sim 600 \mathrm{~mm} /$ year (Figure 32).

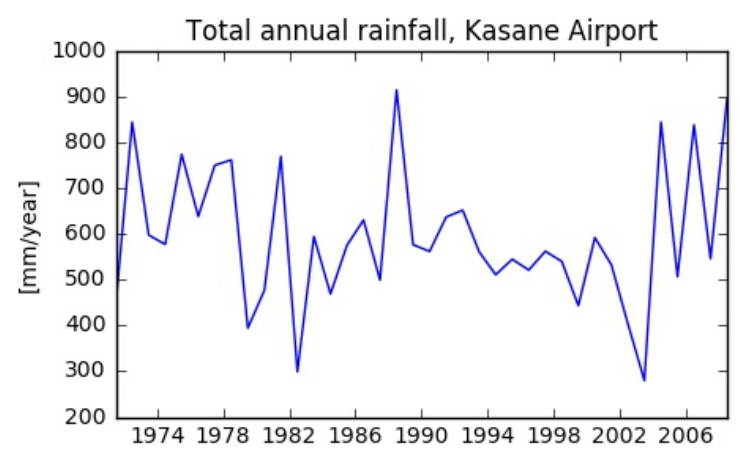

Figure 32 Total annual rainfall, Kasane Airport (Data source: Botswana DMS)

\section{Spatial heterogeneity of climate}

The Chobe District is hydrologically linked to the Zambezi and Kwando catchments extending up to $1,000 \mathrm{~km}$ north of it. The description of climate, and in particular rainfall, has to cover the contributing catchment areas. It is convenient to distinguish three hydrological regions or basins for the purpose of description of rainfall conditions and variability, namely: northern (or headwaters) basin (covering sections of the Kwando and Zambezi catchments falling between $10^{\circ} \mathrm{S}$ and $15^{\circ} \mathrm{S}$ ), southern basin (section of Kwando and Zambezi catchments falling between $15^{\circ} \mathrm{S}$ and $18^{\circ} \mathrm{S}$ ), and the Chobe region covering the Chobe District (Figure 33).

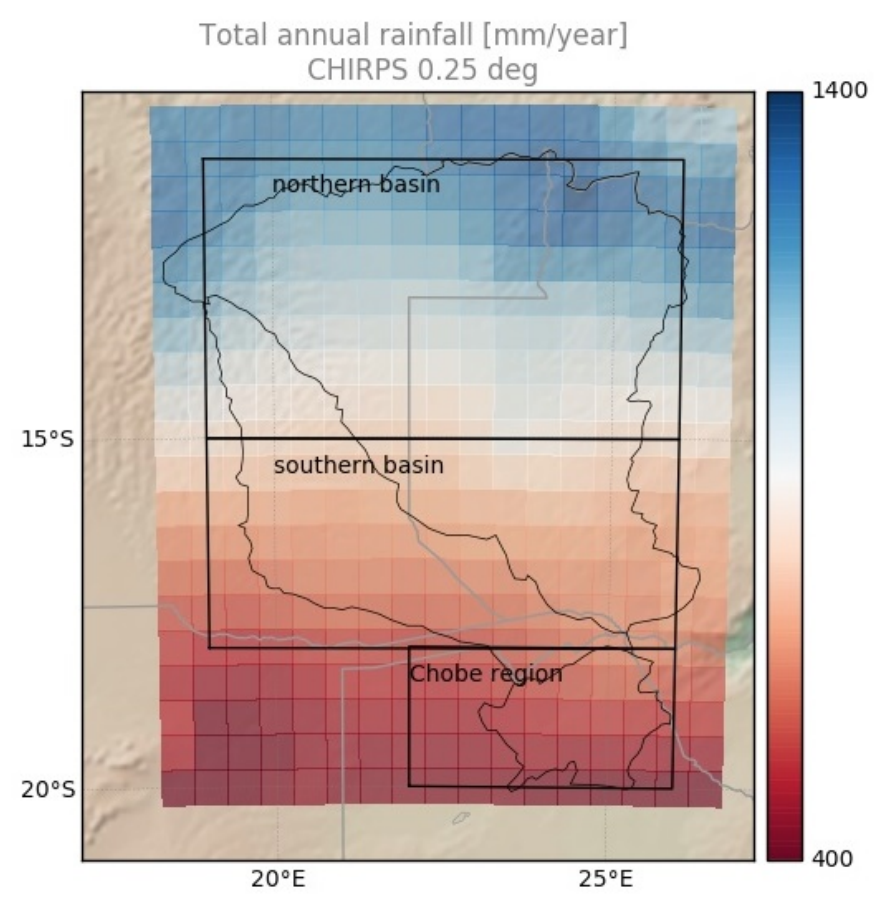

Figure 33 Spatial distribution of mean annual rainfall in the Chobe region and Kwando and Zambezi catchments (based on CHIRPS 2.2 data)

The mean annual rainfall in the upper basin (headwaters of the Kwando and Zambezi Rivers) reaches $>1200 \mathrm{~mm} /$ year, in the region of the Zambezi-Chobe-Linyanti-Kwando wetlands it is around $600 \mathrm{~mm} /$ year, while in the southern parts of the Chobe district it may reach $<500 \mathrm{~mm} /$ year. This pattern is driven by differences in frequency of rainfall events, while differences in rainfall intensity are minor. 


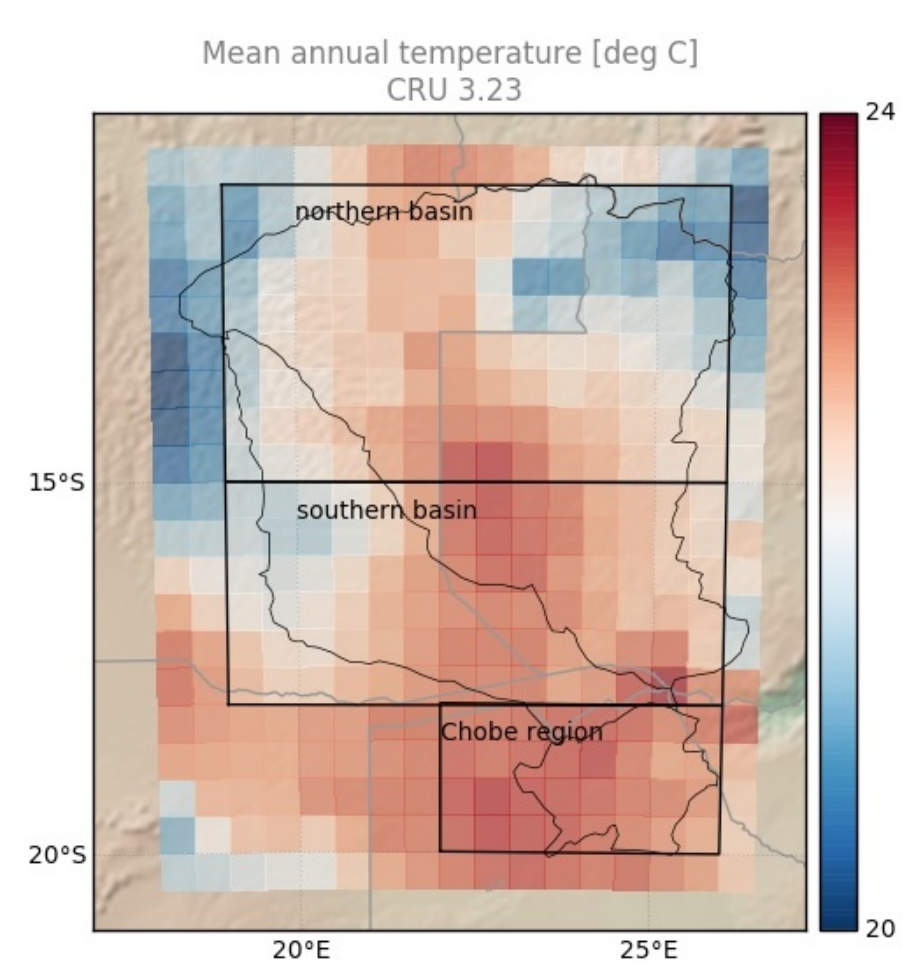

Figure 34 Spatial distribution of mean annual temperature in the Chobe region and Kwando and Zambezi catchments (based on CRU 3.23 dataset)

The spatial distribution of mean annual temperature across the Chobe region is relatively uniform (Figure 34) with mean annual temperature varying between 22 and $24^{\circ} \mathrm{C}$. The northern and southern basins display, however, pronounced regional differences in terms of air temperatures, with cooler temperatures in the extreme western and extreme eastern parts of the basins (Figure 34).

Although no detailed data are available, comparison of relative humidity measured at Maun, Shakawe and Kasane indicates that its spatial heterogeneity across Chobe district is not strong, with slightly higher values in Kasane. This is likely a reflection of the influence of rainfall, which is higher in Kasane than in Maun. Wind speed appears to be less spatially coherent, with regional differences not reflecting the general North-South climate gradient, but rather local conditions.

\section{Microclimates}

Due to the flat topography and relatively uniform land cover, microclimates (or local climates) are not a significant aspect of the climate of the Chobe district. The only conditions facilitating the creation of spatial differentiation of climatic and weather conditions at short distances occur at the interface of dryland and wetland along the Chobe waterfront, as well as along the southern boundary of the Linyanti-Kwando wetlands, particularly because these boundaries are pronounced through the topography. Contrasts in air temperature (lower on the wetland side), humidity (higher on the wetland side) and winds (higher on the wetland side) are expected to occur, but contrasts in rainfall are most likely non-existent.

Temporarily inundated pans present throughout the Chobe district, are in general due to their small size, not likely to create similar microclimatic effects, although they might occur in some larger and topographically pronounced pans. 


\subsection{Water}

\section{Surface Water}

Due to the generally low regional topographic gradients and geomorphological position, the drainage system of the Chobe region considered in this report is complex, and its boundaries are not clearly defined. In general the area falls into two major surface water basins - the Zambezi and the Okavango (Figure 35). The Zambezi section comprises the lower reaches of the Kwando, Linyanti and Chobe rivers and associated floodplain systems, and a short section of the Zambezi itself. The Okavango section comprises the Ngwezumba/Kashaba and Gautumbi/Nunga ephemeral drainage systems. These systems comprise several inactive, or partially active channels, and ephemeral pans scattered throughout the region.

Although usually considered separate, the Okavango and Zambezi systems are hydrologically linked within the Chobe region. The linkages are, however, activated only during wet pluri-annual periods (i.e. multiple years characterized by above average rainfall and river flows). In wet periods the Savuti channel connects the Linyanti swamp with the Savuti swamp that occupies the upper section of the Mababe depression, which is also a terminal drainage for the Ngwezumba and Gautumbi. Another connections occurs through the Makgwegkwana, also known as the Selinda Spillway, which originates in the Okavango, and the terminal part of which may reach the Linyanti wetland. Both these connections were active during the recent wet period (2011-2015), but previously flows in the Savuti channel and the terminal part of the Makgwegkwana were recorded only in the late 1970s.

The hydrology of the Zambezi-Chobe-Kwando-Linyanti floodplains, which are an important element of the hydrological system of the Chobe district, is influenced by a combination of local, direct rainfall and evaporation, and inflows from the Zambezi and Kwando rivers. These rivers originate outside of the Chobe district, in western Zambia and south-eastern Angola, but due to functional dependencies, they have to be considered as part of the hydrological system of the district, as shown in Figure 33 and 34.

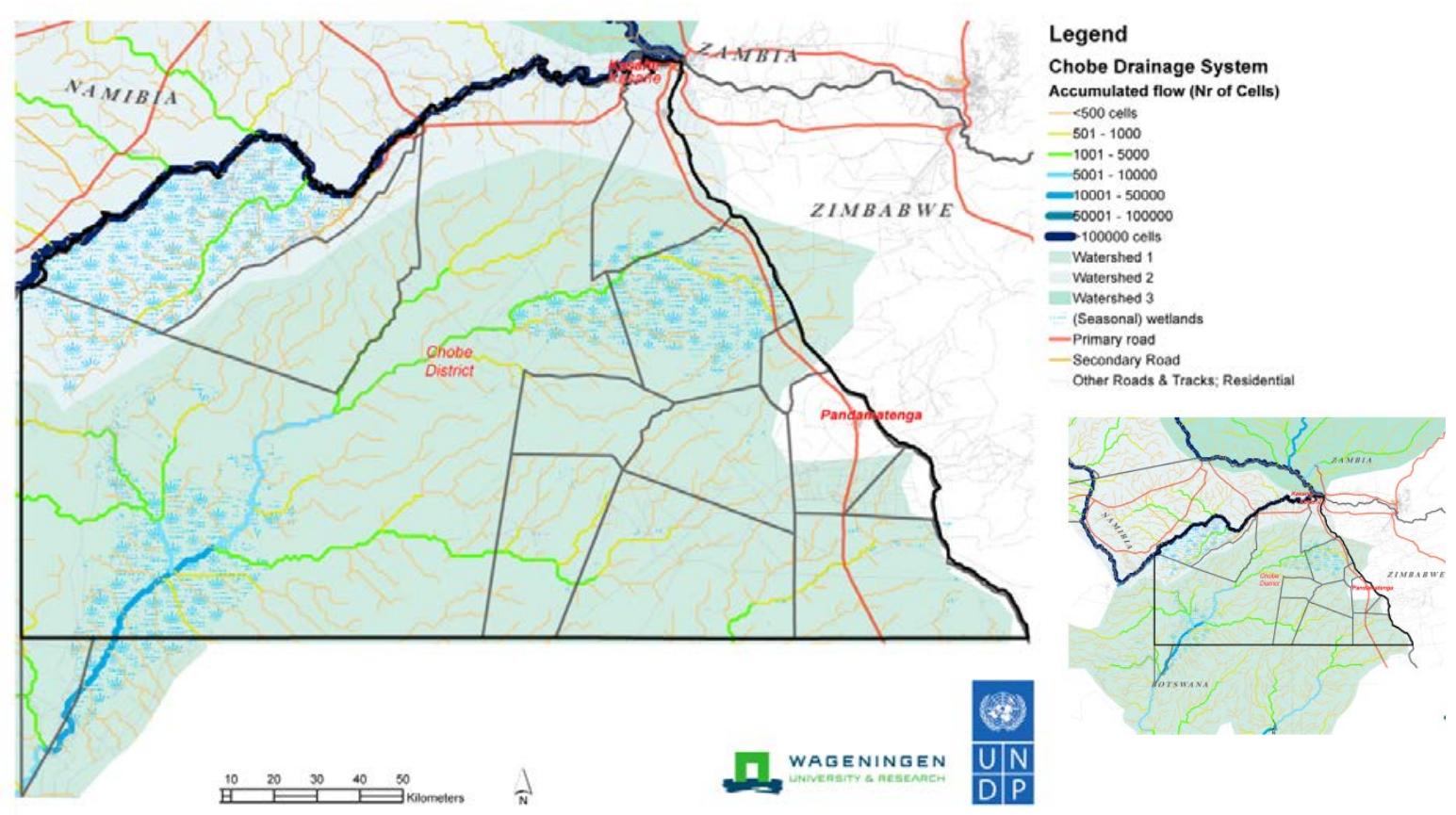

Figure 35 Drainage system of the Chobe district based on HydroSHEDS topography (inset right: larger catchment of the region)

During wet periods Lake Liambezi, located in between the Zambezi, Chobe and Linyanti floodplains, is filled up by the floodwaters of the Zambezi, which reach the lake through the Bukalo channel to the 
NE (Figure 36). The Lake can also be fed by the spillover from the Linyanti system, and even become connected to the Chobe through the southern channel. Under such conditions there is a hydrological continuity between the Okavango, Kwando/Linyanti/Chobe and the Zambezi.

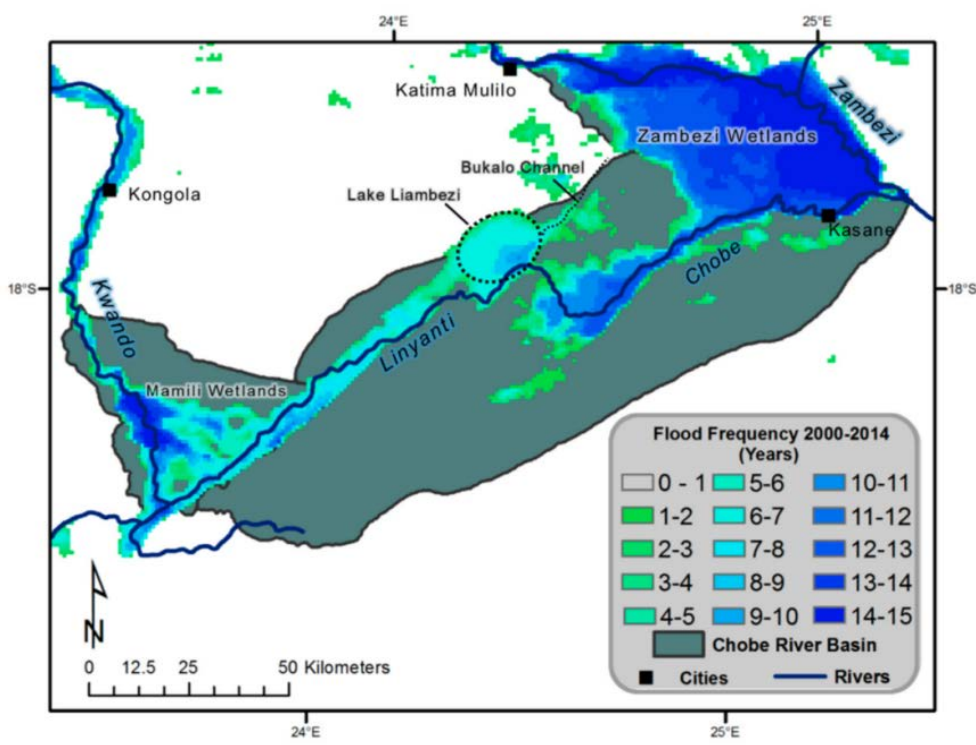

Figure 36 Frequency of inundation in the Kwando/Linyanti/Chobe/Zambezi floodplain system (Burke et al. 2016)

\section{Dominant hydrological processes}

The combination of well permeable soils, highly seasonal rainfall of relatively low intensities, and generally a flat topography creates conditions of limited surface runoff, which may occur only during the highest intensity rainfall events. Most of the rainfall infiltrates into the ground, and is later subject to evapo-transpirative uptake. Due to deep groundwater, and thus high water holding capacity of the soil column, groundwater recharge is limited, typically less than $10 \mathrm{~mm} /$ year, although rates as high as $40 \mathrm{~mm} /$ year were suggested to occur in the Chobe Forest reserve (Brunner et al. 2004).

Surface runoff occurs only in the regions where soils are clayey and thus less permeable, e.g. usually in the vicinity of pans, and occasionally in the headwater region of the Ngwezumba/Kakulwane Plains. There is a number of ephemeral rivers in the southern dryland part of the Chobe district. Those rivers may flow occasionally. Mike Slogrove, a former Kasane resident who ran the Crocodile farm, informed one of the authors about taking motor boats down the Ngwezumba in the 1970s. The episodic flows in these rivers have strong implications to the ecology of the area - they are important to maintain the system of large pans in the North-east Mababe (one of the large ones called Zwei Zwei had Hippo in it in the 1980s). Also, these episodic flows likely recharge river bed groundwater that is responsible for maintaining the few seeps and springs present in the river bed, which provide water to wildlife during dry periods.

The floodplain systems of Kwando/Linyanti/Chobe/Zambezi are fed by inflows from the Kwando and Zambezi, which originate from the higher rainfall zone. Local rainfall plays a limited role in generation of inundation in the system of Kwando/Linyanti/Chobe/Zambezi floodplains.

Although not investigated in the region, it may be expected that in the southern parts of the Chobe district surface water-groundwater interactions are dominated by infiltration of flood water into the ground, with groundwater discharge to the rivers (i.e. baseflow) not occurring, or occurring very rarely. In the northern part of the district however the situation may be different due to higher rainfall. It is likely that rivers provide episodic recharge to the local groundwater, which in turn maintains seeps and springs during the dry season. Seeps are reported in the Ngwezumba valley. The infiltrated groundwater is redistributed through lateral groundwater movement in the upland areas, taken up and evapotranspired by savanna vegetation. 


\section{Seasonal to long-term hydrological dynamics}

The hydrological system of the Chobe region is characterized by strong seasonality and interannual variability, with significant decadal-scale or multi-decadal quasi- (or irregular) periodicity.

The hydrological seasonality is obviously related to the climatic seasonality, but it manifests slightly differently in various parts of the hydrological system. Hydrological conditions of disconnected pans within the Chobe district are shaped by local rains. Pans will thus show increases in water level after individual rainfall events, and will likely reach annual highest water levels towards the end of the main part of the wet season, typically towards the end of February.

Hydrological conditions in the river floodplain system are shaped by a combination of river flows and local rains. Due to complex hydrological connectivity in the Kwando/Linyanti/Chobe/Zambezi floodplain system, seasonal dynamics differ between parts of that system. In general, the entire system is subject to a single annual flood event. However, due to the size of the drainage system, and thus relatively long accumulation time within the Kwando and Zambezi catchments, there is a delay between rains and hydrological responses. Water levels rise typically after November, they peak in February-May, and recede towards the annual low in October. Locally, however, water levels can potentially have two peaks, with the earlier one during the peak of the rainy season in January/ February, arising from strong local rainfall. Additionally, in wet periods, when the Kwando/Linyanti/ Chobe/Zambezi is interconnected, dynamics of distal (i.e. downstream) Linyanti, Lake Liambezi and distal Chobe may be influenced by differences in timing of the Zambezi and Kwando flood - the Kwando peaks several months after the Zambezi has peaked (Figure 37).

Water level fluctuations are strong in the Zambezi-Chobe-Liambezi system, reaching 2.5-3m on the seasonal time scale, but are subdued in the Kwando/Linyanti system $-0.7 \mathrm{~m}$, but may be as little as $0.2 \mathrm{~m}$.

Year-to-year hydrological variability in inundation and water levels is relatively strong (Figure 38) and related to the variability of climate and particularly rainfall. Presence of water storage in the system of floodplains and in headwaters groundwater, creates conditions for the so-called "carry-over" effect, i.e. a situation where water accumulated during a high-rainfall year still influences hydrological conditions in the following year. That effect dampens variability in hydrological responses compared to that of rainfall. Interannual variability, apart from differences in water levels and discharges, also manifests in terms of frequency and duration of inundation of the floodplain system, with the resulting gradation of the hydroperiod (i.e. period of time during which a wetland is covered by water), and thus strong ecosystem implications. The spatial distribution of zones of various frequency of inundation is illustrated in Figure 36.

The quasi-periodicity manifests through the sequences of above-average, and below-average years, that may last 20-30 years. The multidecadal scale variability was not studied in the Kwando specifically, but is likely similar to the variability observed in the Okavango and in the Zambezi (Mazvimawi \& Wolski, 2006). The multi-decadal variability is clearly climate-driven (Wolski et al., 2012). Figure 39 illustrates a period of transition from the dry early 2000 s to the wet mid-2010s. An important consequence of the longer-term variability manifested through transitions between wet and dry multi-year periods is that areas that are dry during dry periods may become regularly seasonally flooded during wet periods, areas that are occasionally flooded during dry periods may become permanently inundated during wet periods etc. This has implications to the ecological functioning of the system, including the distribution of grazing and thus wildlife, fish and other ecosystem services as well as for farmland use.

\section{Geomorphological evolution of the hydrological system}

Apart from being subject to climate-driven dynamics, the hydrological system of Kwando/Linyanti/Chobe/Zambezi floodplains is additionally influenced by geomorphological and geological processes. Their influence has, however, never been studied in the region, and its evidence is conjectural in nature. The Linyanti and Chobe systems are clearly tectonically-bound by prominent faults - the Linyanti Fault and the Kachikau Fault respectively. Additionally, geomorphic processes of channel sedimentation and peat accumulation, as well as floodplain vegetation dynamics, described in detail for the Okavango (McCarthy et al. 1992), may have strong influence on the hydrological system of the Kwando/Linyanti/Chobe/Zambezi floodplains. 
The comparison of inundation extents in the Kwando-Linyanti system recorded between the late 1980s and mid 2000s (Figure 39) suggests that the inundation does not necessary follow the simple upstream-spillover-downstream model, and the water distribution may be strongly affected by activation/abandonment of channels. Additionally, there is also observational evidence of redistribution of flows and migration of channels within the Mamili wetlands, with the northern branch gaining significance in the early 2000s (Dr. Naidoo, Maun DWA, pers.comm.) and leading to desiccation of the Zibadianja lagoon in the west section of the Kwando. Currently, however, there appears to have been a fairly major switch at the apex of the Linyanti fan with a new main channel developing comparatively quickly along the west (M.Murray-Hudson, ORI, pers.comm.). One of the consequences of this already is that the DWA camp at Shumamorei, previously dry, is now on an island, with a channel of $\sim 4 \mathrm{~m}$ deep and $>13 \mathrm{~m}$ wide separating it from the mainland to the west. In the meantime, the central Linyanti fan appears to be getting progressively drier. The Zibadianja lagoon system in the south-west corner of the fan will probably receive proportionately more of Kwando flows. This may ultimately increase flows down the Savuti, and west up the Makgweqana, at the expense of eastward flows into lake Liambezi.

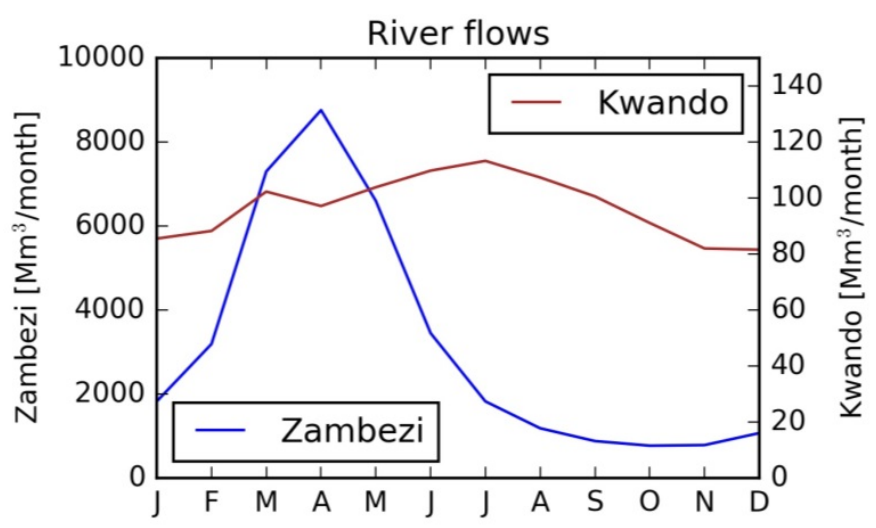

Figure 37 Seasonal water level/discharge cycle of the Zambezi (at Katima Mulilo) and Kwando (at Kongola) rivers. Chobe river follows closely the dynamics of the Zambezi. In the Kwando-Linyanti system, only upstream sections of the Mamili wetland will have dynamics of the Kwando. Downstream, flood peak will be further delayed (Data source: Botswana DMS)
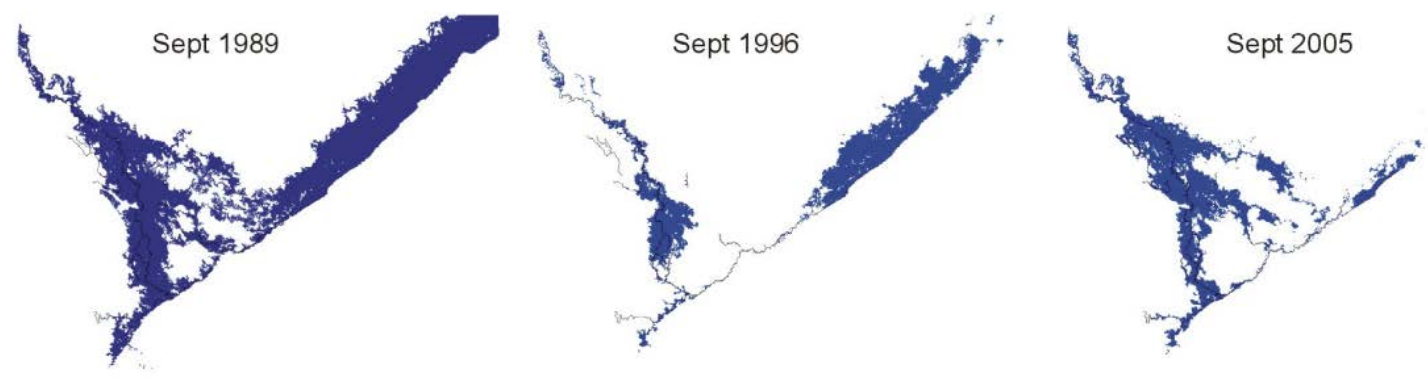

Figure 38 Irregular inundation in the Kwando-Linyanti system: in 1996, one of the drier years (lowest recorded discharge of the Zambezi and the Okavango rivers) Linyanti was extensively inundated. Linyanti was not inundated in 2005, in spite of near average discharges of the Zambezi and the Okavango (Data source: Botswana DMS) 


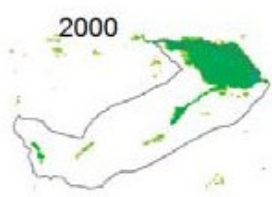

2004
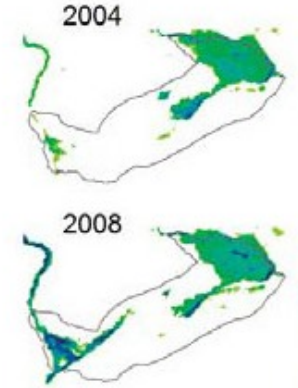

2012

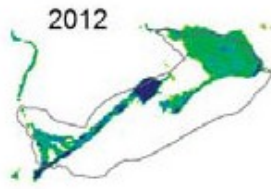

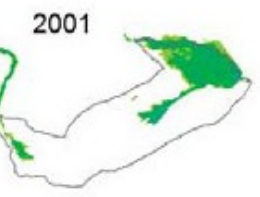

2005
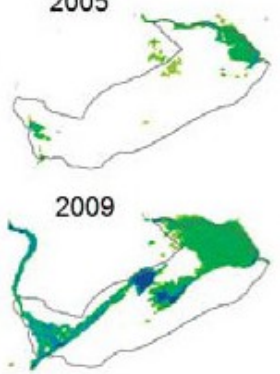

2013

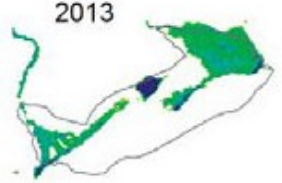

2002

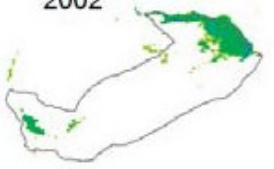

2006
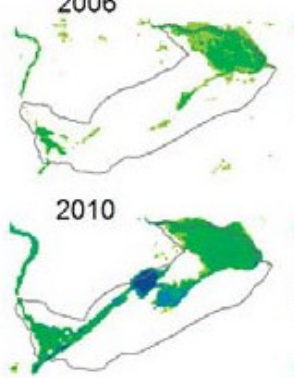

2014

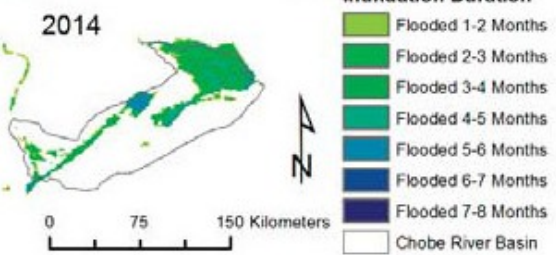

Figure 39 Year-to-year variability in inundation in the Kwando/Linyanti/Chobe/Zambezi floodplain system (after Burke et al. 2016)

\section{Groundwater}

Groundwater in the Chobe district is present within two main types of aquifers:

- shallow, phreatic aquifers in unconsolidated, or partially consolidated Kalahari beds that are present over the majority of the area,

- a number of deep, fractured aquifers in formations such as the Ghanzi group metasediments, Ntane sandstone (upper Karoo) aeolian sandstone occurring in the west and Stormberg basalts in the east. The Kalahari beds aquifer is used for water supply within Chobe area. The aquifer is ubiquitous throughout the area, with a water table between 20 and $40 \mathrm{~m}$ below ground level, but shallower in wetlands and river beds. The Kalahari aquifer has generally good water quality, although locally high salinity may yield groundwater unsuitable to human consumption. The problems with salinity are reported for individual boreholes in the Mababe/Savuti area, in Pandamatenga and in Kachikau/Kavimba.

Recharge rates are low to moderate $1-40 \mathrm{~mm} /$ year. Within this aquifer, good potential for shallow groundwater occurs usually in the vicinity of pans and rivers/floodplains, particularly in locations associated with outcrops of calcrete/silcrete, as well as in the vicinity of outcrops of older crystalline geological strata (hills), due to possible concentration of rainfall water and preferential recharge processes. The aquifers associated with pans/river beds are likely to be dependent in episodic recharge on surface water, and may be in the form of local, perched lenses of groundwater. Groundwater in deep aquifers ( $>60 \mathrm{~m}$ ) is usually of better quality. Little is known about recharge of deep aquifers, and the amount of water resources associated with them.

\section{Water resources and water supply}

The main source of water in Chobe district is Chobe River. Most villages in the District, and all settlements between these villages are supplied with treated water from the Chobe River, although boreholes are still in use in Kavimba. Pandamatenga is the only village in the District, which is supplied entirely by ground water. Total domestic water demand in the District does not exceed $3,000 \mathrm{~m}^{3} /$ day (Table 7 ).

Apart from the water supply to gazetted villages there are a number of boreholes within the district that supply groundwater for wildlife use and for tourism facilities (Figure 40). 


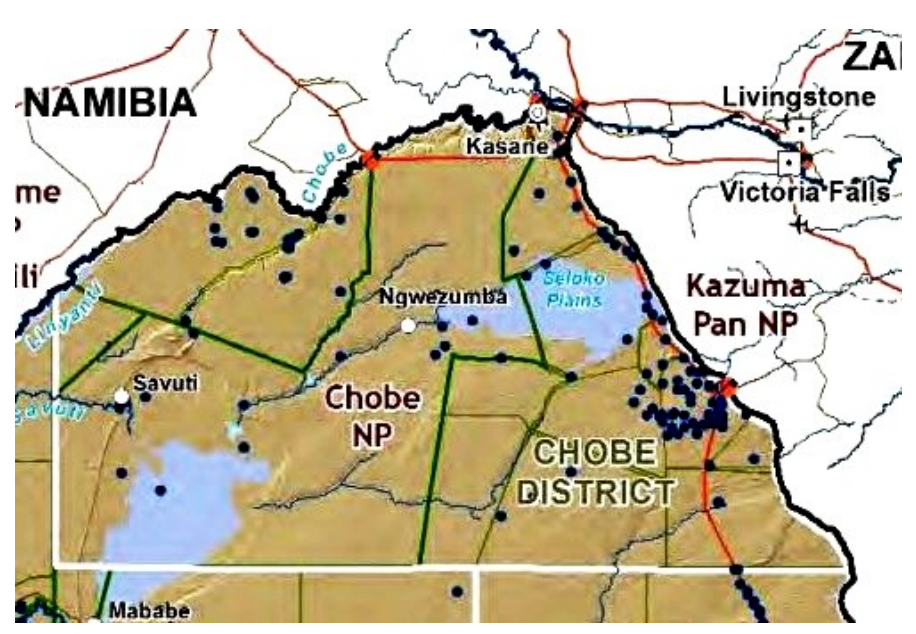

Figure 40 Distribution of boreholes within the Chobe district (KAZA I ntegrated development plan, 2011)

Table 7 Water supply and demand in Chobe district (Chobe District Development Plan, 2010)

\begin{tabular}{|c|c|c|c|c|c|}
\hline Water Source & Village & Yield / hour & Village supplied & Demand & Supply \\
\hline Chobe River & Kasane & $150 \mathrm{~m}^{3} / \mathrm{h}$ & Kasane, Kazungula & $2500 m^{3}$ & $2200 m^{3}$ \\
\hline \multicolumn{6}{|l|}{ Chobe East } \\
\hline $\mathrm{BH} 8889$ & Pandamatenga & $6.5 \mathrm{~m}^{3} / \mathrm{h}$ & Pandamatenga & $200 \mathrm{~m}^{3} / \mathrm{d}$ & $240 \mathrm{~m}^{3} / \mathrm{d}$ \\
\hline $\begin{array}{l}\text { Kazungula } \\
\text { Booster }\end{array}$ & Kazungula & $4 m^{3} / h$ & Lesoma & $274 \mathrm{~m}^{3} / \mathrm{d}$ & $\begin{array}{l}54 \mathrm{~m}^{3} / \mathrm{d} \text {. Augmented } \\
\text { by bowsing }\end{array}$ \\
\hline $\begin{array}{l}\text { Chobe West } \\
\text { Villages }\end{array}$ & & & $\begin{array}{l}\text { Mabele, Kavimba, } \\
\text { Kachikau, Satau, } \\
\text { Parakarungu }\end{array}$ & $\begin{array}{l}650 \mathrm{~m}^{3} / \mathrm{d} \\
\text { (collective) }\end{array}$ & $\begin{array}{l}550 \mathrm{~m}^{3} / \mathrm{d} \text { from } \\
\text { Kasane and } \\
172.5 \mathrm{~m}^{3} / \mathrm{d} \text { from }\end{array}$ \\
\hline BH 8898 & Kavimba & $8 m^{3} / h$ & \multirow{2}{*}{$\begin{array}{l}\text { Chobe West } \\
\text { Villages }\end{array}$} & & \multirow[t]{2}{*}{ boreholes } \\
\hline BH 8901 & Kavimba & $9 m^{3} / h$ & & & \\
\hline $\mathrm{BH} 8841$ & Kavimba & Dry & & & \\
\hline BH 6714 & Mabele & Not operational & & & \\
\hline BH 8980 & Parakarungu & Not operational & Parakarungu \& Satau & & \\
\hline BH 6535 & Satau & Not operational & Satau & & \\
\hline
\end{tabular}

\subsection{Land Tenure}

Botswana recognises three categories of land tenure: state, communal and private (freehold) land. There is, however, no freehold land in Chobe District. Almost $70 \%$ of the district is state land, as is shown in Table 8 and Figure 41 . The remaining $30 \%$ officially falls under the management of the Chobe Land Board. However, about a third of the tribal land in Chobe is set aside as wildlife management area, for which de facto decision-making over management plans and concession awards has increasingly shifted to the Botswana Tourism Organisation (BTO).

The various permutations of tenure-use found in Chobe require close cooperation from a range of government agencies. For example, wildlife-based tourism takes place within Chobe National Park, but also in the Nunga Wildlife Management Area, and in the communal grazing areas in $\mathrm{CH} 1, \mathrm{CH} 5$ and $\mathrm{CH} 8$, and is being explored as an option in the forest reserves. At the same time, a single land use type may require decision-making by different authorities depending on location (e.g., residential plots in Kasane fall under the Department of Lands, but those in the Chobe East and Chobe West villages fall under the Chobe Land Board). Chobe District is also host to some of the country's most productive 
arable agricultural areas, and large commercial farms in extensive blocks are leased out, calling for a key administrative role from the Ministry of Agriculture's Department of Crop Production.

In order to coordinate the roles and interests of the full range of government agencies, Chobe's District Land Use Planning Unit provides a forum for communication and guidance to the land authorities.

Table 8 Main land use categories and their associated land tenure and management authorities

\begin{tabular}{lllcc} 
Land Use Type & Tenure & Management Authority & Area $\left(\mathrm{km}^{2}\right)$ & 11030 \\
National Park & State & DWNP & 40 & 4096 \\
\hline Forest Reserve & State & DFRR & 18.6 \\
\hline Wildlife Management Area & Tribal & Chobe Land Board / BTO & 2350 & 10.7 \\
\hline Residential (Kasane) & State & Dept of Lands & 28 & 0.1 \\
\hline Tribal Multiple Use (residential, & Tribal & Chobe Land Board, and other & 4548 & 20.6 \\
agriculture, community tourism) & & sectoral agencies & 15154 \\
\hline Total State Land & & & 6898 \\
\hline Total Tribal Land & & & 69 \\
\hline
\end{tabular}

Source: Chobe District Development Plan 7, Department of Surveys and Mapping CHA layer. Note, since there is overlap in some land use types, the area does not add up to $100 \%$.

While the State Land Act and Tribal Land Act together ensure that aspects of tenure are clearly accounted for in land use planning, it is important to recognise that land management in Botswana is currently changing. Ministerial savingrams, for example, have been issued suggesting that BTO become the decision-maker and 'estates manager' for all areas and leases issued for tourism purposes. The creation of "land banks" appears to be emerging as an approach to sectoral development. In Chobe District, for example, there are additional blocks of land that have been set aside for the Ministry of Agriculture to administer for potential commercial crop production. Such changes have ramifications for the roles of existing land authorities, particularly for land boards, whose shrinking mandate may mean reduced resources for proper fulfilment of responsibilities. It also has implications for landscape management using an ecosystems approach, where all sectors work together to ensure the ecological integrity and long-term sustainability of the environment.

While the legal implications of the need to change acts of parliament to support this kind of shift in authority over large areas of land are beyond the scope of this plan, implementers need to be aware of the potential changes in responsible parties, and of the consequences that may arise from limiting future use options and the adaptability of land use to changing economic and environmental conditions.

In addition, while both the Department of Lands (managing State lands) and the Chobe Land Board (managing tribal land) fall under the Ministry of Lands and Housing, the structure and composition of land boards generally does not allow them to argue for the interests of their constituents (members of society) with the same level of efficacy as other government agencies (see for example, White 2009). This represents a potential imbalance of power when it comes to deciding on major land use changes, such as the allocation of blocks of land for commercial farms or tourism ventures. The advisory and coordinating role of DLUPU in ensuring equitable representation is therefore vital.

At the same time, combining the needs of different land tenure and land use types is precisely DLUPU's role, and their adherence to the objectives and land use types set in this ILUP will lead to the best overall land use for the district as a whole. 


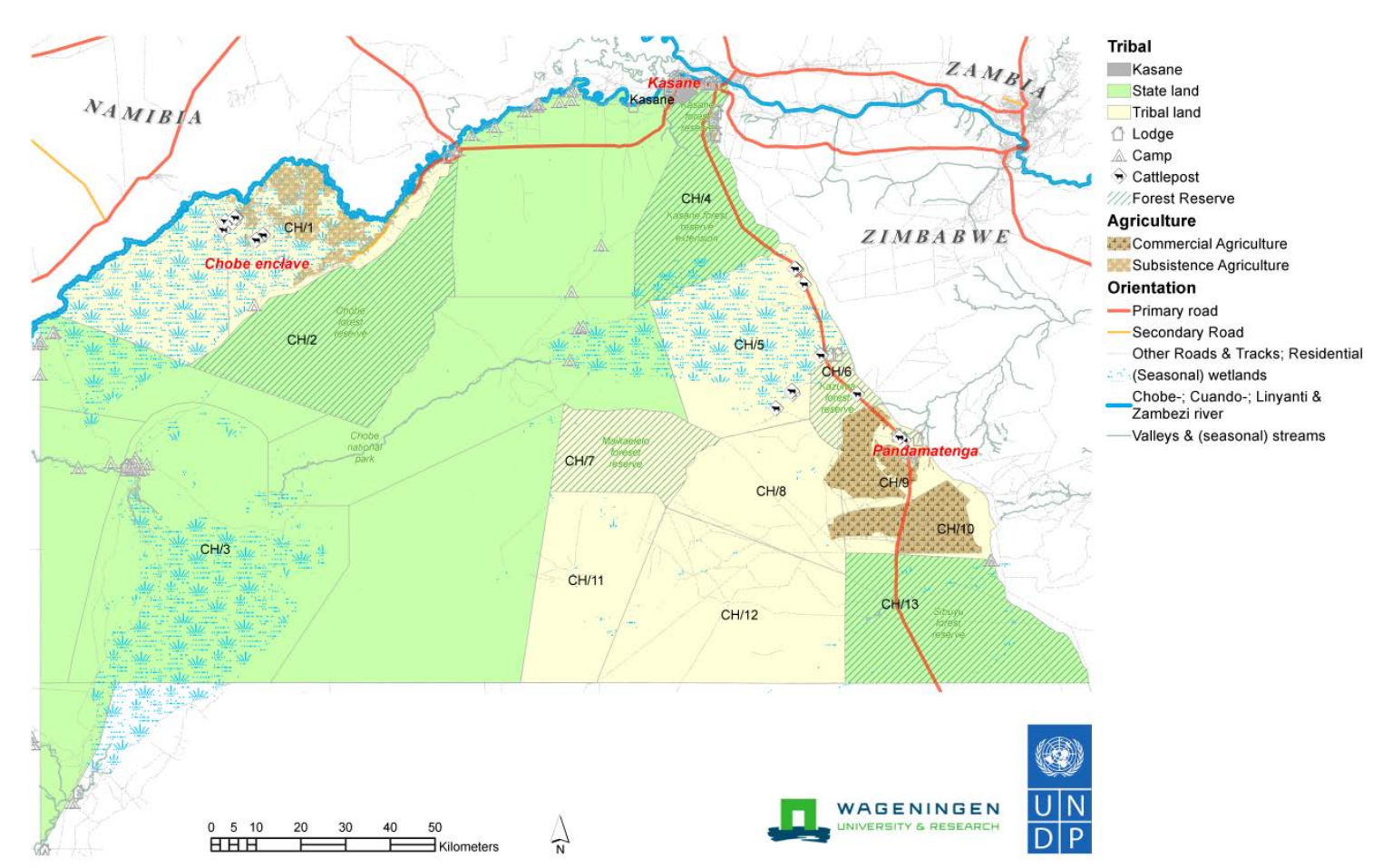

Figure 41 Tribal land and State land in Chobe District

\subsection{Current plan development in Chobe}

The development of this integrated land use plan takes place in the context of existing planning efforts, not only at the district level, but also at levels above and below this. At the national level, all planning falls under the umbrella framework of the National Development Plan (currently NDP 10) and the National Land Use Plan, reviewed in 2009. At the regional level, the KAZA Integrated Development Plan has also been developed. At a lower level, several CHA and site specific plans also guide land use decision-making and management. Recent plans of relevance (discussed in relevant sections of this report), are listed below, categorised according to sector:

- Urban

- Kasane Kazungula Redevelopment Plan (2014) is under review

- Chobe River Front Management Plan (2000)

- Decongestion strategy

- Wildlife

- Chobe National Park Management Plan (2012) is under review

- Pandamatenga Wildlife Management Plan (2014)

- Tourism

- Chobe Enclave Land Use and Management Plan (2003), CH1 Management Plan (in preparation)

- CH12 Management Plan (2013)

- (CH8 is a "tourism in tribal grazing" area, but KALEPA Trust is currently not functioning so no plan currently in place)

- Agriculture

- Pandamatenga Agricultural Infrastructural Development Plan (2008)

- The Zambezi Integrated Agro-Commercial Development Project (2006 MoU)

- Forestry

- Chobe Forests Strategic Environmental Plan (ongoing)

- Forest-specific management plans (to follow once SEMP complete).

There are two plans operating at the same level as this integrated land use plan: the Chobe District Development Plan (currently DDP7) and the Botswana Integrated Development Plan (under the KAZA IDP umbrella). 


\section{Chobe District Development Plan 7}

The District Development Plan cycle is linked to that of the National Development Plan, Iteration 11 of which is currently rescheduled to start this year. This means that DDP 7 will shortly be replaced with its Iteration 8. DDP 7 builds on Chobe District's mandate of providing quality services to its communities, through a district strategy for improving service delivery to improve quality of life. Although the plan is housed by the Chobe District Council, its contents cover the actions and activities for all sectors and departments of government.

Because the plan started in 2009, it is linked to and guided by the Millennium Development Goals and Vision 2016, both of which have recently been replaced by updates: UN Sustainable Development Goals and Vision 2036. According to the plan, land use conflict - particularly through Human-wildlife conflict - remains a key issue in Chobe, as does the transmission and infections rates of HIV/AIDS. Its key objectives are:

- To Promote Sustainable Development and Economic Diversification

- To Promote Diversification in the Tourism Sector

- To Promote Employment Creation and Enhanced Productivity

- To Improve the Quality of Life in the Chobe District

- To Reduce the Spread of HIV/AIDS

- To Promote Sustainable and Sound Environmental Management of the Chobe Ecosystem

Of greatest relevance are the land use sector goals:

- To facilitate efficient and equitable land distribution and development

- To facilitate speedy allocation and servicing of land for development.

\section{Botswana I ntegrated Development Plan (KAZA)}

The main purpose of the Integrated Development Plan (IDP) is to outline how the Government of Botswana intends to manage and develop the Botswana Component of the KAZA Transfrontier Conservation Area as part of its obligations to the KAZA TFCA objectives. The vision for the KAZA TFCA is to enhance ecosystems and cultural resource management through a spirit of collaboration and cooperation among the partner countries. The ecosystem integrity and natural ecological processes will be enhanced by harmonising natural resources management approaches and tourism development across our international boundaries.

The IDP will be used as a reference for detailed conservation planning initiatives, project prioritisation and equitable benefit distribution amongst stakeholders within the Botswana Component of the KAZA TFCA. Linked to the KAZA TFCA structure, the institutional arrangements to facilitate, coordinate and integrate implementation of the Botswana Component IDP shall consist of a National Steering Committee, Joint Management Committee (J MC) and District Committees. The Ministry of Environment Wildlife and Tourism. In the Chobe District, the Extended District Land Use Planning Unit (DLUPU) shall serve as the district implementation structure.

Finally, it is important to note that a Land Use Conflict Identification System (LUCIS) is currently also being prepared for the district, also through the BioChobe project. This project will help planners with land allocations, by analysing development patterns, land suitability, conservation issues and economic preferences. Some of the issues the LUCIS will address include: land shortages for both housing and agriculture, impacts on biodiversity, Human-wildlife conflict, and access to water, by working through a more cohesive and linked land allocation framework. It is therefore important that the zoning options presented in this report can be used to support the LUCIS.

\subsection{Key findings}

- The soils are variable, and in general they pose limitations on agricultural land use, since most of the district consists of poor sandy arenosols;

- The areas with good soils are located in Pandamatenga, but these soils are very heavy and expert knowledge is essential for working the soil;

- In the Chobe Enclave and around Kasane-Kazungula are better soils for communal farming;

- Land resources are very limited, with only $30 \%$ tribal land, $70 \%$ being protected as Chobe National Park or Forest Reserve; 
- The system is driven by long-term dynamics in climate, hydrology and vegetation pattern

- The hydrological system is very complex, and still not fully understood.;

- The variability of climate and hydrology, linked to geomorphological changes, assumes that a flexible approach is used in land use planning, since abrupt changes can occur;

- Groundwater resources are very limited, and often constrained by poor water quality and saline water;

- Surface water is only available for part of the year; the water resources in the center of Chobe National Park are very crucial to sustain wildlife populations;

- There are many ongoing studies and plans developed at the same time. These plans ultimately should be informed by this Integrated Land Use Plan, and the lines set out in this plan. 


\section{Biodiversity and Conservation}

Where politically and administratively the Chobe district is defined as a border area, ecologically speaking the Chobe River is the heart of the ecosystems, wetlands and drylands alike. In such an area where 5 countries meet and everything depends on the functioning of its ecosystems all plans should consider their international dimension.

The proposed revised National Biodiversity Strategic Action Plan (ECOSERV, 2014) gives a high species diversity (including for threatened, vulnerable and endemic species) for Chobe National Park, and even "very high" where the park borders the Chobe River. The NBSAP mentions 7 large herbivores, 5 large carnivores and 25 bird species as being globally threatened. Almost all of these may be found in the Chobe District. For more details see the proposed revised NBSAP.

\subsection{Protected areas}

The biological diversity of Chobe District as one of the last places where the African megafauna can be observed and studied in all its richness, is of great global importance. Apart from the Pandamatenga Farms Complex and the built-up area around Kasane, most of the Chobe District has a coherent network of areas with a conservation status including one National Park, six Forest Reserves and two Wildlife Management Areas. This status also reflects the central role that conservation-based tourism plays in the national economy. Whilst neighbouring countries manage viable wildlife populations within effective and globally recognised National Parks, none can claim to conserve such a singular land mass as that of the Northern Conservation Area of northern Botswana. The Northern Conservation Area covers more than $80,000 \mathrm{~km}^{2}$ of contiguous protected wilderness stretching from the Okavango Delta in the west, to the Savuti and Chobe systems in the north and the Makgadikgadi Pans complex in the south. The area is currently conserved through an interconnected series of National Parks (Chobe, Makgadikgadi and Nxai Pan National Parks) Game and Forest Reserves (Moremi Game Reserve, Sibuyu Forest Reserve, Maikaelelo Forest Reserve, Kazuma Forest Reserve, Chobe Forest Reserve \& the Kasane Forest Extension) and Wildlife Management Areas (WMAs) that surround and connect these protected areas (PAs).

The Protected Area Profile for Botswana from the World Database of Protected Areas, (UNEP-WCMC, 2016, www. protectedplanet. net) lists and characterises the following Protected Areas for Chobe District (Table 3).

Two Wildlife Management Areas ( $\mathrm{CH} 11$ and 12) link the Sibuyu Forest Reserve with the Chobe National Park. A Tourism Management Plan has been finalised for Concession Area $\mathrm{CH} 12$.

$\mathrm{CH} 1$ (the Chobe enclave) is managed as a non-consumptive area, which is essentially an administrative designation established to facilitate the administration and management of the wildlife and other resources in the area, in order to ensure their sustainable utilisation and to maintain the integrity of the area's ecosystems.

$\mathrm{CH} 5,8,9$ and 10 do not have a special conservation status assigned to them. $\mathrm{CH} 5$ in particular has an important role to play in conservation as it not only provides a specific habitat for large grazers, it is also an important corridor between Hwange N.P. in Zimbabwe and Chobe N.P. identified by KAZA TFCA as one of its 6 Wildlife Dispersal Area's.

Other sites under different degrees of legal protection include historical and archaeological sites such as The Mowana Prison Tree in Kasane (Tree historically used as a prison cell), a Baobab with $19^{\text {th }}$ century visitors' markings at Hendriks Pan, the archaeological site at Goha hills caves, the hot springs near Kazungula on the Chobe, the site of the 1840's Makololo capital on the Chobe, The Jesuit mission site at Pandamatenga, and the Lesoma monument. As understandably no comprehensive list exists of such sites, it remains extremely prudent to consult the National Museum before any new development is undertaken, less archaeological or historic sites and buildings are lost. 
Table 9 Protected areas, as recorded in the World Database (UNEP-WCMC)

\begin{tabular}{|c|c|c|}
\hline Protected Area & I UCN-category ${ }^{5}$ & Surface $\left(\mathrm{km}^{2}\right)^{6}$ \\
\hline Chobe National Park & $\mathrm{Ib}$ & 11.000 (incl. a small extension to the Okavango System) \\
\hline Chobe Forest Reserve & 11 & 1432 \\
\hline Kasane Extension & 11 & $641\left(659^{5}\right)$ \\
\hline Kazuma Forest Reserve & 11 & 195 \\
\hline Sibuyu Forest Reserve & 11 & 1194 \\
\hline
\end{tabular}

\subsection{International context, KAZA region}

\subsubsection{The Kavango-Zambezi Transfrontier Conservation Area ${ }^{8}$}

The Kavango-Zambezi Transfrontier Conservation Area (http://www.kavangozambezi.org/) covers the parts of Botswana, Angola, Namibia, Zambia and Zimbabwe, where these countries share the regional ecosystems. The KAZA TFCA Treaty was signed by the Presidents of the five partner countries on the 18th of August 2011, in Luanda, Angola. Covering nearly $520,000 \mathrm{~km}^{2}$, the KAZA TFCA is the largest transfrontier conservation area in the world.

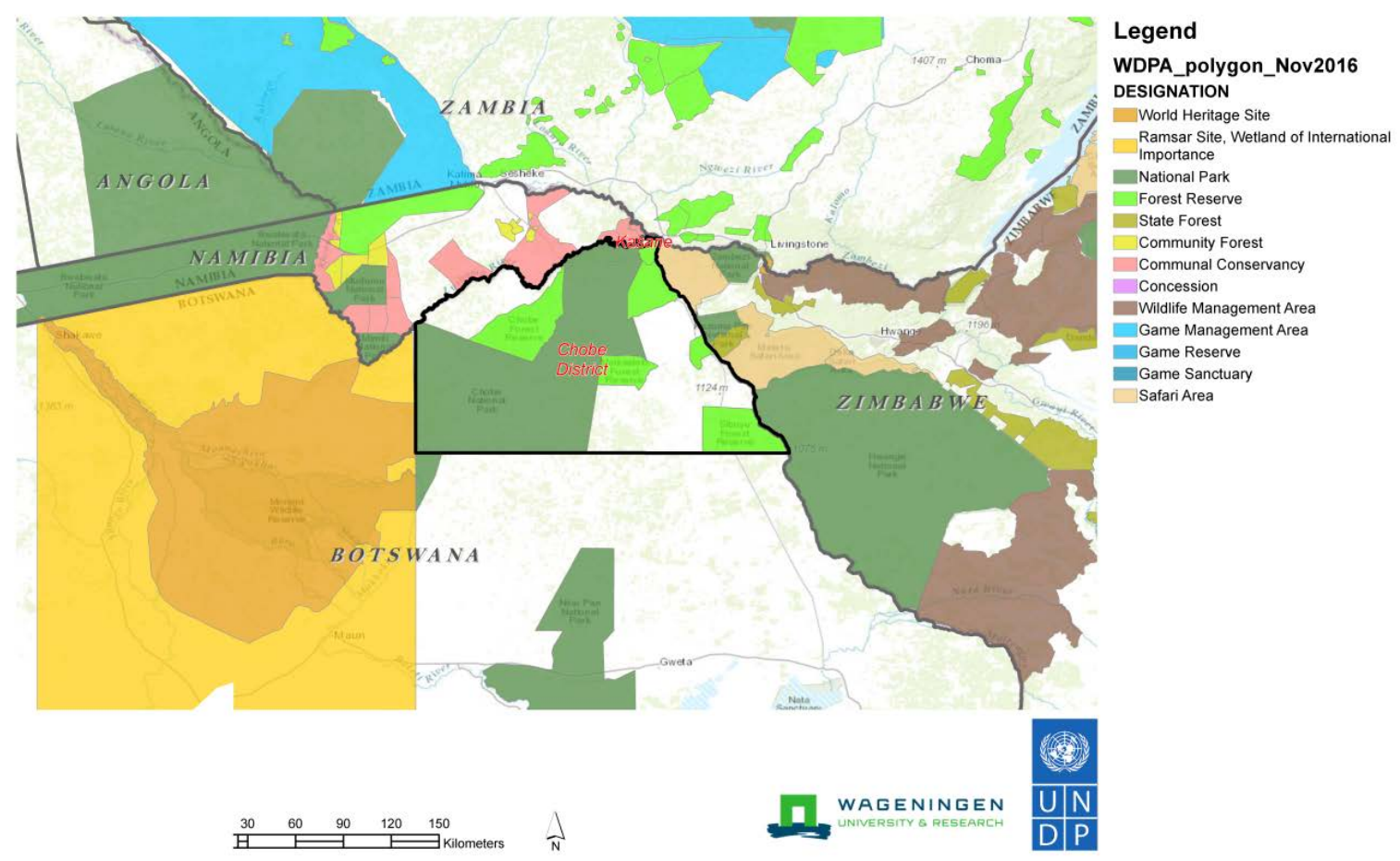

Figure 42 Chobe District in international context, showing protected areas in the region

\footnotetext{
5 Based on WDPA indications. Ib Wilderness Area: Category Ib protected areas are usually large unmodified or slightly modified areas, retaining their natural character and influence without permanent or significant human habitation, which are protected and managed so as to preserve their natural condition.

II National Park: Category II protected areas are large natural or near natural areas set aside to protect large-scale ecological processes, along with the complement of species and ecosystems characteristic of the area, which also provide a foundation for environmentally and culturally compatible, spiritual, scientific, educational, recreational, and visitor opportunities.

6 It is to be noted that these figures from the WDPA differ from what has been stated in the proposed revised National Biodiversity Action Plan. According to the WDPA its information comes from the Department of Wildlife.

7 Calculated area, after degazettement of portion of the reserve.

8 Most information in this section comes from the Kavango Zambezi Transfrontier Conservation area (2014), Master Integrated Development Plan, 2015 - 2020, to which the reader might be referred.
} 
The area comprises 20 National Parks, 85 Forest Reserves, 22 Conservancies, 11 Sanctuaries, 103 Wildlife Management Areas and 11 Game Management Areas. This gives a total of $371,394 \mathrm{~km}^{2}$ under some form of wildlife management, leaving $148,520 \mathrm{~km}^{2}$ for agricultural use including rangEland. Figure 42 presents the KAZA- region with the location of major conservation areas in neighbouring countries, such as Zambezi, Hwange and Kazuma Pan National Parks in Zimbabwe, Mudumu and Babwata National Parks in Namibia, Sioma Ngwezi National Park in Zambia, and Luengue-Luiana National Park in Angola.

There is a shared understanding among the governments that policies across the KAZA region must be harmonised if biodiversity is to be supported and if conservation is to be integrated with sustainable development. This is both within and between nations. Landscape dynamics - at a scale at which national activities cannot work - need to be understood and conserved as the basis for biodiversity management.

The goal of KAZA TFCA therefore is to transform the area into "a world-class transfrontier conservation area and tourism destination", within the context of sustainable development, whereby aspirations of local communities are integrated with biodiversity management, making conservation sustainable from a socio-economic point of view.

The KAZA TFCA mission is: "to sustainably manage the Kavango-Zambezi ecosystem, its heritage and cultural resources based on best conservation and tourism models for the socio-economic wellbeing of the communities and other stakeholders in and around the eco-region, through harmonisation of policies, strategies and practices."

The strategic plan for the TFCA acknowledges 4 critical success factors:

- continued political will and commitment by partner countries;

- financial sustainability;

- flexible collaboration; and

- continuous engagement of local communities.

The Master Integrated Development Plan 2015-2010 of KAZA TFCA prioritises the harmonisation of the following policies and practices:

- Natural Resource Management (NRM)

- Wildlife Corridors.

- Management of shared watercourses for the purposes of harmonising fisheries.

- Harmonised strategies for the conservation and management of single species.

- Tourism

- Addressing economic leakages ${ }^{9}$ by developing economic linkages.

- Commitment to responsible tourism.

- Legal

- Formal legislative recognition of Transfrontier Conservation Areas (upon which legislation all other recommendations will be dependent).

- Combating crime throughout the KAZA TFCA.

The Wildlife Conservation Society estimates that there are about 200,000 Elephants South of the Zambezi River system in the KAZA TFC, and only 30,000 to the North. This inequality is explained by lack of protection in the north, and insufficient facilitation of connectivity between the protected areas North and South of the River Zambezi, which is shared by Angola, Namibia and Zambia.

Even though the KAZA TFCA is thinly populated with 2.7 milLion inhabitants, the requirements for their animal husbandry systems are impediments for wildlife to cross the TFCA. Similarly, migrating populations of wildlife, in particular Elephants, may cause substantial harm to local agriculture-based economies. Therefore KAZA TFCA has identified 6 WDA's (Wildlife Dispersal Areas) for which it seeks to establish safe wildlife-corridors. By creating larger connected areas, the TFCA enables wildlife to move seasonally and make better use of a variety of habitats. Corridors also help wildlife to adapt to climate change, enabling movement away from climate-stressed areas.

${ }^{9}$ The way in which revenue generated by tourism is lost to other countries' economies, it may partially neutralize the money generated by tourism. 
Four WDA's are of interest for the Chobe District

(KAZA 2011):

- The Kwando River Wildlife Dispersal Area, with corridors mainly with a South-Eastern/NorthWestern orientation, between Chobe District and Angola/Zambia

- The Zambezi-Chobe Floodplain WDA. Connectivity along the Zambezi River system between Chobe and Zambezi national parks is facilitated far into

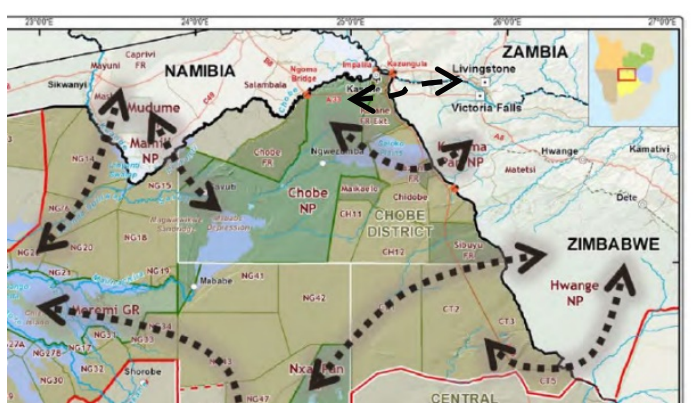
Zimbabwe thanks to a series of areas with an official conservation status.

- The Hwange-Kazuma-Chobe WDA, with a main East-West orientation. The presence of the Pandamatenga Farm complex is mentioned as "land use challenge".

- The Hwange-Makgadikgadi-Nxai Pan WDA. This corridor is at a much larger scale compared to the previous one and includes also a North-South component within Botswana.

\subsubsection{KAZA TFCA Governance}

The highest authority of KAZA TFCA is the Ministerial Committee. The coordinating country rotates every 2 years. The decisions of the Ministerial Committee are operationalised by a Committee of Senior Officials (COSO). COSO in turn supervises a Joint Management Committee that administers and manages the KAZA TFCA.

The Secretariat of KAZA TFCA coordinates the day-to-day operations of the KAZA TFCA; it has taken office in Kasane. Strategic direction to attain the goal and objectives set by the KAZA TFCA partner countries is provided through the Integrated Development Plans being developed for each partner country's component of the KAZA TFCA and the Indicative Development Framework (KAZA website).

At each of the participating countries exists a National Committee to coordinate the implementation of a country specific conservation programme, ensuring alignment between national and KAZA TFCAwide activities. The committees facilitate the participation of national stakeholders in the wider planning processes and seek to ensure that local communities derive benefits from the KAZA TFCA.

\subsection{International conventions and agreements}

Botswana is signatory to most major international environmental conventions. All international obligations that Botswana adheres to are conditional for the present Chobe District-ILUP. The following overview of international conventions and agreements of particular importance for Chobe District summarizes the information as largely provided by the Draft Review of the National Biodiversity Action Plan (2016). For more information one is referred to the respective websites of the conventions.

In May 2012, African heads of states convened for a two day summit in Gaborone, in collaboration with public and private sector partners, where sustainability was at the centre of the deliberations. The summit resulted in the Gaborone Declaration for Sustainability in Africa (http://www.gaboronedeclaration.com/), where countries committed themselves to implement all conventions and declarations that promote sustainable development. The overall objective of the Declaration is "To ensure that the contributions of natural capital to sustainable economic growth, maintenance and improvement of social capital and human well-being are quantified and integrated into development and business practice." Obviously, conservation and strengthening of ecosystem functioning is at the centre of the declaration.

\subsubsection{UN conventions}

- UN Convention on Biological Diversity (https://www.cbd.int). The Convention's three objectives are the conservation of biological diversity, the sustainable use of its components and the fair and equitable sharing of benefits arising from the utilisation of genetic resources. The Conference of 
Parties has adopted a strategic plan 2011- 2020 with 5 Strategic Goals and 18 so-called Aichi Biodiversity Targets. Of particular interest for Land Use Planning is Strategic Goal A (Address the underlying causes of biodiversity loss by mainstreaming biodiversity across government and society) with Target 2 (By 2020, at the latest, biodiversity values have been integrated into national and local development and poverty reduction strategies and planning processes and are being incorporated into national accounting, as appropriate, and reporting systems.

- The Convention on Wetlands of International Importance, called "Ramsar Convention" (http://www.ramsar.org). A member country is obliged to promote conservation of all wetlands and waterfowl through the establishment of nature reserves. Other obligations include research and training to support such conservation.

- Convention on International Trade in Endangered Species (https://www.cites.org). The main objective of CITES is to ensure that international trade in threatened animals and plant species does not threaten their survival.

- UN Convention to Combat Desertification (http://www2.unccd.int). The UNCCD is a product of the Rio Earth Summit (1992). The convention's main objective is to combat desertification and strive to mitigate the effects of drought in countries undergoing serious drought and/or desertification, particularly in Africa.

- UN Framework Convention on Climate Change (http://unfccc.int). This convention is one of the tangible and binding outcomes of the Rio Earth Summit (1992). The critical objective of this Convention is to achieve the "stabilization of greenhouse gas concentrations in the atmosphere at a level that would prevent dangerous anthropogenic interference with the climate system". Botswana has ratified the Paris Agreement in November 2016. Its central aim is to strengthen the global response to the threat of climate change by keeping a global temperature rise this century well below 2 degrees Celsius above pre-industrial levels, and to pursue efforts to limit the temperature increase even further to 1.5 degrees Celsius. It is worth noting the link with the Sustainable Development Goal 13, adopted by the UN Assembly in September 2015: "Take urgent action to combat climate change and its impacts".

- Convention Concerning the Protection of World Cultural and Natural Heritage called "World Heritage Convention"(http://whc.unesco.org). As a party to this convention, Botswana has taken on obligations to identify, protect, and conserve for future generations areas of natural and cultural heritage. Botswana has amongst others submitted the Chobe-Linyanti System for World Heritage status which will provide an opportunity of an additional level of conservation to the existing management.

- In 2015 the UN General Assembly formally accepted a new set of 17 measurable Sustainable Development Goals, SDGs ( http://www.un.org/sustainabledevelopment/sustainable-developmentgoals). Of particular interest for Chobe District - with its exceptional biodiversity values of national and international importance - is SDG 15: "Protect, restore and promote sustainable use of terrestrial ecosystems, sustainably manage forests, combat desertification, and halt and reverse land degradation and halt biodiversity loss".

\subsubsection{Non-UN multilateral agreements of special relevance to Chobe District}

\section{- African Convention on the Conservation of Nature and Natural Resources}

(http://www.au.int/en/treaties/african-convention-conservation-nature-and-natural-resourcesrevised-version). This convention commits the Government to enhance environmental protection, foster conservation and sustainable natural resources use, and to harmonise their policies in these fields. Guiding principles include the rights of all people to "a satisfactory environment favourable to their development" and that such needs are met in a sustainable and equitable manner

- As Botswana is also member of the SADC group of countries, of special reference to Chobe District is the following:

- The SADC Regional Biodiversity Strategy (http://www.sadc.int/documentspublications/show/SADC_Regional_Biodiversity_Strategy.pdf) at the regional level is an important tool for addressing biodiversity issues that occur at ecological scales broader than those encompassed within national borders. The regional strategy provides the necessary framework for transboundary cooperation in biodiversity management.

- The SADC Protocol on Wildlife Conservation and Law Enforcement

(http://www.sadc.int/documents-publications/show/Protocols/), which Botswana signed and 
ratified in 2000, provides some of the linkages between national level conservation priorities and global level ones. Taking into consideration the national laws of each of the member countries, the protocol aims to promote the sustainable use of wildlife; harmonise relevant legal instruments; enforce laws both within and between states; facilitate information exchange on wildlife management; and promote capacity conservation and transfrontier conservation.

- The SADC Protocol on Forestry (http://www.sadc.int/documents-publications/show/Protocols/) seeks to promote the development, conservation and sustainable use of all types of forests and trees, and in so doing, alleviate poverty and generate economic opportunities while supporting environmental protection

\subsubsection{Agreements on international waters covering Chobe District}

Given the central position of the Chobe River for the annual heartbeat of flooding and recession, any use of natural resources in the watershed affects the use over the river basin as a whole. Not only wildlife and tourism will be affected by water management interventions upstream, but also recession farming, dry-season grazing, fisheries and urban development. The following Regional framework agreements on water management issues in the Okavango and Zambezi River Basins are of relevance for the Chobe District:

- ZAMCOM (http://zambezicommission.org) is a river basin organization set up by the eight riparian states that share the Zambezi River Basin. ZAMCOM promotes "the equitable and reasonable utilization of the water resources of the Zambezi Watercourse as well as the efficient management and sustainable development thereof". The ZAMCOM agreement was signed in 2004 at Kasane and came into force in 2011. I ts Secretariat is hosted by Zimbabwe.

- As with high water discharges there exists a physical linkage between the Okavango and Chobe River systems, the Agreement on the Establishment of a Permanent Commission on the Okavango River Basin, OKACOM (http://www.okacom.org/) will have a (limited) bearing on the water management for the Chobe District

Other international agreements that apply covering amongst others aspects of pollution and waste management, which fortunately are of less interest for the present day situation in Chobe, include: The Basel Convention on the Control of Transboundary Movement of Hazardous Waste and Other Wastes (http://www. basel.int/); the Rotterdam Convention on the Prior Informed Consent Procedure for Certain Hazardous Chemicals and Pesticides in International Trade (http://www. pic.int/); the Stockholm Convention on Persistent Organic Pollutants (http://chm.pops.int/); and the Libreville Declaration on Health and Environment in Africa (http://www.afro.who.int/).

\subsection{Regional Cooperation}

The location of the Chobe District matrix bordering three other countries (the $30 \mathrm{~km}$ wide Caprivi Strip separates Botswana from the fourth country, Angola) and its importance as one of Africa's richest wildlife areas necessitates inclusion of a regional conservation dimension in the present Chobe District Land Use Plan. The KAZA TFCA provides an overall developing framework for the conservation sector of the wider region, with special emphasis on the transnational dispersal areas of wildlife. For a solid and coherent implementation of Land Use policies in the Chobe District, the international dimension will have to be considered, not only across the different sectors, but also on both sides of international borders.

While - obviously - the negotiation and conclusion of international agreements and frameworks will have to be left at the appropriate national political levels, these agreements, treaties (such as the CBD) and other collaborative arrangements (such as SADC and the KAZA TFCA) that Botswana adheres to, provide important guidance for the implementation of the Land Use Plan for Chobe District itself.

To operationalise the international dimensions, collaboration across frontiers (geographical and sectoral) is needed. Strategic decision taking at this level involves political levels such as Governors and District Officers of the different administrative units that share the international borders in the 5 KAZA TFCA-countries. However, the preparation of balanced decision taking and the implementation 
of the decisions taken will require technical cooperation from the different (sectoral and other) departments present at district or equivalent level in the different countries of the KAZA region. The Chobe District Land Use Planning Unit, neutral and cross-sectoral as it is by its very nature and mandate, is well positioned to organise such cross-border and cross-sectoral exchanges, facilitate balanced decision taking and - if asked - may streamline implementation of the decisions taken by the competent authorities.

Concern has been expressed (amongst others in the KAZA TFCA Management Plan, 2015) about the different policies on fisheries management and the control of illegal fisheries practices in Botswana and Namibia. That does not only affect the fisheries sector as such, but also the conservation of wildlife, tourism, and even national security services and the transport sector. It is doubtful if these stakeholders communicate with each other, not even within one and the same country let alone across international borders. The occasion of the adoption of this Land Use Plan may provide an opportunity to address this institutional gap.

\subsection{Ecoregions}

Ecoregions requires system managers to think at large spatial and long temporal scales, offering several advantages for conservation planning and action and providing the best basis for establishing conservation priorities (Dinerstein, et al. 2000). The WWF has identified 867 terrestrial ecoregions across the Earth's land surface and of these, WWF selected the Global 200 as the ecoregions most crucial to the conservation of global biodiversity. The Chobe District holds two of WWF's Global 200 Ecoregions; the Central and eastern Miombo Woodlands and the Zambezi Flooded Savannas.

\section{Miombo/ Mukusi Woodlands}

The Miombo/Mukusi ecoregion is extensive, covering an estimated 3.6 milLion $\mathrm{km}^{2}$. It is of outstanding importance to conservation with half of the worlds Elephant population residing within it. It is covered by broadleaved, "dystrophic" savanna woodland (Huntley, 2982), dominated by tree species in the legume subfamily Caesalpinioideae such as Brachystegia, Julbernardia, Isoberlinia, Baikiaea, Cryptosepalum, Colophospermum and Burkea. In Botswana Brachystegia (miombo) is not common and replaced by Baikiaea. The woodlands are therefore in Botswana more correctly referred to as Mukusi woodlands. Across their range the miombo/mukusi woodlands are, in the majority, inhabited by people and are understood to owe their structure partially to human intervention through fire use and pastoralism. Because of this some have ventured to describe the miombo/mukusi as a "social forest" which has contributed to the development of a strong emphasis on the sustainable uses of natural resources and of community-based natural resource management (CBNRM) in some countries in this ecoregion. These community based approaches are based on the premise that if people do not benefit from using the products of miombo/mukusi woodlands, they will be more likely to clear the woodlands for agriculture (Byers, 2001). The miombo/mukusi woodlands are found to the north and east of the Chobe District and are associated with the remaining stands of Zambezi teak hardwoods left within Chobe National Park and the Forest Reserves.

\section{Zambezi Flooded Savannas}

The Zambezian flooded grasslands occurrence is limited within the Chobe District and can be found in the floodplains of the Chobe Enclave. This ecoregion represents some of the most globally outstanding and biologically important flooded grasslands and savannas. The ecoregion includes the Okavango Delta and it is contiguous with that found in Chobe District through its linkage along the Selinda spillway. Across Africa they occur as seasonally or permanently flooded lowlands in the Zambezi basin and neighbouring river basins. The floodplains are often associated with dry and not very fertile miombo and mopane savannas and woodlands (Olson \& Dinerstein, 2002). 


\subsection{Forests and vegetation cover}

\subsubsection{Historical vegetation cover trends}

First information on the vegetation of the Chobe region was recorded by early travellers such as Livingstone (1858), Selous (1881) and Schulz \& Hammar (1897). Livingstone visited the area for the first time in 1851 during a period of average to higher rainfall (Nevill 1908). The South bank of the Chobe/Linyanti was at that time woodland infested with Tsetse fly, causing Livingstone to avoid the area. Livingstone described the North side of the Chobe as covered with extensive reed beds, islands with palm trees and wet grasslands all the way up to Linyanti; a description confirmed by Selous (1881). The latter did visit the South bank and described the vegetation, recording the sand ridges along the south bank in 1874 as "covered with dense jungle or forest. As he travelled westwards from Kazungula the Jungle was seen to be containing right up to the bank of the river with vegetation further west to become more open with Acacia erioloba, covering alluvial soils ca $70 \mathrm{~km}$ from the junction with Zambezi, dense forest again covering the higher sandy areas there. Selous notes lower water levels in the Linyanti compared to Livingstone. The first landscape map of the Chobe (Bradshaw 1881) shows a vegetation sketch along the Chobe between the Chobe Zambezi confluence and approx. I haha. Riverine forest was found along the river in a number of places but notably from present day Kazungula up to the present day Chobe safari lodge location. The high ridges on the south side of the Chobe were covered with thick forest while alluvial flats (such as after Serondela) were covered with thick bush/thicket. Riverine forest was scarce along the latter flats. Acacia erioloba riverine forest occurred again near I haha. The forest tree composition of Chobe forest areas were first recorded by Miller (1938), noting the abundance of important timber trees such as Pterocarpus angolensis (Mukwa), Baikiaea plurijuga (Mukusi) and Colophospermum mopane (Mopane) and the presence of (for Botswana) rare Pterocarpus stevensonii trees on the plateau at Kasane.

In 1975 Simpson (1975) described vegetation in the Chobe national park in particular for the Serondela area. Heavy Elephant utilization was noted for the riverine acacia woodlands. Thickets in the alluvial flats had become more open since 1880. Dichrostachys cinerea shrubland was thought to indicate former agricultural activity (this is indeed the case here). Simpson also noted effects of timber extraction (from 1935-1956, see further the forestry section) much reducing the number of commercially harvested tree species, but since 1994 this area has been recovering from the period of timber extraction (Skarpe et al. 2014). In the Serondela area, Musogelo et al. (2002) estimated the woody vegetation cover changes between 1962 and 1998 on the basis of aerial photographs, showing the continuous decrease in woody vegetation cover in areas near the Chobe river. Riverine forest was shown to have almost completely disappeared in the study area West of Serondela by 1998. Herero et al. (2016) using Landsat imagery (period 1982 - 2009) also showed a continuing trend of reduction of woody cover along a narrow band of approx. $2 \mathrm{~km}$. along the Chobe River. They however also show that beyond this band in many forest/woodland areas woody vegetation cover is currently increasing. Also in more Southern parts of the Chobe National Parks recent increases in tree cover (period 1997 2008) are being reported (Kalwij et al. 2008). Considering the historical records on the woodlands of the Chobe by many early travellers and comparing Mosugelo et. al's river front maps to Bradshaw's sketch map suggests that while forest areas away from the Chobe have been more stable, the vegetation near the Chobe has become more open since the mid 1980's than in Bradshaw's time (the time of previous high Elephant numbers), with the riverine forest fringe dominated by acacia species most heavily affected. In the Linyanti region the effects on mopane forest may extend over a longer distance than on the Chobe riverfront (pers. obs. and Van Langevelde pers. com.). The hinterland here consists of mopane forest and may be utilised by higher numbers of Elephants

Wetlands on the North side of the Linyanti-Chobe river system have with the increase of human population (from 5000 people around 1900 to over 110,000 by 1996; Mendelsohn \& Roberts 1997) become more exploited, as grazing land and crop cultivation expanded. Particularly floodplain areas adjacent to the Chobe and Zambezi in the eastern part of Caprivi show higher densities of grazing, and natural wetlands here are under use. Thus leading to transformation of the early wetland vegetation into more agro-ecological pastures adjacent to the Chobe National Park. Effectively this part of the Chobe system as it was functioning 150 years ago is now dominated by agricultural landuse. 


\subsubsection{Current vegetation types and tree cover}

The Chobe Vegetation (Figure 43) currently shows a large diversity in vegetation types based on species composition, varying from perennial swamp vegetation and annually flooded grassland to broad and fine leaved savanna types and woodlands and forests. The term forest (structurally defined by a tree cover of $>60 \%$ and trees greater than $6 \mathrm{~m}$ with little understory, Torello Raventos et al. 2013) is in general terms of vegetation description probably better avoided, as in very few places tree cover values reach $60 \%$. There is some evidence in woodlands not directly near the Chobe river front that, as in other parts of Africa, tree cover in part of the area may actually be increasing (Herrero et al. 2016, Kalwij et al. 2008). The generally held notion that tree cover has been decreasing is therefore mostly applicable to the vegetation close to the Chobe river front and along the Linyanti, and in some places where timber extraction has taken place in the 80's and 90's. Some individual tree species may have decreased though. In particular the tree species Pterocarpus angolensis, due to forestry operations and as a preferred species foraged on by Elephants. The wide variation in tree cover as observed (Figure 43) therefore mostly reflects soil conditions such as depth and soil fertility and the South-westward declining precipitation regime.

Of particular importance for consideration are the narrow bands of riverine woodland along the Chobe River, consisting of more open acacia dominated woodlands on alluvial soils as found all over the drier parts of Africa, and dense riverine vegetation. These have largely disappeared due to Elephant exploitation and are now found mostly within build-up and fenced areas in Kasane and Kazungula and in fenced off areas elsewhere (e.g. Muchenje campsite and cottages near Ngoma). The riverine forest fringe in the Kasane-Kazungula area is associated with a higher bank and generally has a higher proportion of broadleaved trees such as Diospyros mespiliformis, Ficus sycomorus, Kigelia africana and Croton megalobotris. The riverine fringe forest plays an important role in bird diversity and is the main habitat for Chobe bushbuck.

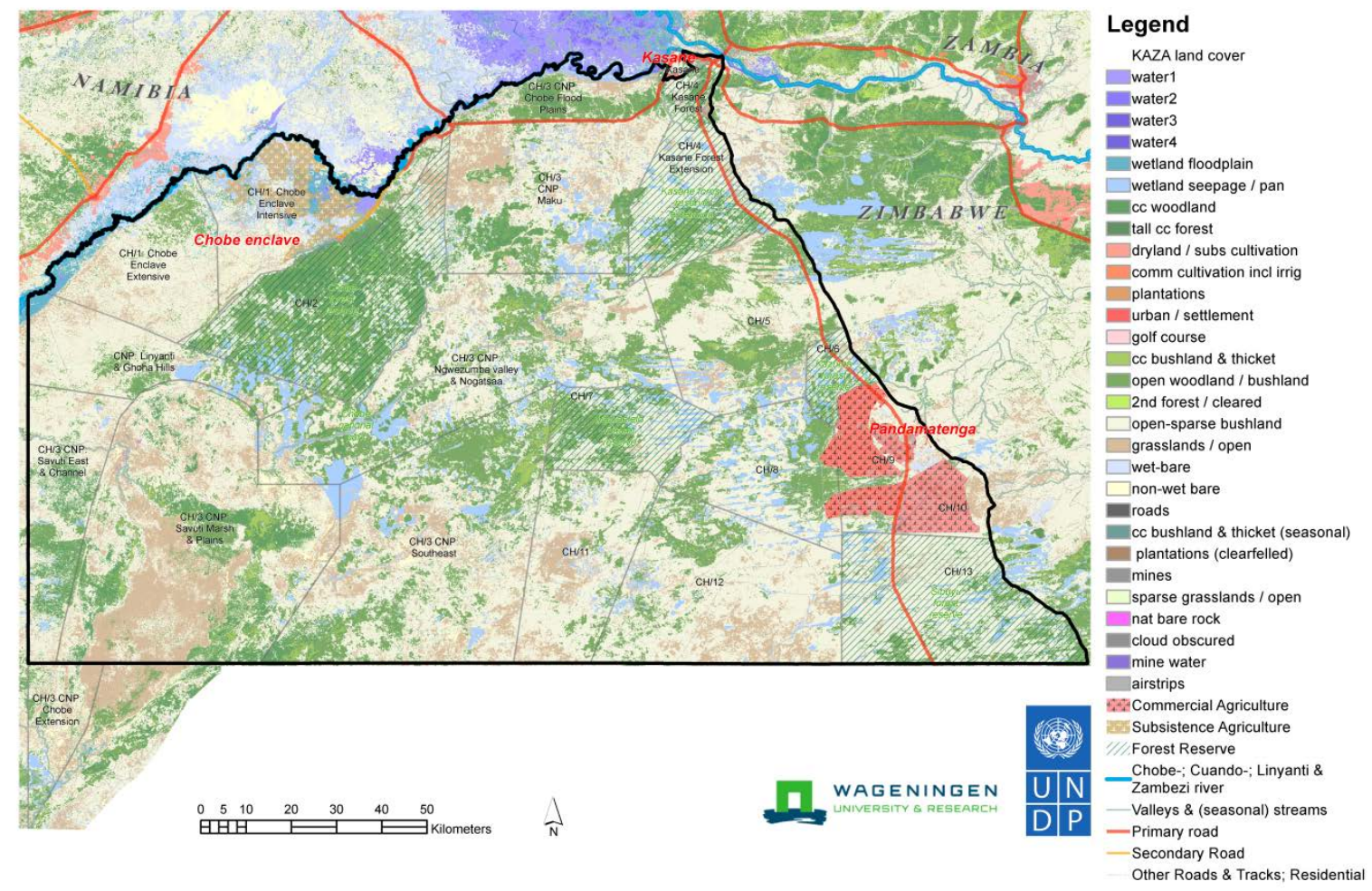

Figure 43 Land cover, based on KAZA land cover classification 


\subsection{Wildlife}

\subsubsection{Connected wildlife populations}

As described in $\S$ 6.2.1 forms Chobe District part of the Northern Conservation Area within Botswana that, in itself, is part of a greater regional conservation area, the KAZA TFCA. This land mass holds some of the most important populations of African wildlife in the continent, with the majority of the global populations of key flagship species such as Elephants, Lions and Wild dogs residing within the KAZA region. Recent research has rated the northern conservation area as Africa's most functional conservation area (Fynn, 2016).

The large size and more importantly the ecological heterogeneity contained within the Northern Conservation Area creates an independently functional ecosystem, which encompasses both wet and dry season resource utilisation zones for a wide variety of different species and entire migratory corridors between these resource use areas; a quality that is increasingly rare and which defines the importance of the area for the conservation of African wildlife. The high level of conservation status currently afforded the Northern Conservation Area would seem to be stable in the current situational climate, but recent changes and further proposals to change the land use within the Northern Conservation Area may undermine the viability of conservation in the region.

Wildlife populations residing within the Chobe District and elsewhere within the Northern Conservation Area have seen recent declines in numbers (Chase, 2011). The 2013 DWNP survey results for northern Botswana also validates this, with observed declines in Duiker, Eland, Gemsbok, Giraffe, Kudu, Lechwe, Sable, Springbok, Steenbok, Tsessebe. However, the DWNP records from 2003 through to 2013 would indicate a slight increase in populations of Buffalo, Hartebeest, Ostrich and Roan, with large increases observed in Elephants, Hippos and Zebra. Shifting numbers could be explained by climatic perturbations, drought cycles or the impacts of poaching as well as natural emigration. Wildlife populations survive and maintain resilience in the face of ecological adversity and environmental change by being able to disperse between different ecological zones. While one subpopulation may become extinct through such adversity, the area can be recolonised by an adjacent sub-population, while dispersal between sub-populations as an on-going phenomenon creates genetic resilience to ecological change. Under these conditions, local populations could fluctuate in numbers; while the sum total of numbers across the region will remain relatively stable (Pulliam, 1988). The underlying principle of such meta-populations is that dispersal, recolonisation and the ability to move between different ecosystems and eco-regions is crucial for species survival.

The Northern Conservation Area forms a source point from which secure and well conserved wildlife species can now been seen to be moving into adjacent conservation areas (Chase \& Griffin 2008, Hunter \& Kerley, 1999, KAZA, 2011, Naidoo et al., 2014). Some of these currently form sinks, where animals may be exposed to higher rates of mortality from poaching incidence or managed off-take through translocation or hunting (Chase \& Griffin 2008), whilst other areas are effectively being recolonised (Chase $\&$ Griffin, 2006), with increasing wildlife numbers generating sustainable and diversified rural economies through wildlife based ecotourism (Chase \& Griffin, 2009). Other neighbouring conservation areas form source locations for wildlife coming into the Chobe District. The critical take home point is that the management of wildlife within the Chobe District cannot be viewed in isolation and that the linkages, in the form of wildlife corridors, that exist within the District borders, across the Northern Conservation Area and at a transboundary regional scale into neighbouring conservation areas must be properly zoned and afforded suitable protection.

\subsubsection{Diversity and Status of Wildlife in Chobe District}

\subsubsection{Herbivores}

Chobe District, with its concomitant National Park, Forest Reserves and Wildlife Management Areas is one of the flagships of Botswana's conservation areas, forming a significant 'hotspot' of biodiversity for a wide variety of mammals and bird species. The area is most renowned for its Elephant population which concentrates along the Chobe River front during the dry season along with many of the other herbivore species and associated predators, which together support a world-renowned tourism 
industry. Whilst the Chobe River front is the most renowned region of the District other sites of noticeable importance include; the Savuti Marsh, home to an annual Zebra migration during the wet season; the Northern Plain grasslands, a unique habitat within Botswana supporting locally rare species such as Oribi; the Chobe enclave, a community managed area supporting a great diversity and abundance of plains game, some of which comes into conflict with the resident communities; the Teak Forests found across the northern and eastern regions of the District, which support a number of habitat restricted bird species such as the Miombo Rock Thrush and Broad-tailed Paradise Whydah.

Wildlife display a season shift in concentration with water dependent wildlife species (Elephant, Buffalo and Zebra) displaying dry season concentration around the perennial rivers and water sources (Chobe, Linyanti, Savuti) to wet season dispersal throughout the National Park, Forest Reserves and Northern Plains (Perkins, 2016), although there are areas of preference located on soils of higher fertility with associated improved grazing. These include the Savuti Marsh grasslands and the Northern Plain grasslands. Some species (I mpala, Waterbuck, Reedbuck and Lechwe) remain resident along the river fronts and around other perennial water sources, whilst the less water dependent species (Eland, Kudu, Giraffe and Gemsbok) are found more distributed across the district. The rare antelope species (Sable and Roan) occur in greater abundance within Chobe District than anywhere else in the country, showing a spatial preference for the northern and eastern regions within the Teak and Miombo woodlands (AWF, 2004, Chase 2013).

A critical and sometimes contentious issue surrounding wildlife concentrations within Chobe is the high number of Elephants and its broader impact upon the biodiversity of the region (Perkins 2016). Some ecologists are of the view that the high number and concentration of Elephants is detrimental to specific habitat structures with consequential impacts felt by many animal species. Studies conducted elsewhere in southern Africa have correlated high Elephant densities with major structural changes in the habitats and direct impacts upon resident Roan, Sable and Tsessebe populations (Martin, 2003). However, studies within Chobe have shown there to be no impact on other wildlife species diversity, although a significant transition from tall closed canopy forests to more open shrubbed woodland is recorded. This transition has been accelerated through the dual impact of Elephants and fire (AWF, 2008). Conserving the wildlife populations of the Chobe District as part of mega-populations within the KAZA region is a priority if natural emigration of Elephants out from Chobe is to help reduce the potential impact that these animals are having on the vegetation structure and on the increasingly recorded incidence of human conflict.

Table 10 is comprised of aerial survey data generated by the Department of Wildlife's National and regional wildlife surveys (DWNP; 2001, 2004, 2006, 2012, 2013) as well as those from Elephants Without Borders (Chase 2013). Where the estimated population size for any specific species was significantly different both estimates are provided, otherwise those figures from Chase (2013) are defined.

The figures for some species vary extensively between aerial surveys by either Chase or the DWNP (Table 10). This is to be expected for those species which occur in clumped herds and where aerial transect widths differ between surveys. To overcome these differences figures from both are supplied where significant differences were observed. Variance is also noted across years by the same surveyors, with Elephants Without Borders estimating a population of 32,000 Elephants (Chase et al., 2015), with 17,000 in Chobe National Park itself. The proportional number of Elephants within the Chobe District could be higher if the figures from the Great Elephant Census (Chase et al., 2016) are used instead of those from DWNP, where Chase et al. estimated a total national population of 130,451 , increasing the relative Chobe population to $31 \%$ of the National Total.

In addition to the above listed species several rare resident species should be noted that include Oribi, Puku, Black Rhino, Chobe Bushbuck, Bush Pig and Porcupine. 
Table 10 Wildlife population numbers, estimated population and status of selected wildlife species in Chobe District, based on aerial surveys

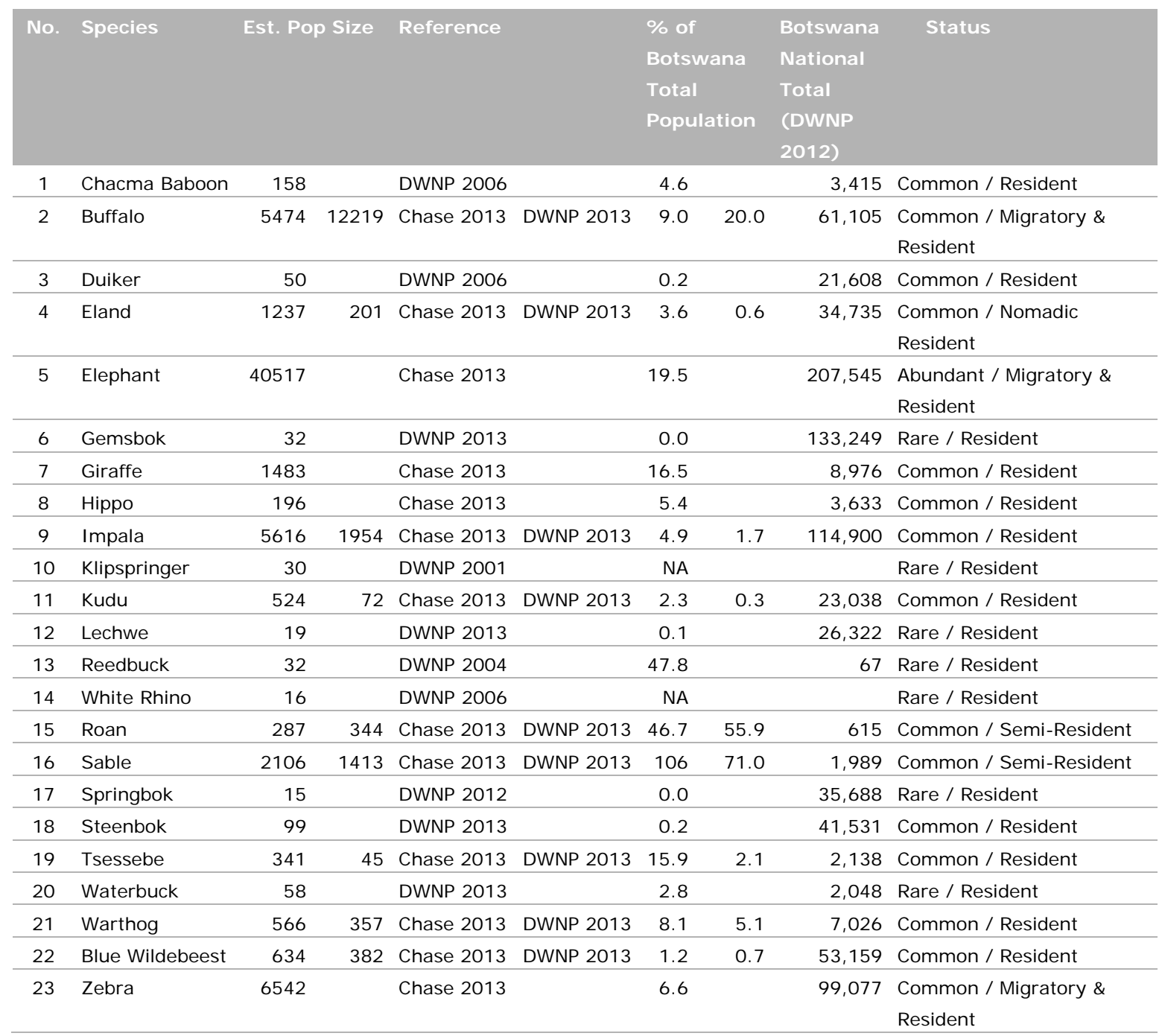

\subsubsection{Carnivores}

The Northern Conservation Area remains one of the most important reserves of carnivore populations in Africa including the Critically endangered Wild dog and the vulnerable Lion, Leopard, Cheetah (IUCN, 2017). According to Woodroffe et al., (1997), northern Botswana may contain the most extensive populations of the critically endangered Wild dog in Africa, with an estimated 500 dogs in the north of the country (Glyn Maude pers. comm.). Presently, there are 3 studies being conducted on predator population estimates across northern Botswana: studies of Brown Hyena (Winterbach c.s.), the Oxford University The Trans Kalahari Predator Project \& Botswana Lion Corridor Project (Loveridge c.s.) and spoor surveys (Wildlife ACT). Ongoing research within KAZA (Funston et al, 2016) estimates more than 1750 Lions spread across a similar area, representing more than $10 \%$ of the global population, although confirmed numbers of Lions are now as low as 7500 across Africa (IUCN, 2017). Within Chobe itself, Andreassen et al., (2014) estimated up to 46 Lions resident along the river front, although no other estimates are available for elsewhere within the District. Similarly there are no reliable estimates for several other larger carnivore species (spotted hyaena and leopard), although confirmation of their presence is confirmed by several authors (AWF, 2004). The extensive forests of the Chobe District are not ideally suited to Cheetah, but the district is home to approximately 30 individuals along the river front and within the Pandamatenga area, with a further 250 individuals estimated in the Northern Conservation Area. On the basis of a continent-wide comparison, northern Botswana ranks in the top two areas along with Kenya, with 28 species of carnivore (Perkins, 2016), with additional notable species including Brown hyaena, Black-backed jackal, Side-striped jackal, Serval, Caracal, Civet and Aardwolf (AWF, 2004). 


\subsubsection{Birdlife}

The Chobe-Kwando-Linyanti swamp area (IBA - BW002) and the Chobe National Park (BW001) are classified as Important Bird Areas by Birdlife Botswana and contain a great diversity of water birds. In addition to the high diversity of birds found along the Chobe River, the Kazuma depression at the eastern end of the Northern Plain is especially rich in birdlife with some 550 species recorded from the region (Perkins, 2016). Arup Atkins (1989) record 21 rare bird species within the Northern Plains alone, including the Slaty egret (Egretta vinaceigula), Wattled crane (Bugeranus carunculatus), Cape vulture (Gyps coprotheres) and Lesser kestrel (Falco naumanni) all of which are listed as 'Vulnerable' by the IUCN.

A number of bird species in Botswana are confined to the Zambezi Teak forests that mainly occur in the northeast of the country: so these bird species have very restricted distributions in Botswana. These include Racquet-tailed Rollers (Coracias spatulatus), Trumpeter (Bycanistes bucinator) and Crowned Hornbills (Tockus alboterminatus), White-breasted Cuckooshrike (Coracina pectoralis), Stierling's Wren-Warbler (Calamonastes stierlingi), Miombo Rock Thrush (Monticola angolensis), Broad-tailed Paradise Whydah (Vidua obtuse), Orange-winged Pytilia (Pytilia afra) and Black-eared Canary (Crithagra mennelli). The open grassland and ephemeral wetlands in forest clearings and in adjacent Kazuma Pan are vital for species as Grey Crowned Crane (Balearica regulorum), Kori Bustard (Ardeotis kori) and smaller bustards (Penry 1994).

Of special importance for bird biodiversity (and due to their easy access for bird tourism) are riverfront forests within the Kasane-Kazungula township. For Botswana rare species such as Scalow's Turaco Tauraco schalowi, Shelley's Sunbird Cinnyris shelleyi and Pel's fishing owl Scotopelia peli are found here. The riverfront also provides roosting habitat for a number of day and night active heron species.

\subsubsection{Fish}

Botswana's potential for long term fisheries development is found in the Okavango Delta, while the Chobe system has relatively lower fisheries potential (Marr, 1965; Nengu, 1995). The Kwando/ Linyanti/ Chobe river system has been a major source of livelihoods for communities since historic times (Cronberg et al. 1995). In fact, the fisheries of the Chobe River and Lake Liambezi are important subsistence and commercial fishing areas (Merron, 1989) in the Chobe system. Despite the fact that the Chobe fisheries are a major source of livelihoods, very little research has been done on the fisheries of this system (Masisi, 2004). Existing information shows that there has always been few fishing grounds in the Chobe system (Welcomme, 1979; Mmopelwa, 2000a,b). According to Mmopelwa (2000a), "steep river banks, lack of stagnant lagoons", and a relatively "fast flowing river" provide very few fishing opportunities for the Chobe fishers. The banks of the Kwando River are confined on the Botswana side, but form a narrow floodplain on the Namibian side (Cronberg et al. 1995). Apart from Marr's (1965) annual fish potential yield of approximately 536 tons from the Chobe River, no further research has been done in the Chobe. Presently therefore, there is no current estimate of fisheries yield for the Chobe system.

During high floods, the Kwando-Linyanti and Zambezi-Chobe rivers systems become inter-linked and create a large floodplain which fills up Lake Liambezi (Næsje et al. 2001). However, a boundary delimitation exercise placed the entire Lake Liambezi in Namibia, which resulted in Botswana losing an important fishing ground in the Chobe system (Mmopelwa, 2004) whose fishery yield was estimated at approximately 2700 tons in 2011/2012 (Tweddle et al. 2015). According to Marr (1965), annual fisheries potential yield for Lake Liambezi was estimated at 759 tons. Generally, the river systems in Chobe have poor fishing grounds. This made Lake Liambezi the main fishing grounds for the Chobe system fisheries (Marr, 1965; Gilmore, 1979; Mmopelwa, 2000a, 2001, 2002; Naesje et al. 2001). In fact, "a Chobe fishing industry is synonymous with Lake Liambezi" (Gilmore, 1979). However, Lake Liambezi is not a permanent water body, and has been subjected to drying spells over the past several decades (Gilmore, 1979; Masundire, 1995; Nengu, 1995; Manyemane, 2000; Mmopelwa, 2000a; Naesje et al. 2001; Tweddle et al. 2015).

Historically, the Chobe-Linyanti system was "heavily fished by people from Namibia" (Masundire, 1995). Many people lost key livelihoods (e.g. income and food) when this lake dried up in the 1980s, and the then Fisheries Unit explored potential fishing grounds in the area (Mmopelwa, 2000b). These fishing grounds were too far from the main fishing villages in the Chobe and this made their 
exploitation uneconomic (Mmopelwa, 2000a). Therefore generally, fishing in the Chobe-Linyanti system offers limited livelihood opportunities to communities in this area.

\section{The fish community}

The Chobe system links the Zambezi and Okavango fish communities during years of exceptionally high floods when the Delta overflows into the Zambezi through the Selinda Spillway and Linyanti River (Welcome, 1979). Therefore, the fish communities of the two systems are similar because of this hydrological connectivity (Marr, 1965). The earliest fish studies in the Chobe system revealed 19 commercially important species which were dominated by Hydrocynus vittatus (Marr, 1965). An experimental fishing exercise carried out in between 1988 and 1989 revealed that Schilbe intermedius ( silver catfish) and Clarias spp. constituted approximately $75 \%$ of the fish catch in the Zibadianja and Matsaudi lagoons found in the Chobe-Linyanti system (Mmopelwa, 2000b). According to Merron (1989), there are 18 fish species in the Kwando River, 12 in the Linyanti River and 29 in the Chobe River with a higher frequency of cyprinid and cichlid species in the Chobe River than the other systems. Out of the three commercially important fish species in the Okavango, Oreochromis andersonii, O. macrochir and C. rendalli (Mmopelwa et al. 2009), all three occur in the Chobe River while only two (O. andersonii and C. rendalli) occur in the Kwando-Linyanti region (Merron, 1989). According to Merron (1989) some of the most ubiquitous species among these three areas are Marcusenius altisambesi, Hepsetus odoe, S. intermedius, and O. andersonii. M. altisambesi and S. intermedius are key subsistence fish species in the Okavango Delta, therefore the preponderance of these species in the Chobe system suggests that there is a potentially good subsistence fishery in the area. Kwando River is the least productive river system in the area while Linyanti is the most productive river system (Merron, 1989).

\subsection{Key findings}

- The Chobe District is a central part of the important Kwando-Zambezi-Linyanti network of protected areas;

- The central position of the area is in particular of importance for the large wildlife populations in the region, which still migrate to a large extent;

- KAZA is an important framework for cross-border planning and development;

- Botswana is signatory of many international treaties and agreements in which it has itself obliged on conservation of natural resources and habitats;

- Miombo woodlands and Zambezi flooded savannas are internationally seen as key ecotones that should be conserved;

- Historical studies of the vegetation change in Chobe set the current landscape in a different perspective, whereby the riverine forest has reduced and become more open, and inland forests may have increased in density;

- The current forest areas are still recovering from the logging operations in the past;

- The Chobe National Park is very rich and extremely important for wildlife and birds;

- The landscape as a whole is essential to sustain the wildlife populations. 


\section{$7 \quad$ Socio-economic conditions}

\subsection{Socio-economic conditions and societal needs}

\subsubsection{Demographics}

Chobe District covers 22,052 $\mathrm{km}^{2}$ in northern Botswana and had a population of 23,347 according to the 2011 Population Census, increasing at about 2\% per year. Assuming this trend has continued after 2011, the District now has a population of just over 25,000 at an average density of about 1 person per $\mathrm{km}^{10}$. However, large parts of the District are not permanently inhabited and people are concentrated in a limited number of more densely settled areas. Over 9,000 people are concentrated in/around Kasane with another 4,000 in/around nearby Kazungula and about 800 in/around Lesoma. More than half (about 14,000 people) the district population is thus living in the Kazungula-KasaneLesoma eastern-Chobe region.

In the Chobe Enclave (1657 $\mathrm{km}^{2}$ ), the villages (and surrounding areas) of Kachikau (1356), Kavimba (652), Parakarungu (1097), Muchenje/Mabele (1005) and Satau (662) together have about 5,000 inhabitants, i.e. almost $25 \%$ of the district population. Here the rural population density is relatively high at about 3 persons per $\mathrm{km}^{2}$.

Another (smaller) concentration of people is around the farming area of Pandamatenga (2625 people), while the rest of the district population is scattered through the remaining portions of the district, including the National Park. People here live on isolated farms and in camps, listed in the Census as 'Localities with no affiliation' (1491 people in 2011).

The population of Chobe, although small, has increased rapidly in recent decades and trebled from 7934 in 1981 to 23,347 in 2011 (NB. 18,258 in 2001; 14,126 in 1991). This increase has implications for the demand for land for housing, farming and other needs. However, specifically, land for houses and farms is required not usually for individuals but mostly for households. The increase in the number of households is therefore a better indicator for the growth in the demand for land. It is often not taken into account that the average household size is continuously declining. This means that the number of households is increasing more rapidly than overall population growth. The demand for land thus also increases more rapidly than population growth, i.e. more in line with the growth in the number of households.

The average household size in Chobe has declined from 4.3 persons per households in 1991 to 4.1 in 2001 and further to 3.4 in 2011 (Table 11). The number of households thus grew more than the overall population from 4,600 households in 2001 to 6,830 in 2011. Significantly, in 2011, one third (33\%) of all households were one-person households, with another $22 \%$ two-person households. Thus over $50 \%$ of the population lives in 1 or 2 person households.

Table 11 Change in average size of Chobe households over time

\begin{tabular}{cccc} 
Census Year & Population Chobe & Households Chobe & \multicolumn{1}{c}{ Avg Household Size } \\
1991 & 14126 & & 4.3 \\
\hline 2001 & 18258 & 4600 & 4.1 \\
\hline 2011 & 23347 & 6830 & 3.4 \\
\hline
\end{tabular}

This trend is responsible for what has been called 'subsistence sprawl'. This occurs when the population grows or household size declines (Liu et al., 2003) as this requires additional residential plots, more land for crops, livestock and for bush-product harvesting. I deally, fresh areas are required, but, alternatively, in-filling of land between villages occurs, leaving only narrow wildlife corridors, which eventually also disappear.

\footnotetext{
${ }^{10}$ Demographic information in section 7.1 is based on official Population Census data.
} 
In the recent past, Chobe district was among the high mortality regions of the country, due to malaria and other tropical diseases. The mortality rate is now much lower than before. The fertility rate has also declined and women now have fewer children than before. The combination of simultaneously declining mortality and declining fertility results in still fairly high population growth levels, currently the rate of natural increase is at $2 \%$ per year. This rate can be expected to decline in the future, but only very slowly.

Chobe districts also attracts migrants, both legal and illegal migrants. Future net-immigration can be expected to contribute to maintaining the current population growth level. However, migration is highly variable from year to year. Large projects/developments such as the construction of the Kazungula bridge may lead temporarily to an increased influx of people. Simultaneously, there is an outflow of young residents looking for opportunities elsewhere in the country.

Due to decreasing household size, the number of households increases more rapidly (over $3 \%$ per year). This implies that there is need to plan for about 200 additional residential plots per year. Most of these will be needed in Kasane and Kazungula.

\subsubsection{Education}

The level of education of the people of Chobe district is a major socio-economic factor impacting upon current and future development opportunities and options. In Chobe, most household heads have limited formal education, which adversely affects household decision making. In 2011, 3038 (15\%) out of 20672 citizens in Chobe district never attended school (1378 of 10578 men and 1660 out of 10094 women).

Moreover, the overall general level of education and skills training is low. This has implications for the employability of the people in e.g. the tourism industry, resulting in people from outside the district taking up those positions. This, in turn, leads to resentment among the local population. At consultation meetings people complained about the tourism industry not employing them.

E.g. from the consultative meeting at Parakarunga in November 2016:

- The community does not benefit.

- No qualified members of the community to take up jobs in hotels, safaris or lucrative tourism ventures,

- No training schools

And at Lesoma, also in November 2016:

- As regards hospitality and tourism opportunities, the community does not see much benefits except at times employment of the Youth in lodges

Lack of formal education and skills training is an indicator of poor human development and can contribute to poverty. If the head of household is uneducated, there is a greater chance of insufficient knowledge about government support opportunities and of lower participation in productive activities such as formal employment or participation in community organizations and committees that would otherwise help in improving the livelihood of the household members. Many children perform poorly at primary and junior secondary school and do not qualify for further education. A contributing factor is also that institutes of higher learning are mostly far from the district.

Unfortunately, at the same time, there is neglect also of old/traditional skills and knowledge. There is potential for the use of such skills in environmental monitoring and also in tourism (guided walks, cultural activities, etc) and developing traditional tourist accommodation. Namibia has done more in this respect. There is a need for more opportunities for informal training in traditional skills and knowledge and for the creation of opportunities to apply these in the tourism industry. Cultural tourism is so far not much developed, and provided that there is community support, this could be developed further.

Nevertheless, more emphasis is also required on training and education of modern employable skills. Too many young people end up unemployable even though they have completed primary or secondary school, simply because their level of useful skills acquisition is too low.

Low education and skills level of the Chobe population requires investment in education and training programmes, facilities and dedicated plots to improve employability and reduce resentment towards skilled outsiders taking jobs in Chobe. 


\subsubsection{Livelihoods, Employment}

In terms of population structure, the population of Chobe is characterised by a fairly high dependency ratio because a large proportion (about 40\%) of the population is under 15 years. On the other hand, the elderly over 65 do not comprise more than $5 \%$ of the population. This leaves a labour force (economically active population) of about $55 \%$ of the total population. This is the official figure, although it is known that quite a few young people between 15 and 20 are still at school, while many older people, over 50 or 55 , have stopped being economically active. The official figure thus exaggerates somewhat the size of the labour force.

The relatively young population of the district ensures for the coming years a continued rapid growth in the number of mainly young people looking for gainful employment. Mostly, they have limited education and skills, as, unfortunately, the labour force of Chobe in general is characterised by a low level of education and skills training.

\section{Livestock and crops}

Like in most rural areas, agriculture remains a main source of livelihood in the Chobe area (Table 12). Many households continue to depend on livestock rearing (46\% in 2011) and crop cultivation ( $51 \%$ in 2011). Cattle production remains an important factor in the rural economy as a source of income, employment and investment opportunities. It also has strong linkages with the rest of the economy as a supplier of inputs for meat and leather processing. Goats are mostly reared for subsistence, but as such are an important livelihood contributor.

Table 12 Chobe District households' livestock ownership and crop cultivation

\begin{tabular}{|c|c|c|c|c|c|}
\hline Households with & 2001 & 2011 & Households Growing & 2001 & 2011 \\
\hline Cattle & $1708(37 \%)$ & $1980(29 \%)$ & Maize & 1203 & 1358 \\
\hline Goats & 1317 & 1288 & Millet & 175 & 277 \\
\hline Game & 3 & 24 & & & \\
\hline No Livestock & $1834(40 \%)$ & $3710(54 \%)$ & No Crops & $\mathrm{N} / \mathrm{a}$ & $3371(49 \%)$ \\
\hline
\end{tabular}

Livestock from Chobe district cannot be sold outside the district due to foot-and-mouth disease control restrictions. Livestock husbandry is therefore less significant in Chobe than in the rest of the country. Nevertheless, for many households, especially those with elderly people, livestock are an essential component for survival. In the Chobe enclave there is lack of grazing land and there is a significant human-wildlife problem as well.

The number of households with livestock continues to increase, even though the percentage of households owning livestock declines (46\% in 2011 from 60\% in 2001). In 2011, the majority of households (54\%) did not own livestock (in 2001 this was 40\%). Nevertheless, the number of households with cattle increased from 1708 in 2001 to 1980 in 2011, while the number of households with goats or sheep declined somewhat. This implies that the number of households requiring land for livestock grazing is still increasing. As long as people have the right to use communal/tribal land for their livestock, the government needs to ensure that they have access to such land. Alternatively, programmes need to be instituted to improve the enhanced efficiency and intensification of the use of communal grazing lands, while ensuring accommodation for wildlife as well.

Similarly, the arable sector remains important as many households have access to land and arable production requires limited inputs. Arable farming in the area is characterised by the growing of traditional crops such as sorghum, maize, beans, water melons and sweet reeds, mainly for subsistence purposes. A small number of households also sells crops commercially.

For many households, especially those with elderly people, the crops from the field are an essential component for survival, their subsistence depends on it.

Arable farming is significantly assisted by government through the provision of farm implements, seeds and technical advice. Nevertheless, productivity and yields are low. Many fields are used 
intermittently and inefficiently. Many fields are 'owned' by elderly farmers who may leave it unused for years. At the same time there are complaints about the shortage of land for the youth. It appears that the shortage of fields may be at least partly resolved by better utilisation of existing land and by intensifying the use of the land. The existing land is not well looked after and yet there are always demands for more land.

Between 2001 and 2011 the percentage of households growing crops or having crop-land declined. For example, in $2011,59 \%$ of households did not have crop-land, compared to only $51 \%$ in 2001.

Nevertheless, the actual number of households growing cereal crops increased between 2001 and 2011 from 2064 to 2433 households. As long as people have the right to use communal/tribal land for cultivation, the government needs to ensure that they have access to such land. This nevertheless means that the number of households requiring land for crop cultivation is still increasing. As long as people have the right to use communal/tribal land for cultivation, the government needs to ensure that they have access to such land. Alternatively, programmes need to be instituted to enhance efficiency and intensification of the use of communal crop lands or to identify and reclaim abandoned fields.

\section{Employment}

In 2011, of the people of Chobe District, 9514 had paid employment, 863 were self-employed and 114 worked on their own field or cattlepost. If one assumes that the self-employed were earning cash income, this implies that 10377 people were engaged in the cash economy. This includes employment in the tourism sector and in the Pandamatenga commercial farming area.

The unemployment rate (defined as people actively looking for work) officially stands at about $10 \%$ of the labour force (in 2011), although this excludes people engaged in part time subsistence farming.

The highest unemployment is in Kasane, Kazungula, Kachikau and Mabele. About 15,000 people in the district have some form of employment, although less than 11,000 have formal paid employment.

The tourism/conservation industry is a major employer of people in the district and provides further opportunities for self-employment. About 1500 people in Chobe are employed directly by lodges, camps, etc. Further supporting economic activities (garages, shops, restaurants, etc) may employ an equal number of people. No doubt some of these are from outside the district because certain skills cannot be found among the resident population. It is probably important to make an effort to enhance the skill level of the Chobe resident population through training programmes. If more people find employment in the sector, attitudes of residents may also change for the better. This is especially important because the tourism/conservation industry is a major land-user in the district. Protected areas, tourism establishments and related services together comprise the largest land use category in the district.

\section{Livelihood security}

As elsewhere in the country, many households simultaneously engage in multiple sources of livelihood to improve their livelihood security and to cope with various forms of shocks (e.g. job losses, HIV/AIDs and droughts). This strategy increases household resilience to tragedies that may befall a household.

Many livelihood sources are dependent on rainfall (e.g. agriculture and collection of veld products) and hence highly variable. Livestock and arable farming, which are the main subsistence sources of livelihood, are susceptible to drought, pests, and diseases, destruction by wildlife and birds, as well as climate change. Despite its importance to local livelihoods, arable production has low yields and is unable to provide food security. Therefore, though a number of households depend on agriculture, it is an insecure source of livelihood hence there is need to supplement with non-agricultural sources of livelihood.

Family death and wildlife destruction are some of the major shocks experienced by households. Drought is also seen as a shock. HIV/AIDS is considered a lesser shock these days due to the available HIV/AIDs treatment. The major response of households usually is to turn to government for Ipelegeng and social welfare programmes and apply for wildlife damage compensation. Cessation of government welfare programmes would have serious adverse short-term impact on livelihoods. 
Access to land (residential plots and ploughing fields) for residences is important for household livelihoods also because many households are dependent on agriculture. Many households do not own their own land: fields are shared with those that do not own land, where they plough a piece of the land for livelihood sustenance. While this offers livelihood contributions for several households, those who do not own the field have an insecure livelihood source. It is possible that households do not see the need to apply for ownership of a field as the returns are low and they are currently able to borrow land. Few households also 'own' a waterpoint for their livestock.

Ownership of 'durables' indicates the level of livelihood prosperity. The number of households with a van or bakkie doubled between 2001 and 2011, while the number of households owning a car trebled (Table 13). 29\% of households in 2011 owned a motorised vehicle. The number of households with a TV quadrupled in the 2001-2011 period, while in 2011 over half of the households (53\%) owned a fridge. On the downside however, in 2011 still 32\% (2169) of the households does not own any durables (the figure for 2001 is not available.)

Notably there is a decline in the number of households owning a tractor. Perhaps this reflects the decline in interest in farming or emerging specialization. In general, though, the increased ownership of durables reflects increased prosperity in the district.

Table 13 Ownership of durables

\begin{tabular}{|c|c|c|}
\hline Households owning & 2001 & 2011 \\
\hline Van/Bakkie & 426 & 871 \\
\hline Car & 367 & 1137 \\
\hline TV & 1067 & 4434 \\
\hline Fridge & $\mathrm{N} / \mathrm{a}$ & 3609 (53\%) \\
\hline
\end{tabular}

\section{Access to sanitation and services}

Table 13 gives indicators of well-being for villages in Chobe district. These indicators have implications for environmental and land use sustainability. The proportion of households without access to toilet facilities is an indication for prevailing hygienic and sanitary conditions. Table 14 shows that the sanitary conditions are fairly good in Kasane, Kavimba, Kazungula and Lesoma where the proportion of households without toilets is $3 \%$ or less. In the other settlements, however, the proportion without toilets is $20 \%$ or higher, and over $30 \%$ in Kachikau, Pandamatenga and Parakarungu. This represents a sanitation challenge of substantial dimension. More than 550 households in the district do not have toilet facilities.

The proportion of households using wood for cooking daily meals is an indicator for environmental issues. Only in Kasane is the proportion low at $11.6 \%$. In all other settlements $30-80 \%$ of households uses wood for their cooking. This implies that over 3,000 households are collecting wood on a daily basis, with associated implications for deforestation.

The use of electricity is still low in several villages even though they are connected to the grid due to the high cost of a household connection. Connecting more households to electricity can contribute to livelihood improvements.

\section{Livelihood constraints and opportunities}

The available information points at several major livelihood concerns/problems. These include the continued importance of subsistence crop production and animal husbandry for many people's livelihoods, both in view of their low productivity and potential conflicts with the commercial sector. Further are relevant the importance of government support programmes for the livelihood of many and the continued shortage of formal employment opportunities, gainful self-employment or employment in CBNRM activities. 
Table 14 Proportion of households in the settlements in Chobe district that a) have no toilet, b) use wood for cooking and c) use electricity for light

\begin{tabular}{lcccc} 
Settlement & Households Nr & No Toilet $\%$ & Wood Cooking $\%$ & Electric Light $\%$ \\
Kachikau & 323 & 33.7 & 63.8 & 47.7 \\
\hline Kasane & 2988 & 0.1 & 11.6 & 90.5 \\
\hline Kavimba & 165 & 1.2 & 29.8 & 92.7 \\
\hline Kazungula & 1239 & 3.2 & 44.0 & 76.4 \\
\hline Lesoma & 159 & 1.9 & 71.0 & 68.6 \\
\hline Muchinge/Mabele & 200 & 21.0 & 61.7 & 35.5 \\
\hline Pandamatenga & 488 & 30.9 & 82.6 & 44.9 \\
\hline Parakarungu & 207 & 35.3 & 69.1 & 29.5 \\
\hline Satau & 191 & 21.5 & 83.9 & 23.0 \\
\hline Other & 366 & 39.9 & 10.4 & \\
\hline
\end{tabular}

The following issues have during the inception phase been mentioned as important according to residents (see Annex 1) in the area:

- Lack of equitable sharing opportunities in tourism, which focusses on high cost tourism, where small local entrepreneurs at entry level are unable to enter the market at a level of quality required.

- Lack of direct market access for community produce and NTFPs (e.g. crafts, thatch).

- Conflicts with wildlife, in particular the large Elephant population, resulting not only in crop damage but also in all other aspects of life in a number of villages.

- The ban on hunting deprives people of revenues from hunting as well as access to meat.

- Livestock predation by wildlife in zones adjacent to the parks and conservation areas.

- Fluctuating fish populations due to irregular flooding and to degradation of resources by residents in other regions (including Namibia).

The unreliability of rainfall is a major constraint for both the livestock and arable sectors. Destruction of crops by wildlife and predation of livestock provide another major challenge.

Nevertheless, opportunities exist in horticulture, agro-forestry and of course tourism, through both private and CBNRM activities. However, tourism development will require extensive awareness raising among the resident population of Chobe and should aim at increased popular participation, to show more tangible benefits and opportunities for a greater proportion of the people.

\subsubsection{Societal needs}

Societal needs can be considered at different spatial scales, from global to local, and differ between social groupings (rich-poor; rural-urban).

At global level, the need exists for ecologically healthy natural areas such as Chobe to function as ecological global lungs. Broad initiatives such as KAZA (but also ZAMCOM) can bring in funds for infrastructure improvement and research as well as expertise useful for appropriate environmental management. Botswana and Chobe district in particular should participate fully in these initiatives. At national level, there is need for national economic diversification. Tourism such as in Chobe plays an important role by creating income and employment for the country. Possibilities for increasing employment (especially of 'residents') and income in a context of environmentally sound management need to be stimulated.

At local (district/village) level, the need exists for livelihood improvement of residents. This can include improvements is housing, sanitation, water and electricity supply, but also increased the income, business and employment opportunities. Such needs differ among Chobe residents, depending on levels of education, prosperity and employment security. Among Chobe residents a dichotomy exists between those mainly pursuing subsistence activities and those engaged in more commercial activities, the majority of the population in fact having a foot in both spheres. Many people keep a foot in the subsistence sector as an insurance against job insecurity. 
Residents of Chobe experience conflicts partly resulting from the mix of economic and subsistence activities in which they are involved. Thus, there are human-wildlife conflicts as well as

conflicts/disagreements over wildlife-hunting and access to exploitable 'veld-products' in e.g. forest reserves. There are also 'land-conflicts'.

As long as residents are 'entitled' to use communal land for livestock and cultivation, the government has the obligation to provide for this entitlement. Inevitably, expansion of grazing and crop land leads to encroachment into natural or wildlife areas. That is unless:

- The entitlement to communal land is modified;

- Communal land is not expanded further but instead more intensive use is made of existing land;

- Viable alternatives are offered (well-paid secure jobs) to allow people to 'let go' of their communal land.

These conflicts are difficult to resolve. Hence, sufficient energy needs to be devoted continuously by the relevant organisations to their solution.

\subsection{Tribal situation}

Historically, settlement in the area that now falls under Chobe District was strongly influenced by environmental factors such as drought, pests and disease, particularly rinderpest and diseases carried by tsetse fly. Nevertheless, many different ethnic groups have settled in the area over the past few hundred years. The first to settle were Bushmen, predominantly of Bugakwhe and ||Anikhwe groups.

Their present-day distribution is now restricted to just south of Chobe in Mababe village. The Bushmen in Lesoma and Pandamatenga, in the east of the district, are of the Shua group (Cassidy et al. 2001). A substantial number of BaTawana are settled in Kachikau, having moved north from Sehitwa and Maun. The increase in commercial farming over the past 30 years to the east of the district, has been accompanied by an increase in settlement by foreigners. These include Lozi, Ndebele, Afrikaners as well as other of European descent. Kasane and Kazungula have seen huge influxes from both within and outside Botswana, particularly from neighbouring countries.

The BaSubiya are the most numerous tribal group in Chobe. In the past, they have settled as far south as Mababe Depression. Their linkages, are however, predominantly to the north of Botswana, in both Zambezi Region of Namibia and the southern part of Zambia (Andersson and Janson 1997). While census data on ethnic composition are not readily available, the BaSubiya have long been recognised as the main tribal group in Chobe (Shamukuni 1972). The paramount chief of the BaSubiya is a representative in the House of Chiefs, giving status to the tribe.

As with elsewhere in Botswana, the authority of the tribal administration system is limited to customary law, and as such its influence tends to be restricted to village level. In the case of the BaSubiya, the links between the people living in Chobe Enclave is strong (Ecosurv 1996), and thus the customary law decisions of the BaSubiya chief are acknowledged throughout this community.

Although for much of Botswana's recent past it has been government policy to downplay ethnicity as a social characteristic, in the last few years there has been increasing awareness that understanding and promoting ethnic differences does not necessarily undermine national identity, and can in fact have several positive effects. Ethnic diversity, as with any other form of diversity, helps build stronger, broader social bases. Ethnic differences help create different ways or relating to resources and economic activities, making for an overall more resilient society. Not least, the combined different cultural practices contribute to a wider indigenous knowledge system than can be found in a single ethnic group. When aiming for equity and sustainable land use, focusing on cultural preferences of different sub-groups of society is important for equitable access to the benefits of resources, and for an understanding of the different ways in which people relate to the land (see for example, Cassidy et al. 2001). 


\subsection{Settlements}

More than $58 \%$ of Chobe's residents are concentrated in a narrow strip of roughly $15 \mathrm{~km}$ along the Chobe River between the eastern edge of CNP to the Zimbabwe border (see Figure 44 and Table 15 below). Because of land tenure and land use arrangements, population density varies extremely, with extensive areas of (mostly state) land uninhabited. While land tenure contributes somewhat to the options for settlement, the initial settlement patterns nevertheless reflect dependence on surface water. Access to potable ground water has limited settlements further away from rivers and floodplains, with salinity levels too high for both human and livestock consumption.

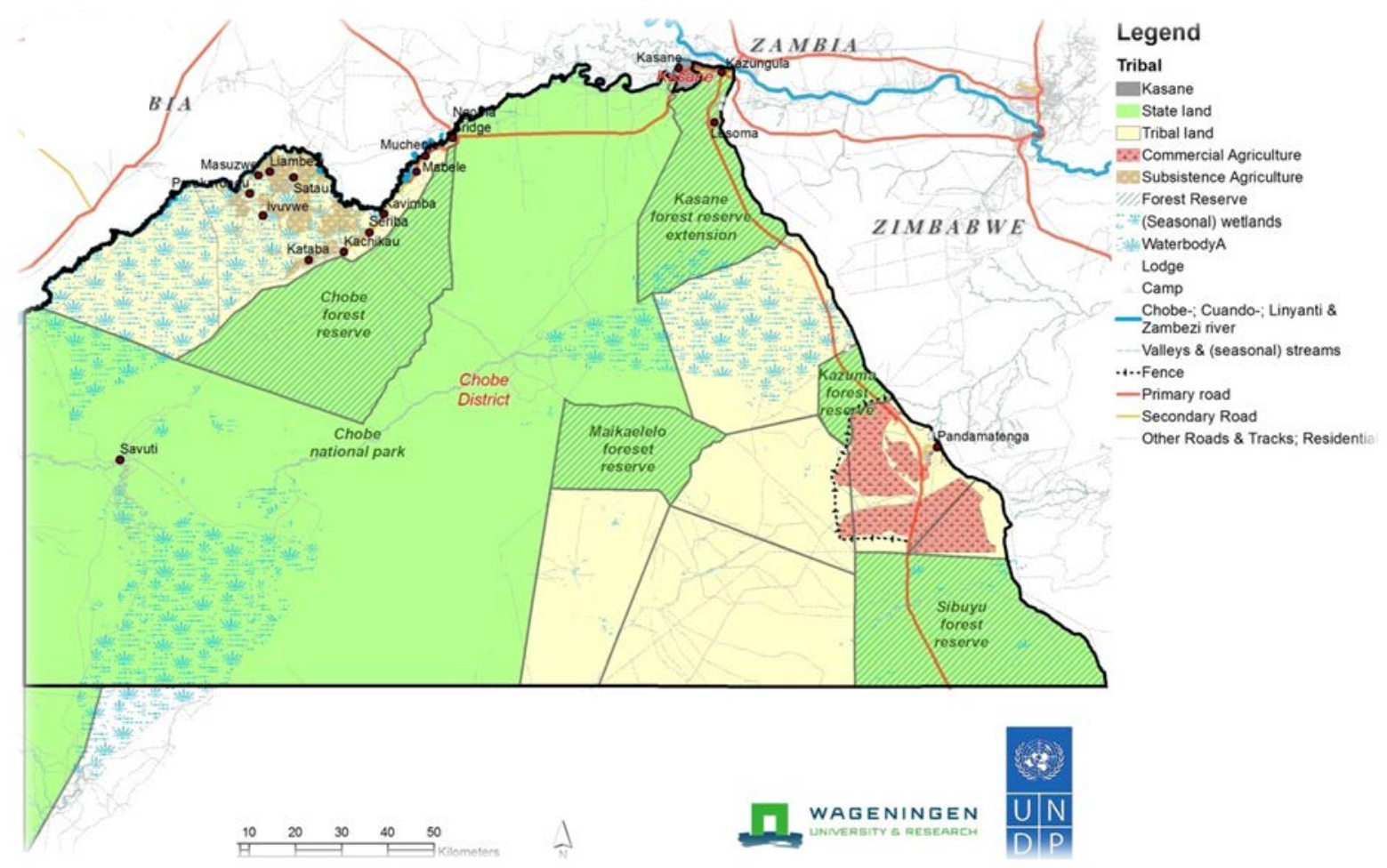

Figure 44 Location of the villages in Chobe District

Table 152011 Population data for villages and associated localities in Chobe District

\begin{tabular}{lrrr} 
Settlement name & Total & Main village & Associated localities \\
Kasane & 9234 & 9008 & 226 \\
\hline Kazungula & 4286 & 4133 & 153 \\
\hline Kachikau & 1472 & 1356 & 116 \\
\hline Kavimba & 652 & 549 & 103 \\
\hline Muchenje-Mabele & 1005 & 773 & 232 \\
\hline Parakurungu & 1086 & 645 & 241 \\
\hline Satau & 622 & 605 & 17 \\
\hline Pandamatenga & 3156 & 1798 & \\
\hline Lesoma & 724 & 613 & 1358 \\
\hline No affiliation* & 1110 & $\mathbf{2 3 3 4 7}$ & $\mathbf{1 9 6 8 0}$ \\
\hline District Totals & & $\mathbf{3 3 8 8}$ \\
\hline
\end{tabular}

Source: Statistics Botswana 2011 census data. *This includes primarily tourist facilities, BDF camps, and DWNP outposts.

In addition to the more urbanised Kasane-Kazungula settlement area, there are two discrete pockets of rural settlement on either side of the district, with other land use types and international boundaries effectively creating islands of area available for expansion of human settlement. 
Chobe West, also known as Chobe Enclave, comprises the 5 main villages of Kachikau, Kavimba, Muchenje-Mabele, Parakarungu and Satau. Most of the associated localities in this area are fields areas and cattleposts. About $15 \%$ of the district's population is found here. Within the Enclave, by far the majority $(\sim 85 \%)$ are concentrated in the main villages. This is an important point, because it reflects the floodplain nature of the northern part of the Enclave, where people live. Three of the villages - Kachikau, Kavimba and Muchenje-Mabele are located on the escarpment and border with Chobe Forest Reserve, while Parakarungu and Satau are on low islands on the floodplain. In all the villages, options for settlement expansion are limited, either due to flooding, or (in the case of the escarpment villages) land tenure.

It is also important to note that the south-western part of Chobe Enclave remains largely uninhabited. While this area encompasses slightly higher (and drier) land, there is limited surface water and groundwater is too saline for human consumption.

In the east, the villages of Lesoma and Pandamatenga are historically associated with seasonal water available in the river channels linking the Botswana and Zimbabwe landscapes. While both settlements have some constraints for settlement expansion due to land tenure and land use zoning, the two villages have followed very different development trajectories. These differences are mainly due to underlying edaphic conditions, with Pandamatenga being located near extensive areas of fertile arable soil. Pandamatenga has a population of over 3,000 people, of which just over half live in the main village. The rest live in associated localities, predominantly on the commercial farms. Pandamatenga has almost doubled in size over the past twenty years (Central Statistics Office 1992, Statistics Botswana 2011), and almost all this growth is associated with the development of commercial agriculture in the area, and the influx of farm labour.

Lesoma, too, has experienced considerable growth over the past twenty years, though it remains one of the district's smaller settlements. Here, growth has been fuelled by shortages of accommodation in the Kazungula area, and more recently, by some localised tourism development.

Importantly, recent village level development plans have resulted in the demarcation of specific expansion areas, with allocations of land being guided according to location in these expansion areas (Figure 45). These village development plans are an important part of the integrated land use planning process, as they show where residential development is prioritised, and highlight the location of areas for other land uses such as crop production and livestock grazing. 


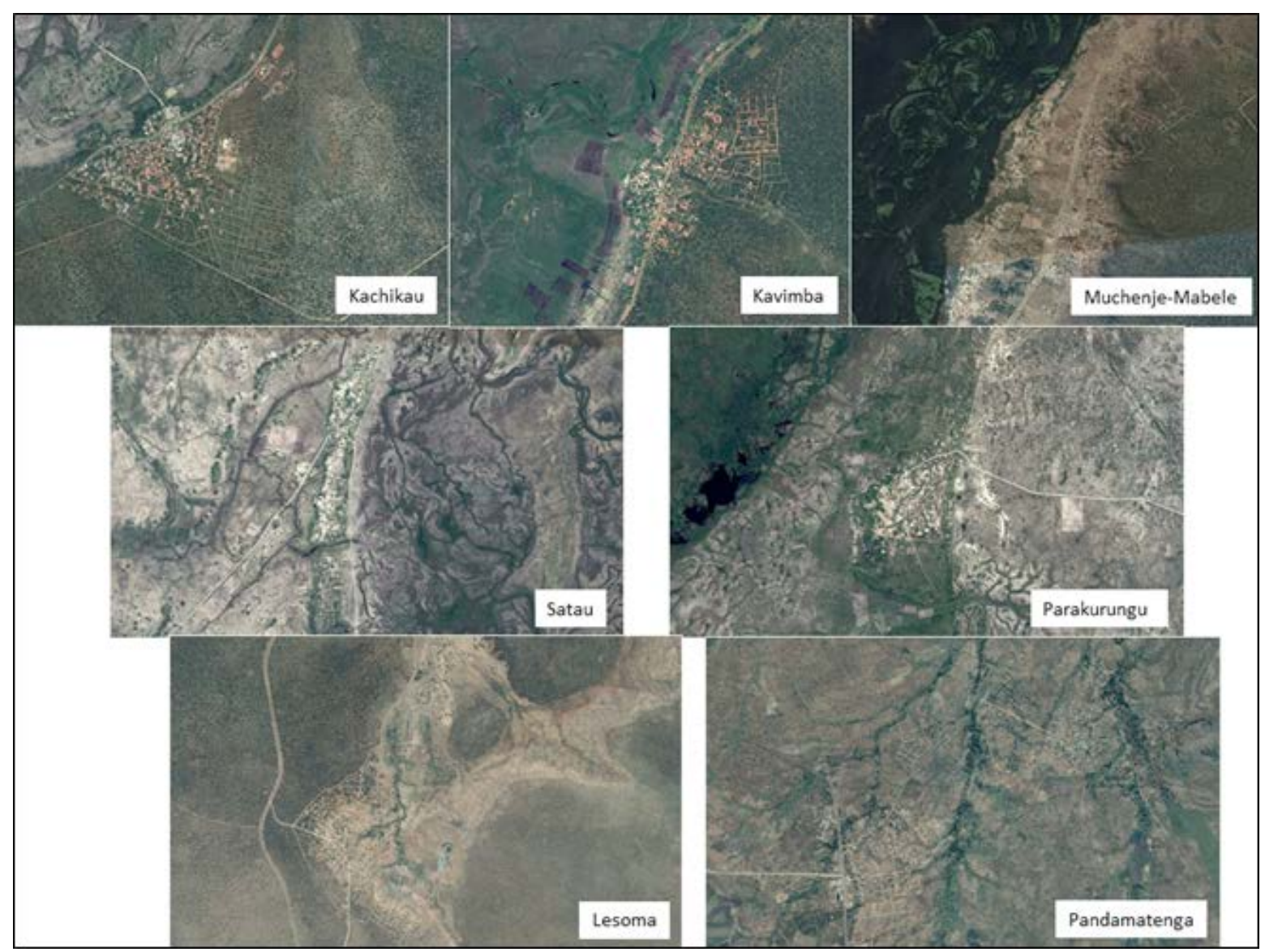

Figure 45 Google Earth overviews of the rural settlements in Chobe, showing the original villages and the new planning areas

\subsection{Kasane and Kazungula Township}

The urban areas of the Kasane and Kazungula area have been identified as areas for re-development in the Kasane-Kazungula Redevelopment plan (2015) and the Kazungula Transportation Hub plans. These plans have been adopted as an important framework for re-development and investment opportunities for what is in the context of NDP11 a major focus for development. From the perspective of the integrated land use plan a number of issues are being planned for:

- The tourism industry will increase massively in the township and has been planned for in the Kasane Kazungula Re-development plan. This trend will likely generate income and employment and needs to be serviced by sufficient space for businesses, residential areas and hotel accommodation, and associated services such as health and education. Simultaneously maintaining other functions such as local agricultural production is important for the social cohesion and diversity.

- The transport hub at Kazungula is associated with new developments (e.g. improved government services related to border crossing). Completion of the bridge will likely attract a unprecedented increase of international transport movements. This requires continuous monitoring of all services associated with transport, as well as management of its less desirable side effects on the human environment.

\subsection{Traditional natural resource use}

As with rural communities throughout Botswana, traditional reliance on natural resources in Chobe's settlements is high. In keeping with the legal distinction between customary and common law in Botswana, it is generally held that commercial use was not historically 'customary', and that therefore traditional natural resources use refers primarily to subsistence use (see, for example, Murray-Hudson 
et al, 1994 and Cassidy 2000). Increasingly, this distinction has become blurred, but for the most part traditional use is still associated with household or community level use.

Historically, chiefs and village headman exercised strong control over who could use what resources where and when. This meant that customary resource use was typically well-regulated, at a time when human populations were also lower and the demand for resources was also lower. Since the introduction of centralised governance 50 years ago at independence, the local-level decision-making and authority of chiefs and headmen has been undermined. This has been associated with a loss of resource management, resulting in the generic governance challenges described in Hardin (1968) and Dietz et al. (2003), such as uncontrolled open access and some resource conflict, and more recently, land grabbing by wealthier households or outsiders.

Environmental resources constitute part of the wealth of rural populations. But the resource base is threatened in many areas by expansion of commercial resource exploitation initiatives, resulting in loss of access to traditional resources and, thus, potentially, increased poverty. This occurs because their value for the rural population is usually underestimated, while the expansion of subsistence resource use is considered incompatible with wildlife-tourism and conservation (De Souza et al., 2003).

The most important resources in terms of area of land are those associated with agricultural production - land, soil and water suitable either for growing crops or grazing livestock. Growing crops for household consumption is still practiced by most households. In the Chobe Enclave farmers combine flood recession farming with rainfed systems, while subsistence crop growers in Lesoma and Pandamatenga rely primarily on rainfed crop production. As with small-scale farmers in many parts of the world (Norman et al. 1995), farmers combine a grain (usually maize or sorghum) with a legume (usually cowpeas) and a cucurbit (pumpkin, butternut or melons). Unfortunately, climatic conditions are highly variable, and farmers are generally not able to rely solely on their own crops every year.

Although there is a long history of keeping livestock (mainly cattle and goats) in the rural settlements, it is important to note that grazing has never been a dominant natural resource use for either the BaSubiya or the BaShua (Tlou and Campbell, 1997). In addition, diseases such as rinderpest and nagana (animal trypanosomiasis) historically made it difficult to keep cattle in the area. People living in the settlements adjacent to the forest reserves have special dispensation from the Department of Forestry and Range Resources to graze their livestock within them. While there are one or two cattleposts located along the border of the reserves (and in the east, one inside Sibuyu, for the most part grazing within these woodland areas is limited by the presence of Dichapetalum cymosum (mogau) which is poisonous to cattle, so typically these areas are used only seasonally when floodplain grazing is unavailable.

Between 20 to $80 \%$ (depending on the village) of all households uses wood for cooking, even where some households may have alternative fuel sources, and firewood is also used during the winter season. Particularly poorer households, firewood remains the sole source of cooking fuel. This may lead to resource depletion around villages, which would negatively impact on people's livelihoods. The availability of firewood to rural households is threatened by an increase in demand from the tourism sector, with an increase in commercial sales along the roadside to passing vehicles which is also observed around the Forest Reserves near Kasane.

People can build very cheap houses when they use (free) poles and thatching grass from the environment. Their depletion would therefore negatively affect livelihoods. Prospects for agro-forestry also exist but are not well developed.

Thatching grass is still in strong demand for roofing material. Some households trade in thatching grass, but the grass varieties found in Chobe Enclave are not preferred by large commercial lodges, so the resource is not as threatened as firewood.

Fish are also very important in Chobe Enclave, though the availability varies according to flooding extent, with both strong intra-annual and interannual variation. At times Lake Liambezi has held enough water to support a fishing cooperative, but many households use their own nets and mokoro to catch for their own needs. 
There are several plant resources that are still used extensively among rural households. It is wellknown that reliance on natural resources is associated with poverty (see for example, Adger 2000) or level of integration into the cash economy. For example, poorer households still use papyrus for sleeping mats, and collect water lily bulbs for food. Beyond this, however, there are several plant foods, as well as medicinal plants, that are harvested on the basis of cultural preference. Among these are various Grewia species (such as moretlwa), Ximenia species (moretologa) and fruit of Hyphaene ventricosa (mokolwane) and Adansonia digitata (mowana) trees, among others.

The leaves of $\mathrm{H}$. ventricosa are also used for making baskets, a traditional craft that many women still do, both for the creation of household items, and for sale to tourists.

Veld products are currently mostly used for subsistence purposes. Households also augment their income through the sale of wild fruits such as moretlwa and morula.

In a broad study of Kasane, Kazungula and Lesoma households, Lepetu et al. (2009) note that firewood is still the most important source of household energy. This study also noted that households regularly collect and rely on resources such as building poles, wild fruits, thatching grass, and natural materials for handicrafts. Factors influencing reliance on natural resource include: education, wealth, and household size, with less diversified and poorer households more dependent on natural resources (Lepetu et al. 2009).

The importance of the forest reserves for natural resource use is well captured in recent work by Garekae et al. (2016). In a study of the three escarpment villages in Chobe Enclave, 92\% of respondents felt that "conserving forests so that future generations may know and make use of them" was positive or very positive, and when presented with a statement about allocating Chobe Forest land to landless people, only $29 \%$ felt that this would be positive or very positive (Garekae et al, 2016).

\subsection{CBOs and CBNRM}

Community Trusts (Community Based Organisations or CBOs) are vehicles through which communities can augment their livelihoods and in the process develop their villages. Generally people feel that they do not benefit much from CBNRM projects at the moment. A few however, acknowledge that CBOs create employment and deliver some community services. There is room for the enhancement of the livelihood benefits of CBOs and CBNRM projects. CBOs need however, to be supported to operate better and deliver more benefits.

There are two main CBOs involved in community-based natural resources management projects at the landscape level in Chobe, having each been allocated tourism head leases over a CHA. The five western villages are grouped together within the Chobe Enclave Conservation Trust, while Kazungula, Lesoma and Pandamatenga are grouped together under the umbrella of the KALEPA (KAzungula-LEsomaPAndamatenga) Community Trust. CECT was the first CBNRM organisation formed in Botswana, starting in 1993. Over time, its revenue has grown substantially. Between 1997 and 2012, its revenue grew from BWP 464,000 to BWP 4,600,000 (Mbaiwa 2013). However, since the demise of the hunting industry, its revenue has, since 2014, dropped dramatically. Much of CECTs revenue has come from joint venture arrangements, primarily the sub-leasing of tourism (both hunting and photographic) rights to commercial tour operators. However, the trust also owns its own lodge at Ngoma.

KALEPA is a younger organisation, and pulls together an even more disparate collection of communities. It has suffered a range of challenges, relating to poor management and business skills, as well as awareness of acceptable practices (Mbaiwa 2013). Its revenue has therefore been unpredictable, as it has had periods without joint venture partners and hence without revenue. To a large extent, the lack of functionality of the trust has contributed to low viability and low income of wildlife-based tourism in $\mathrm{CH} 8$. This state of affairs will likely have influenced the decision to explore setting aside some of the land for commercial agriculture.

Other smaller natural resource user groups have also been formed, such as Katchempati Basket Weavers Co-operative, and Makasupa Basket Weaving Project, as well as the fledgling Seboba Trust in Kasane (Mbaiwa 2013). Seboba Trust operates a cultural village and nature and recreational park near the Seboba rapids at the eastern edge of Kasane village. Although it does not have a head lease over a large CHA as do the other main trusts in Kasane, its potential to support community-based tourism and increase the benefit stream at the community level is strong (see also http://www. botswanatourism.co.bw/community/seboba-cultural-village-and-recreational-park). 


\subsection{Poverty}

Like elsewhere in Africa, pressure is increasing on people's subsistence habitat, affecting especially the poor, who then become compelled to over-exploit local resources or to engage in illegal activities because few fresh communal areas remain, while other options, such as wage employment, are not available (De Souza et al., 2003). Conflicts between subsistence farmers and wildlife-tourism result from trespassing, the (perceived) illegal harvesting of flora and fauna and habitat destruction near protected areas, while communities are mostly concerned about wildlife destroying crops or killing livestock.

The following factors affect the contemporary character of subsistence living and rural sprawl, and contribute to increased poverty and negative community views on wildlife habitat conservation, resulting in trespassing, poaching and negative attitudes toward tourists and outsiders employed in tourism:

1. Land-use change: decline of subsistence land resources due to expansion of protected areas;

2. Legislation disallowing harvesting of environmental resources (especially wildlife);

3. Unemployment of local residents, while outsiders find jobs in the tourism industry;

4. Problems with community based natural resource projects (Vanderpost 2006).

Poverty in the Chobe district is not evenly distributed. Poverty rates are highest in Parakarungu and Kachikau with a poverty rate above 0.35 (World bank 2015) and lowest in Kasane (poverty rate below 0.15). In the District development plan (DDP7) Chobe district has committed itself to poverty eradication through:

- the Community Resilience Programme (CRP) which focuses on strengthening a community's capacity to take intentional action for social and economic change;

- Local Economic Development (LED) which aims to explore, identify and exploit locality specific economic potential;

- The Social Welfare Programme which aims at providing material and psychosocial support to families, individuals and vulnerable groups.

The tragedy of the poverty trap itself is affecting resource utilization in that poor persons within the district have difficulty accessing the resource base and are always at a disadvantage against better resourced people from outside.

- Our community consultations indicated that livestock husbandry and crop cultivation remain important livelihood elements for poor households and that collection of natural products such as firewood and thatching grass are also important livelihood support activities.

- The growth of the tourism sector and the importance of this sector for the national economy has within communities raised awareness of new possibilities for poverty eradication, through formal and self-employment in the tourism industry. However, so far only a limited number of people benefits from these opportunities due to -amongst others- low education and skill levels as well as problems with community-based activities. This is a specific challenge for the Chobe land use plan;

- Growing employment in tourism by district residents is important as it may reduce reliance on subsistence activities, possibly leading to reduced demand for grazing land and, especially, cropland. During community consultations the need for improved skills training of residents and improved CBNRM projects was an important issue. Pro-poor tourism strategies to address poverty eradication have been the subject of several studies in Northern Botswana (e.g. Mosethli 2012, Manwa \& Manwa 2014). Different pathways through which the benefits of the expanding tourism sector can lead to poverty alleviation are best summarized in Figure 46 from Manwa \& manwa (2014). 


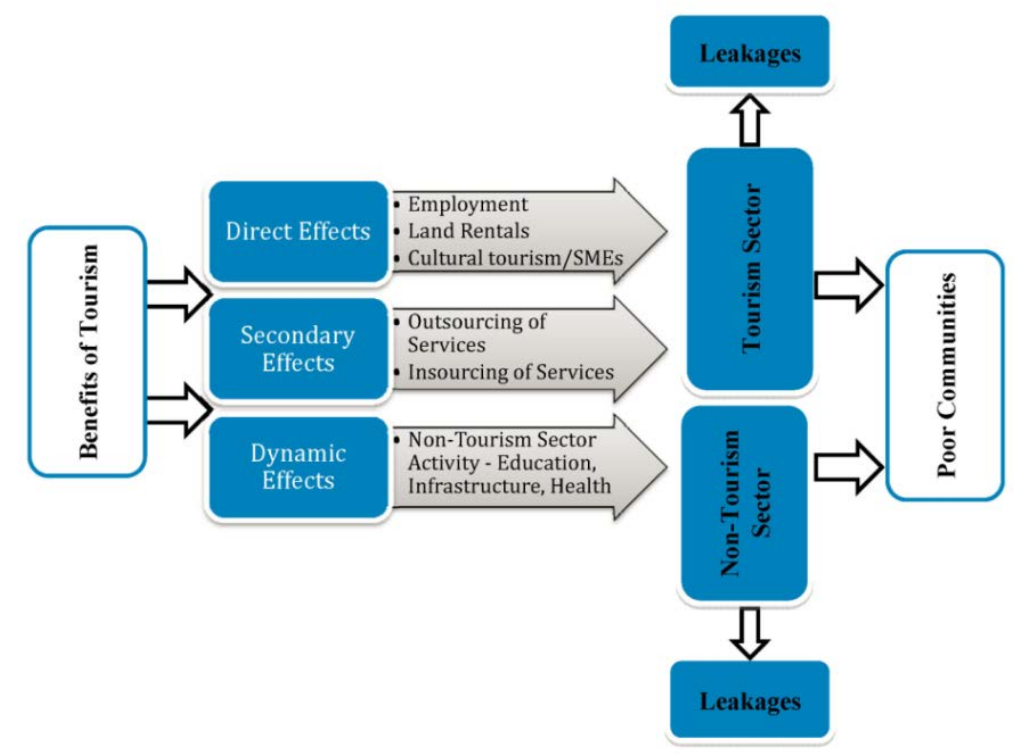

Figure 46 Pathways of benefits from Tourism to the poor (Manwa \& Manwa 2014)

Combining the DDP7 community poverty eradication programmes (addressing rural poor communities) and considering the tourism sector planned growth, a drive to eradicate poverty could be effected through a covenant between the private sector and Government, to focus on the development of a programme of formal and non-formal training and small scale entrepreneurship to alleviate poverty in the district, adjunct to the Social Welfare programme. This should acknowledge that there is already some local training of employees for the tourism industry.

\subsection{Key findings}

- Settlements in Chobe are concentrated in areas surrounded by the Chobe National Park or Forest Reserves, presenting a challenge to land allocation and settlement expansion;

- Sustained population growth, currently at $2 \%$ per year, in combination with declining household size, results in pressure on land resources;

- So-called 'subsistence sprawl', small households which require more and more land, results in expansion in tribal areas and claims on non-tribal land; there are also claims for land resulting from increasing pressure from other regions in Botswana;

- Livestock husbandry and crop cultivation remain important livelihood elements for an increasing number of households. Collection of natural products such as building poles, thatching grass and firewood are also important livelihood support activities. Land needs to be reserved to accommodate the increasing number of households engaged in these activities, although efforts are also needed to improve the efficiency of use of existing land;

- Current levels of poverty and unemployment are at least partly related to the low level of education of the Chobe population; government's social welfare programmes provide a social safety net, while poverty eradication features in national and district level programmes; more efforts are needed toward training and promoting pro-poor tourism;

- Poverty is undermining sustainable resource utilization in the Chobe enclave because poor households rely on subsistence farming and (over)exploitation of resources essential for their livelihoods;

- Increasing formal employment and self-employment are important as they reduce reliance on subsistence activities and may lead to reduced demand for grazing land and, especially, cropland;

- The population is of a very mixed ethnical origin, most people settled here over the past centuries due to the environmental pressures in the past (rinderpest, tsetse fly);

- The location of settlements is very much dependent on availability of water;

- Kasane and Kazungula are rapidly expanding through intense commercial development based on tourism and Kasane-Kazungula's transport hub function; some $58 \%$ of the District population is now living in these semi-urban areas;

- A number of CBOs are present in Chobe, but not all of them are active or effective. 


\section{$8 \quad$ Land use}

\subsection{Agriculture}

\subsubsection{Smallholder arable farming}

In the Chobe Enclave are two arable farming regimes: the molapo flood recession cultivation on the floodplains, and the dryland arable agriculture and gardening away from the river in the sandveld. These subsistence cultivation systems are largely shaped by the cultures of the different ethnic groups of the region. Dryland cultivation depends on rainfall and is practised in the semi-arid Kalahari sandveld soils, mainly by the Batawana and the Hambukushu who plant drought resistant crops such as sorghum and millet, to which they add melons, groundnuts and beans. Molapo farming is practised along seasonally flooded areas on the Chobe river where subsistence peasant farmers make use of the more fertile soils of the floodplains. These soils are characterised by high organic and clay contents which store soil moisture for a long time (Barnhoorn et al. 1994). Small scale molapo farming in Chobe District is mostly practiced by the Basubiya communities. Depending on environmental conditions, farmers sometimes cultivate both types of lands concurrently in order to spread the risk of crop failure (Gumbo 2010).

The size of molapo fields is dictated by the extent of the flood each year, with bigger floods extending the frontiers of the moistened land, which in turn results in cultivators enlarging the size of the field. Due to the fertility and moist conditions of the soil, molapo farming is utilised mostly for growing maize which needs sustained moisture. As a result of the high moisture content on the rich soils, crop yields per hectare in the molapo fields are higher than those in dryland farming. Fallow land provides rangEland for livestock, particularly at times when fodder was scarce (Gumbo 2010). At the same time, molapo farming requires specific knowledge and skills, and proper soil management. In some years flooding of the molapo is a risk, in particular around the low-lying villages of Satau, Parakarungu and Kavimba.

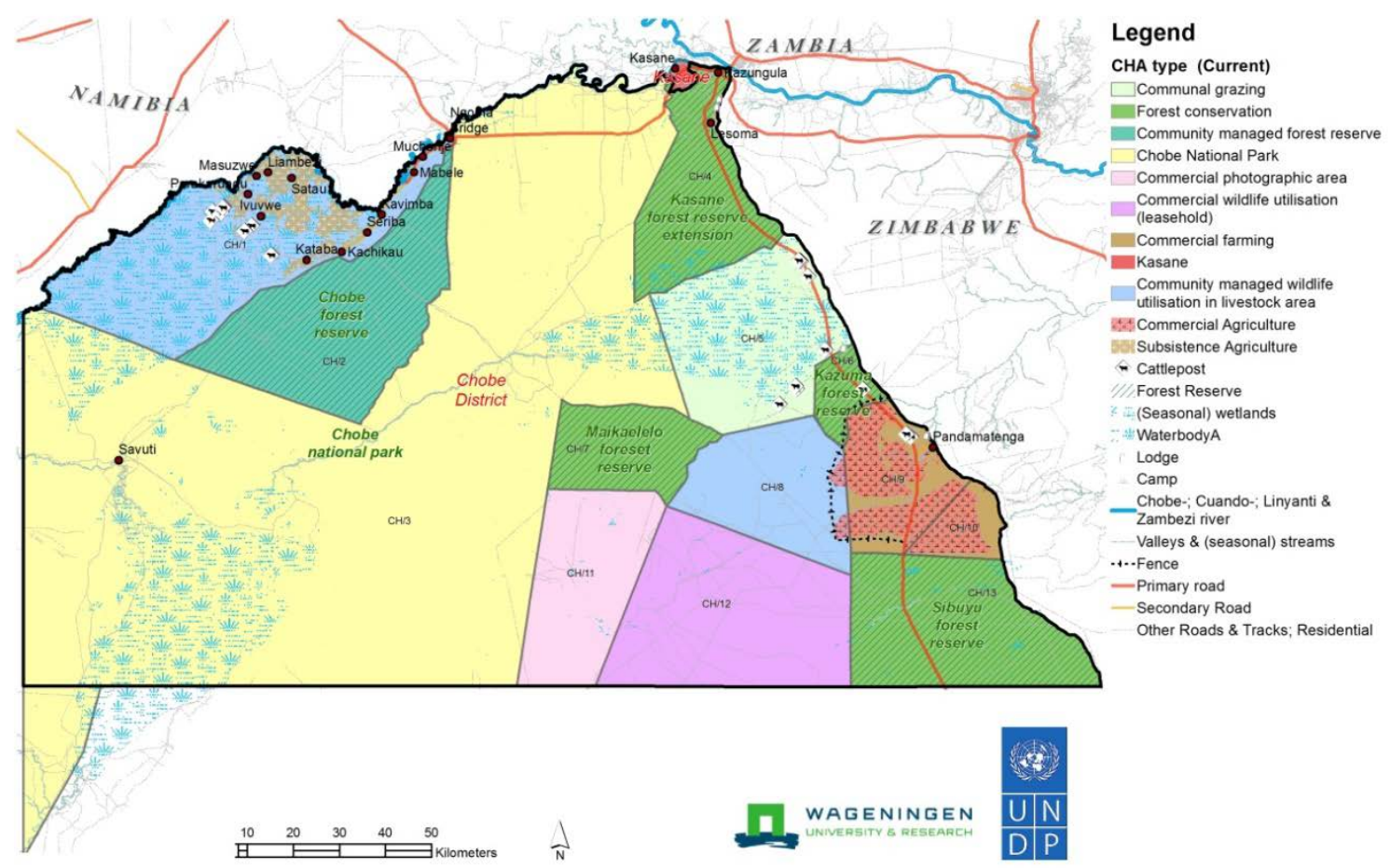

Figure 47 Current land use, based on current policies and planning 
The farmed area varies from year to year, in response to size and duration of the flood, as well as to predicted rainfall, and might in total be some 1200 ha (Table 16). However, over the past years there seems to be a decline in ploughing, possibly as a result of high risks involved related in particular to soil moisture and wildlife damage to crops.

To the east of Chobe, both Lesoma and Pandamatenga also have extensive areas of traditional arable lands (Figure 47). These fields are all rainfed, predominantly on alluvial fields associated with fossil river valleys that carry water seasonally when it rains. As with the dryland farmers in Chobe Enclave, the main crops are sorghum, maize and millet, intercropped with beans and pumpkins or melons.

Understanding the true importance of small-scale arable agriculture to rural lives in Chobe District is difficult, in part because as a traditional activity, some (especially older) farmers farm in the absence of other alternatives. In addition, the 2011 census data may mask some people who are cash employees for part of the year, but still return home to work their fields during the rainy season (Table 17). Those employed solely in subsistence farming comprise only $1 \%$ of the district's population.

Table 16 Total ploughed area in Chobe Enclave (Gupta, 2012)

\begin{tabular}{|c|c|c|}
\hline & $\begin{array}{l}\text { Hectares } \\
\text { ploughed }\end{array}$ & $\begin{array}{l}\% \text { of arable } \\
\text { land ploughed }\end{array}$ \\
\hline \multicolumn{3}{|l|}{ 2010/11 season: } \\
\hline Northern Enclave & 951.08 & 19.02 \\
\hline Total Enclave & 1220.57 & 12.21 \\
\hline \multicolumn{3}{|l|}{ 2009/10 season: } \\
\hline Southern Enclave & 42.88 & 0.86 \\
\hline Northern Enclave & 483.90 & 9.68 \\
\hline Total Enclave & 526.78 & 5.27 \\
\hline Northern Enclave & 952.38 & 19.05 \\
\hline Total Enclave & 1183.89 & 11.84 \\
\hline
\end{tabular}

Table 17 Chobe District employment showing \% working solely in small-scale agriculture (Statistics Botswana 2011)

\begin{tabular}{|c|c|c|c|c|c|c|c|c|}
\hline District & $\begin{array}{l}\text { Employee } \\
\text { (paid } \\
\text { cash) }\end{array}$ & $\begin{array}{l}\text { Employee } \\
\text { ( paid in } \\
\text { kind) }\end{array}$ & $\begin{array}{l}\text { Self- } \\
\text { employed } \\
\text { (no } \\
\text { employees) }\end{array}$ & $\begin{array}{l}\text { Self- } \\
\text { employed } \\
\text { (with } \\
\text { employees) }\end{array}$ & $\begin{array}{l}\text { Unpaid } \\
\text { family } \\
\text { helper }\end{array}$ & $\begin{array}{l}\text { Working at } \\
\text { own Lands / } \\
\text { cattle posts }\end{array}$ & $\begin{array}{l}\text { Not } \\
\text { Stated }\end{array}$ & Total \\
\hline Chobe & 9,506 & 48 & 666 & 197 & 28 & 114 & 6 & 10,565 \\
\hline
\end{tabular}

\subsubsection{Livestock}

Pastoral agriculture in Chobe District is relatively limited compared to the rest of the country. In part this has a cultural component, in that the original settlers of the district were not livestock keepers in the same way as those of Tswana origin. However, there are biophysical factors that restricted colonisation of the area by more pastoral people. Firstly, much of the more sandy areas that underlie the national park and forest reserves contain mogau, Dichapetalum cymosum, which is poisonous to cattle. Secondly, the area was prone to rinderpest outbreaks and infested with tsetse fly (carrying nagana disease) and foot-and-mouth was (and still is) present in the wild ungulates. In addition, the lack of surface water and the salinity of ground water all have contributed to limiting livestock expansion. Currently, the presence of foot-and-mouth disease among the wildlife in Chobe means that 
livestock and meat from the district cannot be exported, leaving only local consumption and the district's tourism sector as the only markets.

Most livestock is found in the Chobe Enclave, the western part of the District (Table 18). Here, close to the Linyanti River, groundwater is sweeter, and most of the land available for boreholes (based on a $5 \mathrm{~km}$ grazing rights radius per borehole) has already been taken up, with approximately 170 cattleposts found in $\mathrm{CH} 1$ (source: spatial cattle post data, Dept. of Surveys and Mapping). In contrast, there are only about 20 cattleposts in Chobe East. None of the cattleposts are in the same area as the actual villages; most are in $\mathrm{CH} 5$, with a few in the Kasane Forest Reserve Extension, and one in Sibuyu.

Table 18 Livestock numbers in Chobe District (Dept. of animal production, 2016)

\begin{tabular}{|c|c|c|c|}
\hline Eastern villages & Cattle numbers & Western villages & Cattle numbers \\
\hline Kasane & 50 & Kachikau & 1826 \\
\hline Lesoma & 241 & Kavimba & 1323 \\
\hline \multirow{2}{*}{ Pandamatenga } & & Parakurungu & 3014 \\
\hline & & Satau & 2878 \\
\hline
\end{tabular}

\subsubsection{Irrigated farming}

Currently there is hardly any irrigation in Chobe District. Tilmant (2012) quotes 4 ha, with plans to expand irrigation with 40,000 ha. This is likely to be in the Pandamatenga area. There are some center pivots present in the northern section of Pandamatenga, as well as irrigation systems at Chobe farms in Kazungula which might not be included in the statistics.

\subsubsection{Commercial farming}

The Pandamatenga region covers a land area of 280,380 ha, of which the Pandamatenga farms covers only 25,074 ha of this total land area (Tapela 2007). The area is generally flat, with a gentle slope, and rain water flows towards the west. The Pandamatenga commercial farming area was revived in 1983 in response to the policy for self-sufficiency in Botswana. For that reason the undertaking was heavily subsidised. The project was even implemented without an EIA, which signifies the importance the Botswana government granted to the farming in Pandamatenga (Kgathi 2012). Currently the Pandamatenga farming is considered a success - and there are plans for expansion. The national interests will make it likely that this has to be incorporated in the plans. There are important soilvegetation combinations of biodiversity value in the area.

The Presidential Directive CAB 128 (2012) approved that the Pandamatenga project is re-designed to focus on grains, oilseeds, and legumes for national food security. It further approves a feasibility study of development of Pandamatenga West, and the use of water from the Zambezi Water Transfer Project (GoB 2012). The water carrier from the Zambezi is supposed to serve Pandamatenga, and most probably cities further south.

The Zambezi Integrated Agro-Commercial Development Project which is currently under study foresees an expansion of Pandamatenga farms with large-scale irrigated farming, for a total area of 15,000 ha rainfed farming and 25,000 ha (net) irrigated farming (34,100 ha gros) (SGI Studio Galli Ingenieri, 2014, Ministry of Lands and Resettlement 2015). The outline indicates that this is a solid block west of the current farms. It assumes that the government of Botswana will take care of investments of the water carrier, but also for the development of the head works and irrigation infrastructure as well as the clearing of fields.

\subsubsection{Horticulture}

Few horticultural projects are present in the area. Some farmers groups are working in the Chobe Enclave with some support from UNDP. These tend to be small-scale, with localised markets. There is 
an opportunity for linking agriculture to tourism, such as through providing a local supply of fresh produce to Chobe lodges and hotels. Not only would this provide employment in a sector supporting tourism, it would represent an important diversification. Increasingly, the concept of "local" is seen as an added-value that is attractive to tourists.

In addition, horticulture lends itself well to conservation agriculture approaches, such as those promoted through the BioChobe project. In areas where there are good soils (such as along the riverfront between Kasane and Kazungula), a well-run horticultural project can not only support the tourism industry, but also be a tourist attraction in itself (such as the Babylonstoren Permaculture Project outside Stellenbosch in South Africa).

\subsubsection{Fish farming}

There are few fish farming enterprises in the area. A large operation was established in between Kasane and Kazungula: Chobe Bream fish-farm started in 2010, and it is an intensive reticulation, aquaculture system. They specialize in the breeding of Chobe Bream or three-spot Tilapia (indigenous Oreochromis Andersonii). They produce for the local market, lodges, restaurants and surrounding Southern African countries. Botswana's demand for fish is 4,000 tons per annum of which only 300 tons are produced locally, the rest is imported from China and South Africa. The government (poverty eradication unit) and MoA are promoting aquaculture.

\subsection{Forestry}

In the Chobe area, 6 forest reserves have been established to protect valuable woodland resources (Figure 47, 48). They comprise the Kasane Forest Reserve, Kasane Extension, Chobe, Kazuma, Maikaelelo and Sibuyu forest reserves, totalling between 4,000-4,500 km² (Ecosurv 2017). The forests, or rather tall savanna woodlands, represent the most southern (lowest precipitation) woodland types of Baikea plurijuga (Miombo) forests in Southern Africa. They may therefore in terms of timber extraction be somewhat marginal due to potentially slow regeneration, but provide genotypic resources of international importance in terms of drought resistance.

Commercial timber exploitation took place in different places between 1934 -1988. Between 1934 and $193840,000 \mathrm{~m}^{3}$ of Baikea plurijuga (Mukusi) logs were extracted from the Chobe Forest Reserve east of Kasane. In the period 1944 - 1954 another 150,000 $\mathrm{m}^{3}$ timber (various species) was extracted for the area West of Kasane. In the period 1983 - 1994 further extraction in the Kasane and Chobe forest reserves occurred (Miller 1987, Kgathi \& Sekhwela 2003). The latter extractions mined to a large extent Pterocarpus angolensis resources (Mukwa). By 1994 commercial forestry operations were stopped as they were deemed not environmentally sustainable by a number of agencies assessing the timber operations. A re-assessment of forest resources as part of the new Chobe Forest Management Plan is currently underway.

The forest reserves form an intrinsic part of the Chobe protected areas and are acknowledged as such by wildlife and tourism officers alike. They provide enhanced carrying capacity for wildlife in the area (e.g. for Elephants). Their use for tourism operations (to relieve pressure on Chobe National Park) is considered an important new forest use (Department of Forestry and Range resources 2016). Also some allowance for boreholes to expand livestock grazing in the reserves has been mentioned (Kasane Forestry Office, Pers. Comm.). Local communities use forest reserves for firewood collection, wild fruit collection, building poles, thatching crafts and handicrafts (see $\S 7.5$ ). While studies differ to the exact quantified importance, all these uses appear important for local communities, with firewood collection providing substantial resources and income for e.g. the community of Lesoma (Kgathi \& Sekhwela 2003).

At present there is a further need expressed to degazette some area of forest reserve around the Kasane and Kazungula areas for township expansion.

These alternative land uses, and the ecosystem services the forest reserves provide, suggest that the forest reserves have greater value intact, and that logging and tree harvesting would serve to undermine both the ecological integrity of the areas and their aesthetic appeal. 


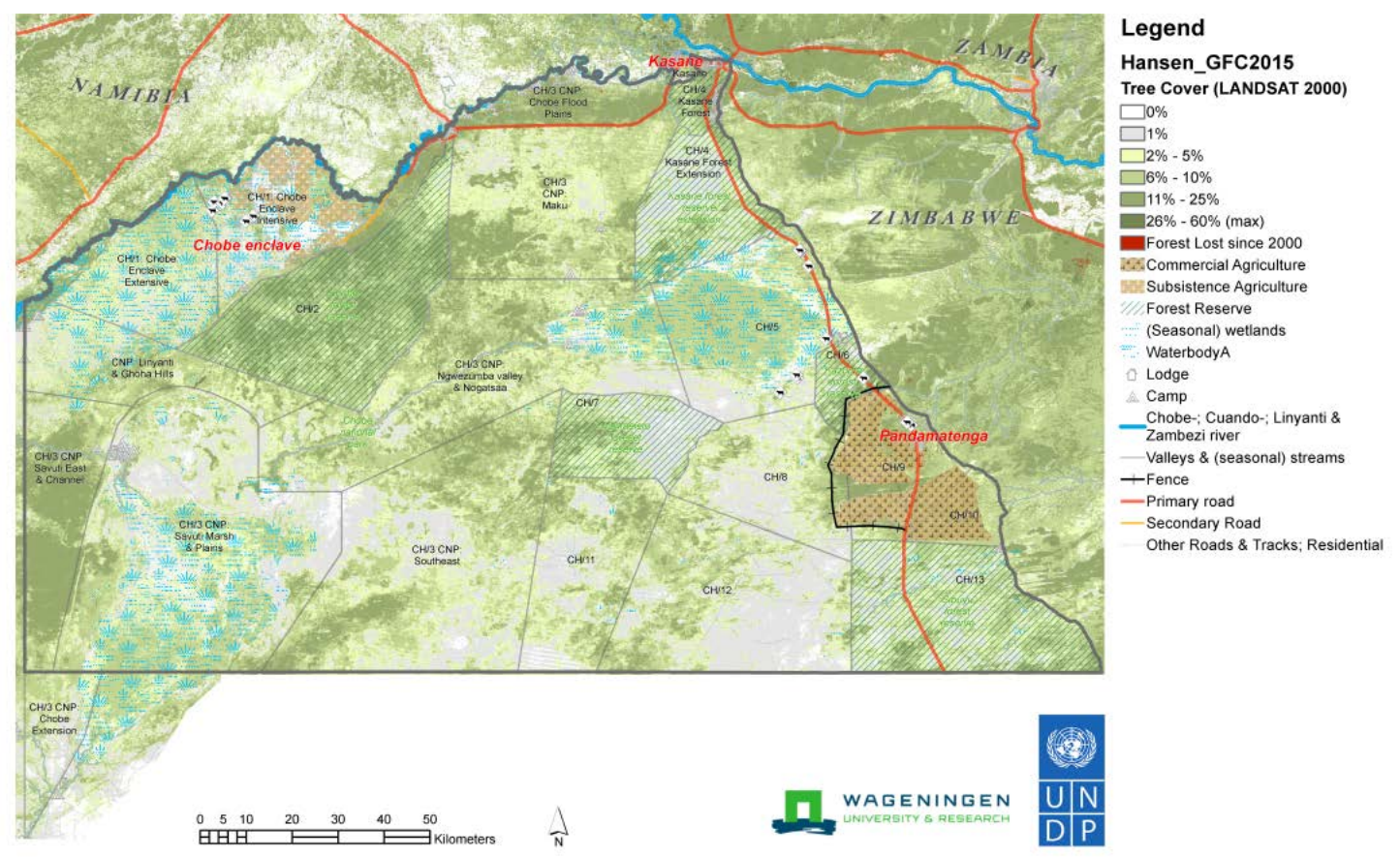

Figure 48 Tree cover, based on Hansen GFC (2016)

\subsection{Wildlife}

\subsubsection{Distribution of Wildlife across Chobe District}

Wildlife are not evenly distributed across the Chobe District. There are clear associations with the presence of permanent surface water (Chobe River, Linyanti River), ephemeral surface water (Savuti River and Marsh) and seasonal rain filled pans, as well as areas with more fertile soils, such as Kazuma pan and Nxai Pan (Figure 49). A study of 2 water points at Savuti (by E. Kasiringua) confirms that the majority of wildlife are water dependent and concentrate around surface available water, with those less water dependent observed at greater distances, such as Elephants, Roan and Zebra.

Camera traps are placed around water points in Chobe to record use (Matt Davies as part of the EWB team) with similar results, some species are observed to use water points further from the river than others, but the majority of species is still spatially restricted along the river front.
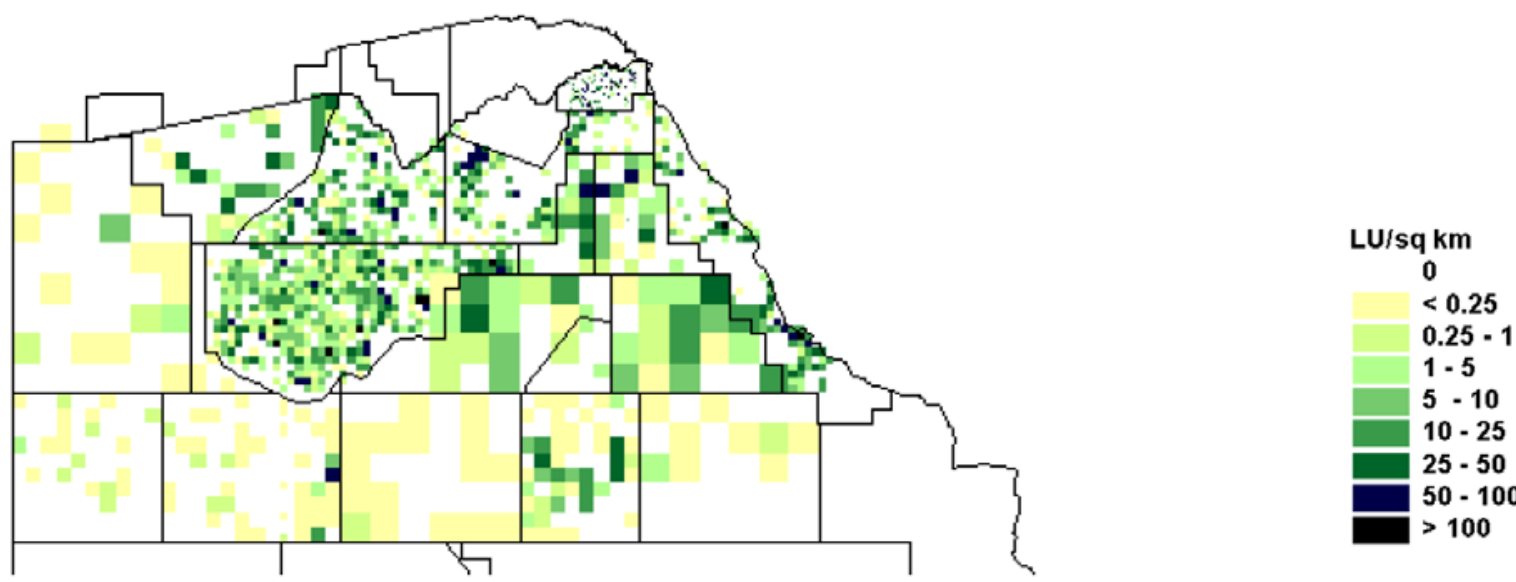

Figure 49 Dry season wildlife biomass density distribution patterns across northern Botswana (DWNP 2013) 
Several regional aerial surveys have been conducted in recent years by the DWNP $(2012,2013)$ and EWB $(2011,2013)$ which have helped to track trends in population numbers and to highlight biodiversity hotspots and seasonal differences in distribution patterns. In addition species specific research with the collaring of Elephants, Zebra, Buffalo, Wildebeest, Lions and Wild dogs has provided additional information on specific movement patterns across the landscape. The latter have helped us to identify and demarcate wildlife corridors and dispersal areas.

\subsubsection{Chobe National Park}

Many protected areas in Africa, such as the Chobe National Park, were established before there was an understanding of ecosystem dynamics and the resource requirements of wildlife populations, so that most protected areas are unable to serve as functional, independent systems, requiring wildlife to leave their protective boundaries in search of seasonal resource requirements (DeFries et al, 2007). Wildlife populations within Chobe District are therefore not confined to the boundaries of the Park, but move across the District in search of optimal resources, which shift temporally and spatially, so that wildlife concentrations are not static. This often brings wildlife into conflict with people within the Chobe enclave and within Kasane township, as well as with the farmers in Pandamatenga. The limiting resource in most cases is water. During the dry season surface water availability is limited within the Park to the Chobe River front, the Khwai River and the ephemeral Savuti Channel and Ngwezumba river system, the 11 artificial water points and within seasonal pans that can hold water for several months following heavy rainfall. As such, wildlife concentrate in large numbers and high diversity along the Chobe riverfront and to a lesser extent the Savuti Channel during the dry season. With high competition amongst wildlife for access to water and the foraging reserves close to water, wildlife has increasingly spread out into Kasane and Kazungula to the east and to the Chobe enclave to the west. The eleven artificial water points were established within the park to try and reduce the concentration of Elephants along the Chobe River front and reduce the incidence of human-wildlife conflict close to Kasane, but their success has been limited in the case of Elephants, although the water points have been useful in attracting other species of wildlife to areas where these water points have been established (AWF, 2008).

Other regulatory factors influencing wildlife distribution include habitat type and resource quality. These factors are driven by soil type and fertility. Within the Park there are three distinct ecozones where soil type is distinctly different to that of the surrounding landscape. These areas, all influenced by historical and current hydrological flows and drainage systems, include the Savuti Marsh, the Mababe depression and Kazuma Pan / the Northern Grassland Plains. The soils have a high water-holding capacity, which indicates a higher clay content. These lacustrine and alluvial soils are relatively mineral rich and associated with grasses of higher nutritional quality, and attract medium to large herbivores on a seasonal basis (Fynn, Chase \& Roeder, 2013). Their importance to the functionality of the system must not be ignored as they provide the stimulus for migratory movement and seasonal nomadic shifts in dispersal for many wildlife species. The ability for animals to preferentially select grazing areas of higher relative nutritional value and to adjust their preference based upon annual rainfall patterns is a driving force behind the resilience and long-term viability of wildlife populations within Chobe. Threats posed to the Northern Grassland Plains through the expansion of agricultural development are therefore of concern. These grasslands attract less water dependent species throughout the year. High concentration of Eland, Roan and Tsessebe are found here in the dry season and joined by Sable and Zebra in the wet season.

The most authoritative account of the seasonal distribution and population estimates of wildlife populations in the Chobe District is provided by Chase (2013). He presents data collected from aerial surveys undertaken in the dry season of 2011 and the wet season of 2012 within the Chobe District. The data is graphically presented (Annex 2 ) in a series of maps displaying the wet and dry season distribution of key wildlife species within Chobe District (Chase, 2013).

\subsubsection{Forest Reserves}

Neighbouring the Chobe National Park and helping to facilitate the seasonal expansion of wildlife home ranges are the Forest Reserves (the Kasane Forest Extension Reserve ( $\mathrm{CH} 4$ ) / Kazuma Forest Reserve $(\mathrm{CH} 6)$ and the Maikaelelo Forest Reserve $(\mathrm{CH} 7)$ ). These serve as important wilderness areas and wildlife refuges, further increasing the regional importance for wildlife. While the Forest Reserves primary function is to protect rare hardwood tree species (Pterocarpus angolensi and Baikiaea plurijuga) (Forest 
Act 1968, Kgathi \& Sekhwela 2003) their proximity to the Chobe National Park and the adjoining wilderness areas of Hwange and Matetsi in Zimbabwe enable wildlife to move and disperse across a large area, creating a continuous wilderness environment. Threats to their land use exist, as it has proven hard for the government to secure sustainable economic returns either through forestry or ecotourism. The dense underlying shrub, thick forest and closed canopy hinder game viewing potential and hence tourism potential. Plans to open up these areas may have exacerbated threats to wildlife through improved access to poachers and increased exposure to the risk of man-made fires. Whilst the majority of plains game do not utilise the Forest reserves in great numbers Elephants and Buffalo do.

The reason that Botswana has such a high Elephant population is because of its extended network of conservation areas, of which the Forest Reserves fill a critical role. Any threats to their existence of their protection will increase the level and extent of threats to the Elephant population. All four forest reserves support extensive Elephant numbers throughout the year, with greater concentrations in the wet season along with increased Buffalo numbers which move away from the Chobe River Front and into the Reserves to graze on the annual grasses. Elephants are attracted into the forest reserves by the quality of the browsing resources and possibly by the lack of human activity. In addition further species such as Roan, Sable and Eland also seek shelter in the Forest Reserves, where aerial survey data shows increased relative concentrations in the Reserves.

\subsubsection{Chobe Enclave}

Much of the Chobe Enclave consists of floodplains across $\mathrm{CH} 1$, with flood water from the Chobe / Linyanti system. As the dry season distribution of wildlife is generally concentrated within $30 \mathrm{~km}$ of surface water (Chase 2013) the enclave subsequently attracts large densities of wildlife (See Annex 2, wildlife distribution maps). Of critical importance to wildlife within the enclave is also the ecotone between these floodplains and the forests of $\mathrm{CH} 2$. This ecotone runs along a relatively high escarpement which further adds value to the habitat diversity of the region. There are distinct seasonal differences in the wildlife utilisation of the forests versus the woodlands, with additional species differentiations. These differences are similar to those described for the Chobe National Park, with dry season concentrations of Elephant, Buffalo and Zebra in the floodplains and a shift to the forests in the wet season. However, Zebra do not make use of the forests in $\mathrm{CH} 2$ and move further south to the Savuti marsh as part of a discernible migration (Vandewalle, 1988). The forests are inhabited though by Eland, Kudu and Sable throughout the year, with some Elephant activity during the dry season.

The significant difference between the enclave and other areas of the District is the higher relative number of people. There is an estimated population of around 5,000 people in the Enclave living within five main villages (see Table 14). Crop production is undertaken by $51 \%$ of the households and livestock is owned by $46 \%$ of households ( $\$ 7.1 .3$ ), with more than 10,000 head of cattle within the enclave. This number of people living and working the land across the $\mathrm{CH} 1$ obviously come into conflict with the significant number of wildlife sharing the landscape (see $\S$ 8.3.4).

Before the hunting ban, negative attitudes towards wildlife were mitigated by a generous hunting quota, which provided a significant source of income to CECT and the Village Trusts. In the year 2000 a study showed the benefits that communities received from hunting and how these economic benefits helped to counter any negative attitudes towards wildlife through human-wildlife conflict (J ones, 2000). With the hunting ban it can be expected that negative attitudes towards wildlife will increase, as communities receive minimal direct benefit. As the human population grows and habitat fragmentation expands across $\mathrm{CH} 1$, incidents of human-wildlife conflict are likely to increase.

\subsubsection{Northern Plains/ Kakulwane Plains (CH5)}

The Kakulwane or Northern Plains are some of the most unique and rare habitats within Botswana (Arup Atkins, 1990). They remain as the sole undeveloped vertisolic clay plain within Botswana (Arup Atkins, 1990) and provide an important habitat for wildlife, especially Eland, Buffalo, Roan, Sable and Tsessebe (KCS, 1987). The region forms an interface between the Kalahari shrublands that dominate the majority of Botswana and the Miombo woodlands that are more synonymous with Zambia and northern Zimbabwe, as a result it forms the most northerly extension of desert species such as Gemsbok, while holding some of the highest densities of Eland, Sable and Roan within Botswana (Annex 2).

The high regional diversity of wildlife species has been directly attributed to the rain filled pans along the grasslands ecotone and the contiguous open wilderness, connecting the protected areas of both 
Botswana and Zimbabwe to permit large scale seasonal migration (KCS 1987). Elephant, Buffalo and Zebra are attracted towards the rain filled pans of the grassland / Miombo ecotone during the wet season and beyond to the Ngwezumba / Nogatsaa region of Chobe, while Eland move in to the region during the dry season (Hunter 1996, Arup Atkins 1990). Child (1968) first reported well defined Elephant pathways leading from southern Chobe around the Ngwezumba River leading towards the rain filled pans in the Pandamatenga region and further towards and beyond the Zimbabwe border, confirming that these movement patterns are of historical significance. The north-western MatabelEland of Zimbabwe, which includes areas such as Hwange National Park, Kazuma National Park, Victoria Falls National Park, Matetsi Hunting Block and Panda Masue Hunting Block (which are directly opposite the project development area) have long been associated with high wildlife populations. Large differences in annual population estimates from aerial surveys of this region suggest that extensive movements occur in and out the area (Bowler 1992). In Matetsi, Zimbabwe, biomass estimates were almost double that predicted from regional rainfall patterns due to the high density of Elephants in the region, but estimates for other species were believed to be significantly below the actual number of animals present (Robertson 2005).

Annual flooding of the plains helps maintain the area as open grassland with occasional fires clearing shrub vegetation (Arup Atkins 1990). The vertisol clays have a poor infiltration rate, which combined with the flat grasslands leads to poor natural drainage (Kgathi, Sekhwela \& Hamandawana 2003). Water that does drain away from the area moves west towards the Ngwezumba channel, but the plains can remain flooded for most of the wet season (November - March) (Thomas and Shaw, 1985). The deep heavy clay soils inhibit movement when wet, and plains game have been shown to avoid such environments as it restricts their movement and increases the energetic costs of locomotion (Anderson \& Talbot, 1965). Soil compaction at the interface between the vertisolic northern grassland plains and sandy/lithosol mixed Miombo woodlands leads to the formation of pans, which are crucial for wildlife during the wet season and early dry season, while the firmer soils aid movement, creating important wildlife corridors (Arup Atkins, 1990). The grasslands are inhabited by specialist grassland species such as Oribi and Reedbuck, which used to be permanent residents on the grasslands with Eland moving into the grasslands during the dry season (KCS 1987, Arup Atkins 1990).

The Northern Plains are also rich in birdlife with some 550 species recorded from the region. Many species of waterfowl and wading birds are represented, including egrets, herons, storks and cranes, all of which are conserved in Botswana, with the Northern Plains providing habitat for 21 rare bird species, over at least part of the year (ESA, 2015).

\subsubsection{Pandamatenga Farms}

The Pandamatenga farms occur within $\mathrm{CH} 9$ and consist of 2 separate enclosed areas, both fenced with a game proof perimeter fence and now, since the year 2000 enclosed by a separate electrified fence. In total the farms cover just over 25,700 ha of the central and southern grassland plains with an additional block of 2500 ha erected in 2012 adjoining the eastern side of the southern fenced section. Separating the 2 areas is a narrow gap that was intentionally left to facilitate wildlife movement along an east-west alignment. The development of the electric fence has removed the opportunity to conserve this migratory corridor for wildlife along the sand ridge between the Central and Southern Plains of $\mathrm{CH}$. Instead, erecting the electric fence trapped many wild animals into the enclosed area, and due to the availability of permanent water many have successfully been reproducing since then with numbers increasing. The majority of crop farmers within the Pandamatenga Commercial Crop Farming area do not currently view wildlife as a problem, and deem the levels of Human-Wildlife Conflict within the confines of the farms as acceptable (ESA, 2015). However, crop damage does occur with farmers controlling damage through off-take of wildlife. During the dry season of 2010 farmers reportedly shot 67 animals to reduce conflict levels. It is estimated that up to 400 animals occur within the fenced area, with almost 200 having been captured and removed by DWNP between 2000 and 2007 as part of their conflict mitigation role (EHES, 2007, ESA, 2015). Predators, especially Lions are attracted into the fenced area to predate on the resident wildlife species, but they also predate on cattle, aggravating aspects of the human-wildlife conflict scenario within the farms. The predominant crop-related problem animals on the Pandamatenga farms are Kudu, Tsessebe and Eland (ESA, 2015).

Of greater concern than the internal human-wildlife conflicts within the fenced farm area is the impact of the fenced block as a restriction to wildlife movement across the landscape. ESA (2015) highlight the 
issue in their wildlife management plan for the farms, stating that a viable migratory corridor to the South and North of the Central Plains should be identified as a priority and should form an integral part of development of the existing Pandamatenga Farms and the proposed Agro-Zambezi Commercial Project on the Northern Plains (§ 8.1.4). In addition, many previous reports and El As have recommended the need for a migratory corridor that links the areas to the west of Pandamatenga to the Matetsi/Hwange National Park in the east and so allow the movement of key migratory species such as Buffalo, Zebra, Sable and Eland. The sand ridge between the Central and Southern Plains has consistently been identified as such a corridor but is no longer an option due to the new electrified fence around the commercial farms.

\subsubsection{Kasane Township}

Increasing Elephant numbers along the Chobe River Front over the past few decades has led to increasing pressure and competition for access to resources, possibly contributing to the increased movement of wildlife into Kasane Township. Wildlife, especially Elephants move through the township to access the river front to drink water. Whilst the town is busy with human activity, these movements occur at night, when most people are asleep and the potential for conflict is minimised. Adams et al., (2015) have proposed that urban corridors running through the township be demarcated and conserved to facilitate the passage of Elephants through towns without causing conflict with urban communities. Their research focused on a series of these corridors to the eastern side of Kasane Township that Elephants were recorded to use throughout the year. Their results indicate that Elephants used corridors measuring distances as small as $3 \mathrm{~m}$ wide at their narrowest point, as Elephants weaved their way through the town's infrastructure along paths that measured up to $1.7 \mathrm{~km}$ long at their greatest. Whilst a full species list is not known, it is assumed that a broad diversity of other wildlife species make use of these same corridors. Blocking them off through unplanned development may lead to increased incidence of conflict as wildlife seek other, less suitable paths through the town. The results have been incorporated in the wildlife management plan for the Seboba Recreational Park, to facilitate the passage of Elephants through the Park, but have not been formally designated elsewhere within the town. Formal protection and designation of urban corridors by the relevant governing bodies would facilitate coexistence between people and wildlife at small spatial scales (Adams et al., 2015).

\subsubsection{Corridors}

The annual migratory routes of African wildlife form an important link between ranges with high quality resources that are only viable during the wet season and back again to dry season ranges that provide year round access to water and average resource quality. Migrations along these nutritional gradients between wet and dry season ranges generally occur on an annual basis and can be seen in many distinct locations across the Chobe District. These include the migratory movements of Zebra and Buffalo from the Linyanti swamps to the Savuti Marsh as well as the movement of Zebra from the Chobe-Linyanti river front to Nxai Pan, both of which movements occur at the beginning of the wet season.

Large scale migratory movements also occur as regular and irregular nomadic events, caused by animals dispersing during the rainy season or moving across greater distances during periods of infrequent climatic changes, such as prolonged droughts, which cause some species to move considerable distances from their normal annual range in search of improved resources. Similar movements are also observed within the Chobe District. These movements do not follow confined migratory corridors but consist of dry season home ranges around restricted surface water supplies and then more disparate wet season ranges used to access seasonally available food supplies. These types of movements are characterised by Elephants and Buffalo moving south from the Chobe River front (see Annex 4).

In most cases wildlife density across most ecoregions in the Northern Conservation Area is low, with high concentrations of migratory and nomadic animals that are concentrated in areas of seasonally available high quality resources, with subsequent dispersal during the rainy season when high quality resources are more widely available, i.e. nomadic movement that follows the variable annual rainfall patterns, or migratory movement along a well-defined nutrient gradient.

A result of this low herbivore biomass across some of the marginal dry land areas of Chobe is the perception that much of the land is under-utilised and may better be utilised by switching the land use to other uses, such as agriculture. The recent advances in our knowledge and understanding of the 
migratory patterns and routes of wildlife in northern Botswana (Bartlam-Brooks et al., 2011, Fynn, Chase \& Roeder, 2013, Naidoo et al., 2014) have generated some much needed hard facts and precise information on the alignment of wildlife corridors across the Northern Conservation Area and highlighted the importance of these otherwise marginal areas to the viability of wildlife across the region.

For the purposes of land use management two things are critical; 1 ) the alignment of wildlife corridors between distinct high-low nutrient zones are demarcated and then properly conserved to ensure the future viability of the migratory species dependent upon them and, 2) that the size of any protected area is large enough to encompass the seasonally used ranges where often wildlife densities may be low and the opportunities for ecotourism restricted. The expanding Elephant population in northern Botswana does however pose several challenges. How much space and access to resources does the Elephant population need. If it is constrained what will the impact be on the structure and quality of the habitats within the conserved spaces. But if land use is converted to maximise the opportunities for human use, what will the relative impact be to the number of human wildlife incidence recorded. Facilitated dispersal of Elephants from high density areas of northern Botswana to protected areas in other countries with low Elephant densities is an attractive potential solution to these problems (Cushman, Chase \& Griffin 2010). It is therefore critical to look at the corridors and movement patterns of wildlife across international boundaries and not just within the District. Aligning the conservation of protection of corridors across international boundaries is critical if the KAZA landscape is to be an effective conservation area.

\subsubsection{Hunting}

Trophy hunting was stopped in 2014, which has led to a strongly reduced local income (through the Chobe Enclave Trust). Hunting was not allowed within a $25 \mathrm{~km}$ buffer from Chobe National Park. An important hunting area was $\mathrm{CH} 12$, the area located in the south of Chobe District, around Bottle Pan (GISPlan 2013). Further, hunting was done in $\mathrm{CH} 8$, a concession run by the KALEPA community trust, but half of $\mathrm{CH} 8$ was also situated within the buffer zone of the park.

The decrease in hunting has had an impact on revenues, and can lead to reduced control of developments in the former hunting concessions: camps are abandoned, which might result in poaching, and farmers apparently could move into the 'vacant areas' with their cattle. The concession areas are not suited to photographic safaris, since the wildlife densities are much lower than in the riverine zone. Besides, the landscape is less aesthetically attractive (boring). It should be considered if some parts of particular concession areas, e.g. the grassy valleys, may have potential for further tourism development.

The decrease of income from hunting has resulted in an outspoken conflict situation between the communities and wildlife, where some of the opinions are that all benefits from tourism are said to go into the governments' coffers, while local communities are suffering the disadvantages from wildlife (dangerous situations with Elephants, livestock predation, destruction of crops). This is also related to the unpaid compensations to communities. An alternative revenue scheme could be devised to compensate local communities for this. Other options to help generate income and employment for the local communities is to further stimulate and diversify local tourism and businesses that support the industry in communal areas, e.g. around Lake Liambezi or the conservation of local woodlands leads to a great birding environment at Muchenje. However it must be noted, that developments, as these, are linked to proper advanced education and training which is required and needed to be employed in the tourism industry in the region.

\subsubsection{Illegal wildlife off-take}

Note: this text is largely based on the SEA for the Chobe Forest Reserves (ECOSURV 2017). Illegal off-take of wildlife, or 'poaching' is a serious concern for management of Wildlife populations in the Chobe the District. Recorded incidents of poaching potentially only touch the surface of the true impact, but figures do show significant off-take of Elephants and some off-take of other herbivore species. The global illicit wildlife trade poses an increasing risk to Botswana's Elephant population, and whilst current off-take numbers are low (DWNP, 2015), the nascent poaching industry should be expected to grow as demand for ivory increases.

The figures from DWNP (Table 19) show a steady number of poaching incidents recorded for Elephants between 2010 and 2015, with a peak in 2012, but otherwise an average annual off-take of around 
40 animals per year. It is very hard for poachers to hide the evidence of dead Elephants, with carcasses spotted from the air and ground. To help reduce the chance of detection poachers also often place poison down around the carcass to kill scavengers such as hyenas and vultures. Mass die-off events of vultures have been linked to the poaching of Elephants in the District, with over 40 vultures killed at one site in 2016 (pers. comm. Raptors Botswana). The Chobe National Parks close proximity to international borders with three countries (Namibia, Zambia and Zimbabwe) makes it especially attractive to Elephant poachers supplying the illegal ivory trade. As a consequence, Elephants are the most poached species in the district. However, numbers of ungulates killed by poachers for the bush-meat trade such as Buffalo are potential not recorded as the carcasses are more easily hidden and buried.

Table 19 List of recorded poaching incidents in Chobe District for 5 years

\begin{tabular}{lrrrrrr} 
Species & 2010 & 2011 & 2012 & 2013 & 2014 & 0 \\
Buffalo & 0 & 0 & 1 & 1 & 0 & 0 \\
\hline Eland & 0 & 0 & 69 & 14 & 41 \\
\hline Elephant & 25 & 54 & 0 & 0 & 1 & 203 \\
\hline Roan & 0 & 0 & 1 \\
\hline
\end{tabular}

Source: Department of Wildlife and National Parks, data provided for this study, 2016.

Conflict between the people living in the villages surrounding the Chobe National Park and the wildlife which move beyond its borders is also of significant concern for the District authorities and poses a challenge for the management of wildlife. Between J anuary 2010 and J uly 2015, more than 1230 problem animal incidents were reported to DWNP (DWNP 2016). Information recorded by DWNP below shows the wildlife species involved in reported incidents over the past five and a half years, as well as the species reported by village location (including settlements associated with that village; Table 20). It is clear from the data that most of the villages within the District suffer from extreme levels humanwildlife conflict. Those animals most associated with this conflict include: Elephants, Lions and Hippo.

Table 20 List of recorded problem animal incidents in Chobe District for 5.5 years

\begin{tabular}{|c|c|c|c|c|c|c|}
\hline Species & 2010 & 2011 & 2012 & 2013 & 2014 & $\begin{array}{r}2015 \\
\text { ( } 6 \text { months) }\end{array}$ \\
\hline Baboon & 0 & 0 & 6 & 2 & 4 & 1 \\
\hline Bushbuck & 0 & 0 & 0 & 0 & 0 & 1 \\
\hline Cheetah & 1 & 0 & 0 & 0 & & 0 \\
\hline Elephant & 90 & 74 & 139 & 33 & 142 & 87 \\
\hline Giraffe & 0 & 0 & 0 & 0 & 2 & 4 \\
\hline Hippo & 5 & 22 & 42 & 13 & 19 & 1 \\
\hline Hyena & 0 & 0 & 1 & 0 & 13 & 7 \\
\hline Monkey & 0 & 0 & 0 & 0 & 1 & 0 \\
\hline Ostrich & 0 & 0 & 0 & 0 & 0 & 1 \\
\hline Porcupine & 0 & 0 & 0 & 0 & 1 & 1 \\
\hline Reedbuck & 0 & 0 & 0 & 0 & 0 & 1 \\
\hline Roan & 0 & 0 & 0 & 0 & 0 & 2 \\
\hline Snake & 0 & 0 & 5 & 0 & 1 & 1 \\
\hline Tsessebe & 0 & 0 & 0 & 0 & 1 & 0 \\
\hline Unknown predator & 0 & 0 & 0 & 0 & 1 & 0 \\
\hline Warthog & 0 & 0 & 2 & 0 & 3 & 0 \\
\hline Wild dog & 3 & 0 & 0 & 0 & 14 & 0 \\
\hline
\end{tabular}

Source: Department of Wildlife and National Parks, data provided for this study, 2016 


\subsubsection{Elephant Impact on Vegetation}

Over the last 200 years Elephant numbers have fluctuated widely under human pressure. In the Chobe Elephants were numerous and probably at the same order of magnitude or even more as today up to around 1870. After approximately 1870 Elephant number rapidly collapsed due to fire-arm assisted ivory hunting. By 1900 numbers were strongly reduced but Elephants were still present in numbers between Mababe and the Chobe Enclave (Reid 1901, Hodson 1912). By the 1930's there were again larger numbers reported in the northern region between Ngoma and Kasane. By 1970 Elephant numbers were estimated between 10,000-20,000 (Spinage 1990). Since then the population in northern Botswana has steadily risen to over 100,000 . There is at present some uncertainty as to what the exact number is (due to differences in census techniques) and whether the population has now become stable or that numbers are still rising.

\section{Elephants and vegetation: A serious problem?}

Elephants (also in combination with small browsers) have had a large impact on riverfront vegetation in the Chobe National park and some areas of the park presently look like a "war zone" and is becoming visually unattractive (Du Toit et al. 2014). Also in the structure and its composition. In Linyanti area vegetation is rapidly being altered by Elephant concentrations. The question is, whether these changes represent a return to a more "natural" pre-hunting era as speculated on in Skarpe et al. (2014).

Comparing the information on pre- 1880 vegetation (the "natural situation" see vegetation section) with the current conditions, suggests that the decline in acacia dominated fringe vegetation represents a return to natural large Elephant population conditions. However the structural changes in the woodlands at a somewhat larger distance from the Chobe Rive appear beyond the 1880 situation. This potentially reflects the insufficient long-term carrying capacity for the Chobe ecosystem to support the larger number of Elephants. A major difference in ecosystem functioning of the present Chobe-Kwando-Linyanti matrix compared to pre-1880 is the changed land-use of the Namibian North bank of the Chobe, where many wetland areas have been converted into arable and pasture areas and are less accessible and of less quality as part of a larger functioning ecosystem. This notion strongly underlines the importance of transboundary migratory corridors and other initiatives as proposed under KAZA.

\subsection{Fisheries}

Historically, there was very low fish offtake from the Chobe system (Marr, 1965). Fish catches in the Chobe system were used "for local consumption fresh and sold gutted" (Marr, 1966). Marr (1966) also reported that large fish catches from the Chobe system were "stored in ice on trucks" and fish were also smoked for preservation. Generally, however, there has been minimal fishing in the Chobe compared to the Okavango Delta. Masudire's (1995) observation that the Chobe- Linyanti river system was heavily fished validates Mmopelwa's (2000a) observation that there are poor fishing grounds on the Botswana side of this system, compared to Namibia which has some narrow floodplains. Another factor regulating fishing activities in the Chobe-Linyanti river system on the Botswana side is the presence of the Chobe National Park (Mmopelwa, 2000a, 2001). Fishing in the Chobe - Linyanti River on the Botswana side is regulated by the Wildlife management regulations, because this area falls within the Chobe National Park (Mmopelwa, 2000a, 2001, 2002), which prohibits fishing on the Botswana side (Mmopelwa, 2000a). However, the absence of similar regulations on the Namibian side of the river has allowed Namibian fishers to exploit the fish resource and sell it in Botswana (Mmopelwa, 2002). This has created disenchantment on the Botswana side (Mmopelwa, 2000a) because Botswana fishers feel disenfranchised by the local regulations. In the past, Namibian caught fish from the Chobe river dominated the fish market in Kasane (Mmopelwa, 2001) due to this uncoordinated transboundary management of fisheries resources. There is no evidence that this has changed in the present.

Another major impediment to fishing in the Chobe system is that most fishing grounds are found within safari concessions in the area. This resulted in conflict between local fishers and concessionaires who prohibited fishing access to local fishers (Mmopelwa, 2004). There is however, some minimal fishing along the Chobe River in Kasane. Masisi (2004) showed that some subsistence fishers in 
Kasane along the Chobe River exploit 9 fish species, where Coptodon rendalli had the highest catch rates. This however, differed from analysis of recreational fishing from the same area where Oreochromis andersonii was the most frequently caught species (Merron and Sehemo, 1985). In fact this study showed that recreational fishers also exploit 9 fish species in Kasane (Merron and Sehemo, 1985), with a relatively similar species composition. Tilapia sparrmanii, which was caught more frequently by subsistence fishers (Masisi, 2004) is not exploited by recreational fishers (Merron and Sehemo, 1985). Total fish catching efficiency from traditional hook and line gear was estimated at $2.6 \mathrm{~kg}$ per hook per day (Masisi, 2004).

Fish data collection was the cornerstone of fisheries management in Botswana, and this was done for all the major fishing areas in the country (Mmopelwa, 2002). Currently, there is limited data collection in the Chobe fisheries which makes it difficult to estimate the exploitation levels. Key factors that have historically contributed to this low data collection effort was the "scattered and migratory nature of fishers, low literacy level of fishers, shortage of fisheries extension staff, and difficulty in accessing some of the fishing grounds" (Manyemane, 2000; Mmopelwa, 2002). Currently, the main focus of Fisheries Division personnel is law enforcement, while little effort is placed on fisheries data collection. Furthermore, the Fisheries Division staff is now engaged more in anti-poaching activities while minimal attention is given to fisheries management. It is also worth noting that historical records show that there was no fish catches recorded from the Chobe fishery between 2000 and 2005. Lack of manpower by the Fisheries Division is a major factor for this observation (Mmopelwa, 2000, 2001, 2002, 2004, 2005). Hence, management should focus on ensuring efficient fisheries data collection through provision of enough manpower in the region.

\section{Conclusion}

Very little information exists on the Chobe fishery, compared to the Okavango Delta (Masisi, 2004). This is possibly due to the fact that there is a higher proportion of people in the Okavango Delta who depend on its fish resources for their livelihoods than the Chobe system. This might also be due to the fact that there are fewer productive fishing grounds in Chobe than in the Okavango Delta. The major factors limiting fishing potential in the Chobe are (i) lack of defined floodplains which normally make good fishing grounds, (ii) the presence of Chobe National Park which prohibits fishing and (iii) the presence of wildlife/tourist private concessions which prohibit fishing access to local fishers which resulted in land use conflicts between local fishers and safari concessionaires.

There is spatial variability in fish productivity in the Chobe system where Kwando River is the least productive system while Linyanti River is the most productive. However, the Linyanti River is relatively inaccessible, compared to the moderately productive Chobe River. Because of its proximity to human settlements, most of the fishing effort in the Chobe system is found along the Chobe river, mostly subsistence fishing. Theoretically, the Chobe River can be utilised for recreational fishing (or traditional hook and line fishing) because of the riverine nature of its fish community, while the Linyanti River can be utilised more for commercial fishing using gill nets. Because of its low productivity, the Kwando River can be utilised for subsistence fishing.

There is a conflict over how well fisheries is regulated on the Botswana side. The strict enforcement of the no-fishing zone on the Botswana side leads to very poor support for DWNP activities in general among the Botswana side people. In the meantime, there is definitely a perception that the Namibians are stretching the boundaries with their activities - that they are reaping the benefit of strong conservation practice on the Botswana side, without paying the cost. International cooperation seems the only possibility to address this. KAZA is also promoting the concept of Fish Protection Areas - they promote these at wildlife corridor routes across the border.

Local solutions suggested by MoA are e.g. fish farming, but with the technical input, capital requirements, and vulnerability of the systems (power supply, water quality control, equipment) this might not be so feasible. Besides, also marketing over larger distances might pose problems. If attempts are undertaken with fish farming, it should be small scale, for local provision and sale to villages, lodges and camps.

There is also the threat from the use of alien species for aquaculture - specifically Oreochromis niloticus. This species has (inadvertently?) been released into the middle Zambezi, and has been extending its range upstream and downstream; its present upper limit is Victoria Falls. It is only a 
matter of time before the range extends to the upper Zambezi, Chobe, and ultimately LinyantiKwando (Zengeya et al. 2015).

\subsection{Tourism}

Over the past 60 years, Sub-Saharan Africa has seen a rise in tourism, with numbers of international visitors rising on average $4-5 \%$ per year (The World Bank 2013). Botswana is no exception with tourist numbers increasing 196\% between 1995 and 2016 (The World Bank 2016). Within Botswana, the tourism sector employs over 72,000 people ( $10 \%$ of the employed population), contributing approximately 2.23 BilLion USD to the total GDP (second largest after diamond mining) (African Development Bank 2016; Department of Tourism 2010).

Botswana is a sparsely populated, politically stable and relatively safe country. Its' largely unspoiled landscape allows for a true wilderness experience. For tourists in Botswana this mainly concerns lowdensity expensive upmarket safaris, with limited budget options. Especially northern Botswana is a world famous safari destination. In a 2016 in-depth analysis of the best African safari parks by SafariBookings.com ${ }^{11}$ the region's parks all ranked Top20 (out of 138 parks). The Okavango Delta ranked \#3, Moremi Game Reserve bordering the southwest ranked \#5, while the Chobe National Park and the Linyanti Concession, which are part of the Chobe district, ranked \#15 and \#18 respectively. Many travellers visit Chobe also in combination with e.g. Victoria Falls, Okavango Delta, and sometimes Hwange or a South African destination.

Wildlife safaris are and will remain the primary reason for most tourists to visit the Chobe district. The intensity of tourism use within the area varies, depending on seasonal, daily and spatial factors.

\subsubsection{Tourism-use depending the season and time of day}

The tourism- use of the Chobe district varies between the tourism high-season, during the dry winter months, and the tourism low-season, during the wet summer months. In the high-season, which roughly runs from May to October, it is easiest to see game as animals congregate around permanent water sources like the Chobe river and waterholes, while foliage is sparse. Also the skies are generally clear, rain is rare and there are fewer mosquitoes. Even though most tourists visit during the dry season, the area is still relatively uncrowded, except for Chobe's riverfront.

The tourism low-season (with lower rates as well) runs from October to April. This period is hot and humid. Roads may become impasSable due to the sticky mud, and lodges and camps may have to close down for a few months, especially between the wettest months of December-February. The safari experience during this period is still great though. The rainy season attracts a huge influx of migratory birds, such as pelicans or storks that arrive here in the European winter. Also most animals give birth during this period, as the landscape is lush and there is an abundance of food. The wildlife experience is different but not less if compared to the tourism high-season.

Most safaris are organised around the twilight zones in the early morning and evening, when most animals are active and the daylight is at its best for making photos. Though wildlife can still be seen during daytime, the safari experience is generally less spectacular, as the animals are mainly resting or grazing, while some may regard the daylight too bright for photo safari's.

\subsubsection{Tourism-use depending spatial factors}

Besides tourism high and low seasons, also high, medium and low tourism-use zones can be recognized within the Chobe District. These zones are characterised as:

- Tourism high-use zones: location(s) with concentration of (non)permanent lodges and other tourism-related infrastructure, and a relatively intense road-network for safari-drives.

- Medium-use zones: some solitary (non)permanent lodges, an extensive road-network for safaridrives.

- Low-use zones: some wildlife camping and a low-density road network to pass through mainly.

\footnotetext{
${ }^{11}$ Analysis of best African safari parks; 3008 reviews between 2013-2016 on 138 parks in the 8 major African safari
} destinations https://www. safaribookings.com/blog/258\#top-50. 
Table 21 gives an indication of present tourism-use of the different zones, Figure 50 shows the tourism infrastructure (lodges and campsites) in the District.

Tourists can become disappointed in the safari-product if they expect an 'unspoiled' wilderness experience at the Chobe Riverfront, due to crowding in this zone. An improved visitor and ecological management of this zone will result in a more sustainable tourism development. The most suitable zones to decrease the visitor pressure in the Chobe Riverfront are those that provide similar wildlife experiences and/or are relatively close to Kasane Airport. These zones are the Chobe Enclave and Chobe Forest Reserve to the southwest of the Riverfront and the Kasane FR and Kasane Extension FR to the southeast:

- The Chobe Enclave is sandwiched between the Linyanti river and its marshes and the Chobe FR. Its potential for wildlife experiences is quite similar and spectacular as compared to the Chobe Riverfront.

- The Chobe Forest Reserve has a good road network, as well as it has good potential for bird watching and game viewing.

- The Kasane Forest Reserves and Extension are easily accessible and suitable for game drives, camping and safari walks. There is no need for permanent structures here as the FRs are close to Kasane, Kazungula and Lesoma.

Table 21 Indication of present tourism-use within the different zones of the Chobe district

\begin{tabular}{|c|c|c|c|}
\hline & Zones Chobe district & $\begin{array}{l}\text { Area } \\
\text { (ha) }\end{array}$ & $\begin{array}{l}\text { Indication present } \\
\text { tourism use }\end{array}$ \\
\hline $\mathrm{CH} 1-\mathrm{N}$ & Chobe Enclave-North & 88.630 & Medium \\
\hline $\mathrm{CH} 2-\mathrm{CFR}$ & Chobe Forest Reserve & 137.200 & Low \\
\hline $\mathrm{CH} 3-\mathrm{R}$ & CNP River Front & 40.000 & High \\
\hline $\mathrm{CH} 3-\mathrm{NG}$ & CNP Ngwezumba valley & 207.000 & Low \\
\hline $\mathrm{CH} 3-\mathrm{SAV}$ & Savuti Marsh and plains & 259.100 & High \\
\hline $\mathrm{CH} 3-\mathrm{CHAN}$ & CNP Savuti West \& Channel & 149.000 & Medium \\
\hline $\mathrm{CH} 3-\mathrm{SE}$ & NP Southeast & 223.900 & Low \\
\hline $\mathrm{CH} 5-\mathrm{KAK}$ & Kakulwane Plains & 115.500 & Low \\
\hline $\mathrm{CH} 6-\mathrm{KAZ}$ & Kazuma Forest Reserve & 17.900 & Low \\
\hline $\mathrm{CH} 7-\mathrm{MAI}$ & Maikaelelo Forest Reserve & 53.800 & Low \\
\hline $\mathrm{CH} 8-\mathrm{PW}$ & Pandamatenga-West & 81.300 & Low \\
\hline $\mathrm{CH} 9-\mathrm{PN}$ & Pandamatenga-North & 57.300 & Low \\
\hline CH10-PE & Pandamatenga-East & 21.200 & Low \\
\hline $\mathrm{CH} 11 / \mathrm{CH} 12-\mathrm{NU}$ & Nunga WMA & 232.200 & Low \\
\hline $\mathrm{CH} 13-\mathrm{SIB}$ & Sibuyu Forest Reserve & 116.300 & Low \\
\hline
\end{tabular}




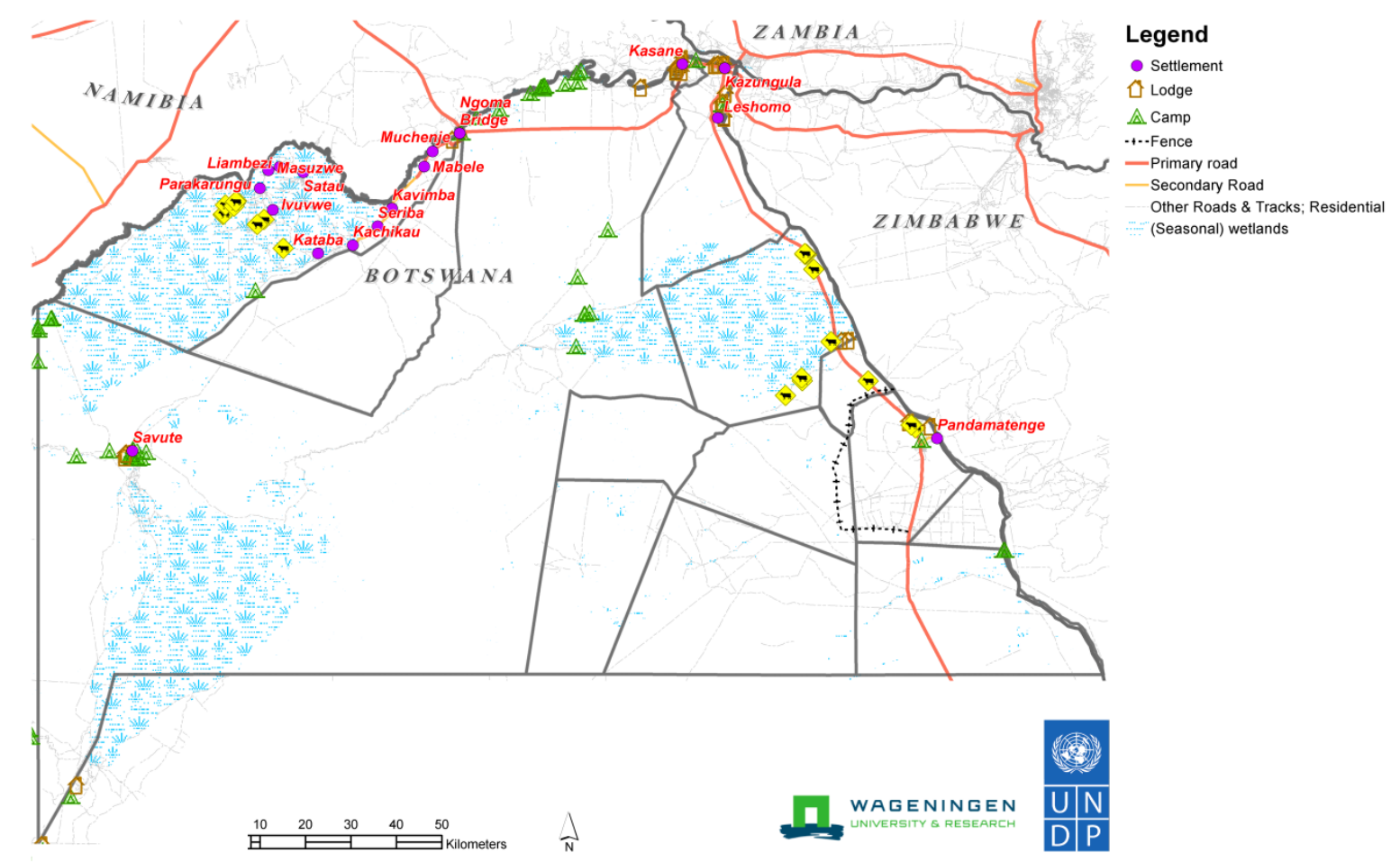

Figure 50 Tourism infrastructure in Chobe District

\section{Tourism high-use zones}

At present two zones within the Chobe district can be regarded tourism high-use zones: the Chobe River Front ( $\mathrm{CH} 3-\mathrm{R}$, Kasane-Serondela-Ihaha area) and to a lesser extent the Savuti Marsh and plains (CH3-SAV). The Kasane-Kazungula township ( $\mathrm{CH} 4-\mathrm{KK})$ is also a high-use zone, but it is urban and therefore different from the natural areas.

The Chobe Riverfront (40,000ha) consists of lush floodplains and dense mahogany, Zambezi teak and other hardwood timber species, which are now largely reduced by heavy Elephant pressure. The Chobe River is a major watering spot for large herds of Elephants and vast numbers of other wildlife like Buffalos, Crocodiles and Hippos. The floodplains are the only place in Botswana where the Puku antelope can be seen. Birding is also excellent here with among others various species of birds of prey, spoonbills, herons, ibis, cormorants, storks, ducks and other waterfowl. This is likely Chobe's most visited area, also because of the proximity to the other major natural attraction, the Victoria Falls in Zimbabwe, and the proximity to Kasane and its airport. Roughly $90 \%$ of the tourism facilities (lodges, jeep and boat safari's, roads etc.) in the Chobe district are located in and around the Chobe Riverfront.

Though the opportunities to see wildlife during the tourism high and low-season are great, there is also serious concern about negative impacts of present high tourism numbers. Not only for its impacts on the natural environment, but also for its impacts on the 'unspoiled' wildlife experience of the safari tourists.

The Savuti Marsh and plains (259.100 ha) in the west of the Chobe National Park ( 50 km north of Mababe Gate) is fed by the erratic Savuti Channel, which dries up for long periods then curiously flows again (see par. 5.4). The extensive savannas and rolling grasslands attracts large herds of herbivores and the area is known for its large packs of Lions and Wild dog, but Cheetahs may be visible as well. Birdlife is especially rich during the wet season. The area is reputed for its annual migration of Zebras. This zone has a relatively well-developed tourism infrastructure, with 170 kilometres of game viewing roads. The northern part of the zone has two lodges, five mobile sites and one public camping site. Besides, there is a staff camp of the Department of Wildlife and National Parks (DWNP), an air strip and three artificial watering points near the camping site, Marabou pan and Rhino Vlei. 


\section{Tourism medium-use zones}

The Chobe Enclave-North borders the Linyanti river and has quite similar features compared to the Chobe River Front in the east. This zone is within one hour drive on tarmac road from Kasane. The area is covered with riverine and open woodlands, lagoons and floodplains. Wildlife is diverse and abundant with many bird species, large predators and herbivores, among which the rarer Red lechwe and Sitatunga antelopes. At present this zone can be considered a medium-use zone. Currently two tourism camps are operating here (Muchenje Campsite and Mwandi View) as well as some community camping, cultural activities etcetera. Also the area of the Savuti Channel is a medium-use zone, due to the potential to see large numbers of game, and presence of good accommodation facilities nearby. Other zones close to $\mathrm{CH} 3-\mathrm{R}$ also have potential but lack the riverine wildlife and views.

\section{Tourism low-use zones}

The remainder of the Chobe district, roughly 1.6 milLion ha, can currently be considered tourism lowuse zones. There are few game viewing roads that pass through. Wilderness camping is allowed at some sites. Forest reserves bordering the Chobe National Park have been allocated for local communities, also to undertake tourism related activities. Safari companies are already taking their clients to the Kasane FR and the Kasane Extension FR (CH4-FR).

\subsection{Infrastructure}

According to the National Settlement Policy, Kasane is designated as a secondary settlement, thus commanding a population of less than 10,000 inhabitants. This consequently restricts the type and level of infrastructure that can be provided for the township itself and subsequently any other place within the Chobe district. For instance there is no fire engine and the township relies on such services from as far as Francistown. The second largest village being Kazungula has a population of just over 1,000 inhabitants and is classified as Tertiary II Centre and therefore grossly limited in terms of provision of physical infrastructure by relevant authorities, especially Council and Government.

The Chobe District is not much developed when one considers the extent of infrastructure and the size of the district. Being the hub of the tourism industry, which is the second largest as regards the contribution to Botswana's economy, and therefore a substantial income earner for the country, the district requires massive upgrading. The positioning of Kasane as a township that links four countries of Zimbabwe, Zambia, Namibia and Botswana, is strategic and requires attractive infrastructure to boost the travel and tourism business potential. The recent investments by the Botswana and Zambian governments in the Kazungula bridge is a major contribution to infrastructural development in the Chobe district.

Medical care is also a consideration for international visitors, currently there is no sizeable private medical facility. The Government-owned Kasane Primary Hospital is inadequate to meet the needs of the residents and the increasing number of visitors and tourists.

The road infrastructure beyond Kavimba all the way to Parakarungu is still earth. Although it has been mentioned or planned in the past that the road to Maun should be tarred, there are no actual plans, and realisation of this road would be harmful and conflicting with the tourism development.

\subsection{Mining}

Chobe District has very limited materials for sand, gravel and stones. Mining activities are mainly concentrated at Kazungula borrow pit and at Lesoma, which are on the Forest Reserve (Chobe District Council 2010). The big Kazungula borrow pit is located near the Botswana-Zimbabwe border post, to supply the Kazungula bridge project with minerals. The borrow pit in the Kasane Forest extension was started legally but is currently illegally operating (Ecosurv 2016). Some smaller borrow pits for road construction are located in the Chobe Enclave and are managed by the District Council.

Two companies are operating quarries, one situated near Mabele, the second near Lesoma. Both mine industrial minerals such as dimension stone, sand and clay. 
Currently no other mining takes place, but there are exploration permits, mostly in the central part of Chobe District within the National Park and Forest Reserve boundaries. Three types of mineral prospecting licenses have been issued for Chobe District: industrial minerals, energy minerals and energy. The prospecting licenses are indicated in Figure 51.

The 13 prospecting licences PL044/2014-PL056/2014 (metals) are held by Henan Yukuang Mining Company (Pty) Ltd and will expire on the $31^{\text {st }}$ December of 2017. In the area of Savuti a prospecting license for metals is held by Henan Afro-Asia Geo Engineering (Pty) Ltd.

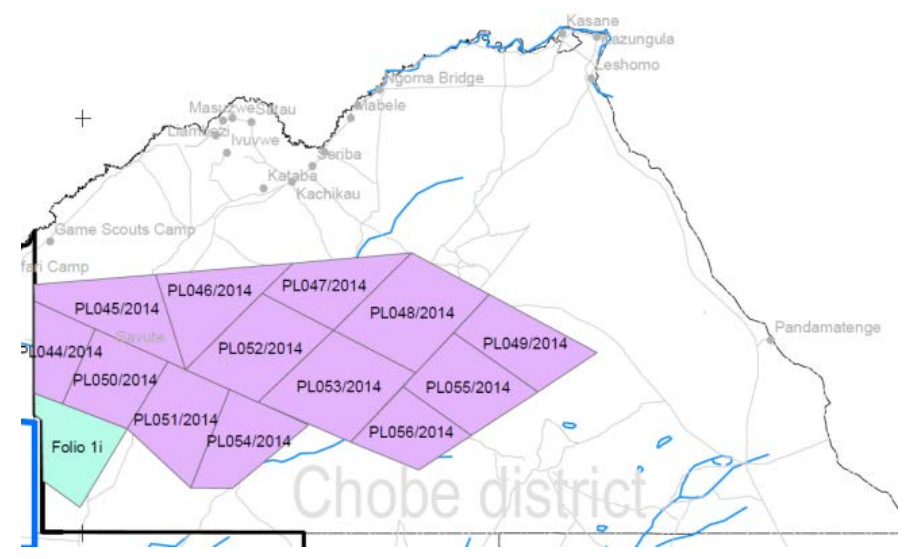

Figure $\mathbf{5 1}$ Mining exploration licences in Chobe

\subsection{Key findings}

- Farming is in the communal areas the dominant land use;

- Arable farming is very dynamic, and continuously adapting to the environmental conditions relating to floods and rainfall patterns;

- Smallholder farming is concentrated in three areas: the Northern part of the Chobe Enclave, at Lesoma and around Pandamatenga;

- Commercial farming has - after initial problems- overcome the starting problems in land management and economic profitability;

- Horticulture and other forms of diversification is still limited;

- There is no commercial timber harvesting, but firewood collection is important for poorer segments of society;

- Wildlife is abundant in the district, and corridors are very important for the necessary wildlife migration between different areas;

- Human-Wildlife Conflict is one of the core problems in the Chobe District, affecting most households and all communities;

- Conflicts have increased as a result of human expansion in the wildlife corridors and dispersal areas, both in Kasane-Kazungula township and in villages such as in the Chobe Enclave;

- There is spatial variability in fish productivity in the Chobe system where Kwando River is the least productive system while Linyanti River is the most productive;

- Tourism is an essential part for Botswana's economy, and expectations' are that it will strongly increase in the coming decade;

- Insufficient planning of tourism, in particular in CNP, results in pressures that should be addressed. 


\section{$9 \quad$ Environmental pressures and risks}

\subsection{Key pressures}

The consultants team had a workshop in Maun (November 2016) to discuss the environmental pressures and important issues regarding land use and zoning. This paragraph presents the ten most important pressures on the Chobe environment that were identified. The areas where these pressures are prevalent are located (spatially) on a map of Chobe District. The pressures (not in a hierarchical order) are:

1. Competing claims: Human-wildlife competition

2. Wildfires

3. Cross-border commercial poaching

4. Unregulated access to the National Park and Forest Reserves

5. Human-wildlife conflicts (Elephant and crops, boating \& birds and Hippo's)

6. Lake Liambezi, fishing versus farming

7. Kasane \& Kazungula expansion, transport hub versus wildlife migration

8. Urban development \& riverfront vegetation

9. Tourism pressure on biodiversity

10. Borehole development vs. sustainable size of wildlife populations

Figure 52 indicates where the pressures occur, the pressures are explained below.

We see that a lot of pressure exists along the Kwando-Linyanti-Chobe River, as well as along the main road from Kazungula southwards. And where those two axes meat, Kasane-Kazungula, seems to be most intense with regard to development issues.

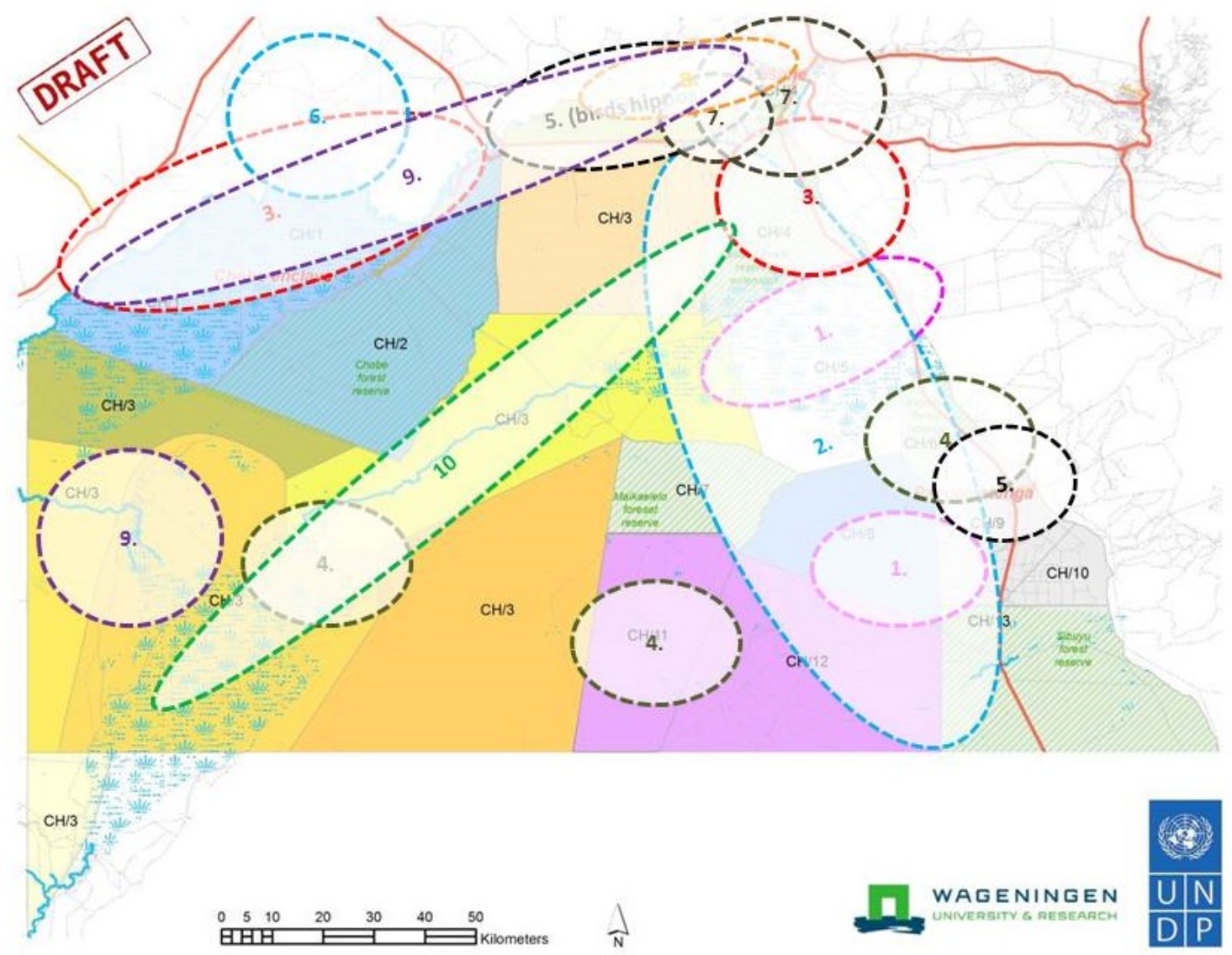

Figure 52 Top-10 environmental pressures, as identified by the research team 


\section{Competing claims: Human-wildlife competition}

Three specific areas have been identified as area for agricultural expansion: the Chobe Enclave, Kakulwane Plains (North of Pandamatenga) and the area adjoining Pandamatenga to the West. The Chobe Enclave (northern part) has for many decades been an area of mixed farming activities, as explained in par. 8.1. Another area identified for farming, and currently still undeveloped, is the Kakulwane Plains (Northern plains). Residents from Lesoma also indicated their interest in expanding farming in this area. Finally, the plains West of Pandamatenga: feasibility studies are currently finalised for irrigated farming here (§ 8.1.3). All these areas have reported high numbers of wildlife, which is also underlined by the Human-wildlife conflicts which are prevalent, and can also be explained from wildlife migration.

\section{Wildfires}

Wildfires have been frequently occurring in most of the district, but the highest frequency seems east of the road Nata-Kazungula, with the prevailing winds towards the East. These wildfires may pose a risk to the regeneration of the dry forests in this area. This is further discussed in $\S 9.2 .4$.

\section{Cross-border commercial poaching}

There is a high incidence in some regions of commercial poaching. The economic conditions in neighbouring countries, the absence of border control in some areas, but also the high prices paid for ivory and in some cases meat, results in increased pressure from poachers. Poaching is in particular prevalent along the Linyanti river, which is easily crossed when the river is dry or with local mekoros, but also in the Lesoma region. Illegal wildlife off-take is further discussed in $\S 10.4 .4$.

\section{Unregulated access to the National Park and Forest Reserves}

Facilities for tourism are spread thinly, campsites are limited and sometimes expensive. Visitors tend to take access to some of the less visited parts of the District. Some sites are promoted via internet, even with coordinates and directions of how to get there. This unregulated access results in decreased income for Park Authorities, uncontrolled developments and even increased risks of fires or incidents with wildlife. Issues of visitor management and infrastructure is discussed in $\S 10.2 .3$.

\section{Human-wildlife conflicts (Elephant and crops, boating \& birds and Hippo's)}

Conflicts with wildlife can be related to the raiding of crops by Elephants (e.g. around Pandamatenga, and many other locations such as around Mabele or Kavimba). This is one of the most pressing issues, discussed in $\S 10.4$.3. There is also pressure from visitors on wildlife populations, physical impacts of engine and boat wake, noise, and visual impacts. The density of boat traffic along the riverfront and backwaters around Kazungula/Kasane, and well into the Chobe National Park has increased radically. Deleterious aesthetic impacts are affecting the image of the Park, and cause stress on wildlife, from shore-birds through to large mammals (see $\S 10.2 .3$ ).

\section{Lake Liambezi, fishing versus farming}

The variability in Lake Liambezi requires adaptive management, and adaptive land use practices. In years of flooding, fishing is an important activity in the Lake Liambezi area, resulting in local trade in fish and additional income for families. Yet when it is dry, it provides an opportunity for farmers to grow crops on more fertile soils. It requires local households to shift between different forms of land use, constant interaction with the environment. It is important that flexibility be built into the use of this area, and that both householders and planners remain aware of longer-term fluctuations so that land does not become locked in to a particular use that 5 years later is not available.

\section{Kasane \& Kazungula expansion, transport hub versus wildlife migration}

The pressure from the urban developments on the forest zone around Kasane and Kazungula, which coincides with the construction of the bridge to Zambia and the development of a transport hub for truck transport to Central Africa, affects wildlife populations as well as migration corridors such as the Sable migration along the Zambezi river. Urban sprawl and development is discussed in § 9.3.

\section{Urban development \& riverfront vegetation}

The riverfront area in Kasane and Kazungula is in high demand, for residential and commercial purposes. Riverfront plots extend their fences up to the river and sometimes riverine vegetation is 
removed or opened to improve the view. Construction activities further reduce the vegetation. In the proposed Kasane-Kazungula development plan, a walking trail along the river is proposed. At the same time this zone is important habitat for species like bushbuck, sometimes Elephants, Hippo's and many bird species. This is further discussed in $\S 10.6 .1$.

\section{Tourism pressure on biodiversity}

Tourism pressure is not equal over the district: the pressure is particularly high near Kasane along the river, gradually decreasing towards Ngoma bridge. There is an increase in tourism development in the Northern part of the Chobe Enclave. The tourism pressure is also high around Savuti and Savuti Marsh with a large number of tourism operators here. Visitor management is discussed in $\S 10.2 .3$.

\section{Borehole development vs. sustainable size of wildlife populations}

Borehole development takes place in the Chobe National Park, in particular along the Ngwezumba River Channel, Nunga River Channel, and Savuti. This takes some (Elephant) pressure of the riverfront area, and increases also the tourism opportunities in areas which are currently little visited. However, there is no conclusive evidence of the negative impact of the permanent wildlife grazing pressure on the vegetation in this area, nor on the wildlife population size This is further discussed in $\S 10.5 .4$.

\subsection{Changing environment}

The larger context comprises here impacts of global change, as well as impacts related to natural climatic and hydrological variability. An additional and important factor are the environmental changes and pressures arising broadly due to increasing population, and the series of feedbacks in the humannatural environment system such changes initiate.

\subsubsection{Changes and risks arising due to human activities within the District}

As a general principle human development results in an ever increasing demand for natural resources which, paired with more vulnerable natural system, may result in exceeding threshold levels and environmental degradation. Environmental degradation and change may arise in underdeveloped communities too due to lack of development of livelihood alternatives and income generation for communities, resulting in poverty and indiscriminate misuse of environmental resources. This may, in turn, lead to a feedback loop, where a degraded environment further jeopardizes economic activities (e.g. natural resources, or ecosystem-services based) which otherwise may facilitate poverty alleviation. The Chobe District in this context is very special as it represents a mosaic of unique protected wildlife areas that experience increasing pressure from tourism, rural areas under increased human exploitation, but with a function for wildlife too, and urban areas also with wildlife component attached (e.g. urban wildlife corridors). Also the Chobe District is a very dynamic area, where humaninduced changes have occurred at different spatial scales over a time span of decades (e.g. rapid expansion of tourism) to centuries (recovery of wildlife after $19^{\text {th }}$-century large scale hunting and the early $20^{\text {th }}$-century rinderpest epidemic). These anthropogenic changes were often compounded, but sometimes compensated for by the natural processes of ecosystem transformation in response to evolving, or fluctuating climatic and hydrological forcing.

A number of issues could be identified that relate to man-initiated environmental changes which create further risks, but can be addressed, at least partly, within the integrated land-Use planning of the Chobe District:

- Land shortage in the district leads to direct conflicts with other forms of land-use (wildlife - versus agriculture, wildlife versus urbanisation, tourism versus wildlife).

- The Chobe Forest reserves play important functions (food, dispersal) in the carrying capacity of the wildlife ecosystem and reserves are important sources of biodiversity and genetic resources, but there are claims for future exploitation (urbanisation, arable agriculture and, Livestock farming, tourism).

- Livestock grazing may locally result in resource depletion, as well as conflicts with other land use (wildlife, farming, NTFPs).

- Wild fires can cause resource deterioration, and possibly long-term environmental changes. 
- Expansion of tourism, while being the most important socio-economic activity in large parts of the Chobe District, may in some areas be close to its maximum capacity (photographic tourism in the Chobe Park riverfront and river), considering the resource base.

- Human health (incl. zoonosis), livestock interests and agriculture and veterinary concern need consideration in integrated land use planning.

- Re-planning of the Kasane-Kazungula urban build up area near the river opens up the opportunity for green city and wildlife corridor planning.

- Blocking of wildlife dispersal routes as a result of commercial urban development and roads should be avoided or redressed.

\subsubsection{Climate or hydrology-related changes}

In order to shed some light on the possible environmental changes arising due to anthropogenic climate change, future climate conditions in the Chobe region are assessed here specifically for this project based on climate change projections available from CMIP5 archive (Taylor et al. 2012). This archive is a cornerstone for the IPCC AR5 report (IPCC, 2014), the most comprehensive assessment of anthropogenic climate change and its global and regional consequences that is currently available. The assessment presented here focuses on RCP8.5 emission/development scenario, which is considered to be the most realistic out of the scenarios included in the IPCC AR5 (Peters et al. 2013).

The assessment of possible future conditions is based on an ensemble of projections from 16 different global climate models (GCM). The illustration of projections is based on the so called "plume" plots (Wolski et al. 2016). These plots present time series of regionally averaged variables (for each of hydrologically-relevant regions, introduced in the section describing District's climate) and highlight statistical significance of departure of their future projected values from values observed in the recent past. In this way, plume plots allow for:

- illustration of convergence/divergence of the ensemble,

- distinguishing the change signal from natural variability,

- capturing timing of emergence of change signal,

- Capturing spatial heterogeneity of the signal.

Plume plots for rainfall for the three basins are shown in Figure 53.

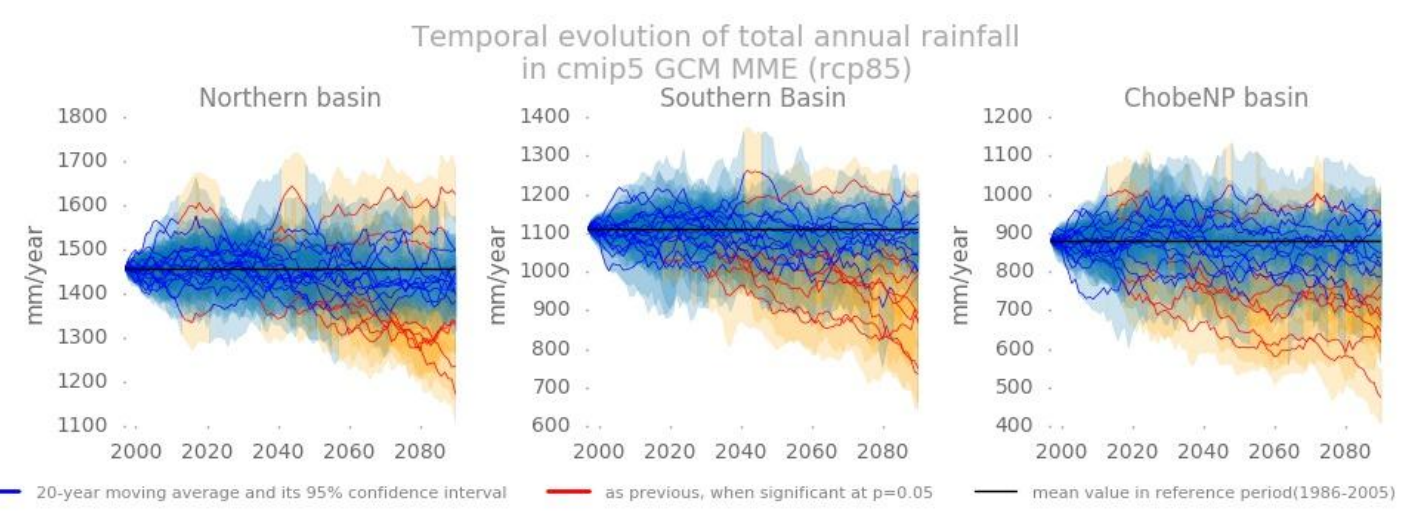

Figure 53 Plume plots, total annual rainfall. Individual lines represent 20-year moving average of total annual rainfall projected by individual models (members) of the ensemble. The band around each line represents confidence interval of the running mean. The band and the line changes colour to orange/red, when departure from the variable's value in the reference period (1990-2010) reaches statistical significance at 95\% confidence level (Wolski 2016) 


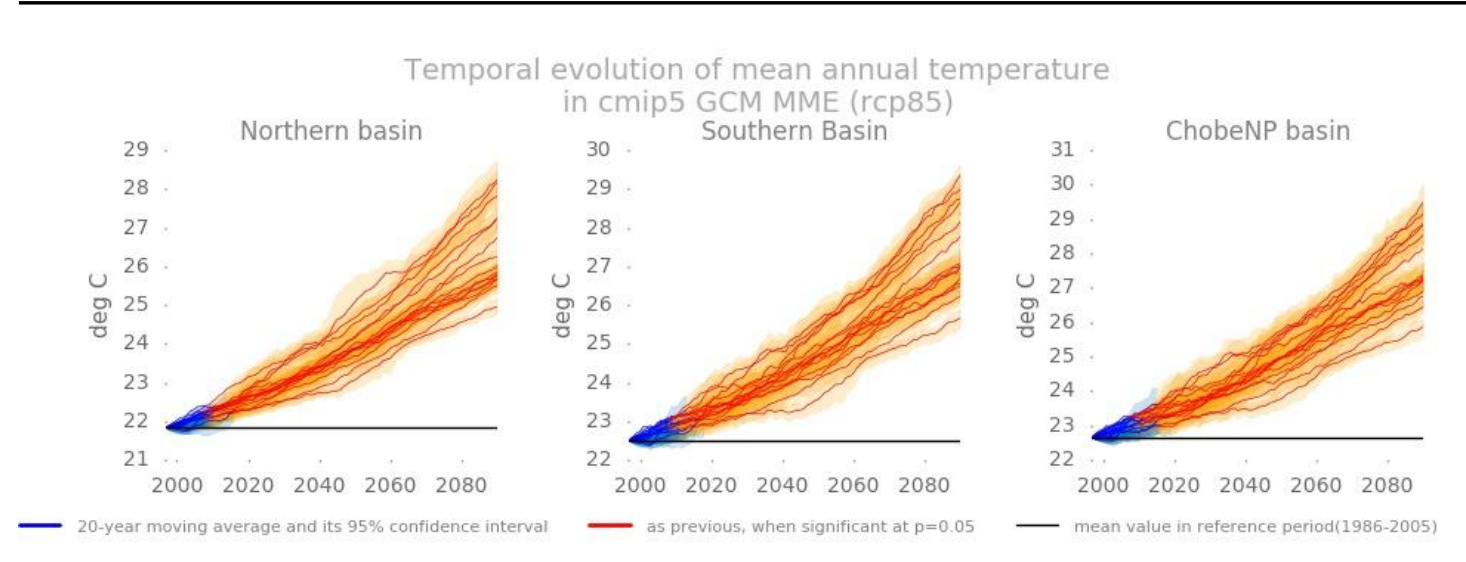

Figure 54 Plume plots for mean annual temperature. Explanation as in Figure 53 (Wolski 2016)

To summarize information in Figure 53 and 54:

- the projections by individual ensemble members consistently indicate an increase in air temperature throughout the $21^{\text {st }}$ century, although there is a considerable uncertainty about the magnitude of that change. The increase may be reaching 3 to 6 deg. $C$ by 2100 in each of the considered regions.

- Rainfall projections appear much less consistent across the ensemble members, i.e. there is no agreement between individual GCMs in terms of direction, timing and magnitude of future climate change. However, there seems to be a signal of rainfall reduction emerging between 2025 to 2060 . Importantly, the weak signal in rainfall magnitudes does not mean that there are no consequences from water resources or broadly environmental point of view. The impacts will be manifest through the compound effects of rainfall and temperature, i.e. through increased evaporation.

Changes and risks arising in the hydrological system can be summarized as follows:

- Anthropogenic climate change, in spite of relatively weak signal in rainfall, will, through increased evaporation loses, cause changes in the hydroperiod in the distal parts of the Chobe and Linyanti system, with associated wetland loss, and implications to wildlife.

- Climate change causing extreme climatic events exacerbating extreme situations, and compounding effects of long-term variability in e.g. flooding patterns and vegetation.

- Climate change driven reduction of groundwater recharge, groundwater table drop, increase in salinity, also impact on vegetation tapping groundwater (e.g. in the vicinity of ephemeral rivers, but also within savanna uplands).

- Shorter inundation of pans under climate change, with consequences to wildlife movement

- Savanna and wetland vegetation and land cover transformation under changing climate due to $\mathrm{CO}_{2}$ fertilization. This is particularly difficult to assess without dedicated studies, as that transformation is a results of multiple change vectors.

- Reduction in runoff in the Ngwezumba headwaters due to human activities and/or climate change with possible reduction of flood events of the Ngwezumba, thus loss of replenishment of river bed aquifers with associated loss of water source, changes in wildlife migration patterns etc.

- To our knowledge, there are no plans for hydroelectricity development in the upper Zambezi and Kwando Rivers, but there is potential for irrigation offtakes (World Bank, 2010). Since both Zambezi and Kwando are perennial, this, if implemented, will be based on run-of-the-river schemes, thus causing withdrawals during the climatological dry season (May-October). Such operation may cause changes in the hydroperiod in the distal parts of the Chobe and Linyanti system, with associated wetland loss. Assessment of the impacts and magnitudes is beyond the scope of this work. Possible is a reduction of the hydroperiod on annual, and wetland extent at interannual to multidecadal time scale, cessation of hydrological connectivity, with wildlife/ecological implications.

- Also, one has to consider possible impacts due to geomorphological evolution of the system possible redistribution of Kwando/Linyanti waters towards the west, or alternatively, increased inflows from the Okavango through Makgwegkwana.

The integrated land use plan can play a role in mitigation of some of these impacts and changes. 


\subsubsection{Overgrazing}

Reports of overgrazing are old, already in 1937 Miller reported about the need for a sand stabilization project in the Chobe Enclave - and evacuation of the people (Child 1968).

Notwithstanding the many reports mentioning overgrazing (Ecoserv 2014), the situation in Chobe District is not as bad as other parts of Botswana. Even at the end of the dry season most areas still have fodder, only near water sources the soil is almost bare. This is observed in some areas of the Chobe Enclave - notably along the escarpment and near water points at Parakarungu and Satauwhere the highest livestock numbers are found (around 3,000 head of cattle, Table 18) as well as in Chobe national park, along the river front. Also around some of the boreholes in Ngwezumba valley there were signs of heavy grazing pressure. The overgrazing can thus be caused by livestock or wildlife, or a combination in some cases.

Wind erosion is observed in the Enclave, and some surface erosion along the river where no vegetation protects the sloping ground. Moreover, the Elephant pressure results in a dramatic decrease in shrubs and tree cover, the Consultants observed in several locations a larger number of dead trees (lying trees) than standing trees (see also 5.3.4).

The impact of overgrazing can be a change in vegetation composition, usually an increase in poorer grasses, mostly annuals, and change in shrub composition. The forest cover can disappear, with shrub encroachment, indicating land degradation. Valuable natural resources, in particular NTFPs, often decline. Shrub encroachment was reported by Child (1968) in the Chobe National Park and in Savuti and the Mababe depression, as result of past overgrazing by livestock.

Overgrazing also results in siltation of streams and wetlands, and consequent change in wetland species and e.g. fish resources.

\subsubsection{Wild Fires}

Wildfires are an inherent component of all drier tropical ecosystems. Already in the nineteenth century it was common practice in the Chobe area to set veld fires in the dry season for the purpose of hunting. Fire impacts depend on the time of fire and its return time, with more moderate impacts at a return time of 3-4 years on tree cover than at 1 year return times. Built up of grass fuel load across years does not or hardly occur. Increased fire intensity and impact through built up dead wood biomass is anecdotal in evidence and not substantiated in the fire experiment literature (see e.g. Veenendaal et al. 2017 for an oncoming review). Grazing reduces fire impact through reduction of biomass. Fire impact on woody vegetation cover can be enhanced long term, if forest cover has been opened up through e.g. forestry operations, as took place in the Kasane Forest and Forest extension. Fire also occurs in the Chobe enclave where it may be used as a grazing management tool.

Whilst natural fires ignited by lighting events and even human fires, with a return time of 3-4 or more, may be of lower impact or even beneficial to Miombo woodlands, the current situation is different in a number of areas in the planning area (Figure 55). The map shows the total 'fire count' in the period 2001-2012, the number showing the interval between fires. Fire records from Chobe District indicated that the wild fires are, as elsewhere in Africa, almost exclusively started by people (NFS, 1992). Fires occur predominantly during the cold to hot dry season between April and October, when no lighting storms occur, but instead where people purposefully or accidently ignite a fire. People can be prosecuted and fined for negligence in starting fires in Botswana, which results in most fire reports describing an unknown origin. The causes vary widely, but known and suspected sources of ignition include; campfires, discarded cigarettes, vehicle fires, hunters, safari expeditions, wildlife poachers, field burning, intentionally set fires by villagers and also fires that cross from neighbouring countries (e.g. Zimbabwe) (Perkins, 2015).

Most fires occur in the Eastern part of the planning area with a present fire return time of $2-3$ years but with a particularly high 1-2 years frequency along the Kazungula Nata Road in CH4 (comprising the community area of Lesoma and the Kasane forestry extension). During the fire season fires tend to start in the East and travel to the West due to often strong Easterly winds during this period. The fire break on the Western side of $\mathrm{CH} 4$ appears effective in reducing bush fire spread. Since $\mathrm{CH} 4$ has a history of past logging activities, fire protection efforts may be important here. Also in $\mathrm{CH} 8$ and in the some of the open areas of the Chobe National Park higher fire frequencies are observed. 
The Government of Botswana has instituted a Bush fire operations management plan that rates the risk for different areas based on danger to human life, assets and wildlife and vegetation (MEWT 2016-2017). Critical areas include lodges and campsites while other areas (e.g. Kasane International Airport, Chobe west Power lines, the Pandamatenga farming area and various park elements and forest reserves) are considered to by high risk areas. Fire management is effected through fire management teams and a network of fire breaks.

The Kasane Forest and Forest extension ( $\mathrm{CH} 4)$, having a combination of High Fire risk and a history of past logging practice, should be considered for extra measures to reduce fire. For other areas the immediate impact of fire on natural resources appears less critical if the present bush fire operations plan is maintained.

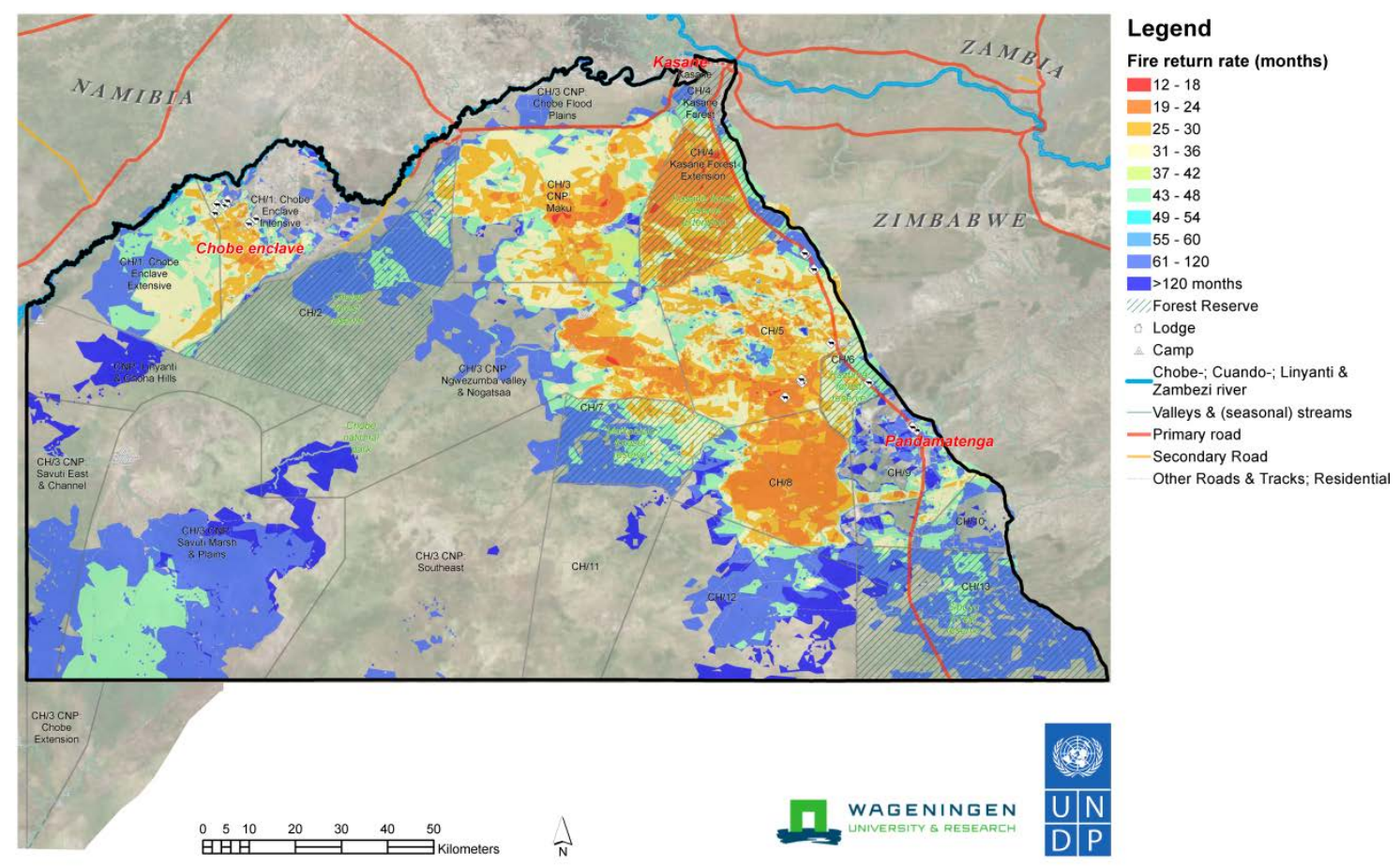

Figure 55 Fire frequency in Chobe District; map based on MODIS data

\subsection{Urban sprawl}

Currently Kasane is a township, with limited urban features. The Kasane-Kazungula re-development plan aims at re-development and densification of the built-up area to give it a more urban and modern look (Figure 56). The Plan allows for high rise buildings within the central part of Kasane. Once the plan has been implemented, it would result with the area in question developed and this would mean that adjacent villages will be under increasing urban influence. Similarly the Chobe District ILUP may create urban sprawl as it would identify additional land for allocation by the Chobe Land Board. A considerable number of these new plots would be for residential, commercial and industrial development.

The urban parts of Kasane and Kazungula area have been identified as areas for re-development in the Kasane-Kazungula Redevelopment plan (2015) and the Kazungula Transportation Hub plans. These plans have been adopted as an important framework for re-development and investment opportunities for what is in the context of NDP11 a major focus for development. From the perspective of the integrated land use plan a number of issues deserve attention. 


\section{Plan Coordination consistency}

In the maps for the Kasane - Kazungula re-development plan the developments of the Transportation hub are not included. Also the total planning area for Kasane-Kazungula is larger than in e.g. the Kasane-Kazungula re-development plan. As an overarching principle, the two plans need to be integrated into one for all developments on the Eastern Boundary of the planning area. The total Planning area must be large enough to allow for the planned economic development as well as for all nature, tourism and transport functions. At present there is no consistency between the two plans. A strongly increased demand for all services related to transport can be expected once the bridge opens. These will need to be planned in detail and with utmost care to allow for the remaining open space near the river to function still as a corridor for wildlife.

\section{Wildlife corridors within the township}

Wildlife Corridors have been planned and are/have been gazetted (Figure 57). Corridors play an important role in the movement of animals to and from the river. They also provide wilderness experiences for the Tourists visiting the townships. Moreover they provide together with the large lodge plots inside and outside the CNP the remaining refuge for the highly endangered Chobe Bushbuck in Botswana. The development plans and initiatives under this umbrella need to respect these corridors and clearly indicate how the corridor areas (minor and major) are integrated. An EastWest wildlife corridor on the North side of the BDF camp will be needed.

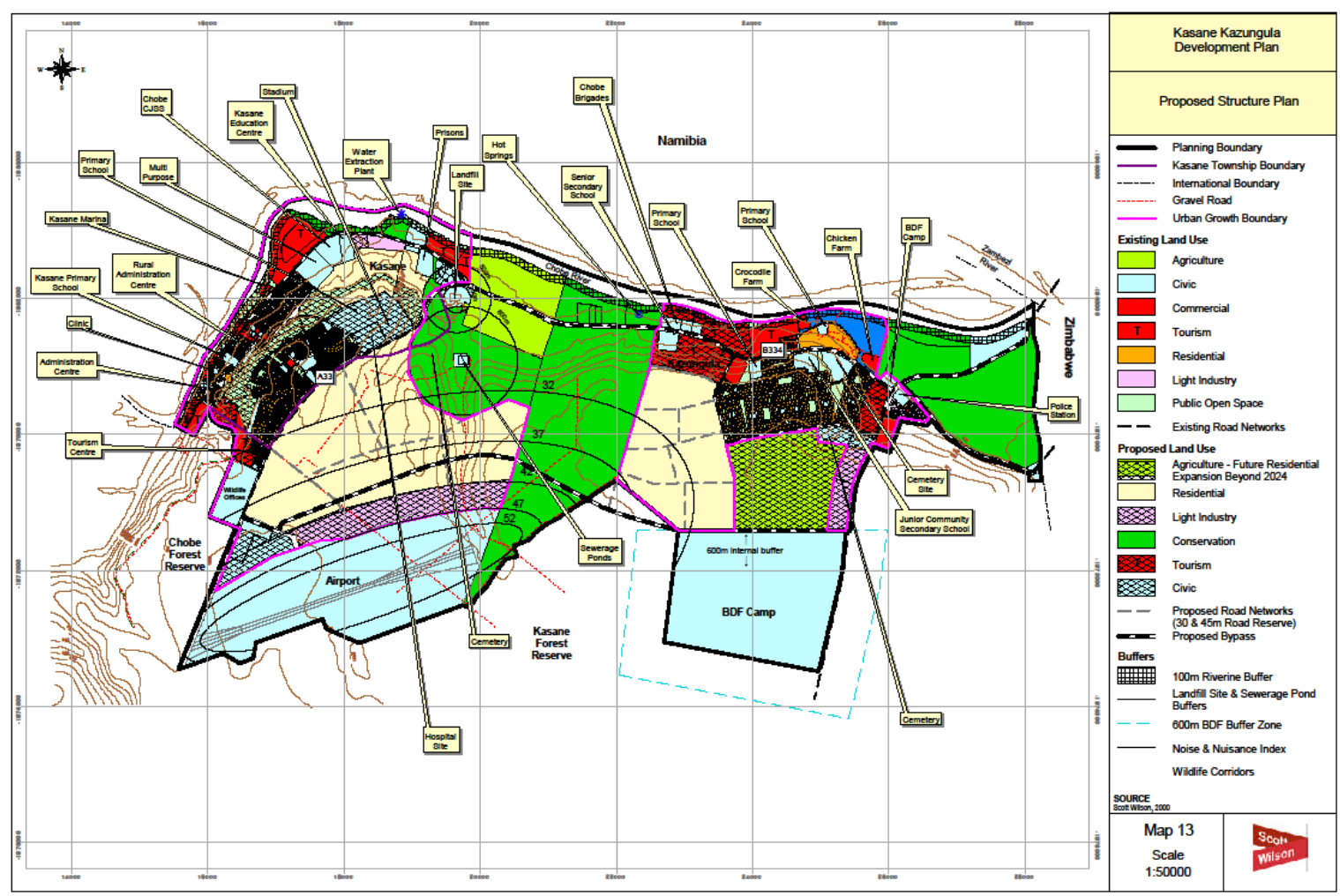

Figure 56 Kasane Kazungula Re-Development Plan, Proposed Structure Plan as at 2009 (Scott Wilson) 


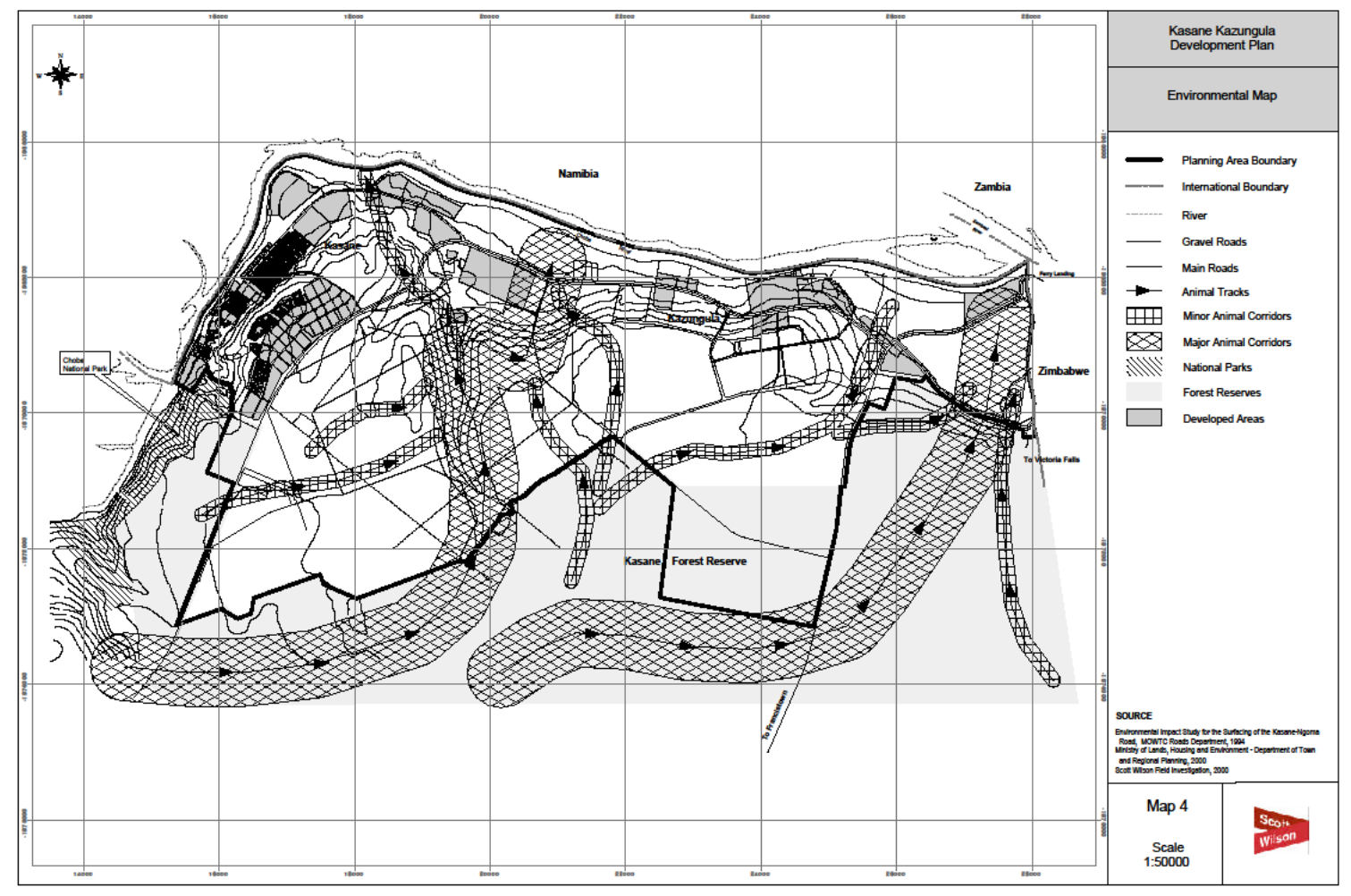

Figure 57 Major and minor animal corridors around Kasane (source Scott Wilson 2009)

\section{Agricultural zones within the Township}

In the current Kasane-Kazungula Development Plan a number of areas, selected on the basis of soil quality and irrigation potential have been reserved and zoned for agricultural use. This zoning has several important functions. 1) A supply of agricultural produce for the townships and tourist industry 2) local employment opportunities for people not working in other sectors; and 3) business opportunities for small to medium scale agricultural entrepreneurs. In addition this form of land-use contributes to the openness and diversity of the peri-urban landscape (in simple words not only residential, shopping complexes and tourist lodges) and thus also to a more complete tourism experience. To retain the diverse quality of the urban landscape as well as a local agricultural production capacity, the agricultural zones in the development plan should continue to be protected against encroachment by other activities (small businesses such as scrap yards and shops, residential encroachment, and hotels and guesthouses).

\section{The Kazungula transportation hub}

Particular attention to the Kazungula junction area needs to be paid to ensure plan integrated functions such as planned wildlife corridors, border facilities and a proposed railroad track. The plans do not take account of the development stimulus that the Transportation hub will bring to an already highly congested area (Figure 58). There are no clear arrangements for the activities (economic, accommodation, parking) that will be needed. More planning in a larger area (e.g. making space by moving the weighing bridge and a developing truck holding areas further away from Kazungula could be considered) is needed to minimise wildlife human conflicts in this important hotspot for development. 
LEGEND

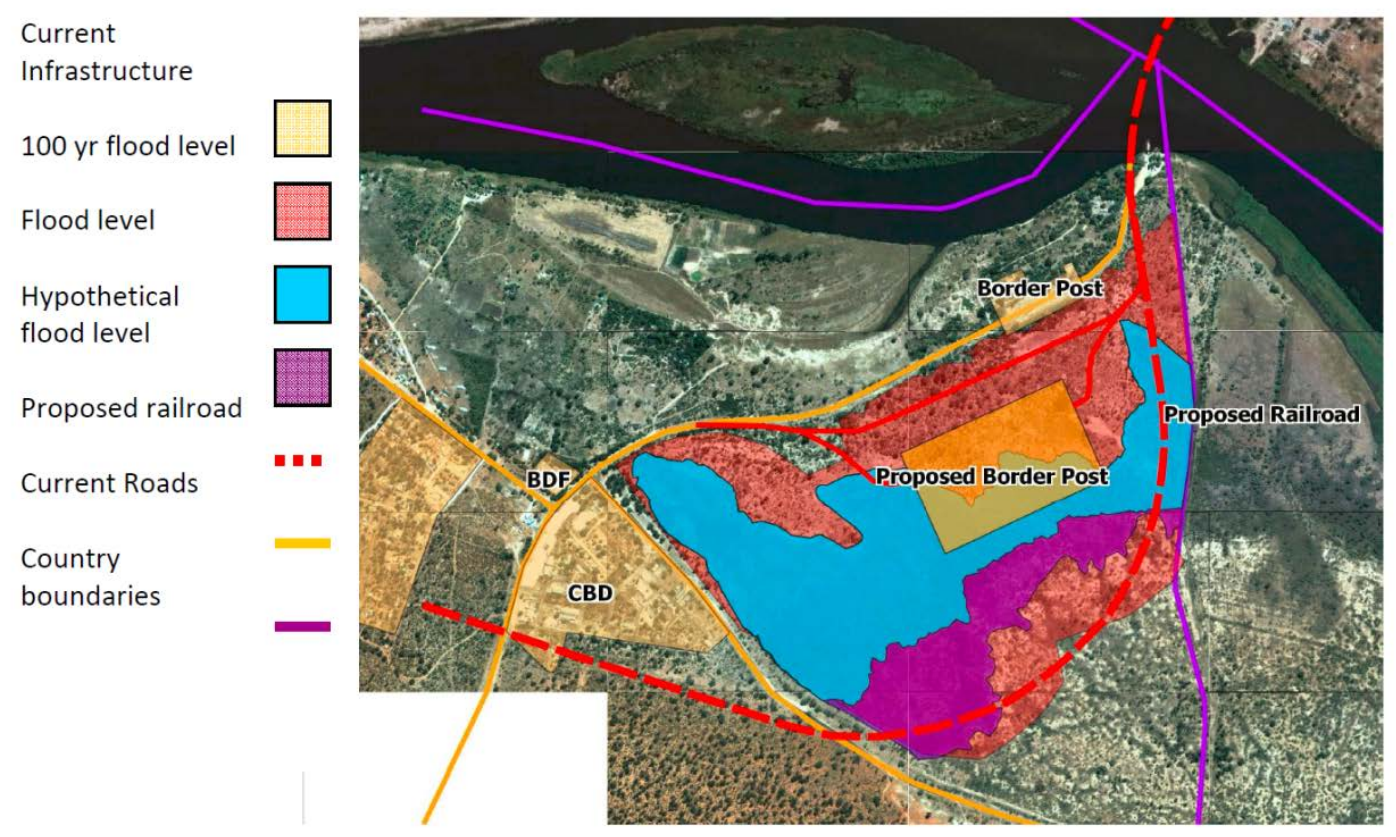

Figure 58 Proposed new border post and railroad, current infrastructure, and water levels (ISP project)

\section{Tourism hub}

The various lodges, hotels, $B \& B$ s as well as the various companies that provide services to the tourism industry, seem now randomly spread over Kasane, and to some extent Kazungula. Some concentration is in the centre of town, and near the major government offices. It is expected that without a proper lay-out for small commercial areas the haphazard development may spread further, which is not efficient, and does not fit the township area as major development centre in the North. Local artisans, craftsman (woman) are either located in small stalls, along the parking lots, or right out of town (women's cooperative). In particular, the small entrepreneurs, but also currently jobless people, could with limited means take part of the local tourism market have in this way no opportunities to partake in tourism.

The new lay-out of the township should better reflect and reinforce the important role of tourism for Kasane-Kazungula. It should provide opportunities for small and medium sized enterprises, in particular local entrepreneurs should be stimulated to develop e.g. as supplier in the tourism industry or services business.

\subsection{Environmental pollution}

Environmental pollution encompasses pollution of the environment by hazardous substances, e.g. chemicals, as well as waste disposal, which relates also to littering of the countryside.

The DDP7 notes already that littering of plastics and waste disposal poses hazard to animal health. It makes the environment unsightly, which also affects tourism. DDP-7 foresees an intensification of public education campaigns on the need to keep our environment clean.

The absence of the Department of Waste Management and Pollution Control (DWMPC) in the District results in issues of proper waste management and control not being taken on board at the initial stages of planning (Chobe District Council 2010).

Only part of Kasane and Kazungula have sewage services. In DDP-7 the Kasane-Kazungula Sewerage scheme which will be implemented.

Kgathi (2003) reported about considerable pollution around Pandamatenga, due to the use of agrochemicals. These resulted in pollution of the soil, groundwater, killing of wildlife and birds, as well 
as posing a threat to humans' health. The situation may have improved due to environmental policies that have been adopted since then, but it is likely that there is still a lot of environmental pressure in this region.

There can be potential chemical or biological pollution arising from houseboats and other boats, but these risks seem somewhat exaggerated. In general terms, this is easily regulated, and the operators of these boats are keen to cooperate with any recommended courses of action concerning waste disposal.

In terms of accidental (or deliberate) spillage the aquatic ecosystem has a high assimilation potential, and so the threat of impacts is neither high (strong probability/high risk), nor large (big effect), nor long-term. Even in the case of emissions from engines, or oil spillage/leakage from engines, the environmental assimilation capacity of the riverine and floodplain ecosystem is more than enough to cope with accidents.

\subsection{Human-wildlife conflict}

\subsubsection{Livestock predation}

A high incidence of Lion damage was reported by Caracal in the Mabele-Muchenje area. The NGO Caracal has been mapping human-wildlife conflicts in the Chobe Enclave, from 1994 till 2002. This provides detailed accounts of the location of incidents. The number of conflicts may not necessarily be up-to-date, but the location and species involved are indicative for livestock predation (Kathleen Alexander, unpublished data 2004).

In 2002 the number of reports showed a strong increase up to 80 incidents, the majority of incidents on the escarpment. Only a few cases per year of leopard kills were reported, between Mabele and Muchenje.

In Parakarungu reported damage was limited, reduced from 12 incidents in 1998 to 1 in 2002. All incidents were south-west of the village, around the cattleposts (Kathleen Alexander, unpublished data 2004).

Carnivores mentioned by communities (other than Lion) that preyed on livestock (in approximate order of severity) were Hyena, Leopard, Jackal, Caracal and Wild dog. Honey badgers were mentioned as problem animals that prey on chickens in Lesoma Village (World Bank 2016).

More recent numbers were provided for the period 2012-2015, in the frame of the World Bank project (World Bank 2016). It is noted that in particular Lesoma is experiencing the highest Lion densities, since it is located in between Chobe National Park and Matetsi game area in Zimbabwe. Lesoma has lower livestock numbers and the number of kills is therefore not so high as in some other areas. The villages in Chobe District are not encouraged to keep livestock and cattle numbers are less in that area.

In support of the World Bank study, DWNP data for the period 2010 to 2015 shows that among the carnivores, Lion are most often reported as problem animals, followed by leopard. Leopard appear to be a much bigger problem in the Chobe Enclave (particularly in the three escarpment villages) than in Chobe East. The highest levels of predation were reported in Pandamatenga, with 67 Lion-related incidents in the past 5 years. This is in keeping with information from current research projects that suggest considerable movement by Lion between Botswana and the protected areas in Zimbabwe. An overview of the number of incidents over the past 5.5 years is given in the SEA for Forest Reserves (ECOSURV 2017). It highlights that Elephant and Lion are most frequently involved in Human-wildlife conflict.

\subsubsection{Crop damage due to wildlife}

One of the biggest challenges to integrated land use is human-wildlife conflict on arable lands, particularly with Elephants. The presence of crops near the protected areas, near rivers and close to wildlife migration routes has resulted in a high incidence of crop damage. Crop damage is mostly attributed to Elephants, Buffalos, warthogs and several antelope species. 
In the past five years, there have been on average between 10 and 25 conflict incidents per year per settlement. In Chobe Enclave, in the escarpment communities of Kachikau, Kavimba and MuchenjeMabele, 93\%, $89 \%$ and $88 \%$ of these incidents respectively involved Elephants (DWNP data, 20102015), whereas in the communities of Satau and Parakarungu Hippo accounted for $68 \%$ and $42 \%$ of problem animal incidents respectively. In Lesoma, all the reported incidents were with Elephant, while in Pandamatenga ${ }^{12}$ Elephant incidents comprised about $55 \%$ of those reported.

Elephants have a daily movement pattern, whereby they generally drink in the evening and spend the night in the vicinity of water bodies, but disperse into the drier woodlands during the day. Villages and cultivated fields are located near the water and much of the crop raiding therefore occurs at night. Cluster farming and Elephant fences is currently considered to be a solution. Initiatives however have not been so successful thus far: it's hard to fence for Elephants, and very expensive. The Ministry of Agriculture has a programme to assist farmers in installing cluster fencing, whereby a group of farmers will fence their fields together. Unfortunately, there have been some instances where the fences have blocked off traditional Elephant movement corridors (pers. comm, Elephant Without Borders staff), particularly in Chobe Enclave. The fencing materials provided under the NAMPAAD programme, were also not suited to Elephant areas, with high tensile steel not snapping when Elephants walked into it, but instead both cutting the Elephants and pulling out the fence posts. (pers. comm., Dept. of Crop Production). There is a cluster fence in Lesoma funded by the DWNP (World Bank), and KAZA has funds approved from their donor KFW, to erect a fence around Pandamatenga local village.

The fencing of molapo farming in the plains near Lake Liambezi is according to some of the resident farmers not necessary, since Elephants disperse in the forest in the cropping season.

A crop damage compensation scheme from DWNP was since 2014 not well executed due to cash shortages in government.

The NGO Caracal reported most Buffalo damage between Mabele and Ngoma junction, around Muchenje. The number varies from 5-10 incidents a year. In the same area a lot of Elephant damage is reported as well, up to 50 incidents per year. This area is recognized as a wildlife corridor, with animals moving from the forest towards the floodplain and river. In these days hunting was still practiced, therefore the number of reports has increased a lot over the past years.

The World Bank reported the highest incidence of Elephant conflicts around Kachikau, with some 35 cases in the period 2010-2015 (World Bank 2016).

In Pandamatenga the large herbivores that were fenced into the commercial crop area in 2,000 have successfully reproduced within it and are currently causing large scale crop damage in the cultivated fields. The majority of crop farmers within the Pandamatenga Commercial Crop Farming area do not currently view wildlife as a problem, and deem the levels of Human-Wildlife Conflict within the confines of the farms as acceptable (pers comm. Mrs Bolla-Swart). However, these animals are utilizing the commercial crops (herbivores) and attract predators. Reports by DWNP indicated that the main problem species within the farmed area are Eland, Tssessebe and Kudu (Figure 59). The dry season (April - October, inclusive) is the most prevalent time for Human-Wildlife Conflict. The lack of water and forage forces the animals to utilize whatever is available. The end of the dry season coincides with field preparation and planting of crops, and the wildlife uses the cover provided by the teak forests during the day, and raids the growing crops at night (ESA 2014).

\footnotetext{
12 Note that this figure includes the commercial farms, which are surrounded by electrified fences which have worked well to deter Elephants. It is possible that Elephants remain the wildlife species of greatest concern for Pandamatenga smallholders.
} 


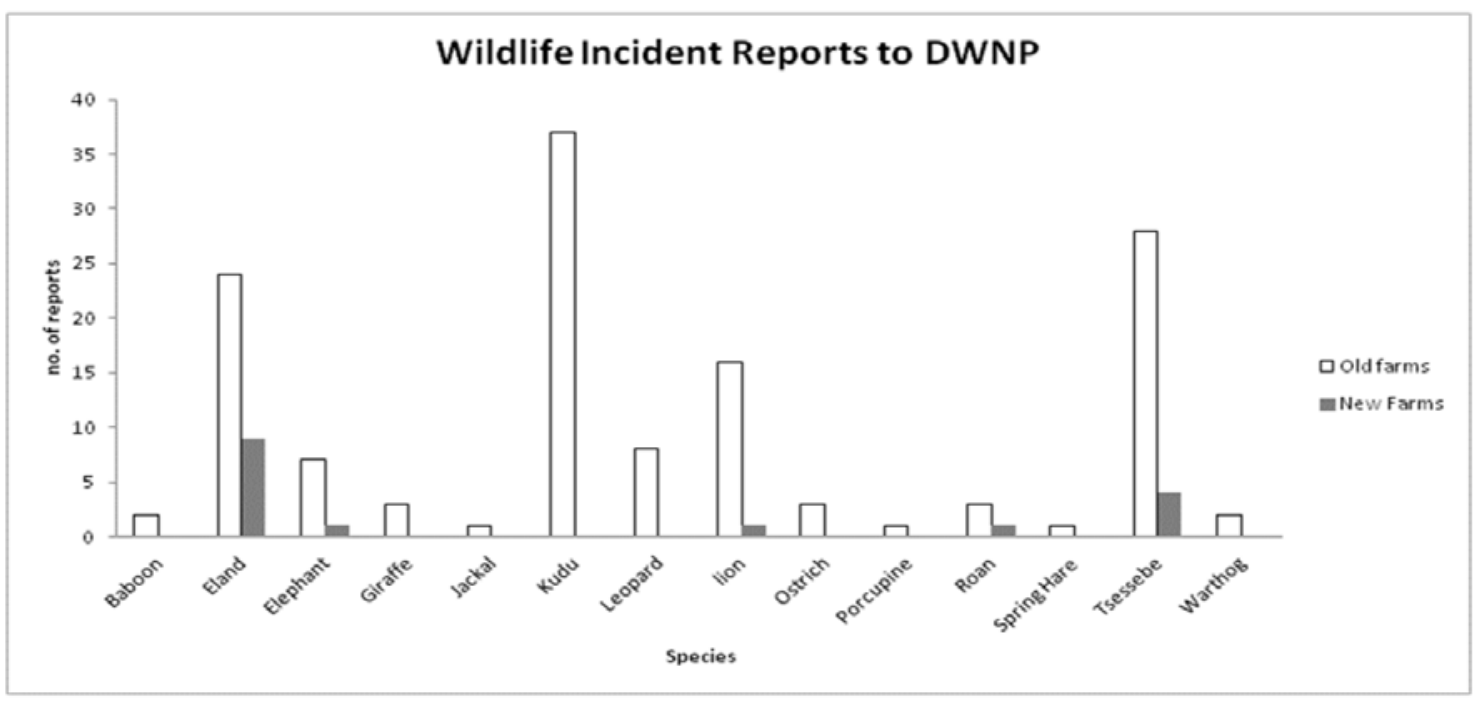

Figure 59 Wildlife incident reports for Old and New Farms, from March 2011 - March 2014 (ESA 2014)

\subsubsection{Approaches to deal with human-wildlife conflict}

The wildlife populations, and in particular the Elephants, Lions and Buffalos, are vital for tourism in Botswana. Since tourism is a very important sector for the economy, and still growing, it seems inevitable that the Human-wildlife conflict is something that must be dealt with: the wildife populations will remain or expand in the foreseeable future, and approaches are needed to mitigate these conflicts with communities and find ways to promote a form of coexistence between communities and wildlife.

The World Bank has supported the 'Northern Botswana Human Wildlife Coexistence Project', which finished in 2016 (World Bank 2016). The project focused on reducing the number of conflicts, improved communication and extension activities by DWNP, training of community members and an increased number are employed in the tourism sector. In the World Bank project a variety of approaches were tested to decrease the human-wildlife conflict, such as erecting 'chilli fences', burning chilli, use of honey bees as deterrent, cultivating early maturing crop varieties, electrified fencing, predator-proof kraals, and use of guard dogs to protect livestock. The World Bank report concluded: "The government policy for addressing human-wildlife conflict does not encourage farmers to take ownership of protecting their crops and livestock."

Potentially the best way to deal with livestock predation is appropriate management of livestock, in particular herding cattle at daytime, and holding livestock in a predator proof kraal at night (Gusset et al. 2009). He sees limited scope in compensation of livestock losses, since it does not increase the acceptance level of the people.

There are schemes for compensation of damage, which are administered by the Department of Wildlife. However, they confirmed in a meeting that compensation is outstanding since 2014, and several milLions of Pula are owed to crop and livestock owners.

A critical issue is that a compensation scheme is re-installed, and generous use should be made of this to ensure that the tourism potential can be monetarized in future. The income generated through tourism benefits the entire Nation and should be shared with the communities, either through payment from tourism revenues by government or through instalment of a community fund by safari companies. It also underlines how the Botswana government values the social responsibility, which is also beneficial for marketing Botswana as (sustainable) tourism destination.

Also increased participation of community members in the tourism sector can be beneficial, either through employment or (participation in) businesses. 


\subsection{Key findings}

- Some 10 key-pressures were identified that affect the Landscape System of Chobe District;

- The backbone of the entire landscape system is the hydrological system of the Ngwezumba valley, where water from Pandamatenga and Kakulwane plains drains into the valley, which feeds finally the area of Zwei zwei pan, Savuti and Mababe;

- The latitudinal relations (wildlife movements, water movements, fires) require careful planning to ensure sustainable development;

- Pressures result in challenges, but also provide opportunities within the framework of the Land Use Plan, to stimulate different forms of growth;

- Climate change affects the system, in a way that temperatures will increase by as much as 3-6 degrees, rainfall is likely to become less, and more erratic;

- Climate change will reduce the extent of wetlands like Linyanti and Kwando Swamps, and reduced water inflow in pans. This will result in a reduction of wildlife populations, and a decrease in wildlife may affect in due time the revenues generated through tourism;

- Decreased water availability for wildlife as a result of climate change puts pressure on wildlife populations in the dry season;

- Overgrazing and veldfires are occurring, but seem to have less impact in the long term;

- Kasane-Kazungula township is confined between the Chobe River, Chobe National Park and Forest Reserves. Urban sprawl is a major environmental pressures and needs to be redressed, also in smaller settlements;

- Agricultural land resources are lost in Kasane-Kazungula area due to urban sprawl, commercial developments, and probably plots not being developed;

- Several large plans such as the Kasane-Kazungula re-development plan, the Transport Hub and Tourism Hub, require improved coordination and adjustment between these plans, also with a view on maintaining wildlife corridors;

- A lot of Human-Wildlife-Conflict occurs, both in the East and West of Chobe District, and local communities suffer most from wildlife;

- Currently the scheme for compensation of crop damage (operated by DWNP) is not functioning since no funding has been made available, which acerbates the wildlife conflict;

- There is an urgent need to re-install the compensation scheme, and make generous use of this to ensure that the tourism potential can be monetarized in future;

- The income generated through tourism, which benefits the entire Nation, should be shared with the communities, either through payment from tourism revenues by government or through instalment of a community fund by safari companies.

- Social responsibility and justice can also benefit the position of Botswana as tourism destination. 


\section{Development aspects}

Currently farming focuses still on extensive (mostly subsistence) dryland farming. Besides being low in output, it is a vulnerable system, demanding a lot of land. Crop protection is costly due to vast areas being farmed, or results in environmental degradation (bush fences) or Human-Wildlife conflict.

\section{$10.1 \quad$ Agriculture}

\subsubsection{Intensification and increased value of produce}

Currently farming focuses still on extensive (mostly subsistence) dryland farming. Besides being low in output, it is a vulnerable system, demanding a lot of land, and with little input providing limited yields. Crop protection is costly due to vast areas, or results in environmental degradation (bush fences) or Human-Wildlife conflict.

It would therefore be recommended to intensify the production, by:

a. intensive cropping on small areas, which can be properly protected, and

b. production of crops with higher values, such as horticultural produce, or

c. processing crops into products.

There are various systems of intensive cropping, such as Permaculture, Conservation Agriculture, Hydroponics, etc. They combine often intensive use of the soil with year-round production, use of compost or manure and sustainable farming techniques. In particular Conservation Agriculture is less management intensive and better accessible to most community farmers.

The MoA should support the application of conservation farming (zero-tillage). It is recommended for MoA tractors to use rippers rather than traditional ploughs. This has been proven to increase yields even on poor soils within Botswana and is also a more climate resilient approach to small scale farming. Also water harvesting techniques can supplement needs for irrigated agriculture, be it water harvested from roofs or as mini-catchments in fields, at small scale but also in the commercial Pandamatenga farms such opportunities exist (see e.g. Alemaw 2006).

In the case of small farmer groups or small women groups, assistance could be provided with support for the (electrified) fence, water system and some of the farming tools. These can be shared by the group.

\subsubsection{Agricultural support and integration}

Agricultural programs should be further integrated to ensure effective implementation of support measures. Different programs are ongoing: the District Council has a program to support the poorest households, MoA has various programs for support and tools and implements, and also UNDP and KAZA are supporting farming or horticultural activities in its corridors.

It is essential that these different programs are bundled and further integrated. The programs should move away from individual support to a village-based approach, where efforts are combined, and funds are concentrated. Here also supportive measures for crop protection can be implemented. An agricultural officer, preferably attached to both MoA and e.g. KAZA, could support farmers and farmers groups with improved farming techniques in a defined and targeted area. Reviving and strengthening existing village-level structures such as agricultural conservation committees could provide the local level arrangements for encouraging farmers to work together, and to adopt conservation agriculture practices and collaborative efforts - both for crop and livestock production. Strong collective decisionmaking at the local level is vital to ensure understanding of, and support for, zoning and maintaining corridors.

Ngamiland District is experimenting with a multi-stakeholder platform approach for sustainable land management to be housed and guided by either DLUPU or the Okavango Wetlands Management Committee. Such a platform could provide the forum for district stakeholders to coordinate their support efforts. 


\subsubsection{Commercial farms development}

In Paragraph 8.1.4 the commercial farming is described, but also the current development of plans for extension of the farming area with the development of irrigated farming.

The Consultants acknowledge the demand for expansion of commercial farming, also to increase food security and increased self-reliance of Botswana. However, the Consultants see the development of irrigated farming as undesirable for reasons that are related in particular to sustainability of the project, but also for economic reasons, investment costs, as well as the possible risks which are related to the assumptions of the project design:

- Sustainability

Although we acknowledge that there might be overriding factors which lead to a political decision to construct the water carrier, we do not support the development of a water carrier for irrigated farming. It is a form of vulnerable infrastructure (ranging from accidents, to sabotage or unauthorized water extraction as happened in the past with the Orapa water pipeline). Much energy is involved in the pumping of water, there is increased dependency on water from the Zambezi which may have effects downstream in the view of climate change (see also Par. 10.5.3 on water resources).

- Economic benefits

It seems that large investments must be made, mostly by the GoB, in the order of 400 Million US\$. The foreseen benefits thus do not take into account the investments made in clearing of land, construction of head works and irrigation facilities.

\section{- Risks}

The vertisols in Pandamatenga are difficult to work, and demand specific expertise from the manager, which resulted in many failing and reclaimed farms in the past (Kgathi 2003). Developing this irrigation farming area bears the risk of a new long learning curve, developing the right techniques and management practices. Compounding factor may be the variability of the soils, which may also require adaptive management.

- Community involvement

The expertise and level of investments in irrigated farming will exclude participation of local farmers, and is likely to attract mostly foreign farmers or business man from Gaborone or abroad. Participation of members of the community is likely to be nil.

The lay-out as prepared by the consultant (SGI Studio Galli Ingenieri, \& Metaferia Consulting Engineers 2014) shows the proposed area as a single block with irrigation infrastructure. This will cause increased wildlife conflict, since the wildlife movements through the farming blocks should be facilitated also in the new development area, which would decrease the available irrigation land, but would probably also increase costs, and thus decrease the feasibility considering the high investments required. Moreover, also the Department of Water Affairs (2015) has serious questions about the strategic use of water resources for large scale irrigation, and states that such decisions must be subjected to economic costs benefit analysis and "judged from a water efficiency and other key development planning priorities (e.g. poverty, food security). The opportunity cost of water consumption by such projects need to be considered and the ability to pay for water should be considered."

Considering the proportional allocation of water to agriculture within SADC and the proportional output from the agricultural sector to GDP within SADC, such investments do not make economic sense; especially within a global economy where the country is so exposed to the impacts of climate change. Aspects of the Water Carrier are discussed further under par. 10.5.3, large scale water transfers.

If the Botswana Government does proceed with commercial irrigated farming, it is recommended that climate smart approaches are incorporated into the design at an early stage. Large scale water efficient irrigation schemes have been shown to be effective and viable in other parts of southern Africa with significant improvements in water use efficiency. This approach would reduce the farming's exposure to the impacts of climate change and potential closure of the Zambezi's water allocation

The Consultants do, as mentioned, acknowledge the need for expansion of farming. However, it proposes an extension of the farming area further west in a way that it does not block wildlife movement. The current opening between the northern and southern farming block should be re- 
opened, the electric fence should be re-aligned, and the new extension should allow the east-west migration, and this should be incorporated in the design.

We would propose that expansion is done in phases of approximately 8-10,000 ha, and -in line with adaptive management- that new phases will evaluate experiences made in previous phases.

Finally, in the community meetings there was an urgent wish of possible allocation to members of the Pandamatenga community. This should be seriously assessed, and it should be explored whether with support and coaching from established farmers at Panda this would be possible.

The design should be prepared in an open planning process, without pre-conceived development formats for the consultant.

A SEA would be required to do a detailed investigation of the impact of development, and the possible solutions to come to an optimal farm lay-out which also allows benefits and knowledge transfer to local communities.

\subsubsection{Agricultural Co-existence}

There are opportunities for co-existence of wildlife and agriculture. We can draw on recommendations on the Okavango Pandhandle Ecoexist project. The Ecoexist Project seeks to reduce conflict and foster coexistence between Elephants and people. In areas of heightened competition for access to water, food, and space, they seek and facilitate solutions that work for both species. Also in the Chobe Enclave trials were done in the World Bank coexistence project (World Bank 2016).

The project in the short term empowers farmers with practical, affordable, and effective tools to deter crop-raiding and reduce conflicts with Elephants. In the long-term, they collaborate with local, national and international groups to create an enabling environment for a range of policies and programs that tackle the root causes of conflict. That might be early growing varieties of crops, to avoid the Elephants, but also scaring animals away or burning of chillies.

For Chobe District there might be opportunities to learn both from the experiences in the Enclave and the Panhandle in Ngamiland. The DWNP should continue supporting the promising trials for co-existence.

\subsubsection{Cluster fencing}

The NAMPAAD policy that recommends protection through farmers working as groups to fence clusters of fields should be continued, in particular for higher value crops, horticulture, and vegetable gardens. In some instances build-up areas or villages could also be fenced in. However, as the district agricultural office is aware, the current procedures need additional guidance to avoid some of the challenges existing cluster fencing projects faced. Various reasons for the challenges have been mentioned: siting of the location of the fence in wildlife corridors, the size of fenced areas, materials used, construction, faults in wiring and lack of maintenance.

We provide the following guidelines, for assistance in cluster fencing:

- The size of enclosures should be limited, to reduce environmental impacts and costs, to a maximum of 400 ha or a length of $8 \mathrm{~km}$.

- No fencing takes place in defined wildlife corridors or frequently used migration routes.

- Farmers should contribute in the development of fences, to ensure ownership of fencing.

- The geometry of Elephant exclusion needs to be carefully thought through: exclosures should be designed to progressively lead animals away from cultivated areas, with gentle tangents in both directions. This will help reduce the "incidental" incursions that take place while animals are moving between forage areas and water.

- Each CHA where cluster fencing can be introduced, should have a formal, independent assessment and mapping of cluster options conducted by a wildlife biologist, land use planner, and agricultural expert - the zones need to be located where the best yields can be made but also to ensure that the fence alignment permits movement of wildlife with minimum conflict and threat to people and their livelihoods.

A lot can be done to design the flow of movement with GIS, knowledge of the terrain and knowledge of habitual pathways (use of indigenous knowledge in this is invaluable, and use of LUCIS can be instrumental as well). Finally, how much area can be used for agricultural fields remains to be determined. 


\subsection{Tourism development}

The Chobe district is a $20,000 \mathrm{~km}^{2}$ area with a high potential for nature-based tourism development, especially in easily accessible zones with an abundant wildlife and high landscape values. Wildlife is Chobe's core-attraction and tourism development must therefore be subordinate to wildlife needs. This does not automatically mean that tourism development must be kept at a minimum, as the positive impacts of tourism should not be underestimated. Tourists are for instance 'the eyes on the ground' in the battle against poachers. But most of all can tourism development have a positive impact on the natural resource management and local community development, if a reasonable part of the revenues are reinvested in the Chobe district. This is a key principle if our aim is to develop sustainable tourism.

Tourism has an important role to bring employment, whether through community or direct employment through companies. One of the aims for the ILUP is to realize the best use of the land to provide employment and livelihood. At the same time, it is essential to take the long-term perspective: the aim is not to maximize employment. Sustainable development is the key, not maximizing short term growth. We refer in particular to par. 7.7, Figure 46, on ways for poverty alleviation and participation of people in tourism.

Tourism has shown an extraordinary growth since the 1950s. International tourist arrivals worldwide surpassed 1 bilLion in 2012 and is anticipated to reach 1.8 bilLion in 2030 (World Tourism Organization 2011). For Africa this mainly concerns an increase in wildlife watching as this represents $80 \%$ of the total annual sales of trips to Africa, with safari as the most popular product (World Tourism Organization 2014). Botswana does not stay behind in tourism prospects. In 2015, the country attracted roughly 2,693,000 international tourists. By 2025, this is forecast to total 4,065,000 arrivals, an increase of $4.7 \%$ per annum. In 10 years of time this means a $50 \%$ growth in international tourist arrivals and an increase in revenues from roughly US\$ 1 billion in 2015 to US\$ 1.5 billion in 2025 (WTTC 2015). Based on these figures it is reasonable to expect that the Chobe district as well will receive $50 \%$ more international tourists in 2025, compared to 2015. Most of these tourist will come to enjoy an 'unspoiled wildlife experience'. A lot needs to be done however, to ensure that the safari product of the Chobe district will (still) meet the expectations of the tourists in 2025.

\subsubsection{Tourism target groups}

Current tourism development in the Chobe district mainly focusses on upmarket safari tourism which is concentrated in the Chobe-Savuti-Linyanti areas. More of the same would not be a good strategy for the future. Diversification is recommended in terms of attraction of different tourism target groups and development of tourism infrastructure within the different zones of the Chobe district. The tourism product development matrix below (Table 22) may help to understand the situation.

Table 22 Tourism product development matrix illustrating the need for improvement, enlargement, adjustment and innovation of tourism products (bullets represent key-words explained below)

\begin{tabular}{|c|c|c|}
\hline & Same product & New product \\
\hline Existing target groups & $\begin{array}{l}\text { I mprovement } \\
\qquad \text { Upmarket safari }\end{array}$ & $\begin{array}{l}\text { Enlargement } \\
\qquad \begin{array}{c}\text { Budget safari (also domestic), cultural } \\
\text { heritage }\end{array}\end{array}$ \\
\hline New target groups & $\begin{array}{l}\text { Adjustment } \\
\qquad \text { Emerging economies }\end{array}$ & $\begin{array}{l}\text { I nnovation } \\
\text { Specialist groups: birding, sports fishing, } \\
\text { archaeology, Adventure tourism, } \\
\text { voluntourism, low cost / improved community } \\
\text { based access and cultural based tourism. }\end{array}$ \\
\hline
\end{tabular}




\section{Upmarket safari-tourism - improvement of the product}

Upmarket safari tourism may currently be considered the main existing tourism target group. This will remain an important target group in the future, as 'seniors requesting high-quality experiences' and 'active and adventure travel like safaris' are significant travel trends (Burkhard et al. 2016).

Several upmarket safari lodges have already been constructed, especially along the Chobe river near Kasane and Kazungula. Improvement (Table 22) of the safari product should mainly focus on safeguarding an 'unspoiled safari experience', as 'mass-tourism' and habitat-loss are considered important constraints for this zone.

Stronger marketing for the tourism low-season is part of the solution, but improvement of both visitor management and natural resource management of the Chobe riverfront are essential. This means avoidance of tourism crowding during game drives and boat game views (see $\S 10.2 .2$ ), but also ensuring that the access of wildlife to and along the riverfront is not obstructed by fencing the tourism lodge territories.

Habitat loss is mainly caused by overgrazing or -browsing of habitat, especially by the numerous Elephants during the dry period. This results among others in the disappearance of riverine forests and associated species which negatively affects the aesthetic value of the landscape. Natural resource management should set a limit of acceptable change to halt the loss of forested area along the river. Reforestation or greening of the urban area with native trees and scrub can be part of the solution, as the browsing pressure will be much less here, while it will be a safe haven for birds and other small wildlife, attractive to tourists.

\section{Tourists from emerging economies like China - adjustment of the safari product}

An increasing number of tourists will come from 'new' places of origin, as many emerging economies have shown fast growth of outbound tourism over recent years. China leads the global outbound travel. Though still relatively small, Africa is becoming increasingly popular among Chinese tourists (World Tourism Organization 2016). In 2015 approximately $1.6 \%$ of tourist arrivals $(43,000)$ in Botswana were from China. These tourists may have different needs compared to the 'regular' tourists, which may require adjustment of the present safari-product.

\section{Budget safari tourism - enlargement of the safari product}

Budget tourists enjoy same wildlife safaris as upmarket tourists do. Though not really a new target group, budget accommodations are currently very limited within the Chobe district. An increase in this segment is recommended, whether 3-star hotels, Bed \& Breakfasts, homestays or wildlife camping. This will also increase the opportunities for domestic tourists. Development of budget tourism will offer more employment opportunities for local tour operators in joint venture with local communities and prevent that the tourism market is dominated by external (foreign) tourism businesses. It will comply with the observed travel trend for responsible tourism products where tourists choose for companies with 'a strong social focus' and where 'homestays gain more interest than traditional hotels' (Burkhard et al. 2016).

In line with this, cultural heritage has not received much attention thus far. Cultural resources are present and it is therefore recommended to develop opportunities for cultural heritage, such as rock paintings and national monuments, in addition to the game viewing product.

\section{Specialist groups - innovation of tourism products}

Tour operators must innovate, develop new tourism products and attract new target groups. Understanding about travel trends is important. What are for instance the specific interests of the millennials, officially the largest generation in history (Burkhard et al. 2016)? Some tourism products that can become successful are:

- Bird watching: roughly 3 milLion international trips are taken each year worldwide for the main purpose of bird watching, and many more trips combine birding with other activities (Anonymous, 2014). Bird watching is part of the safari-product in the Chobe district already. However, the diversity and density of charismatic species allows for a stronger focus on specialised bird-watching tours. Well trained and knowledgeable guides are a crucial element in the development of a successful product.

- Archaeology: development of archaeological sites to showcase Botswana's cultural history might add to the safari experience, especially for domestic tourists. 
- Voluntourism: voluntourism is the intersection of international volunteering and tourism. It is the practice of individuals going on a working holiday, volunteering their labour for worthy causes. For example aiding or alleviating the material poverty of some groups in society, restoration of certain specific environments or research into aspects of society or environment, alongside touristic activities. In 2008, a Tourism and Research Marketing survey of 300 organisations estimated the voluntourism market size to be 1.6 milLion volunteer tourists per year worth $f 1.3$ bilLion (Stein 2012).

- Sports fishing: sports fishing is one of the most popular outdoor activities. In 2015 for instance more than 45.7 milLion Americans took at least one fishing trip. Fishing trips are possible at the Chobe river, like fishing on the illusive tiger fish between the months of January and March. The potential for fishing tourism packages should be further explored.

- Hunting tourism: A special position has trophy hunting, an extreme example of low volume high income tourism. This target group is not new for Botswana, but it was banned since January 2014. Many of the forest reserves, which are not interesting for safari tourism, were previously used for trophy hunting. It provided substantial income for the poor local communities that managed the forest reserves, while it did not harm the species populations (Mbaiwa 2015). The International Union for Conservation of Nature recognizes that trophy hunting, when well-managed, can be sustainable and generate significant economic incentives for the conservation of target species and their habitats outside of protected areas (IUCN SSC 2012). Despite arguments to ban trophy hunting there are also good arguments to reconsider this ban.

\subsubsection{Sustainable tourism development principles}

Detailed management plans, including tourism, must be developed for each of the zones within the Chobe district. These plans should integrate sustainable tourism development principles like on zoning, visitor management, law enforcement, training \& education etc.:

\section{Tourism zoning}

Each zone which for tourism (both inside CNP and outside, Forest Reserves etc) needs a spatial zoning plan which indicates zones for tourism infrastructure development, wildlife corridors (like to and along the river) and wildlife core areas (not accessible for tourists). These core areas might be permanent or temporary, depending on the vulnerability of the species concerned. Breeding islands for colony breeders like Skimmers for instance, as well as a bufferzone around the island, should be forbidden to be entered during the breeding period (picture 1).

Tourism development must respect designated corridors to enable wildlife free access to the river. Strip development along the river front must not be permitted, rather tourism development should occur in nodes.

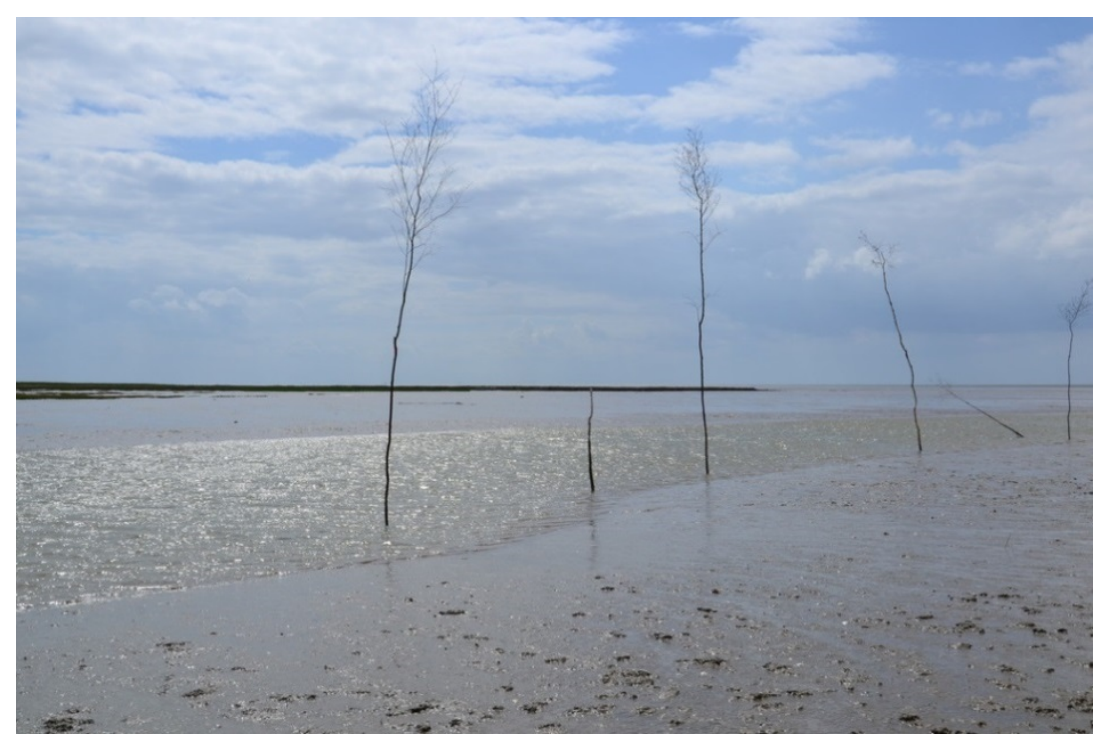

Picture 1 Wooden poles can be used to mark waterways or to mark no-go areas aimed to protect natural values. It could be tested whether it works for the rivers in the Chobe District as well 


\subsubsection{Visitor management}

Some areas can become overcrowded with tourists, whether permanent, seasonal or only during certain parts of the day. The number of boats and vehicles have increased so much, that visitors complain that it affects the 'nature experience'. In one afternoon one may easily see 20 boats on the river, from houseboats with maximum eighty people upto small motor boats of 8-15 people. Often these boats are not full, in some cases only few people are on the boat, since most hotels or lodges operate their own boats or vehicles.

Direction of visitor flows to other, less-used zones within the Chobe District is one option (see § 8.2), but also establishing an alternative entrance gate can be considered, as can a set limit, or carrying capacity of boats on the CNP river front at any time.

Self-regulation of the tourism sector would be a possibility to ensure that the number of vehicles or boats are being reduced. Setting limits to the number of cars and boats in a zone through licensing is another strategy, or closing certain zones altogether - such as closing parts of the river for boats, as described by the KAZA plan (2011).

It should be ensured that boats keep a safe distance from e.g. breeding birds like Skimmers. It might be considered to install a system of zonal use amongst the different hotel groups and self-drives. This also might require active self-policing, similar to current HATAB rules.

It is possible to set a limit of boats and vehicles. One approach could be that only one boat per large lodge or hotel is permitted, and that these hotels could buy seats of e.g. mobile operators that offer boat trips or vehicle-based safaris. This would seriously reduce the over-capacity, and would in the end also increase the profitability since the facilities are used more effectively. It would also stimulate that visitors plan their activity, and possibly select alternative options, such as guided walks, or a boat trip outside the National Park (e.g. a birding trip towards Kazungula).

These measures can be combined with pricing in the sense that being a single tourist in a car or boat will be much more expensive than a shared price if the vehicle is fully booked.

\subsubsection{Training, education, awareness raising}

Training, education and awareness raising at all levels, whether National Park staff, local communities, tour operators and tourists is crucial to ensure that the management of the Chobe district meets a high quality standard. Comprehensive awareness activities are required.

Currently Chobe District lacks schooling facilities, in particular higher education, but also informal and vocational training. Training in the tourism and service industry and guide training are currently offered in Maun at a private schooling facility. This makes it difficult for Chobe residents to enter such training while it is also costly and probably only affordable for staff already employed in the tourism sector. To ensure increased involvement of Chobe District residents in general, and from remote villages in the District in particular, it is important that secondary schooling is available in the Chobe Enclave, so that its residents can qualify to be employed in the tourism sector. In addition there is need for more vocational training through practical courses.

Relevant NGO's could be sponsored to offer training courses for community members, aimed at promoting employability. Land/plots should be allocated for this purpose. The private sector could also be encouraged to offer more training and internship programmes.

Further, informal training can be stimulated further by making specific arrangement with commercial tourism enterprises for e.g. extended 'on the job' staff training at the (commercial) lodges.

This is already happening at a small scale, but much more can be done. There are apparently some examples, such as (Africa Albida Tourism - Ngoma lodge) is doing.

Awareness raising should include a focus on facilitating access for disadvantaged groups to government support programmes. Assistance with the application process for programmes such as CEDA, Youth programmes, crop and livestock support, etcetera may be required. This should include compensation programmes for damage caused by wildlife. For poor and uneducated household heads the 'red tape' around such programmes may be a major hindrance. 


\subsubsection{Community based tourism}

Botswana has adopted a high-value, low-volume tourism strategy aiming to minimize negative environmental impacts and maximize socioeconomic benefits. Magole \& Magole (2011) have stated that this strategy has contributed towards a skewed foreign ownership of large tour operator companies and leakage of profits from Botswana and that this strategy is not sustainable or suitable for a country like Botswana with a large rural population that is highly dependent on natural resources. However, it could also be said that The high value tow volume tourism strategy, as advocated for within Botswana's Ecotourism Strategy (2002), has been one of the foundations for the country's successful tourism industry. The strategy has ensured that the country has promoted the development of tourism within the highly sensitive delta on a sustainable basis. To support mass tourism in the Delta and other sensitive part so of the country would lead to undermining the natural resources Magole refers to. To address some of the other concerns raised by Magole and Magole, the Botswana Tourism Board is now working towards a diversification of the tourism sector based upon a land use strategy of zoning. Areas of sensitivity, such as the Okavango Delta, the Savuti Marsh etc remain as high value - low volume. Management Plan such as this provide the opportunity to promote further zoning to spatially divert medium and low cost tourism into more ecologically resilient areas, whilst still preserving the sensitive areas as high cost - low volume.

An increase in the opportunities for the medium to lower tourism segment within ecologically resilient areas would substantially increase the opportunities for local tour operators. These can have the form of joint ventures with local communities, and might for instance offer all-inclusive lodging, guiding and wildlife viewing. Opportunities especially arise for local communities that are located in or near the socalled future intensive and intermediate tourism-use zones, see Figure 3: Possible future tourism intensity, based on tourism potential.

\subsection{Forestry development}

\subsubsection{Collecting firewood and veld products}

The offtake of firewood and veld products should be quantified and monitored. The question is who can do this, currently DFRR might not have sufficient capacity. This is a key opportunity to expand on the community monitoring through the MOMS approach, with guidance and reporting to DFRR built in. Communities can build on traditional practices of deciding which areas are designated as collection areas for particular resources in a given season or year, and community members, once informed of these, would be expected to adhere to them, as was historically the case when a village headman determined areas and timing for different natural resources.

\subsubsection{Fire management}

Fire management in the Chobe District should focus upon reducing the current frequent and severe fires through pre-emptive early dry season burns (Perkins, 2016), whilst improving the effectiveness of fire breaks in specific areas. The goal of any fire management approach should not be the complete absence of fires in forest areas, but the mitigation of frequent fires occurring every 1-2 years and the return to a more natural cycle of longer cyclical fire events every 4 years or longer.

It is recommended that a critical review of the existing network of firebreaks is implemented by DFRR with an assessment of their overall effectiveness. Observations undertaken by the SAREP program in Ngamiland have shown that the alignment of fire breaks is not effective, whilst better use could be made of other man made features such as vehicle tracks and fence lines in conjunction with fire breaks through a targeted back burning program. Perkins et al., (2015) suggest that firebreaks are insufficient to control wildfire and may in fact even accentuate the frequency and extent of fire by the access to wilderness areas they have opened up. This is in particular applicable to the situation in the Eastern part of the planning area where fires usually start. In this area (in particular $\mathrm{CH} 4$ ), using existing, or ideally an improved alignment of fire breaks in conjunction with other man made features a system of early dry season burns should be trialled so as to break up the spatial homogeneity of the fuel load. 
Implementation of DFRR's Bush Fire Management Strategy for Chobe must be supported by multiple stakeholders, many of which see fire management as the preserve of DFRR until an emergency situation is called by the District Commissioner compelling action by other parties. In Namibia, where community based approaches to fire management have proven to be successful, the Integrated Forest Fire Management (IFFM) pilot project, covering an area of 1.2 milLion hectares of forests, was launched to show that the local people can be fully involved in forest fire control activities if properly educated and motivated. In particular the IFFM involved (From Perkins et al., 2015):

- a massive fire education campaign that targeted all levels of people, politicians, traditional leaders, schoolchildren and their teachers and local farmers.

- education of the general public and through the training of people in local communities in prescribed burning of $1,000 \mathrm{~km}$ of firebreaks each year. The emphasis was laid on the ability of local people to use fire as a tool for land clearing or for improving the grass sward for the purpose of animal grazing or for the production of reeds and thatch for fencing and roofing.

This approach should be adopted for the Eastern part of the planning area, in particular in and around $\mathrm{CH} 4$.

\subsection{Wildlife Management}

\subsubsection{National Park Zoning}

Tourism is currently concentrated along the River Front and Floodplains and it is very intensive. To improve the tourism experience and increase the sustainability of the activities, zoning measures are required within the National Park. The aim would be to create areas with limited disturbance of wildlife and thereby reducing any negative impact from tourism on wildlife behaviour and to improve the wildlife viewing experience for tourists. The impact of densely concentrated safari vehicles along the river front can be large, as can a similar density of boats crowding the river front, in particular on Hippo's and birds. A visitor management plan as discussed in par. 10.2 can effectively spread the pressure more over the park.

A visitor Management Plan should look into the options on tourism zoning, movement of vehicles, selfregulation within the safari sector, and infrastructure development. A new tourism and roads management plan should urgently be developed for this zone. This management plan should consider to install a system of zonal use amongst the different hotel groups and self-drives. This also might require active self-policing, similar to current HATAB rules. Also measures are required to close some river stretches for boats, or to ensure that boats keep a safe distance from sensitive areas e.g. sandbanks with breeding birds like African Skimmers.

This is strongly linked with the issues mentioned under tourism development above as well, since tourism is, so far, largely focused on Chobe National Park. The last management plan for Chobe National Park had shortcomings which made it not effective and for various reasons it has never been adopted by MEWT. By now this plan is also largely outdated. Preparations for a new management plan are being made for early 2017. It is recommended that in the brief for the consultant the identified issues will be included to address these issues and to work out proposals to redress these in the new management plan.

\subsubsection{National Park rates and revenues}

The management costs of the Chobe National Park should (largely) be covered from park fees and tourism revenues.

The rates for the visitors might be considered low, both for citizens, residents and foreign visitors. It would be recommendable that the pricing scheme would be revised, a new fee structure is being developed, so that it is competitive with fees that are used elsewhere ${ }^{13}$. The prices for the park were

\footnotetext{
${ }^{13}$ In Uganda, for example, the visitor will pay 50 US\$ for a $24 \mathrm{hr}$ permit to visit a park which might be comparable to Chobe. Foreigners buy these permits in foreign currency.
} 
reviewed in 2012. The Act in which the new prices would have been brought into force, has so far not been passed by Parliament. Therefore, a new revision would be necessary, to ensure that prices are market conform.

It would be advisable to set the price for foreign visitors at a rate in a foreign currency, be it Euro or US\$, which is less susceptible to changes in exchange rates, and would remain therefore stable - not requiring frequent reviews.

Pricing is a tool to manage visitor behaviour, it can reduce the pressure on the park, e.g. through variable pricing for high-intensity or low intensity zones. If the prices for CNP River Front and Ngwezumba valley would be respectively 60 and 35 US\$ per 24 hours, some visitors will reduce the length of the visit to the River Front in favour of Ngwezumba valley, or some visitors may bypass the River Front altogether.

\subsubsection{Human-Wildlife Conflict}

One core problem faced in Chobe District is the Human-Wildlife-Conflict (HWC), and this is difficult to resolve through just zoning alone. As described in par. 9.5, the pressures from HWC are large and have been increasing over the years with wildlife numbers mounting.

There have been trials with deterring wildlife, and some practices were to some extent successful. At the same time it was reported that Elephants are smart, and they will circumvent for example the chillies that are burnt or hung on the fence (World Bank 2016). It is recommended that trials with the most successful means are continued and extended. Trials outside of the Chobe District combining chilli pepper deterrents and solar powered electric fences along with small (5-10 ha) cluster fields placed outside of known wildlife corridors which have been implemented by the NGO Ecoexist in Ngamiland along the Okavango Panhandle.

The possibilities for cluster fencing could also bring some relief, this has been discussed under par. 10.1.5. As a last resort, also management of conflict through the PAC-unit should be effective; in consultations it was mentioned that the Quick Response team from DWNP in Kasane and Kachikau was merely for recovery of tusks when Elephants have died (or were killed), and not so much to assist farmers.

An important approach is the financial compensation of farmers and residents. This can have various forms, it can be direct compensation from the Government; a development fund for the community; a fund developed by the industry as a share of the turnover from each company; compensation of wildlife and crop losses; if the hunting ban would be lifted, revenues could be turned in a trust again as was done until 2014

Although there are many options to choose from, it does not matter so much which model is chosen. It should do justice to the distribution of income from tourism and the disadvantages from wildlife and who bears these most. And it is important that the link is clear for communities, that the payments are tied to the wildlife resource, so that this will also affect their attitudes towards wildlife and conservation.

Three models that we recommend are:

1. The Compensation payments by DWNP are re-installed, with immediate effect, and outstanding payments since 2014 should be covered. This can be done from the park revenues through the Ministry;

2. A percentage of the turnover (e.g. 2.5\%) of all Chobe based tourism companies (all hotels, lodges and safari operators) should be paid into a fund, from which rural community support projects can be paid, but e.g. also training of people from the rural areas as private entrepreneur, tour guide etc. This can be done through some of the existing CBO's or trusts that are operating in the area. Relevant NGO's could be sponsored to offer training courses for community members, aimed at promoting employability. It is a matter of Corporate Social Responsibility for the tourism industry to take its share in alleviating poverty and sharing of the benefits;

3. The PAC should intervene and be more effective in cases where continued conflicts are reported. 
"We see that visitors from far come to the country, they pay money, but that all goes to the governments' coffers. We live here with the Elephants every day, and government tells us there is no money to pay us. They owe us money for the crop compensation since 2014. We cannot send our child to the house after four o'clock, because it is not safe. Elephants walk every day through the village. Elephants destroy our crops. Hyena's take our cattle.

In the past we got money from hunting $(\mathrm{CH}-2$, Elephant trophy hunting), which benefitted us all through the CECT. But that has stopped.

If Government gets all that money, why can't they pay us for our suffering?"

Communities need to see improved economic benefits and improved active participation in ecotourism. If economic benefits from the promotion of (photographic) tourism are not meeting expectations then the Government should undertake a detailed review of the hurdles to photographic tourism development in these areas. Alongside this review, the Government should continue to monitor wildlife population trends, where populations are seen to be increasing and stable. Where concerns of the risks of poaching are increasing, the Government should look to revise the ban on hunting to improve the flow of economic benefits to communities.

The current hunting ban could be re-evaluated at some point in time provided that the hunting is strictly monitored. This is mostly a political decision, in which the consultant does not wish to express a strong opinion. The consultant notes though that from an ecological point of view there may not be much objection against hunting, since wildlife numbers are high, and this potentially could benefit the communities if they receive a share of the profits. It would however affect the wildlife viewing in some areas, as wildlife would be vigilant and keep more distance to people and human property. This however would also decrease the damage to crops and livestock. Lifting the hunting ban ultimately can also have an impact on international visitor numbers, due to NGOs that advocate against hunting.

Considering the importance of wildlife for tourism, and the income and employment generated through the tourism industry, this issue of compensation of costs incurred by wildlife should be resolved as a matter of urgency. In this way it can be ensured that communities are compensated for livestock losses, crop damage or other damage incurred as a result of wildlife.

BOX 2: Mr. Magosi, Chobe Land Board

When I came here in 1984, the integrated land use was in place. You could see all the uses around the communities, they were co-existing. It was integrated. There were few conflicts emanating at that time. Then we came as planners up with policies and laws that we want to improve the plan. Chobe is a unique district, where else can you see a town neighbouring so many countries, on a river like this, four countries meeting at one point.

There were minimal conflicts, people could walk to Lesoma, or between Kavimba and Mabele. Now they can't. We have Human Wildlife Conflict, now they have come back to human-wildlife coexistence. But isn't that where we were back in 1984? People were farming, growing, selling eating their products. Wildlife numbers are increasing, they are everywhere, and at the same time, how many fences are we erecting? We have more and more requests for fencing. In 1984 there was no conflict. 


\subsubsection{Illegal wildlife off-take}

Law enforcement is crucial to ensure that the park rules are respected. The presence of park staff and the risk of a fine is usually sufficient to prevent tour operators from breaking the rules. Tourists generally appreciate the fact that they are guests in an area that is protected well.

Another aspect may be that visitor presence in wildlife areas ensures that poaching is reduced, since the presence of visitors or camp staff will deter potential poachers entering the area. The positive impacts of tourism is that tourists are 'the eyes on the ground' in the battle against poachers.

\subsubsection{Corridors}

One system for identifying and demarcating corridors using data from wildlife researchers and integrating these data into District and Sub-District level land use planning approaches has been effectively implemented in Ngamiland. The Land Use Conflict Identification System (LUCIS) is a participatory GIS-based method trailed and now being implemented by The Tawana Land Board. Almost 100 Elephant corridors were identified along the Okavango Pan Handle. These were then ranked according to relative level of use by the Elephants (in this case through the use of GPS collars, but camera trapping assessing dung density or track density approaches could also be used to gauge the intensity of corridor use), with a map of the most critical corridors presented to all stakeholders and communities. A participatory mapping exercise was employed to get buy-in from stakeholders to conserve these corridors and to get agreement amongst stakeholders and from the Land Board that no future allocation of land should be permitted within the boundaries of these demarcated corridors. Land adjacent to the corridors must be properly zoned to help reduce conflict where possible, with suitable land uses such as ecotourism or conservation prioritised. Where this is not possible and corridors pass through existing arable land then the promotion of fenced, clustered farms must be applied. The combined use of solar powered electric fences and chili pepper deterrents have proved to be effective at stopping transgression by Elephants in Ngamiland. However, providing a $1 \mathrm{~km}$ wide buffer zone from the edge of a demarcated corridor has also been proven to reduce the incidents of human-wildlife conflict by $60 \%$ (Songhurst, 2012). Where this space is not available then the use of solar and chili fencing can be used to protect fields and settlements.

The above approach should be applied where corridors are not currently obstructed with development. In cases where developments do occur within the aligned edge of a corridor then Land Board should implement a Policy of voluntary relocation with alternative suitable land offered to the owner who wishes to move and escape the exposure to high levels of human-wildlife conflict. In some cases corridors have been entirely blocked off by development.

One of the corridors that has currently been blocked-off, is the corridor through Pandamatenga (see par. 8.3.1.5). An electric fence has been placed some years back to protect the crops and keep wildlife out of the farm. This fence has been poorly sited: wildlife were captured inside the fence and have even reproduced there. There is therefore an urgent need to open up the corridor again: the electric fence needs to be relocated to open the corridor following all impact assessments and earlier studies done, and to release enclosed wildlife. In future no building and construction of infrastructure should be allowed within the corridor. Also, no other fence should be linked to the fence since the impact will become too large.

Some recently developed farms almost block the current corridor. Implementation of the ILUP and the expansion of Pandamatenga Farms would create an opportunity to relocate such farms in the new development area. Some of the structures present seem of a temporary nature, and might be easy to remove. There would be costs involved for compensation, but if alternative land can be offered of similar quality, it is mainly the cost for removal itself, and possible clearing of the new land.

\subsubsection{Fisheries}

It is recommended to develop transboundary Fish Protection Areas within the Chobe River system, where there is mutual management of the fisheries resources. The areas where these could be developed would be in the Chobe Enclave and possibly close to Kazungula. These have been successfully established within Namibia (see the Kasika Channel FPA, Tweddle \& Hay 2013) in 
collaboration with communities. Communities are responsible for their management and monitoring, and they establish their own specific bye-laws to improve the conservation of the fish and be able to stop other people from fishing within them. Without such decentralised, community based conservation of fisheries the fish stocks may be increasingly threatened in the future.

Within the KAZA framework there should be looked into the international fishing regulations, to ensure that bordering nations operate under the same rules, and e.g. Namibian fishers do not fish within the Chobe National Park.

As is indicated, there are good opportunities for further development of fisheries. Chobe District has ample water resources, and in particular fisheries in the Kasane-Kazungula area and the LinyantiKwando area could be further developed (in the National Park fishing is forbidden).

The marketing from the Chobe Enclave (Liambezi, Linyanti) could be improved, by supporting the local fishers cooperative - which has been operating for many years- with transport, or companies from Kasane could buy fish on site. UNDP and KAZA could look in these opportunities.

Around Kasane there is still shortage of local caught fish from the river. A local marketing point could improve this situation, it could also be an initiative from the tourism sector to market more local fish. There may be potential for commercial fish farms in Kasane area. This however is a capital intensive venture (and bears some risks as well), and is therefore only possible for business developers.

Extreme caution is required for use of exotic species, therefore fish should be kept away from the river to ensure that no fish escapes, nor diseases can spread into the natural system.

\subsection{Water Resources}

Availability of reliable and potable water supply is one of the most important prerequisites for human well-being and an important driver of growth for all sectors. So far, the demand for potable water in the Chobe District has been low compared to the available resources. This does not mean, however, that all the water demand is being satisfied, and that there are no issues that project on future development and activities around water supply. The issues of water demand/water supply in the Chobe district, currently, and in the future are influenced by several factors:

- availability of water resources

- water supply infrastructure

- institutional setting of water management and water supply

- large scale water transfers and the broader context of water demand (Botswana and other countries in the Zambezi basin)

\subsubsection{Water resources availability}

As mentioned in the section above, Chobe district is one of the better positioned regions in Botswana in terms of available water resources. It has access to the permanent Chobe River to the north, to the Zambezi River in Kazungula, and, unlike the rest of the country is located in the zone of relatively high rainfall (>450 $\mathrm{mm} /$ year), which favours groundwater recharge. The groundwater potential is classified as "High and uniform" in Chobe enclave, "Good but variable" in the Pandamatenga region and "Fair but variable" in the rest of the district. Groundwater table is typically less than 40m deep, and recharge rates are $1-40 \mathrm{~mm} /$ year. In this context, the Chobe district's potable water demand of $\sim 3,000 \mathrm{~m}^{3} /$ day is a miniscule fraction of the average flow of the Zambezi river, which is $\sim 100,000,000 \mathrm{~m}^{3} /$ day, or the renewable groundwater resources of the district, which considering the lowest recharge estimate, i.e. $1 \mathrm{~mm} /$ year, equates $60,000 \mathrm{~m}^{3} /$ day. Obviously, not the entire amount of water resources mentioned above can ever be available to human use, firstly because Zambezi is a shared resource, secondly there is a necessity to maintain environmental reserves, and lastly, demand is localized within towns and villages rather than distributed throughout the district, and technological and economic reasons prevent capturing the entire available groundwater.

Apart from the potable water demand in the population centres, which, apart from Pandamatenga, are supplied by piped surface water, there is also demand for water for livestock, (small) irrigated agriculture, small industry and tourism. That additional demand is distributed throughout the district, 
and partly focused along the Kasane-Kazungula corridor, in the Chobe Enclave and along the KasanePandamatenga road. This demand, away from the Chobe river banks, is satisfied from groundwater by the system of private boreholes. The entities in the vicinity of Chobe river, such as Chobe Farms, utilize surface water.

The implications of the above are as follows:

- water shortages, or in general water deficits, if occur, are related to technological and management aspects rather than to unavailability of resources. This is further expanded on in the section below.

- it is likely, that in locations where demand is concentrated, depletion and resulting conflicts between users might occur now, or in the future. The areas particularly susceptible to such processes are the Kasane-Kazungula strip, and Pandamatenga. To alleviate such emerging issues, requires permitting, monitoring and policing. As the demand continues to increase (as it inevitably will), appropriate planning and allocation of resources, monitoring of state of the resource (both in terms of quantity and quality), evidence-based permitting and water rights allocation, and policing of withdrawals compliance with allocated water rights will become an imperative. This is particularly important at the Kasane-Kazungula corridor, in the Chobe Enclave and in the Pandamatenga region.

\subsubsection{Water supply infrastructure and institutional context}

Historically, there has been a shift from supply provided from groundwater, towards supply sourced from surface water, with the effect that currently the only larger settlement that is supplied exclusively from groundwater is Pandamatenga. While this has changed the water source, it has also changed the nature of the water supply system and its infrastructure. While groundwater-based supply was distributed in nature and essentially relied on water resources available at or near the point of demand, the surface water-based system is centralized, with relatively little infrastructural redundancy, and major infrastructural investment needed when there is a need to meet a growing demand, and reliance on water resource availability and conditions at the point of abstraction. At this stage, majority of water supply issues in the Kazungula-Kasane-Kavimba region are caused by the inefficiency/inadequacy of water treatment plant (build in the 1990s, and incrementally upgraded), as well as other minor infrastructural failures rather than by the lack of the resource. The need for adequate upgrade of the water treatment works has been highlighted in the District Development Plans since the early 2000s, and it remains a challenge today. Perhaps a factor contributing to the slow solution to the issue is the fact that potable water supply is dependent on three institutions: Department of Water Affairs, Water Utilities Corporation and District Council's Water and Wastewater Department, with relatively clear mandates, but with economic models not facilitating quick solving of water supply problems. This aspect seems to be a limiting factor and projects strongly on the development outlook in the District.

\subsubsection{Large scale water transfers and the broader context of water demand (Botswana and Zambezi basin)}

An important element of the water resources landscape in the Chobe district is the Zambezi/Chobe water transfer scheme, originally meant to supply water from the Zambezi to Pandamatenga for primarily agricultural purposes. That scheme has been conceptualized in the early 2000s and outlined in the 2006 National Water Master Plan. Since the Zambezi is an international river, that intent had important broader implications, as access to shared water resources is regulated by the 1995 SADC Protocol on Shared Watercourse Systems and, in case of the Zambezi, mandated through the Zambezi River Authority and later Zambezi Rivercourse Commission. Under the Protocol, the Botswana government has a right to withdraw water from the Zambezi near Kasane, and in the 2006 NWMP proposed abstracting of $495 \mathrm{Mm}^{3}$ annually from the Zambezi for use in agriculture in Pandamatenga by 2022 , with possible extension to supplement water needs in the south of the country. In 2009, Botswana had discussed plans to extract the water at various Zambezi Water Authority and Zambezi Rivercourse Commission meetings, and had received no objections. In 2010, a pre-feasibility study was carried out on a pipeline to connect Pandamatenga to North-South water carrier. The entire Chobe-Zambezi transfer project was, however, on "slow-burner" since then. More recently, in the 2015-2016, Ministry of Minerals, Energy and Water Resources, faced with water shortages in the south and particularly in Gaborone, reactivated the idea, fielding a proposal to reprioritize the transfer 
scheme, but with primary purpose of supplying water to the south of the country. At that stage, Zimbabwe has opposed Botswana's withdrawal from the Zambezi, and the budgetary restrictions (the Chobe-Pandamatenga scheme is projected to cost Pula $65 \mathrm{Bln}$, while 2017 budget for water resourced development is about Pula $11 \mathrm{Bln}$ ) prevent the project from being implemented fully and timely. While the future of the project seems to be uncertain, it is obviously an initiative that, if implemented, may have a significant consequence to the development in the region, particularly through enabling irrigated agriculture. It is not in our mandate to comment on the intended use of the transfer scheme to satisfy water needs in the southern part of the country. However, the extent the Zambezi water is used within the Pandamatenga area should be cognizant of the environmental and thus economic costs and benefits related to large scale irrigation, particularly considering the primarily tourism and wildlife-oriented direction of economic development proposed for the Chobe district in this document.

\subsubsection{Boreholes for wildlife}

Several water points have been established in the interior of the park (e.g. Ngwezumba Valley). Boreholes in CNP attract game, and thus improve game viewing and the tourism potential of the area. However, a study should be undertaken on the existing pumping strategy and its effect on wildlife use and on the biosphere around these water points, as well as the possible role that the water points have on predator densities and subsequent impact on rare and endangered herbivore species. Experiences e.g. in Kruger national park have shown the negative impact of water points on wildlife diversity, which have been closed down subsequently.

It should be considered to restrict water provision to some months in the dry season only, and pumping water into existing pans.

\subsection{Township and village development}

\subsubsection{Green development of Kasane-Kazungula Township}

Kasane would benefit from a green development approach: nature and green areas can extend right into the centre of town. This concept has been applied in different planning regions in the world, such as in Copenhagen, Denmark with the 'Green Finger Plan' (Vejre et al. 2007), I stanbul (Hosgor 2011), Barcelona, Arnhem and various other European cities (Lafortezza 2013). It would strengthen the image of the town as a tourism hub, and would improve the appreciation of the natural environment. In the current plan a number of developments are planned with an open waterfront (e.g. Kasane Waterfront, jetty and immigration offices area in Kasane and the Kazungula Public square and Waterfront) which detract from the wilderness experiences which tourists seek in Northern Botswana. The tourism service companies, servicing and maintenance industries, safari companies, rental companies and planning offices are currently spread all over the township. In the re-development of the township it should be considered to concentrate these in one area. Operational hotels and lodges with river frontage could remain in their location.

The role of riverfront forest vegetation for Heron species and as habitat for rare forest bird species (see section 6.7.2.3) and this for tourist use just cannot be over-emphasised. We strongly suggest a "Green" conservation zone along the river of at least 500 meters. All planned future developments under the Kasane-Kazungula redevelopment umbrella plan should include proposals for integration of Nature and Tourism functions and an assessment of the impact on bird- and wildlife. The need for environmental impact assessments of riverfront developments has been emphasised in the Kasane Kazungula re-development plan, but we recommend to institutionalise this requirement within the ILUP. Also general requirements for residential plots in terms of green space could be formulated. The re-developed commercial zone as well as the living quarters must be conducive for wildlife migration. Before the layouts are designed the wildlife corridors must be clearly identified using accurate wildlife research data, and a layout must be planned to ensure corridors are not cut, whilst a buffer zone of $1 \mathrm{~km}$ is conserved around the corridors to further minimise conflict. A relative low building density is aimed for which allows for the presence of wildlife and birds, also tree-lined streets are in keeping with the tourism potential of the town. 
This walk which is proposed in the Kasane-Kazungula redevelopment plan will cause a number of problems not foreseen in the plan at present such as a) disturbance of the bird habitats (e.g.

heronries, Owl roost location; habitat for Scalow's Turaco and other riverine forest birds). b) reduction of the quality of the present Tourist lodge and planned hotel(s) c) conflicts between tourism and wildlife particularly in the early morning and evening when tourist are most likely to use the walk. We propose as an alternative to develop a walking trail that leads through the built-up areas leading to the landmark spots in the plan, and in addition include some strategically chosen look-out points for birds while avoiding crossing wildlife corridors. This walk would integrate tourism activities with conservation in a safe and commercially viable way.

\subsubsection{Township expansion and degazettement of Forest Reserve}

The township is 'locked-in' between the Chobe River, the Chobe National Park and the Forest Reserve. The tourism industry and the transportation function of Kasane and Kazungula are rapidly expanding, therefore there is a need for Kasane-Kazungula to fulfil its function as a centre of economic growth and development, regionally and nationally. Therefore the need for further expansion of KasaneKazungula township is evident.

The expansion of the Kasane-Kazungula township area should be allowed only under strict conditions:

- The best area is identified between the airfield and current build-up area

- Corridors are essential, and should remain open (see § 8.3.2);

- Closed-off corridors should be restored

- The Kasane-Kazungula re-development (main street, renovated area) must be 'green' and of high environmental quality;

- Denser construction takes place in other quarters of town, to increase the capacity for housing people;

- Undeveloped plots that have been acquired more than five years ago, should be reclaimed, in line with legal procedures that are available; such plots can be re-used, exchanged for other plots, or given out again; a policy which is in line with DDP-7 (see also DDP-7: par. 3.4, par. 5.3.3, par. 5.6 and 5.7)

- Keeping land or acquiring land for speculation purposes (land grab) should be avoided by Land Board at all costs;

- The current zoning of land for agricultural functions in the development plan should be maintained to retain a diverse multifunctional landscape, a diversity of employment opportunities and local agricultural production capacity.

- Experts must prepare a proposal for the expansion of town for the medium term (10-15 years), indicating the area for expansion. Possibly a LUCIS approach should be followed to ensure the participation of residents in the planning process;

- A detailed SEA is done by independent experts of the to-be-degazetted area, which includes a Land Use Planner, Wildlife biologist, Town planner and Forestry expert.

\subsubsection{Development of villages and rural settlements}

Special and deliberate consideration should be made for the Chobe district infrastructure and the Chobe ILUP should advocate this as given the population figures alone, there is very little justification for the provision of physical infrastructure. For instance there is no Secondary School in Kasane (only a CJSS) and students are expected to attend Nata Senior Secondary which is at least $200 \mathrm{~km}$ away upon graduating from the Chobe CJSS.

In Chobe west the settlements Kavimba, Mabele, and Kachikau gradually link up, with development of houses and some shops or other services in between the villages. There is also pressure for new commercial developments, shops, guesthouses, tuck shops and so on. Some new developments take place West of the main road, except for some lodges (Muchenje Campsite and lodge) currently a petrol station is constructed just West of the main road. This bears risks with potential high floods, which can result in huge environmental damage.

To contain the developments, for each village a development zone for is designed of approximately $3 \mathrm{~km}$ from the center of the village. However, no development in the Floodplain should take place, the 
development contour should be East of the main road. For Parakarungu and Satau, this contour should concentrate on the high ground, where the risk of flooding is limited.

Lesoma village is part of the Kasane Forest Reserve. This results in an unwanted situation whereby all developments are technically illegal. The presence of the village and structures such as the kgotla or school are a fact. It seems therefore justified to degazet some forest for the village area, within this area farming can take place, and some concentrated expansion of the village is possible. The lodges currently present just north of the village would be included in the contour. Outside this village contour no further expansion should be allowed. No new lodges or other structures are permitted outside the village.

Other aspects to be considered for infrastructure development are:

- Improving road connectivity

- Sanitation, Storm water drains, Dumping sites, Landfills

- Relocation of public institutions, especially along the river front

- Improving public transport

\subsection{International cooperation}

The Institutional set-up as described in the KAZA TFCA Master Integrated Development Plan (see section 3.2) does not seem to provide explicitly for the facilitation of field-level cooperation among district administrations at both sides of the border, e.g. between Chobe District Land Use Planning Unit and its counterparts in Namibia or Zimbabwe. The present land use plan therefore foresees the establishment of a technical unit in Chobe District, that - with a mandate from the highest political authorities in the districts bordering the countries - will organise technical meetings across borders and sectors. At these meetings approaches to implementation of policies affecting land use can be harmonised across international frontiers, results will be evaluated and necessary adaptations may be proposed to the relevant authorities. Such a technical meeting might be organised once a year or more often as circumstances require. Guidance and collaboration should be sought with the KAZA TFCA secretariat in Kasane, which organisation - by doing so - will be strengthened. 
In summary: While the Chobe District ILUP as a national plan cannot regulate for planning across international borders it should comply with the provisions of the KAZA TFCA. Management of the following pressures/constraints and opportunities identified at Chobe District need to be harmonised across international borders:

- Resource requirements of migrating wildlife populations beyond the boundary of the planning area that needs facilitation by the creation of international corridors/dispersal areas within the Land-use plan.

- Livestock areas that transgress beyond international boundaries putting livestock (and wildlife-) at risk because of diseases being transmitted.

- Fisheries management needs to be harmonised, especially where this activity is practised within the riverbeds and floodplains where international borders are located.

- There are opportunities for diminishing tourism pressure and equity sharing across borders thereby developing an attractive and diversified tourism product for the KAZA region as whole. This requires a spatial planning in accordance with international agreements.

- International wildlife crime is becoming more and more large scale and violent. The borders provide easy escape routes for illegal activities like poaching. Poaching is more and more facilitated by communities across the border in countries like Namibia and Zimbabwe. There is an urgency to address this in an international context. As wildlife is known to seek refuge in areas where their safety is secured, such poaching tends to increase the pressure on the natural resources of the protected areas in Botswana, where animals like Elephants are relatively safe. To the North West, at the other side of the international border with Namibia, road construction has opened up the area which has facilitated cross-border-poaching and possibly other illegal activities.

- Economic opportunities may attract people from the poorer regions within the KAZA-area or beyond to settle in Chobe District. Settlement and employment policies need to be developed in a timely way to prevent undesirable impacts of such immigration. Further expansion of farms might jeopardize migration even further.

- Wildlife migration out of Hwange National Park (Zimbabwe) towards the West is obstructed by the presence of Pandamatenga farms in Botswana just across the river.

- A bridge is currently constructed across the Zambezi river into Zambia. The feeder road to that bridge already brings more incidence of degrading activities like fires and poaching that are likely to be stepped up when the bridge will be functional.

\subsection{CBNRM}

\subsubsection{CBOs}

The underlying premise of CBNRM - that those who bear the costs of wildlife must also receive the benefits in order to tolerate and even support it (Cassidy 2000) - becomes more and more important as human and wildlife populations expand, and land and resources become more scarce. Humanwildlife interactions are inevitable in a shared landscape; the trick is that the positive interactions should outweigh the negative.

Experience has shown that the older model of CBNRM that expects rural communities to function as corporations is dysfunctional (Blaikie 2006) based on flawed logic. For groups whose only common interest is that of shared location and exposure to nature, active participation in running CBNRM enterprises is challenging (Balint \& Mashinya 2006), because of different values, motivations and relations to the resource base.

The Namibian conservancies continue to function well, and there are indications that this is because most focus on a strong financial partnership (such as a joint venture agreement), instead of trying to assume management and employment functions themselves (Barnes et al. 2002).

The two major CBOs in Chobe District, CECT and KALEPA, have very important roles in ensuring a flow of benefits from wildlife back to their constituent members. The most effective way for this flow to continue happening is through sound partnerships such as sub-leasing tourist activities, or land for tourism facilities, to individuals or corporations with the necessary skills and interests to make the venture a success.

This is not to say that such individuals or corporations should not come from within the community; indeed, this could work well, but that the actual operation should be granted to someone with a very 
specific focus in that operation, who pays fees to the $\mathrm{CBO}$ for the privilege of running the operation in the CBO's area.

At the same time, there is sufficient supporting legislation, and enough room, for the bigger CBOs to function as an umbrella that supports smaller, interest-based enterprises such as cooperatives and user groups focused on specific natural resources. This allows diversification of products as well as management styles, and so builds resilience and sustainability into the CBNRM model.

Most importantly, the gap between rural community life and the international tourism industry is still very large, and likely to remain so - by very definition in the contrasting "rural" and "international" worlds. This means that continued facilitation of $C B O$ participation in the tourism is vital, and that the support of NGOs and extension agents is a prerequisite for the ongoing functioning of CBNRM in Botswana. NGOs in Botswana are themselves challenged, with limited access to funding due to the country's middle-income status. This means that it is imperative that the government find the resources to support communities, and ensure both their continued growth and skills development, and their continued acceptance of the disruption that wildlife so often represents in their daily lives.

\subsubsection{Joint Venture Partnerships}

In the principles for the plan approach (par. 1.3) the role of JVPs is mentioned. The emphasis on JVPs is made in order to show that such arrangements are preferable to the community trying to run a tourism enterprise directly through the $\mathrm{CBO}$, since the constitutional arrangements are too cumbersome. We prefer J oint venture partnerships with safari companies under the assumption that this will include a transfer of entrepreneurship and managerial skills in tourism business from companies to members of local communities, and there is an acceptable division of benefits for both communities and companies. Importantly, the concept of JVP should not be restricted to mean only outsider partners; such partners could be local companies, cooperatives or even individuals with appropriate resources. That is, the JVP concept does not exclude local entrepreneurs starting a commercial venture within a $\mathrm{CHA}$, in cooperation with the community.

The local conditions differ per area, and there cannot be a blueprint for the approach: the chosen approach should be based on local knowledge and expertise, on experiences made in the past, available entrepreneurs or safari companies that are willing to be involved etcetera. This should be assessed and worked out in the detailed management plan for the area.

\subsection{Poverty alleviation and economic development}

As indicated in par. 7.1 and 7.7, poverty is still widespread, in particular in rural areas and in remote settlements. Specific actions have been identified to improve the livelihoods of those that are having the least resources and opportunities to partake in Botswana's growth and development. The land resources are limited, as has been described in the several paragraphs from Chapter 8. Intensification rather than expansion is the way toward improved productivity.

The most important opportunities for the poor are the following:

- stimulate employment creation, e.g. in tourism and service providers

- improving rural livelihoods, by increasing farming success

- ensure (continued) access to common resources by the poor, e.g. building materials

- support for projects targeted at the poor, e.g. conservation agriculture, small enterprises related to tourism, firewood etc.

It is important to realise that wildlife tourism brings benefits to individuals, companies and the nation, but that the tourism sector cannot employ or directly benefit every household. However, it is important to ensure that the regions and people that bear the cost of wildlife tourism do receive sufficient benefits or compensation to offset those costs (which may include crop damage by wildlife or reduced access to common resources including game meat).

Employment creation can be through expansion of jobs in the tourism sector, both private and community based. However, considering the level of skills that may be required, this is only of limited potential (often unskilled staff) to employ the target group. Existing complicated regulations and permit requirements are a further impediment. It could be considered to organise for community-run 
campsites and other tourism initiatives to be temporarily exempted from some of the permit/regulation requirements, as is the case for e.g. the Khwai community campsite. Government could also attempt to support community trusts but also cooperatives of residents in starting tourism related activities.

Opportunities are also likely to lie in service provision for the tourism industry. This may be food production (e.g. horticulture), small shops in towns and villages or sale of crafts at a craft centre, possibly run as a cooperative as e.g. in Shorobe. The transport sector may also offer opportunities provided people can be trained: e.g. combi's for trips to Victoria Falls or boat rides near Kasane. Regarding development of tourism in e.g. the Forest Reserves care should be taken that in particular residents from nearby communities can benefit e.g. by including relevant in-service training opportunities Also, any community level benefits will needed to flow into the Chobe communities.

funds could be made available from government or BTO to assist communities to set up a cultural village in the Chobe enclave with related cultural activities, including guided (animal-spoor/plant) walks or visits to traditional homes. This will create some income and a few jobs.

Funds should be found to sponsor NGOs to work with communities on conservation agriculture (Tocadi Trust or Pabalelo trust) or on natural product harvesting and marketing (Wilds fruits of Africa). Funds are available through the Dept. of Forestry and Range Resources (e.g. US donor funds).

To secure rural livelihoods, farming success can be increased by good protective measures. Smaller horticultural projects can be better protected from e.g. Elephant intrusion than large fields. At the same time adequate technical support is required from the support staff of the Min of Agriculture. This support is a condition to improve the output from agriculture and for reaching these target groups. Such support should focus on crop choice (less maize; more horticulture), marketing and improved yields, e.g. through conservation farming techniques. Support and training can contribute to improved and intensified use of existing crop land and thus to reduced demand for land.

Animal husbandry can benefit from the production of fodder crops and improved rotational grazing.

The forest resources, as indicated in par. 4.5, are of particular importance for the rural communities that have few other resources to rely on. It is therefore important that they have continued access to the resources, but also that forest and veld management is supportive of maintaining the resources. Sustainable off-take levels should be observed, and it may be required conduct studies to assess the current levels of off-take, and define off-take levels that will ensure sufficient replenishment or recovery of resources (e.g. firewood, building poles).

\subsection{Key findings}

- Chobe being a core area for conservation, requires a sustainable development approach that ensures long-term opportunities for employment generation and social and economic development;

- Agriculture should focus on intensifying production, through e.g. small-scale irrigation, conservation farming etcetera;

- Irrigated farming might be of commercial interest but is not considered sustainable and is likely not economically feasible if all costs (and investments) are taken into account;

- Cluster fencing should be well-tailored and well-planned, with involvement of communities, wildlife specialists, agricultural and land use planners;

- Fenced areas should be limited in size, and not in potential corridors or dispersal areas; the geometry of the fence is also important to reduce the impact, and thus the effectiveness of the fence;

- The role of tourism in the region is dominant for future development of the larger region;

- More (self-)employment in the tourism industry can be created through improved skills training of residents and improved CBNRM projects;

- Chobe National Park urgently requires a management plan which addresses issues of infrastructure development and tourism development;

- The human-wildlife conflict must urgently be addressed in line with the suggestions made in par. 9.4.3; 
- A review of revenue system should ensure the development of funds to compensate residents for costs incurred due to wildlife damage;

- The wildlife corridors are essential to maintain the wildlife populations. These populations are vital for future economic development;

- Development of Kasane as a 'green township' would be fitting to its role as tourism hub, and in line with development of urban centres elsewhere in the world;

- The urgent need for room for expansion for Kasane-Kazungula township might need to be honoured, but a thorough study of the realignment is required, involving both town planners, forestry staff and wildlife and environmental experts;

- Water resources are limited, and careful planning is essential; the extent the Zambezi water is used within the Pandamatenga area should be cognizant of the environmental and thus economic costs and benefits related to large scale irrigation, particularly considering the primarily tourism and wildlife-oriented direction of economic development proposed for the Chobe district;

- Fisheries management should focus on ensuring efficient fisheries data collection through provision of enough manpower in the region;

- There is a good potential for fisheries development, through improved marketing for regional use;

- Fish Protection Areas should be established in an international context, in discussion with local communities, to ensure that important fish resources will be conserved;

- Wildlife and thus tourism puts many constraints on the communities, this however can be changed in an important opportunity for improving livelihoods of the rural population in Chobe District. 


\section{Information gaps \& research}

There has been a wealth of studies of northern Botswana, and Chobe in particular. Through archives, libraries and databases, as well as research organisations and NGOs many of these studies have been recovered.

However, at the same time fields were identified that have been insufficiently covered thus far. Below are some suggestions for further study and information gathering.

- A study of soils along the Chobe River between Kasane and Kazungula is lacking. This area may be very suited for farming, but no detailed soil mapping data was found to underpin this. A detailed soil survey would support the planning of e.g. irrigated farming and intensive horticultural production. This would facilitate better allocation of the scarce land resources, at the same time provide opportunities for local employment and production.

- Artificial water points have been developed for wildlife management, in particular in the northern part of Chobe National park and in Savuti. Further study is required of the pumping strategy and the impact of water provision on the biosphere (see par. 10.4.1). In other regions this has led to closure of water points for wildlife.

- It is largely unknown what the actual tourism carrying capacity is for Chobe District. Not so much the ecological capacity, but social capacity: what are visitors' expectations and how do they value the tourism product, is the increase that has taken place approaching limits for the region, what is the potential for further expansion? There is pressure for further increase of the volume of tourism, but it should be avoided at all cost that limits are exceeded.

- Long-term studies on ecological changes in the Forest Reserves are lacking. Such monitoring projects, that also study aspects of fire regime, forest regeneration and vegetation shifts would provide valuable information for management of the Forest Reserves.

- No fisheries monitoring data has been collected over the past 15 years. Such data is essential to install effective fisheries management planning, and should be collected again as part of all environmental monitoring efforts. 


\section{References}

Aarrestad PA, Masunga GS, Hytteborn H, Pitlagano ML, Marokane W, Skarpe C (2011) Influence of soil, tree cover and large herbivores on field layer vegetation along a savanna landscape gradient in northern Botswana. Journal of Arid Environments 75(3):290-297

Adams TS, Chase MJ, Rogers TL, Leggett KE (2016) Taking the Elephant out of the room and into the corridor: can urban corridors work? Oryx: 1-7

Adger WN (2000) Social and ecological resilience: are they related? Progress in human geography 24(3): 347-364

Alemaw B, Chaoka T, Totolo O (2006) Investigation of sustainability of rain-fed agriculture through soil moisture modeling in the Pandamatenga Plains of Botswana. Physics and Chemistry of the Earth, Parts A/B/C 31(15): 960-966

Andersson L-G, Janson T (1997) Languages in Botswana: language ecology in southern Africa. Longman Botswana

Andreassen, H.P., Wegge, P. \& Neo-Muhapeleng, G. (2014) The Chobe riverfront Lion population: A large predator as responder to Elephant-induced habitat heterogeneity. Elephants and savanna woodland ecosystems: A study from Chobe national park, Botswana. (eds C. Skarpe \& J.T.a.M. du Toit, S. R.). J ohn Wiley \& Sons, Ltd., J ohn Wiley \& Sons, Ltd., New York City,USA.

Arup Atkins (1990) Pandamatenga Development Study Final Report \& Environmental Impact Assessment. Gaborone. Botswana.

Anonymus, 2014. Market Analysis of Bird-Based Tourism: A Focus on the U.S. Market to Latin America and the Caribbean Including Fact Sheets on The Bahamas, Belize, Guatemala, Paraguay

AWF, 2004 - African Wildlife Foundation 2004. Biodiversity of the Four Corners Area: Bibliography. Occasional Publications in Biodiversity No.13, Eds. Timberlake, J., Bailey, M. \& Mundy, P. Biodiversity Foundation for Africa, Bulawayo / Zambezi Society, Harare.

Balint PJ, Mashinya J (2006) The decline of a model community-based conservation project: Governance, capacity, and devolution in Mahenye, Zimbabwe. Geoforum 37(5):805-815.

Barnes JI (2013) Economic Analyiso of Land Use Policies for Livestock, Wildlife and Disease Management in Caprivi, Namibia with Potential Wider Implications for Regional Transfrontier Conservation Areas.

Barnes JI, Macgregor J, Weaver LC (2002) Economic efficiency and incentives for change within Namibia's community wildlife use initiatives. World development 30(4):667-681

Barnes ME (2001) Effects of large herbivores and fire on the regeneration of Acacia erioloba woodlands in Chobe National Park, Botswana. African J ournal of Ecology 39(4): 340-350

Bartlam-Brooks H., Harris. S \& Bonyongo C (2011) Will reconnecting ecosystems allow long-distance mammal migration to resume? A case study of a Zebra Equus burchelli migration in Botswana. Oryx 45 (02): 210-216

Barnhoorn F, Jansen R, Riezebos HT, Sterkenburg J (1994) Sustainable development in Botswana: an analysis of resource management in three communal development areas. Koninklijk Nederlands Aardrijkskundig Genootschap

Beekma J, Bijsterbosch W, Brouwer L (1989) The Chobe enclave: soils, hydrology and range ecology inventories for land use planning.

Blaikie P (2006) Is small really beautiful? Community-based natural resource management in Malawi and Botswana. World development 34(11): 1942-1957

Blair Rains A, McKay A (1968) The Northern State Lands, Botswana. Land Resource Study. Ministry of Overseas Development,

Bowler MC (1992) Aerial cencus of Elephant and other large mammals in northwestern MatablelEland. October 1992. Department of National Parks and Wildlife Management, Harare, Zimbabwe.

Botswana CfAR (2013) Forest management and use in Botswana: brief situation analysis and options for the Forest Conservation Strategy. Forest Conservation Botswana,

Botswana Statistics (2014) Botswana Environment Statistics: Human Settlements Report. Gaborone: Statistics Botswana,

Botswana Statistics (2015) Mapping poverty in Botswana 2010. Gaborone: Statistics Botswana, 
Botswana Statistics (2016) National Accounts Statistics Report 2014. Gaborone: Statistics Botswana,

Bourquin S, Brooks C (2013) Protocol for the monitoring of fauna and flora within Ngamiland,

Botswana. SAREC,

Bradshaw BF Notes on the Chobe River, South Central Africa. In: Proceedings of the Royal Geographical Society and Monthly Record of Geography, 1881. vol 3. JSTOR, p. 208-213

Broekhoven G, Savenije H, Von Scheliha S (2012) Moving forward with forest governance. Tropenbos International

BTO Botswana Ecotourism certification system.

BTO (2015) Terms of reference for consultancy services for the development of a management plan for Concession area $\mathrm{CH} 1$.

Brunner P, Bauer P, Eugster M, Kinzelbach W (2004) Using remote sensing to regionalize local precipitation recharge rates obtained from the Chloride Method. J Hydrol 294:241-250.

Byers, B. (2001) Conserving the Miombo Ecoregion. WWF Southern Africa Regional Programme Office (SARPO)

Burke J, Pricope N, Blum J (2016) Thermal I magery-Derived Surface Inundation Modeling to Assess Flood Risk in a Flood-Pulsed Savannah Watershed in Botswana and Namibia. Remote Sensing $8(8): 676$

Burkhard, Sara, Kow, Nicole and Lucy Fuggle, 2016. Travel trend report 2017. 42p.

Campbell A (2004) Establishment of Botswana's national park and game reserve system. Botswana notes and records 36:55-66

Campbell A, Tlou T (1984) History of Botswana. Botswana: Macmillan: 229-37

Cassidy L (2000) CBNRM and legal rights to resources in Botswana. SNV/IUCN Gaborone, Botswana

Cassidy $L$ (2001) Improving Women's participation in CBNRM in Botswana. Citeseer

Cassidy L, Good K, Mazonde IN, Rivers R (2001) An assessment of the status of the San/Basarwa in Botswana. Legal Assistance Centre, Namibia

Central Statistics Office (1992) Population of Towns, Villages and Associated Localities in August 1991. Government Printer, Gaborone.

Centre for Applied Research (2009) Development of the Botswana Guidelines for Utilisation of Forest Reserves for Ecotourism Activities. UNDP,

Chase M (2011) Dry season fixed-wing aerial survey of Elephants and wildlife in northern Botswana. Elephants without Borders, San Diego Zoological Society, Department of Wildlife and National Parks. Report: 138

Chase M (2013) Status of wildlife populations and land degradation in Botswana's forest reserves and Chobe District. Published by Forest Conservation Botswana, Elephants Without Borders, and Zoological Society of San Diego

Chase M, Landen K (2011) View from the top. Afr. Geogr. 19:39-47

Chase MJ (2007) Home ranges, transboundary movements and harvest of Elephants in northern Botswana and factors affecting Elephant distribution and abundance in the Lower Kwando River Basin. ProQuest

Chase MJ, Schlossberg S, Griffin CR et al. (2016) Continent-wide survey reveals massive decline in African savannah Elephants. PeerJ 4:e2354

Chevallier R, Harvey R (2016) Is Community-Based Nat ural Resource Management in Botswana Viable?, Policy Insights. South African Institute for International Affairs,

Child GF (1968) An ecological survey of northeastern Botswana. Food and Agricultural Organization

Chobe District Council (2003) Chobe District Development Plan 6: 2003-2009. Government Printer, Gaborone

Chobe District Council (2010) Chobe District Development Plan 7: 2010-2016. Government Printer, Gaborone

Cordry G (2010) Assessing the Potential Ecological Impacts of the Proposed Kazungula Border Development at Cassandra Farms.

Cronberg G, Gieske A, Martins E, Nengu JP, Stenström I (1995) Hydrobiological Studies of the Okavango Delta and Kwando/Linyanti/Chobe River, Botswana I Surface Water Quality Analysis. Botswana Notes and Records: 151-226

Curson H (1932) Distribution of glossina in the Bechuanaland protectorate. Transactions of the Royal Society of Tropical Medicine and Hygiene 26(3):297-300 
Cushman SA, Chase M, Griffin C (2010) Mapping landscape resistance to identify corridors and barriers for Elephant movement in southern Africa. Spatial complexity, informatics, and wildlife conservation. Springer, pp. 349-367

De Cauwer V, Geldenhuys CJ, Aerts R, Kabajani M, Muys B (2016) Patterns of forest composition and their long term environmental drivers in the tropical dry forest transition zone of southern Africa. Forest Ecosystems 3(1):23

De Satgé R, Kleinbooi K, Tanner C (2011) Decentralised Land Governance: Case Studies and Local Voices from Botswana, Madagascar and Mozambique. Institute for Poverty, Land, and Agrarian Studies, University of the Western Cape

De Souza R-M, Williams JS, Meyerson FAB (2003) Critical links: Population, health, and the environment. Citeseer

Deloitte and Touche Management Consultants (PTY) (1992) Chobe National Park Management Plan Vol. 1.

DeMotts R, Hoon P (2012) Whose Elephants? Conserving, Compensating, and Competing in Northern Botswana. Society \& Natural Resources 25(9):837-851

Department of Forestry and Range resources (2010) Ecotourism manual for forest reserves. MEWT, Gaborone,

Department of Forestry and Range resources (2016) Forest reserves ecotourism guidelines in Botsewana (draft). MEWT, Gaborone,

Department of Forestry anof Range Resources (2016a) Chobe District bush fire operations management plan 2016-2020.

Department of Forestry anof Range Resources (2016b) Chobe District bush fire risk management plan 2016-2020.

Department of Water Affairs, Centre for Applied Research (2015) Policy Brief Botswana's Agriculture and Water Resources. In: Botswana W. (ed). Policy Brief 3: Agriculture \& water resources in Botswana, Gaborone,

Dietz T, Ostrom E, Stern PC (2003) The struggle to govern the commons. science 302(5652): 19071912

Dinerstein, E, D. Olson, J. Atchley, C. Loucks, S. Contreras- Balderas, R. Abell, E. Inigo, E. Enkerlin, C. Williams, and F. Castelleja. 2000. Ecoregion-based conservation in the Chihuahuan Desert: A biological assessment. World Wildlife Fund and others.

Dos Santos J (2011) Long-range movements of three savannah Elephants (Loxodonta Africana Africana) within a transfrontier conservation area (TFCA) - Adaptive Management Implications. Elephant Movements and Human-Elephant Conflict in a Transfrontier Conservation Area: 11

DTRP (2014) Kasane Kazungula redevelopment plan. Ministry of Lands and Housing,

Du Toit, J. T., Skarpe, C., \& Moe, S. R. (2014). Elephants and heterogeneity in savanna landscapes. In C. Skarpe, J. T. M. du Toit, \& S. R. Moe (Eds.), Elephants and savanna woodland ecosystems: A study from Chobe national park, Botswana. New York City, USA: John Wiley \& Sons, Ltd., John Wiley \& Sons, Ltd.

DWNP (2011) Anthrax related wildlife mortality. Preliminary report (2004-2010).

DWNP (2012) Aerial census of animals in Botswana. 2012 dry season.

DWNP (2014) Wildlife Conservation Strategic Research 2014-2018.

Ecosurv, (1996) Chobe Enclave Socio-economic Study, Main Report. Produced as part of the Natural Resources Management Project (USAID Project 690-0251.33). Department of Wildlife and National Parks, Gaborone, Botswana.

Ecosurv (2014) Review / Update of the National Biodiversity Action Plan (NBSAP).

Ecosurv (2017) Scoping Report - Strategic Environmental Assessment of the Chobe Forest Reserves Management Plans. Gaborone, Department of Forestry and Range Resources, and Forest Conservation Botswana.

Eliot NB, Cushman SA, MacDonald DW \& Loveridge AJ (2014) The devil is in the disperser; predictions of landscape connectivity change with demography. Journal of Appl. Ecol. 51. 1169-78.

EHES (2007) Environmental and Social Impact Assessment Report for the Pandamatenga Commercial and Small Scale Farms - Agricultural Infrastructure Development and Agricultural Production I mprovement.

ESA (2014) Pandamatenga Agricultural Infrastructure Development Project; Development of a Wildlife Management Plan 
European Commission (2016) LARGER THAN ELEPHANTS. Inputs for an EU strategic approach to wildlife conservation in Africa.

Ferguson K, Chase M (2010) Elephants and fencing conflicts in the GLTFCA and KAZA TFCA.

Forest Conservation Botswana (2013) Forest Conservation Strategy 2013 - 2020.

Fullman TJ (2009) Spatial dynamics of Elephant impacts on trees in Chobe National Park, Botswana. University of Florida

Fullman TJ, Bunting EL (2014) Analyzing Vegetation Change in an Elephant-Impacted Landscape Using the Moving Standard Deviation Index. Land 3(1): 74-104

Fullman TJ, Child B (2013) Water distribution at local and landscape scales affects tree utilization by Elephants in Chobe National Park, Botswana. African J ournal of Ecology 51(2):235-243

Funston P., Henschel P., \& Maclennan S. (2016) Assessing the distribution and status of Lions and other large carnivores in South-Eastern Angola. Panthera

Fynn RWS (2014) The Savuti-Mababe-Linyanti ecosystem of northern Botswana: policy implications for management and conservation of an unmodified ecosystem of global scientific significance. ORI policy documents. SASSCAL,

Fynn, RWS., Chase, M. \& Röder, A. (2014): Functional habitat heterogeneity and large-herbivore seasonal habitat selection in northern Botswana. South African J ournal of Wildlife Research 44(1): 1- 15

Gilmore KS (1979) An investigation into the decline of the Yambezi Fisherman's Co-operative Society. Botswana Notes \& Records 11(1): 97-102

GISPlan (2013) CH/12 Concession area Management Plan.

GISPlan (2016) Land Use and Management Plan For Concession Area CH1 (Inception report.

GIZ 2013 Carbon Emission Accounting Report - Botswana Test Site, Development of Integrated Monitoring Systems for REDD+ in the Southern African Development Community (SADC). GIZ, Bonn.

Government of Botswana (2000) National Parks and Game Reserves Regulations. Gaborone,

Government of Botswana (2008a) Forest Act.

Government of Botswana (2008b) Tourism Act. Government Printer, Gaborone,

Government of Botswana (2009) Botswana fourth national report to the Convention of Biological Diversity.

Government of Botswana (2010) Unesco World Heritage nomination Chobe Linyanti System.

Government of Botswana (2011a) Integrated Development Plan: Botswana Component of the KAZA TFCA, pp. $145 \mathrm{pp}$

Government of Botswana (2011b) National Parks and Game Reserves regulations.

Government of Botswana (2012) Re-design of the Zambezi Integrated Agro-Commercial Development Project. In: Agriculture M. o. (ed), CAB Memo 128. Government Printer, Gaborone,

Government of Botswana (2013a) Presidential Directive - Introduction of integrated farming in agricultural land. CAB 2(B)/2013. Government Printer, Gaborone,

Government of Botswana (2013b) Wildlife Policy. Government Printer, Gaborone,

Government of Botswana (2014) Wildlife Conservation and National Parks (prohibition of hunting, capturing or removal of animals) Order. Government Printer, Gaborone,

Government of Botswana (2016a) Fish Protection regulations. Government Printer, Gaborone,

Government of Botswana (2016b) Wealth Accounting and the Valuation of Ecosystem Services (WAVES). Botswana Country Report 2016.

Government of Botswana. (2016c). Draft National Development Plan 11; April 2017-March 2023: Ministry of Finance and Development Planning, Gaborone, Botswana.

Government of Botswana. (2016d). Vision 2036 - Achieving prosperity for all: The vision 2036 presidential task team, Gaborone, Botswana.

Government of Botswana, Mozambique, Tanzania, Zambia, and Zimbabwe (1988) Agreement on the action plan for the environmentally sound management of the common Zambezi River System.

Gumbo GB (2010) Economic and social change in the communities of the wetlands of Chobe and Ngamiland, with special reference to the period since 1960. University of Cape Town

Gupta AC (2013) Elephants, safety nets and agrarian culture: understanding human-wildlife conflict and rural livelihoods around Chobe National Park, Botswana. Journal of Political Ecology 20:238254 
Gusset M, Swarner MJ , Mponwane L, Keletile K, McNutt JW (2009) Human-wildlife conflict in northern Botswana: livestock predation by Endangered African Wild dog Lycaon pictus and other carnivores. Oryx 43(1): 67-72

Hachileka E (2003) Sustainability of wildlife utilisation in the Chobe District, Botswana. South African Geographical J ournal 85(1):50-57

Hall B (1956) Notes on a small collection of birds from Panda Matenga, NE Bechuanaland. Ostrich 27(3): $96-109$

Hancock P (1990) Future of Botswana's Elephants. Kalahari Conservation Society

Hardin G (2009) The Tragedy of the Commons*. Journal of Natural Resources Policy Research $1(3): 243-253$

Hemson G, Maclennan S, Mills G, Johnson P, Macdonald D (2009) Community, Lions, livestock and money: A spatial and social analysis of attitudes to wildlife and the conservation value of tourism in a human-carnivore conflict in Botswana. Biological Conservation 142(11):2718-2725

Herrero HV, Southworth J, Bunting E (2016) Utilizing Multiple Lines of Evidence to Determine Landscape Degradation within Protected Area Landscapes: A Case Study of Chobe National Park, Botswana from 1982 to 2011. Remote Sensing 8(8): 623

Hitchcock RK (2002) 'We are the First People': Land, Natural Resources and Identity in the Central Kalahari, Botswana. J ournal of Southern African Studies 28(4): 797-824

Hitchcock RK, Sapignoli M, Babchuk WA (2011) What about our rights? Settlements, subsistence and livelihood security among Central Kalahari San and Bakgalagadi. The International J ournal of Human Rights 15(1):62-88

Hodson, A. W. (1912). Trekking the Great Thirst: travel and sport in the Kalahari Desert: C. Schribner's Sons.

Hoşgör, Z., \& Yigiter, R. (2011). Greenway Planning Context in Istanbul-Haliç: A Compulsory Intervention into the Historical Green Corridors of Golden Horn. [Landscape Research]. Landscape Research, 36(3), 341-361.

Hunter, C.G. (1996) Land uses on the Botswana/Zimbabwe border and their effects on Buffalo. Southern African J ournal of Wildlife Research 26(4): 136- 150.

Huntley BJ (1982) Southern Africa Savannas. In: Huntley BJ \& Walker BH (eds) Ecology of Tropical Savannas. Berlin: Springer-Verlag.

Hunter TCG \& Kerley GIH (1999) African Buffalo responses to risks and boundaries in hunting, agriculture, national parks, $\&$ urban land uses. Proceedings of the third international conference on wildlife ecology and transportation (icowet)

Holdich T, Gibbons M, Coryndon M, Reid PC (1901) J ourneys in the Linyanti Region: Discussion. The Geographical J ournal 17(6):585-588

Hoşgör, Z., \& Yigiter, R. (2011). Greenway Planning Context in Istanbul-Haliç: A Compulsory Intervention into the Historical Green Corridors of Golden Horn. [Landscape Research]. Landscape Research, 36(3), 341-361. doi: 10.1080/01426397.2011.555529

IUCN S (2012) IUCN SSC Guiding principles on trophy hunting as a tool for creating conservation incentives. Ver 1:1-11

IUCN (2017) www.iucnredlist.org /

Jansen R, Kamweneshe B (1999) Transboundary approaches to the conservation and utilisation of the Chobe-Caprivi Wetlands. Workshop report. Kasane, Botswana, pp. 72

Jones BT (2002) Chobe Enclave. by: IUCN/SNV CBNRM Support Programme

J ones BT \& Taylor R (2013) Climate Change Adaptation, Complex and Corridor Development in Caprivi Region. SAREP 2013

Jones BT, Diggle RW, Thouless C (2015) From Exploitation to Ownership: Wildlife-Based Tourism and Communal Area Conservancies in Namibia. Institutional Arrangements for Conservation, Development and Tourism in Eastern and Southern Africa. Springer, pp. 17-37

Kalwij J, de Boer W, Mucina L, Prins H, Skarpe C (2008) Long-term effects of artificial water supply on tree dynamics in the savanna ecosystem of Chobe (Botswana).

Kavango-Zambezi Transfrontier Conservation Area (2014) Master integrated development plan 20152020.

Kaynak E, Marandu EE (2006) Tourism market potential analysis in Botswana: a Delphi study. Journal of Travel Research 45(2):227-237

KCS (1987) Preliminary Environmental Impact Assessment. Mpandamatenga Commercial \& Communal Farms. Kalahari Conservation Society. Gaborone 
Kgathi D, Sekhwela M (2003) Sustainability of the commercial exploitation and management of the Chobe Forest Reserves in Botswana. South African Geographical J ournal 85(1):26-34

Kgathi D, Sekhwela M, Hamandawana H (2003) Sustainability of commercial agriculture in Chobe District, Botswana. South African Geographical Journal 85(1): 18-25

Kgathi DL, Mmopelwa G, Mosepele K (2005) Natural resources assessment in the Okavango Delta, Botswana: Case studies of some key resources. Natural Resources Forum 29(1):70-81

Kgathi DL, Ngwenya BN, Sekhwela MB (2012) Potential impacts of biofuel development on biodiversity in Chobe District, Botswana. Bioenergy for Sustainable Development in Africa. Springer, pp. 247260

Lafortezza, R., Davies, C., Sanesi, G., \& Konijnendijk, C. (2013). Green Infrastructure as a tool to support spatial planning in European urban regions. [Green Infrastructure as a tool to support spatial planning in European urban regions]. Forest - Biogeosciences and Forestry/Forest and Landscape Management, 6(3), 102-108. doi: 10.3832ifor0723-006

Lepetu J (2005) Socio economic impact analysis and stakeholders' preference to the conservation of Kasane Forest Reserve, Northern Botswana.

Lepetu J, Alavalapati J, Nair P (2010) Forest dependency and its implication for protected areas management: A case study from Kasane Forest Reserve, Botswana.

Lepetu J, Alavalapati J, Nair P (2012) Forest dependency and livelihood around Kasane Forest Reserve, Botswana.

Lepetu J, Garekae H (2015) Attitudes of Local Communities towards Forest Management Practices in Botswana: The Case Study of Kasane Forest Reserve. International J ournal of Agriculture and Forestry 5(2): 138-145

Liu J, Daily GC, Ehrlich PR, Luck GW (2003) Effects of household dynamics on resource consumption and biodiversity. Nature 421(6922): 530-533

Livingstone D (1858) Missionary Travels and Researches in South Africa: Including a Sketch of Sixteen Years' Residence in the Interior of Africa, and a Journey from the Cape of Good Hope to Loanda on the West Coast; Thence Across the Continent, Down the River Zambesi, to the Eastern Ocean. Harper \& Brothers

Macdonald D, Loveridge A, Rabinowitz A (2010) Felid futures: crossing disciplines, borders, and generations. In: Macdonald D. a. L., A. (ed), Biology and Conservation of Wild Felids. Oxford University Press, Oxford, pp. 599-650

Magole, L. I., \& Magole, L. (2011). Revisiting Botswana's high-value, low-volume tourism. Tourism Analysis, 16(2), 203-210.

Manwa H, Manwa F (2014) Poverty alleviation through pro-poor tourism: the role of Botswana forest reserves. Sustainability 6(9):5697-5713

Manyemane, J.M (2000). Constraints to fisheries development in Botswana. In Proceedings of a "Workshop on co-management of shared freshwater fisheries" held at Zambezi Lodge, Katima Mulilo, Caprivi, Namibia, 14 - 16 November, 2000. Annexure B

Marr, A (1965). Report on Fisheries Survey in Bechuanaland B.P, in the years 1963/64. OXFAM, UK. Marr, A (1966). Fish manufacturing level at village level in Ngamiland, Bechuanaland B.P. OXFAM, UK. Martin JD (1939) The Baikiaea forests of Northern Rhodesia. Empire Forestry J ournal 19(1):8-18

Martin RB (2003) Species report for Roan Hippotragus equinus, Sable Hippotragus niger and Tsessebe Damaliscus lunatus. Ministry of Environment and Tourism, Windhoek, Namibia

Masundire $\mathrm{H}$ Wetlands of Botswana: Ecology, management and conservation. In: Proceedings of the Conference on Wetlands Management in Botswana, 1994. p. 21-33

Mazvimavi D, Wolski P (2006) Long-term variations of annual flows of the Okavango and Zambezi Rivers. Phys Chem Earth Parts ABC 31:944-951. doi: 10.1016/j.pce.2006.08.016

Mbaiwa J (2013) CBNRM status report of 2012/13. Gaborone: Kalahari Conservation Society

Mbaiwa JE (2005a) Enclave tourism and its socio-economic impacts in the Okavango Delta, Botswana. Tourism Management 26(2): 157-172

Mbaiwa JE (2005b) The Socio-cultural Impacts of Tourism Development in the Okavango Delta, Botswana. Journal of Tourism and Cultural Change 2(3):163-185

Mbaiwa JE (2015) Community-based natural resource management in Botswana. Institutional arrangements for conservation, development and tourism in Eastern and Southern Africa. Springer, pp. 59-80

Mbaiwa JE, Spenceley A (2008) The realities of ecotourism development in Botswana. Responsible Tourism: Critical issues for conservation and development: 205-224 
Mbaiwa JE, Stronza AL (2011) Changes in resident attitudes towards tourism development and conservation in the Okavango Delta, Botswana. Journal of Environmental Management 92(8): 1950-1959

McCarthy TS, Ellery WN, Stanistreet IG (1992) Avulsion mechanisms on the Okavango Fan, Botswana: the control of a fluvial system by vegetation. Sedimentology 39:779-795.

McCulloch G, Kootsositse MV, Rutina L (2009) Botswana's protected Important Bird Area's - Status and Trends report.

Mendelsohn J, Roberts C (1997) An Environmental Profile and atlas of Caprivi. Directorate of Environmental Affairs.

Merron, G.S (1989). A Checklist of the Fishes of the Kwando River, Selinda (Magwegqana) Spillway, Lake Liambezi and Chobe River Systems with Notes on their Biology and Distribution. Botswana Notes and Records, 21: 135-151

Merron GS, Sehemo T (1987) Analysis of fish catches during the 1985 Chobe fishing competition. Botswana Notes and Records 19:91

MEWT (2008?) Chobe National Park Plan.

MEWT (2016) Guidelines for Agro-tourism.

Millar C (1987) Exploitation of Botswana's Forest Reserves: A cause for concern. Forest Association Report, 1986-87:31-41

Miller O (1939) The Mukusi Forests of the Bechuanaland Protectorate. Empire Forestry J ournal 18(2): 193-201

Ministry of Agriculture D (2015) Consultancy services for the feasibility study for the Zambezi Integrated Agro-Commercial development project. Conceptual design report. Final report.

Ministry of Environment WaNP (2013) The Integrated Development Plan for the Kavango-Zambezi Transfrontier Conservation Area for the Botswana Component. Government of Botswana, Gaborone. Gaborone,

Ministry of Lands and Resettlement (2015a) Baseline report (Vol. 1) for the Zambezi Integrated Regional Land-use Plan. Windhoek, Namibia,

Ministry of Lands and Resettlement (2015b) Integrated Regional Land-use Plan for the Zambezi Region (Vol. 2). Windhoek, Namibia,

Mmopelwa G, Mosepele K, Mosepele B, Moleele N, Ngwenya B (2009) Environmental variability and the fishery dynamics of the Okavango Delta, Botswana: the case of subsistence fishing. African Journal of Ecology 47(s1): 119-127

Mmopelwa, T.G (2000a). Policy and legislation pertaining to Botswana fisheries. In Proceedings of a "Workshop on co-management of shared freshwater fisheries" held at Zambezi Lodge, Katima Mulilo, Caprivi, Namibia, 14 - 16 November, 2000. Annexure B

Mmopelwa, T.G (2000b). A historical account of fisheries research in the Okavango and Chobe/ Linyanti systems. In Proceedings of a "Workshop on co-management of shared freshwater fisheries" held at Zambezi Lodge, Katima Mulilo, Caprivi, Namibia, 14 - 16 November, 2000. Annexure BMarco MD, Brooks T, Cuttelod A et al. (2015) Quantifying the relative irreplaceability of important bird and biodiversity areas. Conservation Biology

Mmopelwa T (2001) Fisheries Annual Report for 2000/2001. Fisheries Section, Ministry of Agriculture, Gaborone, Botswana

Mmopelwa T (2002) Fisheries Annual Report for 2001/2002. Fisheries Section, Ministry of Agriculture, Gaborone, Botswana

Mmopelwa T (2004) Fisheries Annual Report for 2003/2004. Fisheries Section, Ministry of Agriculture, Gaborone, Botswana

Moganane BG, Van Waveren E, Remmelzwaal A (1990) Soils of the Pandamatenga Plains. FAO, Gaborone,

Morton H, Winter E, Grote U (2016) Assessing natural resource management through integrated environmental and social-economic accounting The case of a Namibian conservancy. The Journal of Environment \& Development: 1070496516664385

Mosetlhi BBT (2012) The influence of Chobe National Park on people's livelihoods and conservation behaviors. University of Florida

Mosugelo DK, Moe SR, Ringrose S, Nellemann C (2002) Vegetation changes during a 36-year period in northern Chobe National Park, Botswana. African Journal of Ecology 40(3):232-240 
Muboko N, Chigumira T, Mashapa C, Gandiwa E, Chibememe G, Muposhi VK (2014) Impacts of Wood Poaching on Vegetation Structure and Composition in Mukuvisi Woodland, Zimbabwe. Journal of Environmental Protection 2014

Muposhi VK, Gandiwa E, Chemura A, Bartels P, Makuza SM, Madiri TH (2016) Habitat Heterogeneity Variably Influences Habitat Selection by Wild Herbivores in a Semi-Arid Tropical Savanna Ecosystem. PloS one 11(9): e0163084

Murray-Hudson M, Parry D, Murray M, Cassidy L, Moelesti B (1994) Natural Resources Utilisation: A Compilation of Documented Natural Resource Use in the Multiple Use CHAs of the Okavango and Kwando WMAs. Gaborone: NRMP, DWNP \& Tswana Land Board,

Næsje TF, Hay CJ, Kapirika S, Sandlund OT, Thorstad EB (2001) Some ecological and socio-economic impacts of an angling competition in the Zambezi River, Namibia. NINA - NIKU Project Report 14: 1-31

Naidoo R, Chase M, Beytell P et al. (2016a) A newly discovered wildlife migration in Namibia and Botswana is the longest in Africa. Oryx 50(01):138-146

Naidoo R, Stuart-Hill G, Weaver LC, Tagg J, Davis A, Davidson A (2011) Effect of diversity of large wildlife species on financial benefits to local communities in northwest Namibia. Environmental and Resource Economics 48(2): 321-335

Naidoo R, Weaver LC, Diggle RW, Matongo G, Stuart-Hill G, Thouless C (2016b) Complementary benefits of tourism and hunting to communal conservancies in Namibia. Conservation Biology

National Marine Fisheries Service, 2014. "Fisheries Economics of the United States 2012" pages 6 and 8, NOAA Technical Memorandum NMFS-F/SPO-13.Ndeinoma A, Wiersum KF (2016) Diversity of governance arrangements for indigenous natural products in communal areas of Namibia.

Nduwayezu J, Mafoko G, Mojeremane W, Mhaladi L (2015) Vanishing Multipurpose Indigenous Trees in Chobe and Kasane Forest Reserves of Botswana. Resources and Environment 5(5):167-172

Nellis MD, Bussing CE (1990) Spatial variation in Elephant impact on the Zambezi teak forest in the Chobe national park, Botswana. Geocarto International 5(2):55-57

Nengu S (1995) Status of fisheries in wetlands. In: Masundire H. M., Eyeson, K.N and Mpuchane, S.F (editors), Wetlands management in Botswana: (ed), Wetlands Management in Botswana,

Wetlands Coordinating Committee, Botswana. WCC, Kasane, 14 - 16 November, 1994, pp. 59-64

Norman MJT, Pearson CJ, Searle P (1995) The ecology of tropical food crops. Cambridge University Press

North West District Council (2007) ODMP Sustainable Tourism \& CBNRM Component. Final Report. Maun,

OITC2 (2011) Environmental and social impact assessment (ESIA) Kazungula Bridge.

Olson, D. M. \& Dinerstein, E. (2002) The Global 200: Priority Ecoregions for Global Conservation. Annals of the Missouri Botanical Garden. Vol. 89, No. 2. pp. 199-224

Owen-Smith N, Chafota J (2012) Selective feeding by a megaherbivore, the African Elephant (Loxodonta africana). J ournal of Mammalogy 93(3):698-705

Pardo M, Ristori G, D'Acqui L, Almendros G (2003) An assessment of soil fertility and agronomic constraints in southern African savannas: A case study of the Pandamatenga area, Botswana. South African Geographical J ournal 85(1):35-41

Parks DoWaN (2015) Chobe National Park Management Plan.

Parry D, Campbell B (1992) Attitudes of rural communities to animal wildlife and its utilization in Chobe Enclave and Mababe Depression, Botswana. Environmental Conservation 19(03): 245-252

Penry (1994) Bird Atlas of Botswana. Glen Lorien Books

Natural Resources and People (2009) Consultancy for the Review of Wildlife Management Areas (WMA) Regulations and the Community, Wildlife \& Natural Resources and Tourism Lease Agreements. BioKavango,

Perkins, J (2016) Consultancy to Identify Forest Areas in Communal Areas in Central, North and North-Western Botswana. FCB

Pricope NG (2013) Variable-source flood pulsing in a semi-arid transboundary watershed: the Chobe River, Botswana and Namibia. Environmental Monitoring and Assessment 185(2): 1883- 1906

Pricope NG, Binford MW (2012) A spatio-temporal analysis of fire recurrence and extent for semi-arid savanna ecosystems in southern Africa using moderate-resolution satellite imagery. Journal of environmental management 100:72-85 
Purchase G, Mateke C, Purchase D (2007) A review of the status and distribution of carnivores, and levels of human-carnivore conflict, in the protected areas and surrounds of the Zambezi Basin. Zambezi Society

Ramotadima M, Vandewalle M, Mucheka J, Cattadori I, Drake N 2.4 Long-term Changes in Elephant Distribution and Seasonal Factors: Influence on Conflict Incidence and Impacts on Gender Specific Rural Livelihoods-KA Alexander. TOWARDS RATIONALIZING TRANSBOUNDARY ELEPHANT MANAGEMENT AND HUMAN NEEDS IN THE KAVANGO/MID-ZAMBEZI REGION: 36

Reid PC (1901) J ourneys in the Linyanti region. The Geographical J ournal 17(6):573-585

Remmelzwaal A, Van Waveren E, Baert G (1988) The soils of Chobe district

Reside AE, VanDerWal J, Kutt A, Watson I, Williams S (2012) Fire regime shifts affect bird species distributions. Diversity and Distributions 18(3):213-225

Robertson F. (2005) Ecological Processes within the Four Corners Area. Occasional Publications in Biodiversity No.16. Biodiversity Foundation for Africa. Bulawayo, Zimbabwe

Roever CL (2013) Spatial determinants of habitat use, mortality and connectivity for Elephant populations across southern Africa. University of Pretoria

Roever CL, Van Aarde RJ, Chase M (2013) Incorporating mortality into habitat selection to identify secure and risky habitats for savannah Elephants. Biological conservation 164:98-106

Roever CL, Van Aarde RJ, Chase MJ (in preparation) Similarity in habitat preferences impedes humanElephant coexistence. Ecology Letters

SAREP (2013) IRDNC/SAREP Wildlife Complex Corridor Monthly Activity Report

Sayer J, Sunderland T, Ghazoul J et al. (2013) Ten principles for a landscape approach to reconciling agriculture, conservation, and other competing land uses. Proceedings of the National Academy of Sciences 110(21):8349-8356

Schulz A, Hammar A (1897) The new Africa. A journey up the Chobe and down the Okavango River. London (Heinemann),

Seaman MT, Scott WE, Walmsley RD, van der Waal BCW, Toerien DF (1978) A limnological invesstion of Lake Liambezi, Caprivi. J ournal of the Limnological Society of Southern Africa 4(2): 129-144

Sebele LS (2010) Community-based tourism ventures, benefits and challenges: Khama rhino sanctuary trust, central district, Botswana. Tourism Management 31(1):136-146

Selous FC (1881) A Hunter's Wanderings in Africa: Being a Narrative of Nine Years Spent Amongst the Game of the Far Interior of South Africa, Containing Accounts of Explorations Beyond the Zambesi, on the River Chobe, and in the Matabele and Mashuna Countries, with Full Notes Upon the Natural History and Present Distribution of All the Large Mammalia. R. Bentley \& son

SGI Studio Galli Ingenieri, Metaferia Consulting Engineers (2014) Zambezi Integrated Agrocommercial development Project. Executive Summary.

Shamukuni DM (1972) The baSubiya. Botswana Notes and Records 4: 161-184

Simpson CD (1975) A detailed vegetation study on the Chobe River in north-east Botswana. Kirkia 10(1): 185-227

Skarpe C, Aarrestad PA, Andreassen HP et al. (2004) The return of the giants: ecological effects of an increasing Elephant population. AMBIO: A Journal of the Human Environment 33(6):276-282

Skarpe, C., Hytterborn, H., Du Toit, J. T., \& Aarrestad, P. A. (2014). Historical changes of vegetation in the Chobe area. In C. Skarpe, J. T. M. du Toit, \& S. R. Moe (Eds.), Elephants and savanna woodland ecosystems: A study from Chobe national park, Botswana. New York City, USA: John Wiley \& Sons, Ltd., J ohn Wiley \& Sons, Ltd.

Snyman S (2014a) The impact of ecotourism employment on rural household incomes and social welfare in six southern African countries. Tourism and Hospitality Research 14(1-2):37-52

Snyman S (2014b) Partnership between a private sector ecotourism operator and a local community in the Okavango Delta, Botswana: the case of the Okavango Community Trust and Wilderness Safaris. Journal of Ecotourism 13(2-3): 110-127

Songhurst. A., (2012) Community Based Human-Elephant Conflict Management in the Okavango Delta Panhandle, Botswana. PhD Thesis, London Imperial College.

Spinage C (1990). Botswana's problem Elephants. Pachyderm, 13, 14-19.

Spinage C (2012) African ecology: benchmarks and historical perspectives. Springer Science \& Business Media.

Statistics Botswana (2011) Botswana Population and Housing Census. Government Printer, Gaborone. Statistics Botswana (2011 Labour Statistics Report 2011. Statistics Botswana, Gaborone.

Stein N (2012) Is 2012 the year of the volunteer tourist? Travel Mole (17 January 2012) Retrieved 23 
Stone LS, Stone TM (2011) Community-based tourism enterprises: challenges and prospects for community participation; Khama Rhino Sanctuary Trust, Botswana. Journal of Sustainable Tourism 19(1): $97-114$

Stone MT (2015a) Community-based ecotourism: a collaborative partnerships perspective. J ournal of Ecotourism 14(2-3): 166-184

Stone MT (2015b) Community empowerment through community-based tourism: the case of Chobe Enclave Conservation Trust in Botswana. Institutional arrangements for conservation, development and tourism in Eastern and Southern Africa. Springer, pp. 81-100

Stone MT, Nyaupane GP (2016) Protected areas, tourism and community livelihoods linkages: a comprehensive analysis approach. Journal of Sustainable Tourism 24(5):673-693

Tapela M, Pule-Meulenberg F, Kayombo B (2007) Potential for No-Tillage Agriculture in the Pandamatenga Vertisols of Botswana. Yoshisuke Kishida, Publisher \& Chief Editor Contributing Editors and Cooperators 38(2): 42

Thakadu OT (2005) Success factors in community based natural resources management in northern Botswana: Lessons from practice. Natural Resources Forum 29(3): 199-212

Thomas, D.S.G. \& Shaw, P.A.(1987) The Kalahari Environment Cambridge University Press, Cambridge.

Thomson G, Penrith M-L (2011) Animal health policy, legislation and trade in beef in the five participating states of the Kavango-Zambezi transfrontier conservation area (KAZA TFCA). Technical Report to the Wildlife Conservation Society's AHEAD Programme,

Tilmant A, Kinzelbach WCW (2012) The cost of noncooperation in international river basins. Water Resour. Res. 48(1):n/a-n/a

Timberlake J, Chidumayo E (2011) Miombo ecoregion vision report. Biodiversity Foundation for Africa, Famona, Bulawayo, Zimbabwe 20:1-76

Todd MC, Washington R (2004) Climate variability in central equatorial Africa: Influence from the Atlantic sector. Geophys Res Lett. doi: 10.1029/2004GL020975

Torello-Raventos, Mireia and Feldpausch, Ted R and Veenendaal, Elmar and Schrodt, Franziska and Saiz, Gustavo and Domingues, Tomas F and Djagbletey, Gloria and Ford, Andrew and Kemp, J eanette and Marimon, Beatriz S and others\} (2013) On the delineation of tropical vegetation types with an emphasis on forest/savanna transitions\}, Plant Ecology \& Diversity, 6, (1) 101-137.

Tweddle D, Cowx I, Peel R, Weyl O (2015) Challenges in fisheries management in the Zambezi, one of the great rivers of Africa. Fisheries Management and Ecology 22(1):99-111

Tweddle D, Hay CJ (2013) A transboundary fisheries management plan for the okavango/kavango/cubango basin. Governments of Angola, Namibia and Botswana,

Tyson and Preston-Whyte, 2000. The weather and climate of southern Africa. Oxford University Press Southern Africa, Cape Town,

Van der Sluis T, Mbaiwa JE, Veenendaal E (2016) Chobe-Kwando-Linyanti Integrated Land Use Plan., Inception report. Alterra, ORI, Kasane, Botswana, pp. 40

Van der Duim R, Lamers M, van Wijk J (2015) Novel institutional arrangements for tourism, conservation and development in Eastern and Southern Africa. Institutional arrangements for conservation, development and tourism in Eastern and Southern Africa. Springer, pp. 1-16

Van der Heiden L (1991) Land-use and development plan: Kwando and Okavango Wildlife Management Areas. First Draft. Maun: Ministry of Local Government and Lands

Van der Sluis T (1992a) Baseline Survey, Western Communal Remote Zone (Planning Zone 6), Ngamiland West. Maun, Botswana: North West District Land Use Planning Unit and Regional Agricultural Office,

Van der Sluis T (1992b) Land Use Plan and Development Plan for Natural \& Human Resources, Planning Zone 6, Ngamiland West. Ministry of Agriculture / District Land Use Planning Unit, Maun, Botswana,

Van der Waal BCW (1980) Aspects of the fisheries of Lake Liambezi, Caprivi. J ournal of the Limnological Society of Southern Africa 6(1):19-31

Vanderpost C (2006) Pathways of human sprawl in wilderness buffer zones. Population and Environment 27(3): 285-306

Vandewalle ME, Joos. (1988) Abundance and distribution of large herbivores in relation to environmental factors in Savuti. Chobe National Park. Botswana. University of the Witwatersrand

Vejre H, Primdahl J, Brandt J (2007) The Copenhagen finger plan. 
Von Gerhardt K, Van Niekerk A, Kidd M, Samways M, Hanks J (2014) The role of Elephant Loxodonta africana pathways as a spatial variable in crop-raiding location. Oryx 48(3): 436-444

Wato YA, Heitkönig IMA, van Wieren SE, Wahungu G, Prins HHT, van Langevelde F (2016) Prolonged drought results in starvation of African Elephant (Loxodonta africana). Biological Conservation 203:89-96

Wegmann M, Santini L, Leutner B et al. (2014) Role of African protected areas in maintaining connectivity for large mammals. Philosophical Transactions of the Royal Society B: Biological Sciences 369(1643)

Welcomme RL (1979) The inland fisheries of Africa. Food and Agricultural Organization of the United Nations

White, R. 2009 Tribal Land Administration in Botswana. Policy Brief 31, PLAAS Institute for Poverty, Land and Agrarian Studies, School of Government, University of Western Cape, South Africa. Available online at: http://www. plaas.org.za/sites/default/files/publications-pdf/PB\% 2031.pdf

Winterbach, C. W., Maude, G., Neo-Mahupeleng, G., Klein, R., Boast, L., Rich, L. N., \& Somers, M. J. (2017). Conservation implications of brown hyaena (Parahyaena brunnea) population densities and distribution across landscapes in Botswana. Koedoe, 59(2), 1-16.

Winterbach CW, Whitesell C, Somers MJ (2015) Wildlife abundance and diversity as indicators of tourism potential in northern Botswana. PloS one 10(8): e0135595.

Winterbach HE, Winterbach CW, Somers MJ (2014) Landscape suitability in Botswana for the conservation of its six large African carnivores. PloS one 9(6): e100202

Wolski 2012, Status and trends in water resources. Cubango-Okavango River basin. CubangoOkavango River Basin Water Accounting (CORBWA) project. OKACOM/FAO.

Woodroffe, R., Ginsberg, J.R. Macdonald, D.W. and the IUCN/SSC Canid Specialist Group. 1997. The African Wild dog - Status Survey and Conservation Action Plan. IUCN, Gland, Switzerland.

World Bank (2016) Northern Botswana Human Wildlife Coexistence Project. Project Evaluation Report. pp. 91

World Tourism Organization, 2011. Tourism Towards 2030 / Global Overview. UNWTO, Madrid. 49p.

World Tourism Organization, 2014. Towards Measuring the Economic Value of Wildlife Watching Tourism in Africa - Briefing Paper, UNWTO, Madrid.

World Tourism Organization, 2016. Tourism Highlights. 2016 Edition, UNWTO, Madrid. 16p.

World Travel and Tourism Council, 2016. WTTC Travel \& Tourism Economic Impact 2015. Botswana. $18 p$. 


\section{Annex 1 Community Consultations}

\section{Summary Notes Parakarungu Consultations, 14-11-2016}

The consultations/discussions took place at the Parakarungu Kgotla and were guided by 5 questions, which were formulated by the consultants. There was a sizeable number of respondents/delegation brought from the villages of Kachikau, Kavimba, Satau, etc

\section{Crops}

The residents mentioned that their crops are getting damaged by wildlife and therefore there is need to consider cluster fencing as part of the solution. Both molapo and dryland farming is being affected. It was mentioned that wildlife movement should be "controlled" and restrictions imposed on access to crop land by wildlife especially Elephants. Wildlife should stay within the park!

Crop land is also affected by floods and salinity. Some field lie fallow as current owners have no real interest in cultivating their land, after fields were inherited, following death or old age of the original owners.

\section{Grazing}

Grazing land was totally dismissed as not being available, due to "lack of rights" on it. There should be allocation of water rights to enhance grazing land. Furthermore, the residents required that miniranches be allocated. They pointed out to some locations which used to be regarded as grazing areas, which the Land Board has overlooked.

\section{Forest reserves}

The Forest reserve was seen as a good resource that should be protected, enjoyed by mankind as a creation by God. The residents mentioned that some of the trees which used to be there are no longer visible due to exploitation, hence a need for protection of the species and restoration/reintroduction and preservation for descendants to appreciate. Furthermore, the law for the conservation of the forest resources as not prohibitive as they allow regulated use of the forest resources.

\section{Wildlife}

This is where the real challenge and lack of appreciation is. The residents mentioned that there is divided view on wildlife and this is not helping the community. Some see wildlife as a good thing while others see it as a menace. The latter view has been developed mainly due to the hardships being experienced due to having the "live with the animals" that cause a lot of damage and threat.

Basically, the wildlife numbers have increased, animals don't fear people anymore, the DWNP does not care about compensation to farmers, no economic benefits/returns to the community, etc. So the perception has changed - as residents no longer view wildlife positively.

\section{Tourism}

The community does not benefit.

No qualified members of the community to take up jobs in hotels, safaris or lucrative tourism ventures,

No training schools

Lack of awareness/adequate knowledge by Batswana tourism practitioners

Land shortage due to forest reserves and national parks

The industry is over regulated and highly restrictive in terms of participation by Batswana 
Conclusions

The issue of the planning boundary and extent of coverage by the ILUP. There is a general feeling that the Chobe District boundary along the Nata-Kasane road has been "tempered with". This must be considered.

Finally that the draft/final report should reflect the views of the people - as a provided by the consultation that is taking place

\section{Summary Notes Pandamatenga Consultations, 16-11-2016}

The Consultancy Team was met by Kgosi Mafikizolo of Pandamatenge, the Honourable Councillor Mr. Tuelo and Headman of Arbitration Ms. Amos. The meeting embraced other 12 members of the community and discussions took place at the Kgotla.

Issues were:

Crop

That subsistence farmers are allocated arable land that is too small for economic viability. Commercial Banks only regard 500 hectares and above as commercial, hence arable farmers with less than that cannot get assistance, and therefore remain poor. The Land Board is therefore requested to increase hectares of even subsistence land allocation to a least 50 for cost effectiveness. There continues to be crop damage by wildlife hence a need for animal proof cluster fencing that is electrified.

The Government of Botswana has done a lot of empowerment to the "White" community of Panda by allocating them massive land of even up to 10,000 hectares per farm. It is therefore time that the same be deliberately done as an empowerment drive/strategy for the "Blacks" to close the divide - as they also should be viewed as commercial farmers.

The consultations also pointed out to the need for "middle class" commercial farmers, thus commercialization of subsistence farmers owning at least 150 hectares.

J ob Creation

The commercial farms do provide employment for the Panda community. However, job creation and sustainability needs to increase and employee/employer relations have to improve, as there are many labour issues surrounding employment of locals by commercial farmers. The issue of minimum wage of around P800, which is too low, is also a matter to be addressed since arable agriculture in Panda is "commercial", as opposed to subsistence.

\section{Suggestions/Solutions}

1. There is need for equitable land allocation and distribution by the Chobe Land Board.

2. Commercial arable land allocations should be 500 hectares.

3. Land allocated to White farmers needs to be caped as the community feels the land is just too much of up to 10,000 hectares per farm.

4. In view of the fact that there is increased land shortage for commercial arable production, the community feels land from DWNP and DFRR should be de-gazzetted and allocated to commercial agricultural production.

5. Pandamatenge is like an "island" - as it is bounded by fences etc. Therefore the remaining land being Dekar and Forestry reserves should be viewed as a natural expansion for Panda. This is $22 \mathrm{~km}$ from Panda towards Nata, at 117/115.

6. There has to be empowerment of the Panda community to increase their voice as most of the time their issues are overridden by the District Commissioner's office in Kasane.

7. The ongoing proposal for the Agro-Zambezi project aimed at expanding tribal farming land should be expedited in the interest of allocating land to the community and residents, as there is dream of additional 40,000 hectares. Furthermore, the allocation should be equitable and must not use the tender system as it disadvantaged the "have nots" 
8. The relationship between the White commercial farmers and the community Leaderships need improvement as whites do not attend Kgotla meetings.

9. As regards compensation for wildlife damage to crops and livestock, the DWNP should increase species that compensation must apply to, as currently the list is very limited.

\section{Summary Notes Lesoma Consultations, 17-11-2016}

Lesoma should have been consulted on November 16, but failed due to ill preparations. So the Consultancy Team came back the following morning. The community members mainly comprised of the VDC, Police, DWNP, and the village Leadership. About 14 people attended.

Issues

1. The village population is growing hence must be catered of in terms of land requirements.

2. Agricultural production (arable) has been a backbone of the Lesoma livelihood.

3. Land Board should allocate land to increase the available land base.

4. Integrated land use must be encouraged as the community is integrated and land is limited.

5. Livestock grazing should be catered for at 256 , but not on temporary basis as this does not grant investment options and is not recognized by commercial financiers.

6. The 40 by 40 square metres grazing land allocations at 256 is just small and does not allow for the required integrated agricultural production.

7. There is no real relationship with Pandamatenge commercial farming as compared to Chobe farms.

8. Compensation for damage caused by wildlife should embrace other species, for example hyenas as they cause massive damage including killing livestock.

9. As regards hospitality and tourism opportunities, the community does not see much benefits expect at times employment of the Youth in lodges.

In conclusion

The community of Lesoma needs to be given land on permanent basis to increase their security of tenure. Furthermore they should be made aware of opportunities that are presented by "proximity" to Kasane as a tourism centre. As of now, they are not aware and/or knowledgeable of how they should be participating to improve their livelihood. 


\section{Annex 2 Consulted people and Organisations}

\begin{tabular}{|c|c|c|c|c|}
\hline Name & Organisation & & Place & Date \\
\hline Mrs. K. Dikole & UNDP & Operations Officer & Gaborone & $17-10-2016$ \\
\hline Mr. L. Dikobe & KCS & CEO & Gaborone & $18-10-2016$ \\
\hline Mrs. R. Masilo-Rakgoasi & UNDP & Project Leader & Kasane & 19-10-2016 \\
\hline Mr. R. Kanguaiko & UNDP & Finance officer & Kasane & 19-10-2016 \\
\hline Mr. Nelson S. Masule & Chobe Land Board & Chairman & Kasane & $19-10-2016$ \\
\hline Mr. M. Mokolwane & Chobe Land Board & Land Use Officer (DTRP) & Kasane & 19-10-2016 \\
\hline Mrs. K. Tsokedi & DC Administration & District Officer Admin & Kasane & $19-10-2016$ \\
\hline Mr. R. Sebadieta & MoA & District Coordinator & Kasane & 19-10-2016 \\
\hline Mr. Mokgomedi & ВТо & Chairman?? & Kasane & $20-10-2016$ \\
\hline Mrs. B. Mokele & DC Administration & Poverty Eradication & Kasane & $20-10-2016$ \\
\hline Mr. Kgosi Mmualefhe & Tribal leadership & Chief Kachikau & Kasane & 20-10-2016 \\
\hline Hon. M. R. Shamukuni & MP-office & Member of Parliament & Kasane & $20-10-2016$ \\
\hline Mr. R. Ntshwabi & MP-office & AdMin & Kasane & $20-10-2016$ \\
\hline Mr. M. Vandewalle & Caracal & CEO & Kasane & 20-10-2016 \\
\hline Ms. K. Landen & Elephants without borders & Project officer & Kasane & $20-10-2016$ \\
\hline Mr. Robert Sutcliffe & Elephants without borders & Project officer & Kasane & 20-10-2016 \\
\hline Mrs. P.C. Masire & Dep. of Tourism & Act. Tourism officer & Kasane & 21-10-2016 \\
\hline Mr. Sekwele & Forestry Dept. & District Coordinator & Kasane & 21-10-2016 \\
\hline Mr. K.B. Mabenya & Forestry Dept. & Project Coordinator & Kasane & 21-10-2016 \\
\hline Mr. C.J. Mlazie & Kaza & Country Liaison officer & Kasane & 21-10-2016 \\
\hline Mrs. B. Willems & Muchenje Camp & Lodge \& campsite owner & Muchenje & $22-10-2016$ \\
\hline 10 farmers & - & Farmers, residents & Parakarungu & $22-10-2016$ \\
\hline Mrs. P. J ibajiba & DWNP & Regional Wildlife Officer & Kasane & $18-11-2016$ \\
\hline Mr. S. Aaron & Chief physical planner & Chobe District Council & Kasane & $18-11-2016$ \\
\hline Mr. Morris Z. Mtsambiwa & KAZA-TFCA & Executive Director & Kasane & $18-10-2016$ \\
\hline Mr. N. Smart & KfW-KAZA program & Project Director & Johannesburg & 29-11-2016 \\
\hline
\end{tabular}




\section{Annex 3 Wildlife Distribution Maps}

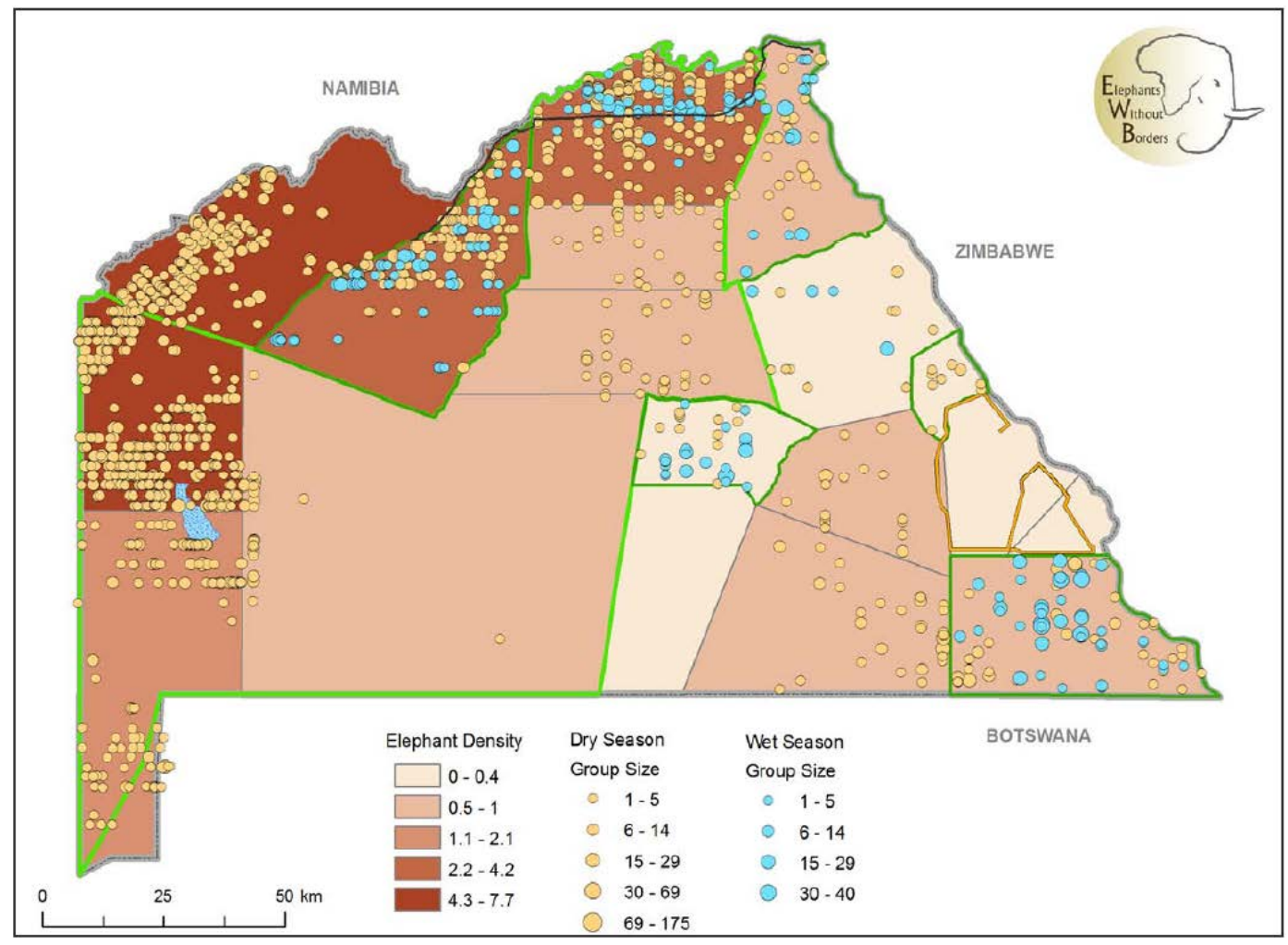

Elephant Distribution

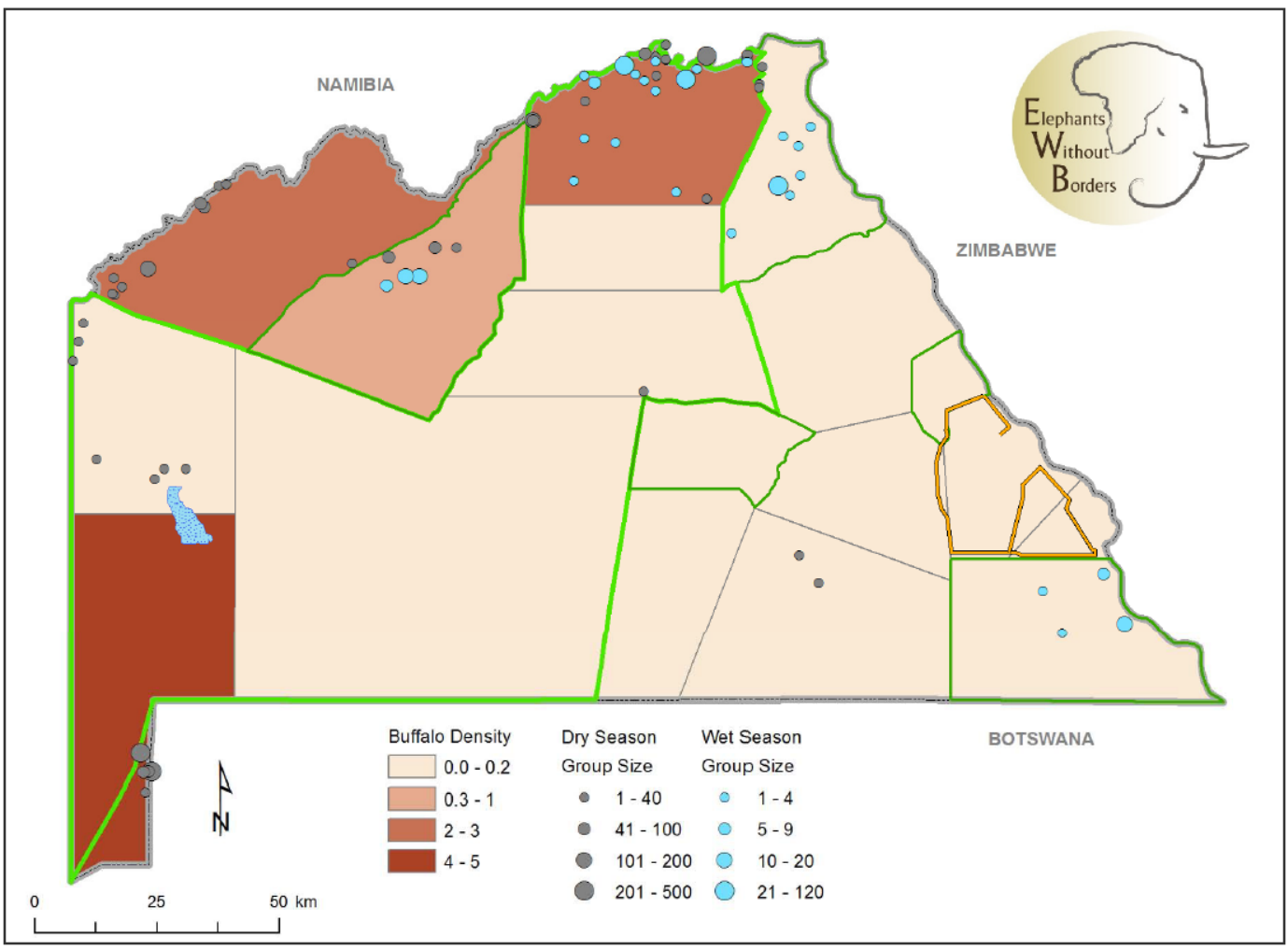

Buffalo Distribution 


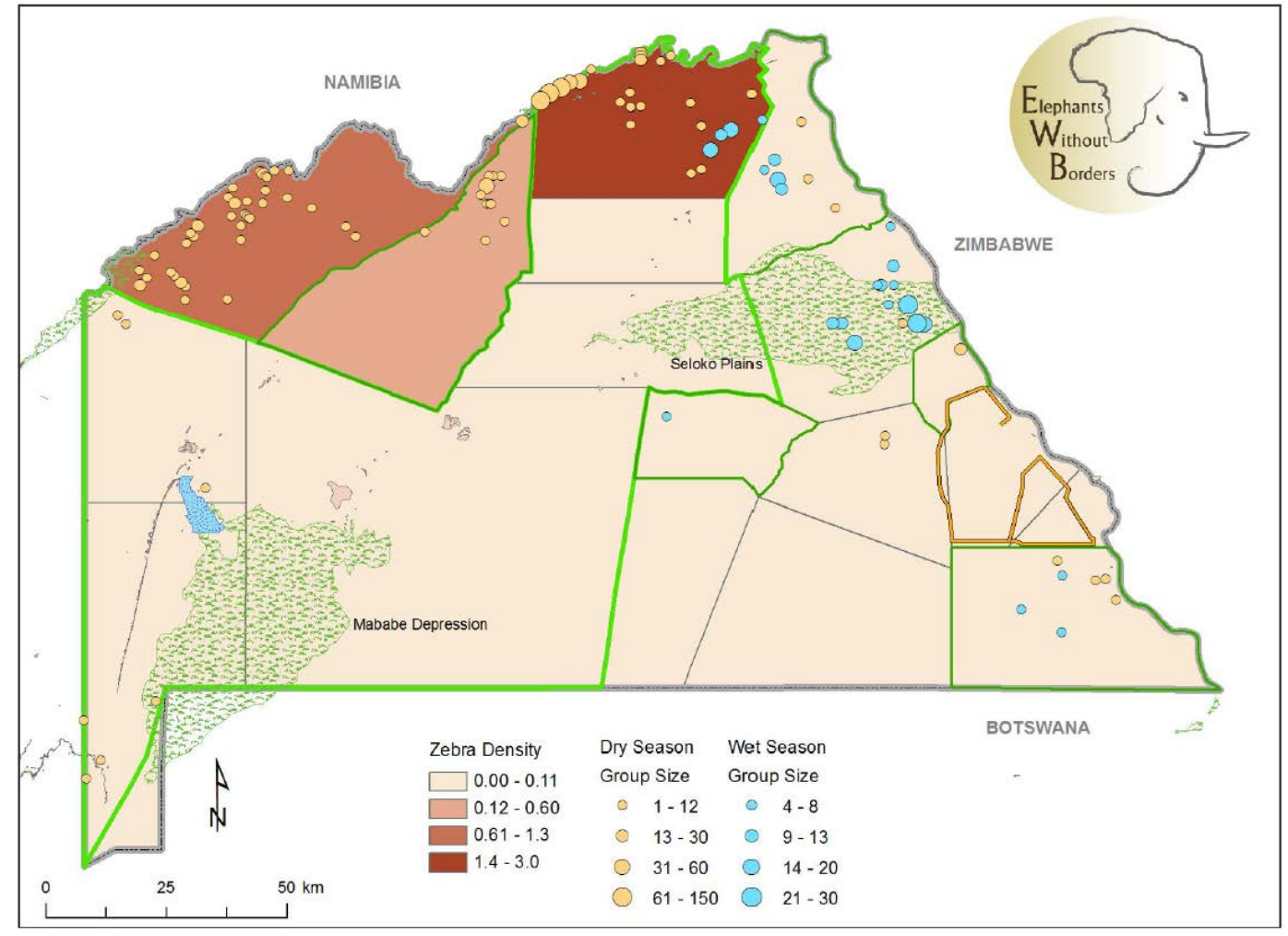

Zebra Distribution

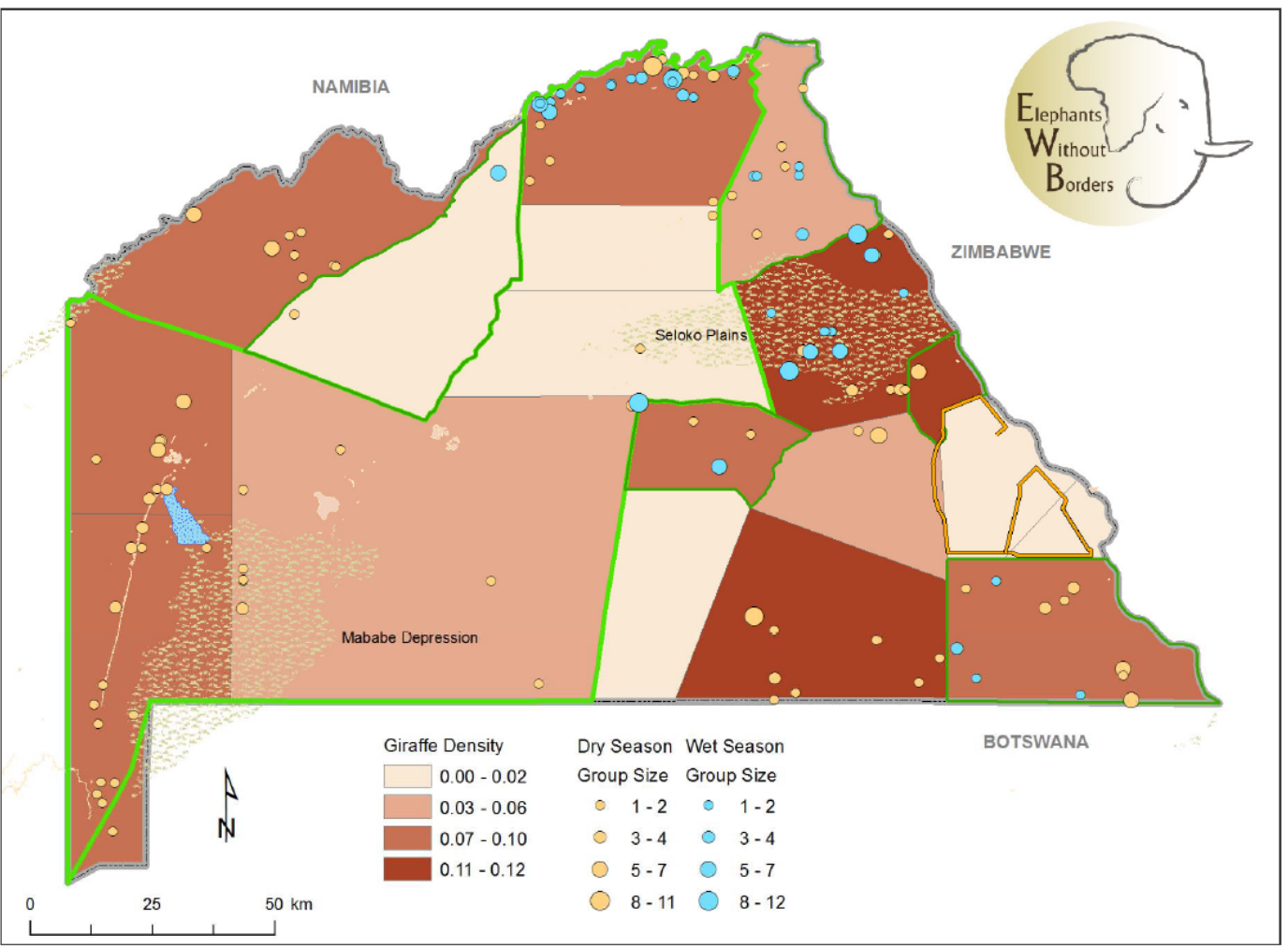

Giraffe Distribution 


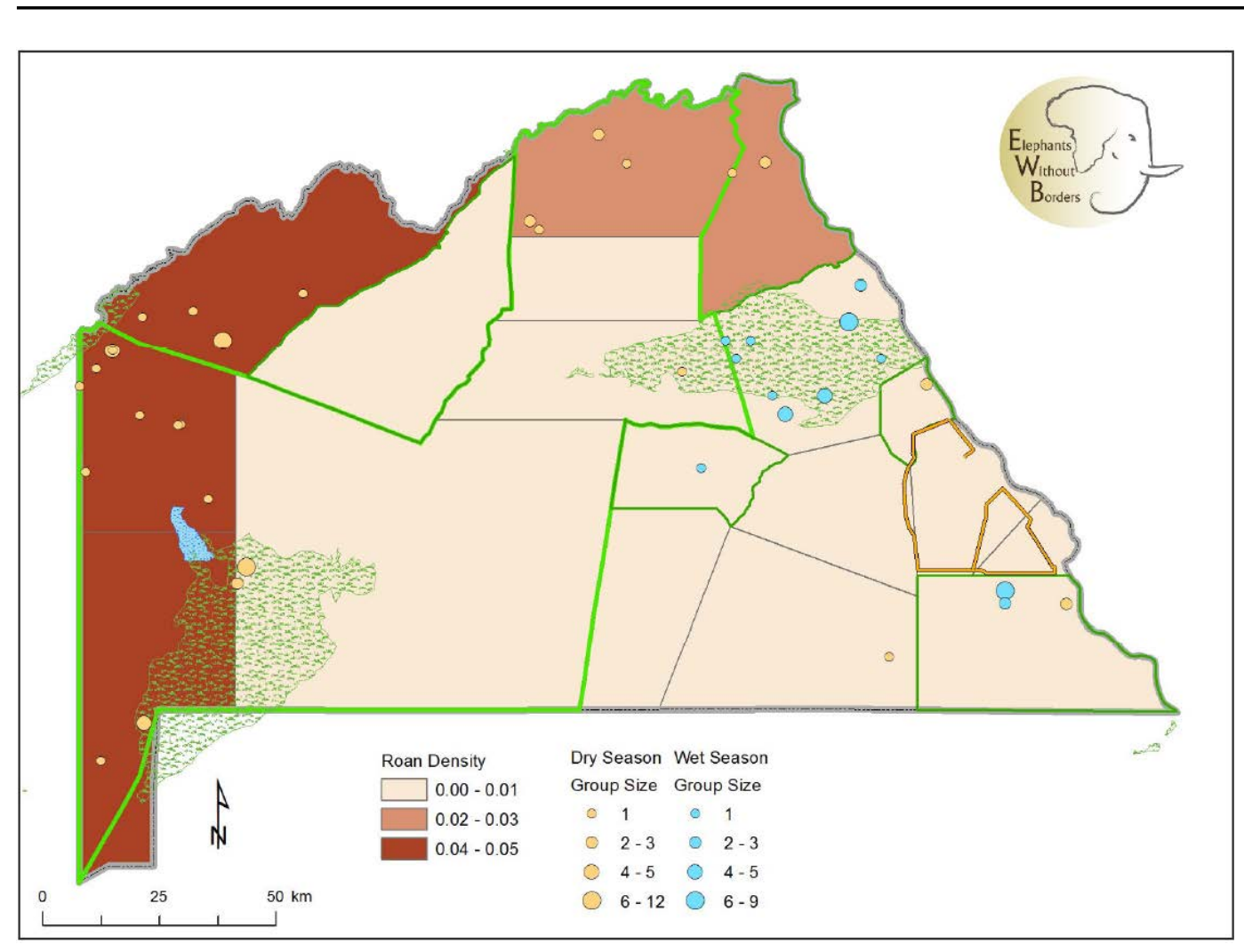

\section{Roan Distribution}

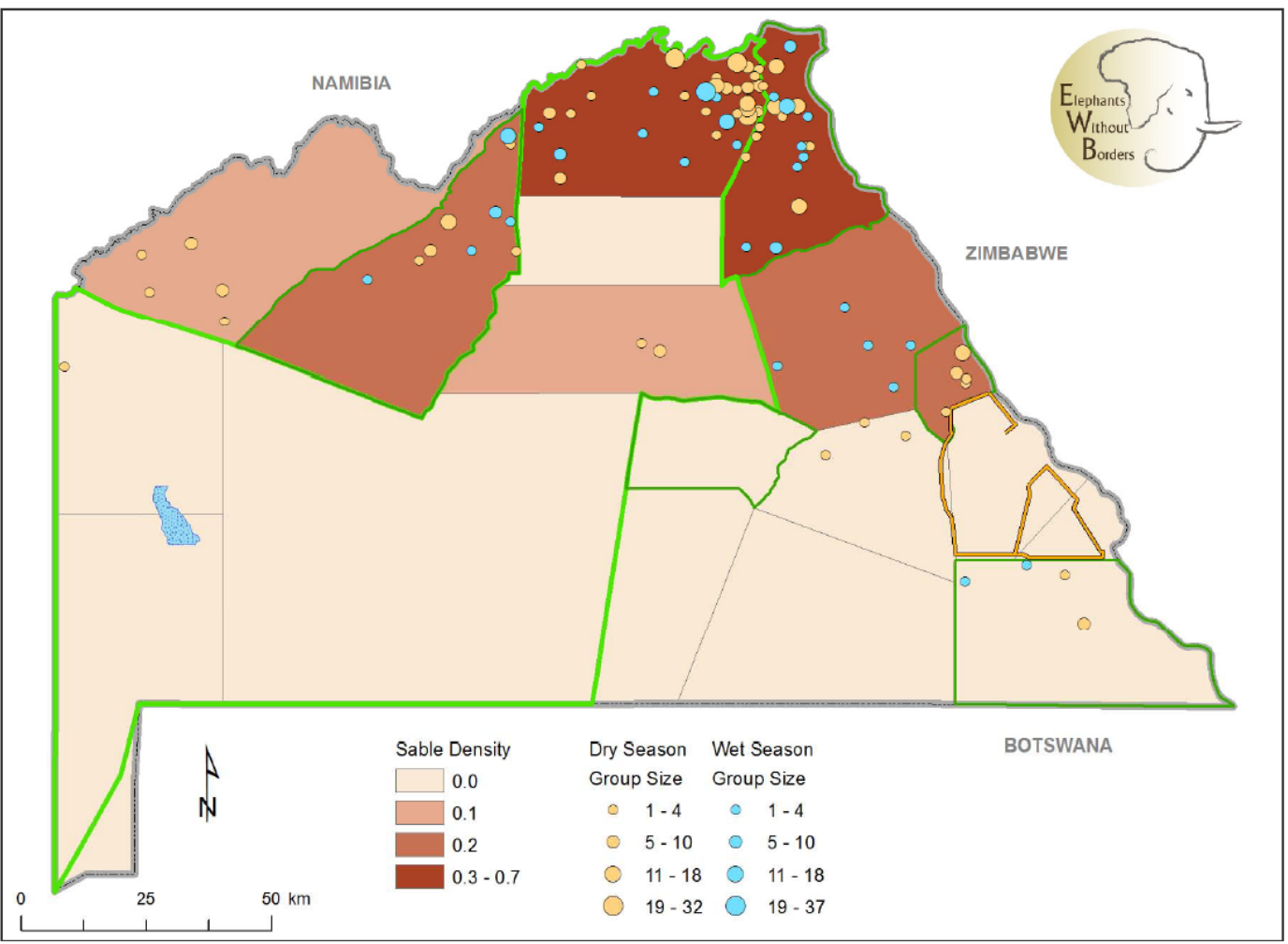

Sable Distribution 


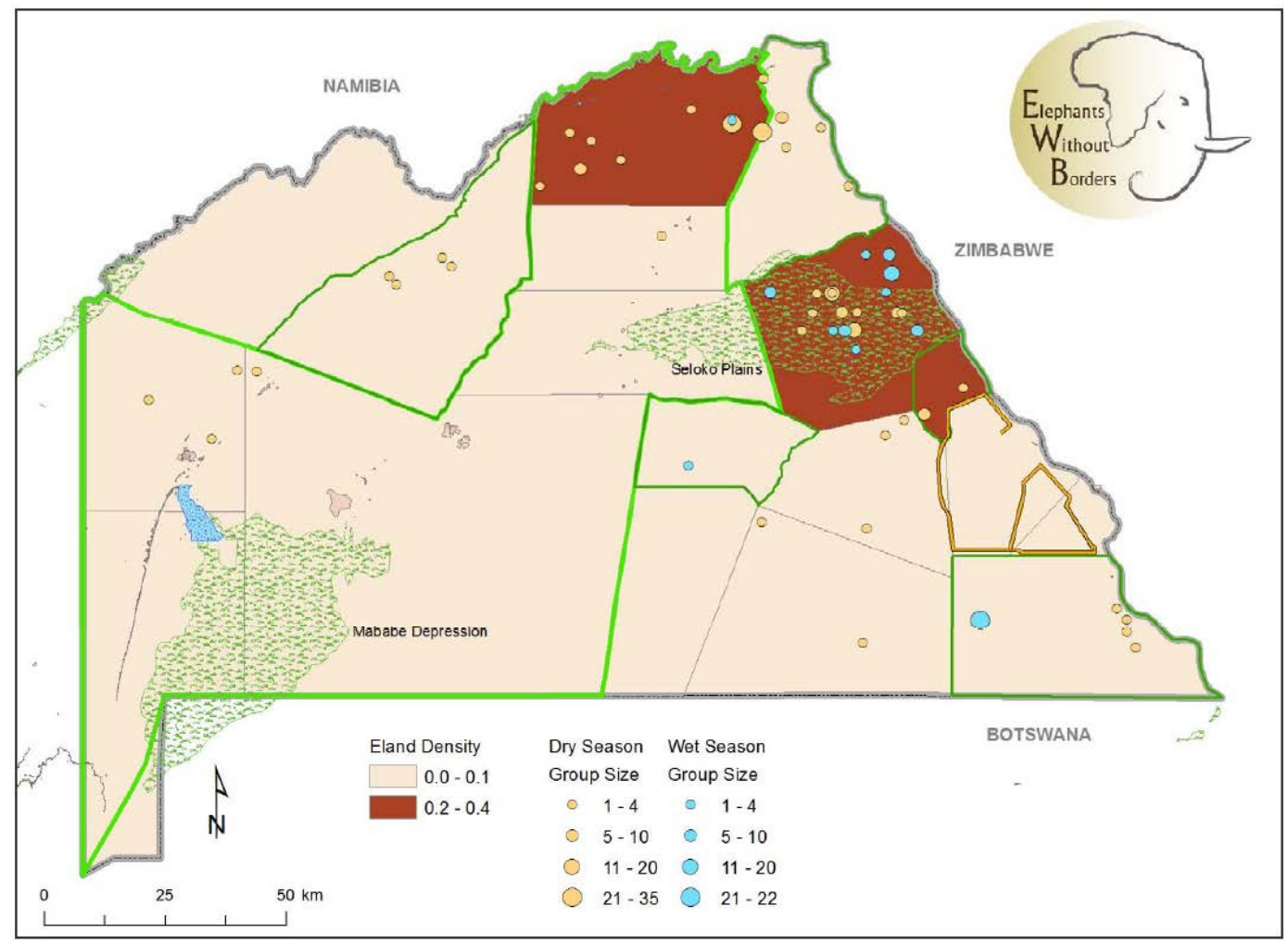

Eland Distribution

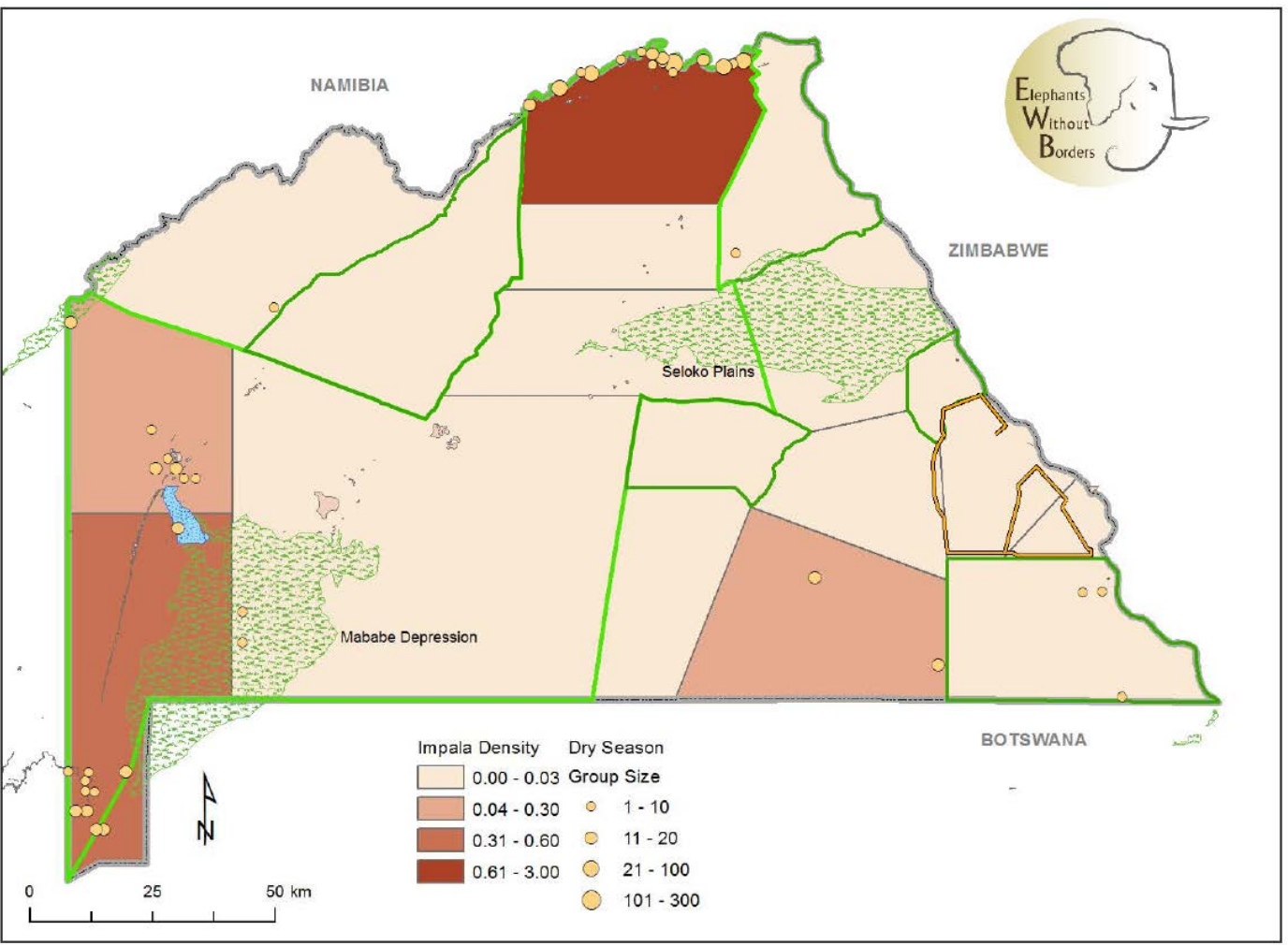

Impala Distribution 


\section{Annex 4 Wildlife Corridors}

The following notes outline the specific details of known wildlife corridors for elephants, buffalo, zebra and lions, and specific movement patterns within the Chobe District:

\section{Elephants}

- Linyanti / Chobe River front to Zambezi Region, Namibia

The Chobe District forms one of the most important areas for transboundary connectivity for Elephants between Botswana and neighbouring countries. Research undertaken within Namibia has identified migratory corridors across the Zambezi Region (formerly known as the Caprivi) to the Botswana border formed by the Linyanti and Chobe River. Any land use planning to zone corridors within Chobe District must take cognisance of these international transboundary corridors. The following figure was produced by Brian J ones and Russel Taylor for work commissioned by SAREP (2013), where they used local community knowledge to define and demarcate corridors within the Caprivi (Figure 60).

Similar paths have also been identified within Chobe District by Elephants Without Borders, who have recorded large scale movements of Elephants out from Chobe and into the Caprivi region, where Elephants move further beyond into Zambia and the Sioma Ngwezi National Park and through to Angola into the recently established Luiana-Luengue and Mavinga National Parks (Figure 61).

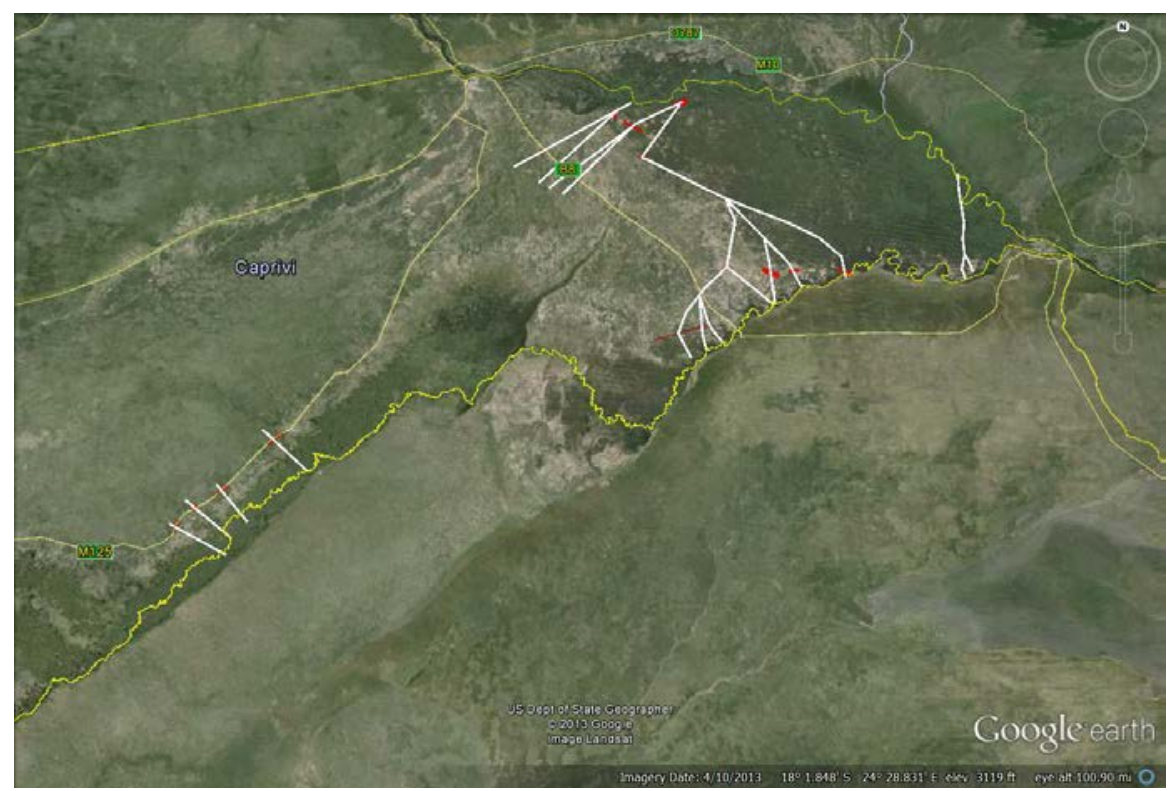

Figure 60 Wildlife corridors (J ones and Taylor, 2013) 


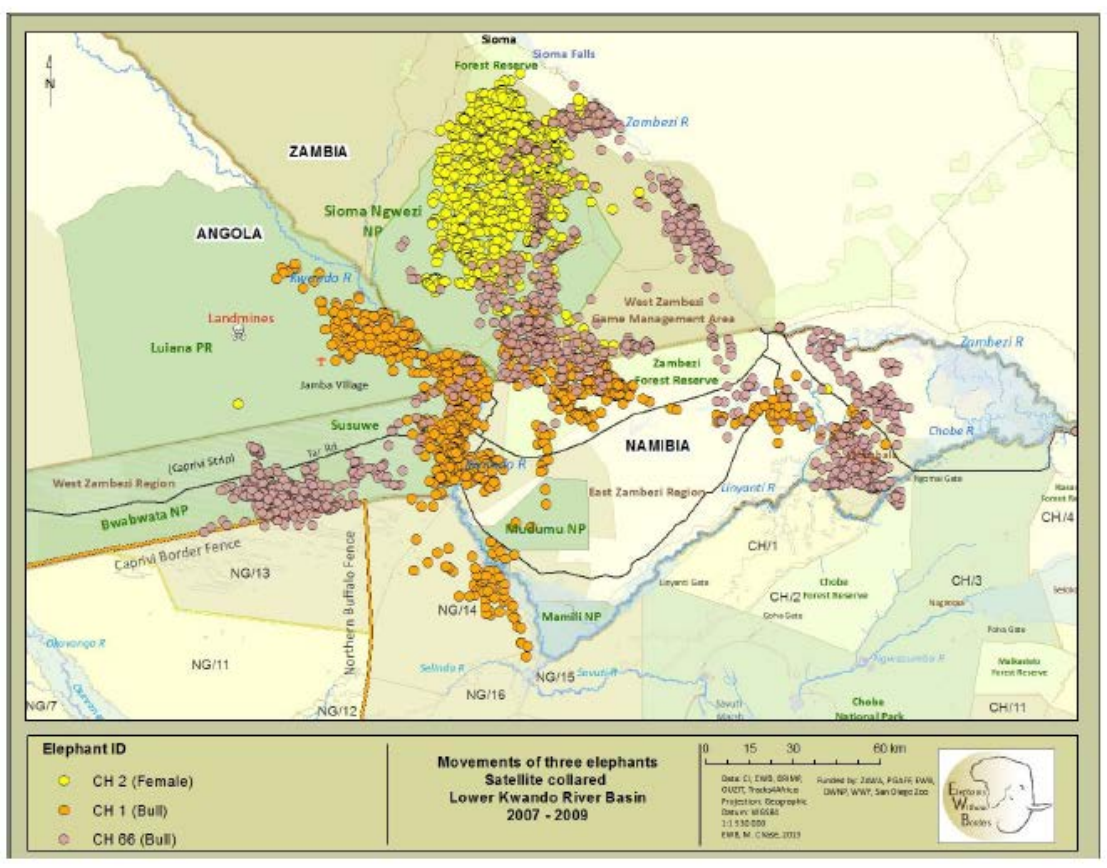

Figure 61 Elephant movements through Caprivi recorded by Elephants Without Borders (2015)

\section{- Kasane Micro-corridors}

Due to the density of human populations along the Chobe River front and the expansion of settlements and land use change within the Caprivi the movement paths of Elephants in this are sometimes very precise and constrained. Work by Adams et al., (2015) has identified these urban corridors in detail and enhanced our knowledge of the extent and often constrained size of these corridors (Figure 62). Figure 63, developed by Elephants Without Borders highlight the same movement paths of Elephants from the Chobe forests through Kasane township as those published by Adams et al. (2015) and additional corridors through Kazungula down towards the Chobe River front. The red lines corridors are frequently used by large numbers of Elephants, with red zones identifying high conflict areas and the yellow, agricultural land and other large developments.

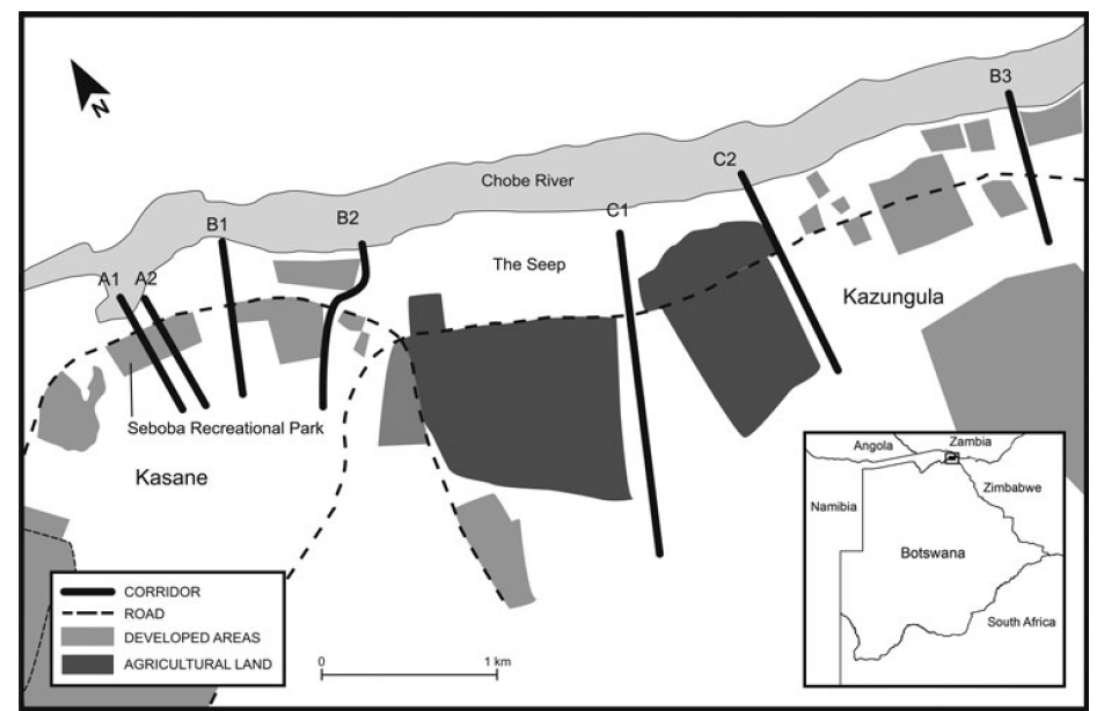

Figure 62 Elephant corridors through Kasane Township (Adams et al., 2015) 

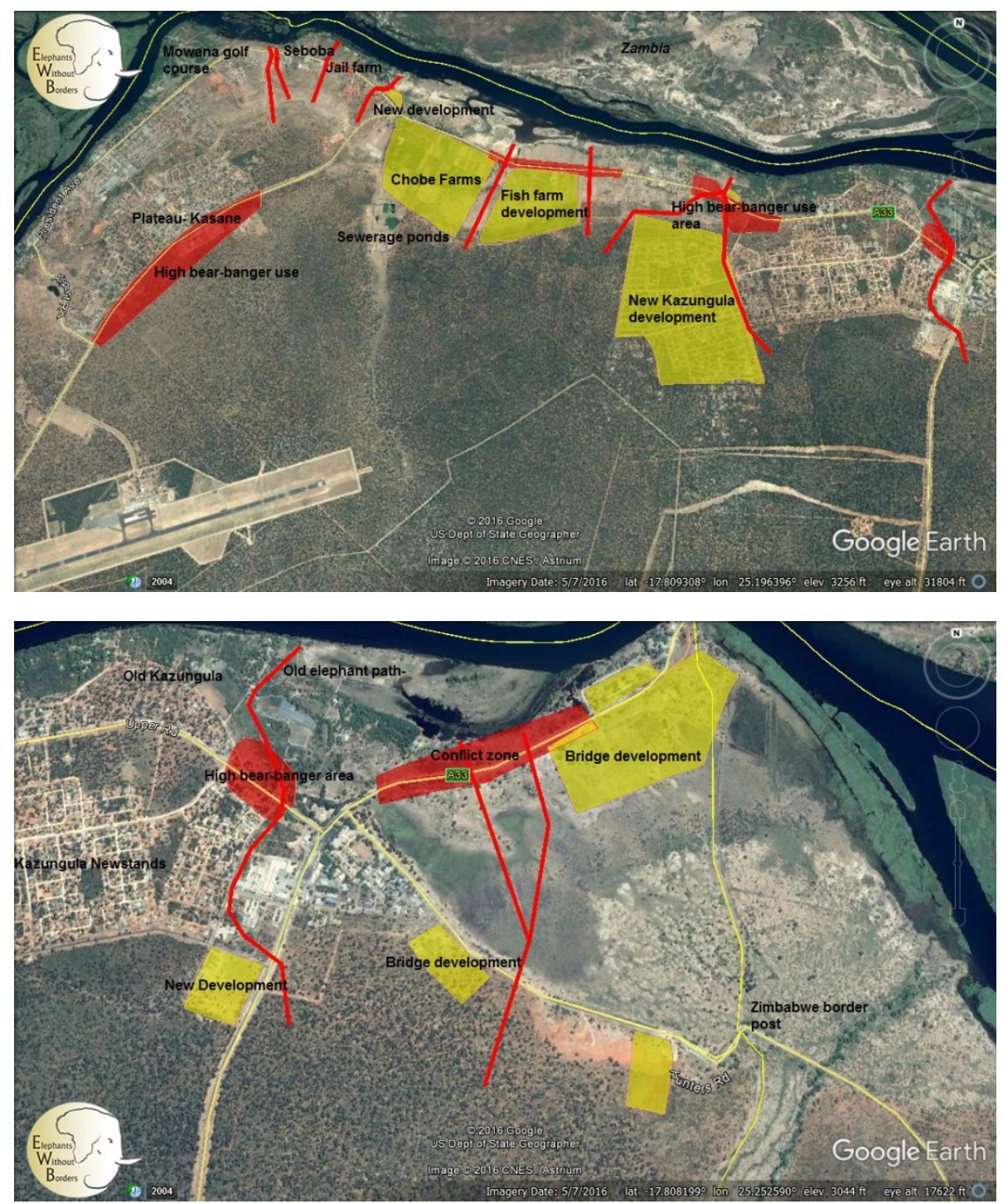

Figure 63 Elephant corridors recorded by Elephants Without Borders in Kasane (top) and Kazungula (bottom) (2017)

\section{- Chobe Enclave}

The southern part of the Chobe Enclave is a really important migration route for wildlife, particularly Zebra, moving between Namibia's Zambezi Region and Nxai Pan. This means that from a wildlife perspective, it would be good to keep the south-western portion of $\mathrm{CH} 1$ unfenced, and with limited settlement, to avoid disruption of the migration, and increased human-wildlife conflict. Further corridors are recorded around the settlements of Mabele and Muchenje west of Ngoma (Figure 64). 


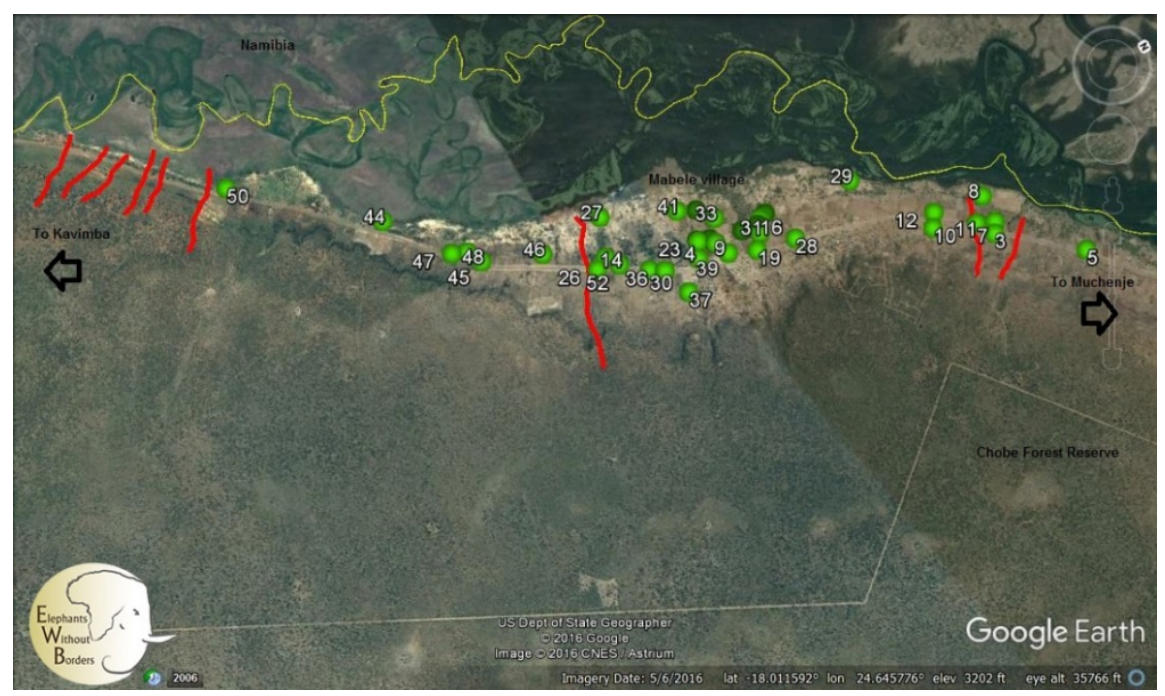

Figure 64 Elephant corridors recorded by Elephants Without Borders in the Chobe Enclave (2017)

- Chobe District to Matetsi and Hwange, Zimbabwe

Movement of Elephants out from and back to the Chobe District through Zimbabwe has also been well recorded. Movements out from Chobe follow some distinct preferences into Zimbabwe, with areas of Victoria Falls, Kazuma and Hwange all preferentially selected (Figure 65). Transboundary movement to the areas occurs along diffuse and more open corridors than those observed along the Chobe and Linyanti River Fronts. Human development and activity along this international border is less prominent, with fewer constraints to wildlife movement.

The defined movement between Chobe and the Kazuma National Park in Zimbabwe was also highlighted as a critical corridor for many other species by Chase (2013). This corridor is aligned along the northern grassland plains further expressing the ecological importance of these grasslands to wildlife within the greater KAZA region (Figure 66).

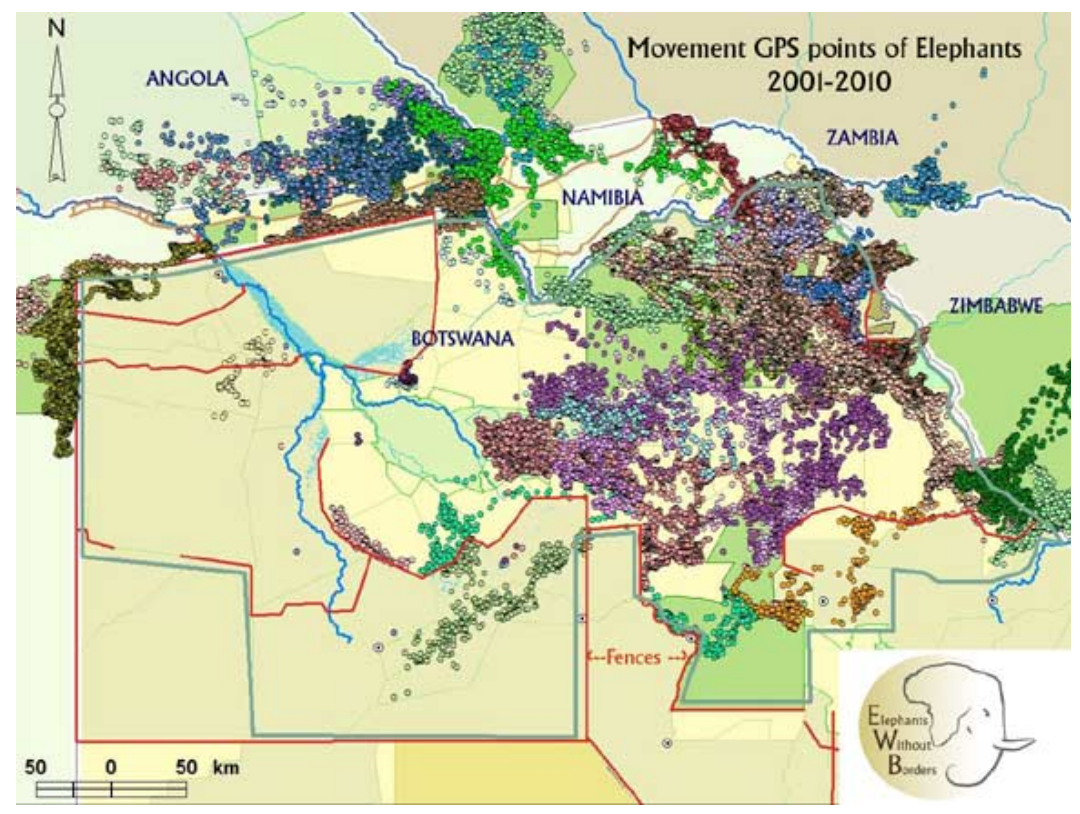

Figure 65 Elephant movements across and out from Chobe District recorded by Elephants Without Borders (2015) 


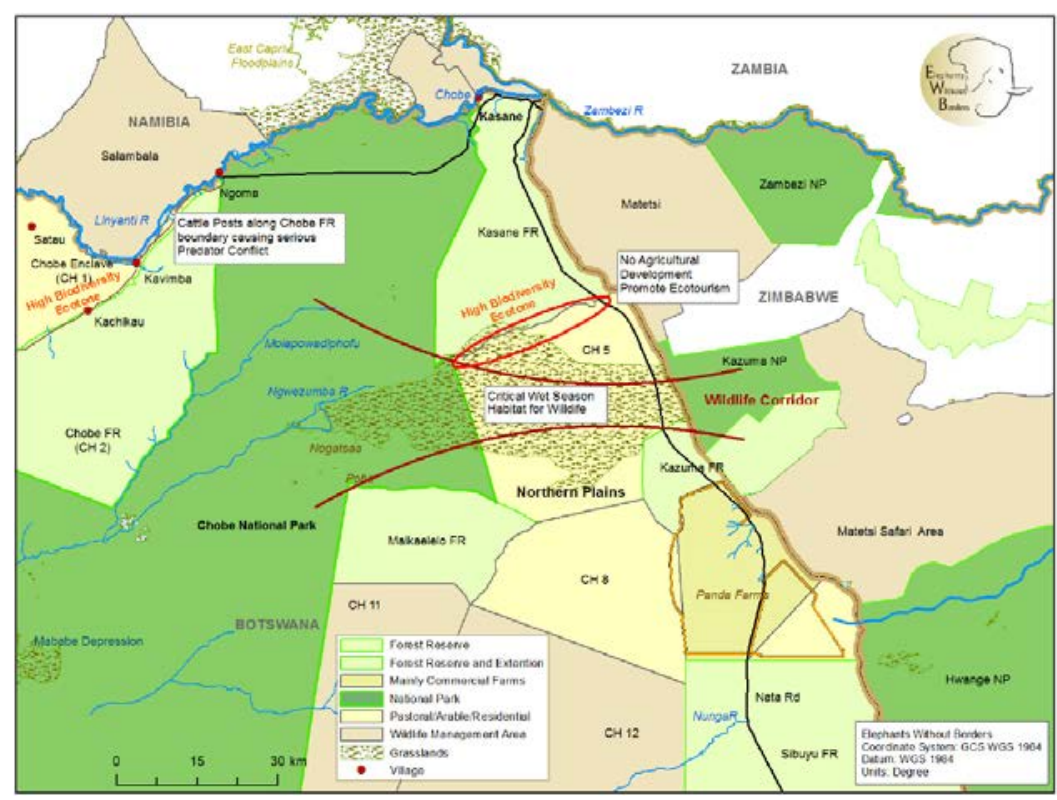

Figure 66 Wildlife corridor along the Northern Grasslands in CH5 through to Kazuma National Park in Zimbabwe (Chase 2013)

\section{Buffalo}

As discussed previously there are numerous seasonal movement and dispersal patterns of Buffalo within the Chobe District. Most of these are wet season dispersal movements out from the Linyanti / Chobe River Front out to the Forests, but some distinct corridors paths have been recorded (Figure 67). Most noticeable of these is the movement along the Savuti Channel out from Savuti and up to the Linyanti and the floodplains of the Chobe enclave, which was recorded by Fynn, Chase and Roeder (2014). This research also recorded similar movement along this corridor by other species such as Zebra.

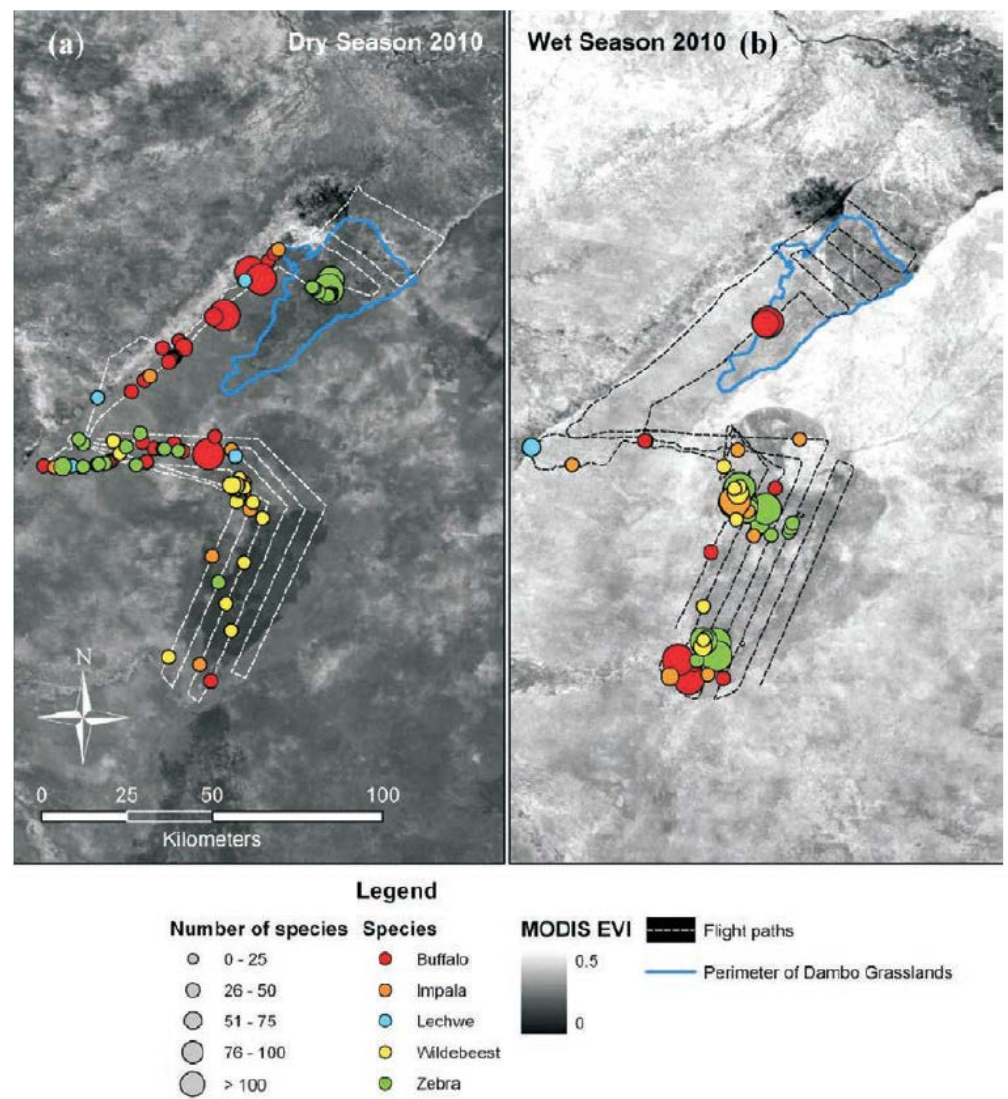

Figure 67 Buffalo movement along the Linyanti and into Savuti Marsh (Fyn 2014) 


\section{Zebra}

Zebra populations in the Chobe District make classical migratory movements along nutrient gradients from the Chobe River Front south to the Nxai Pan grasslands (Figure 68). The Nxai Pan grasslands occur on fertile lacustrine soils, high in salts and nitrogen content. The resulting nutritional grasses are ideally suited to milk production and bone development which enhance juvenile survival rates and improve development. These factors combined with a lower relative predator population (Hemson, 2001) attract Zebra to walk the considerable $250 \mathrm{~km}$ from Chobe to Nxai Pan. The movement is in most parts direct and well oriented to ensure minimal energy is lost and wasted across such a long journey.

Additionally, further sub-populations of Zebra within the District also make other distinct seasonal migratory movements following the seasonal distribution of nutrients. In the Mababe-Savuti-Linyanti system Zebra concentrate along the Linyanti River front in $\mathrm{CH} 1$ and the Chobe National Park during the dry season and then move towards the Zibilianja lagoon and down the Savuti Chanel in the early wet season, before concentrating in the Mababe depression and or the Savuti marsh in the middle of the wet season. Zebras are attracted to the more nutritious short grazing grasses within these wet season home ranges which, in many years are devoid of surface water during lower rainfall cyclic periods. Towards the end of the wet season, Zebra make the return journey back north towards the Linyanti River front.

Both Zebra and Buffalo cross regularly between Botswana and Namibia across the whole length of the Linyanti system, and keeping areas of this border undeveloped (such as the south-western portion of $\mathrm{CH} 1$ ) is critical to the maintenance of migration options for these species.

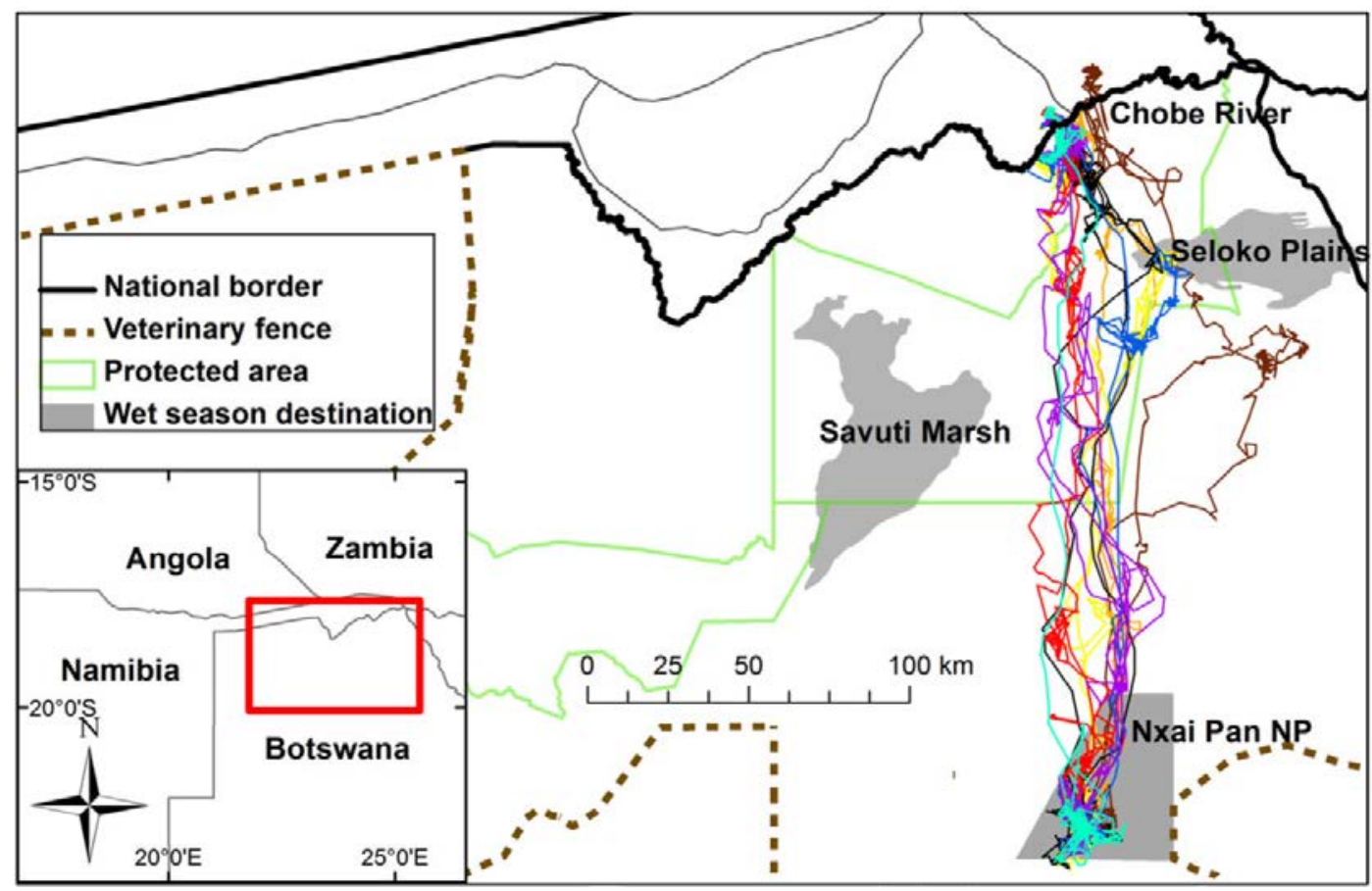

Figure 68 Zebra corridor stretching from the Chobe River Front to the Nxai Pan National Park (from Naidoo et al., 2014)

\section{Lions}

There are also records and publications of predator movements from Botswana to Zimbabwe through the Pandamatenga area (MacDonald 2010, Elliot, Cushman, Macdonald and Loveridge, 2014). This species specific research further highlights the importance of regional connectivity to species viability. Using 10 years of data collected from the movements of more than 50 Lions Elliot et al. (2014) looked at patterns of connectivity to not just identify existing wildlife corridors but to define where there was resistance to movement and what was related to that resistance. The graphics produced create resistance maps (Figure 69) of wildlife dispersal across the Chobe District highlighting the resistance to movement at an international level into the Caprivi Strip of Namibia and beyond the Matesi / 
Hwange regions of Zimbabwe, as well as as a National level within Botswana. In Botswana there is increased resistance to movement around the periphery of the Northern Conservation Area, again highlighting the importance of the conservation of the land mass.

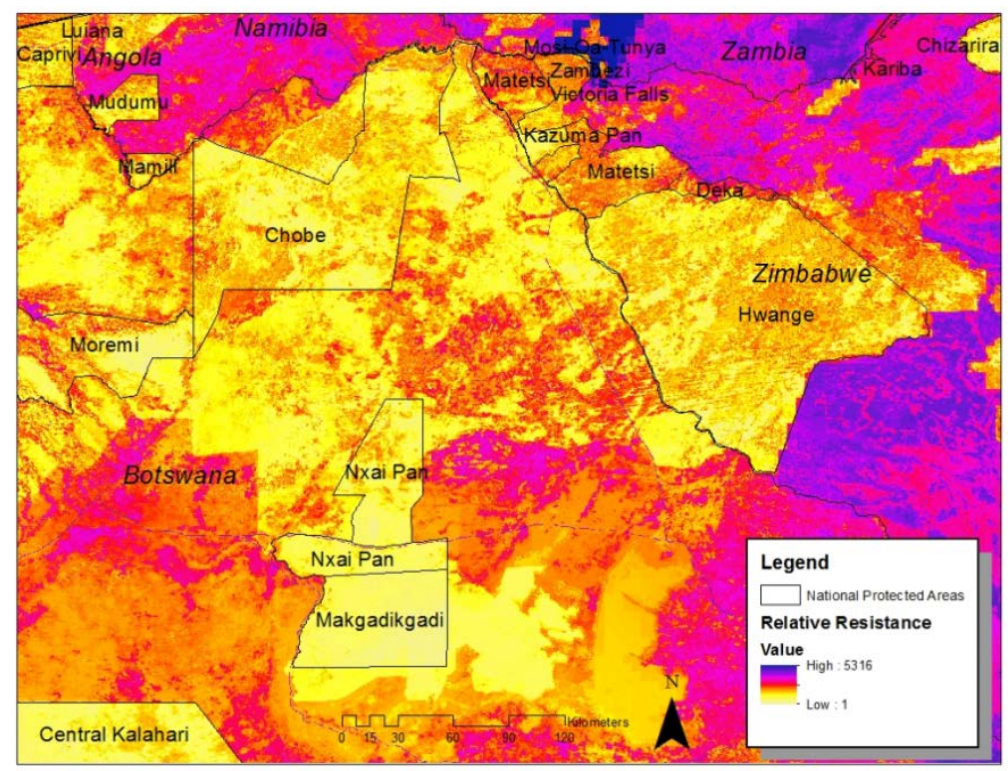

Figure 69 Resistance landscape for dispersing Lions. Cells (pixels) coloured in yellow and orange shades represent low resistance (i.e. areas Lions are easily able to move through. Red, pink, purple and blue shades represent areas Lions are likely to find increasingly difficult to traverse (work by Elliot, Cushman, Macdonald and Loveridge, 2014)

Whilst Figure 39 highlights the resistance to movement of wildlife outside of the northern conservation area as well as outside of part of the KAZA region, wildlife does still move into these areas. Often causing conflict as it does. The movement into these areas of higher resistance, which are often associated with an increased human footprint and more intense activity, are also demonstrated by collared Lion movements from Chobe and into Hwange and beyond (Figure 70, displaying further work by David MacDonald and Andy Loveridge at the University of Oxford).

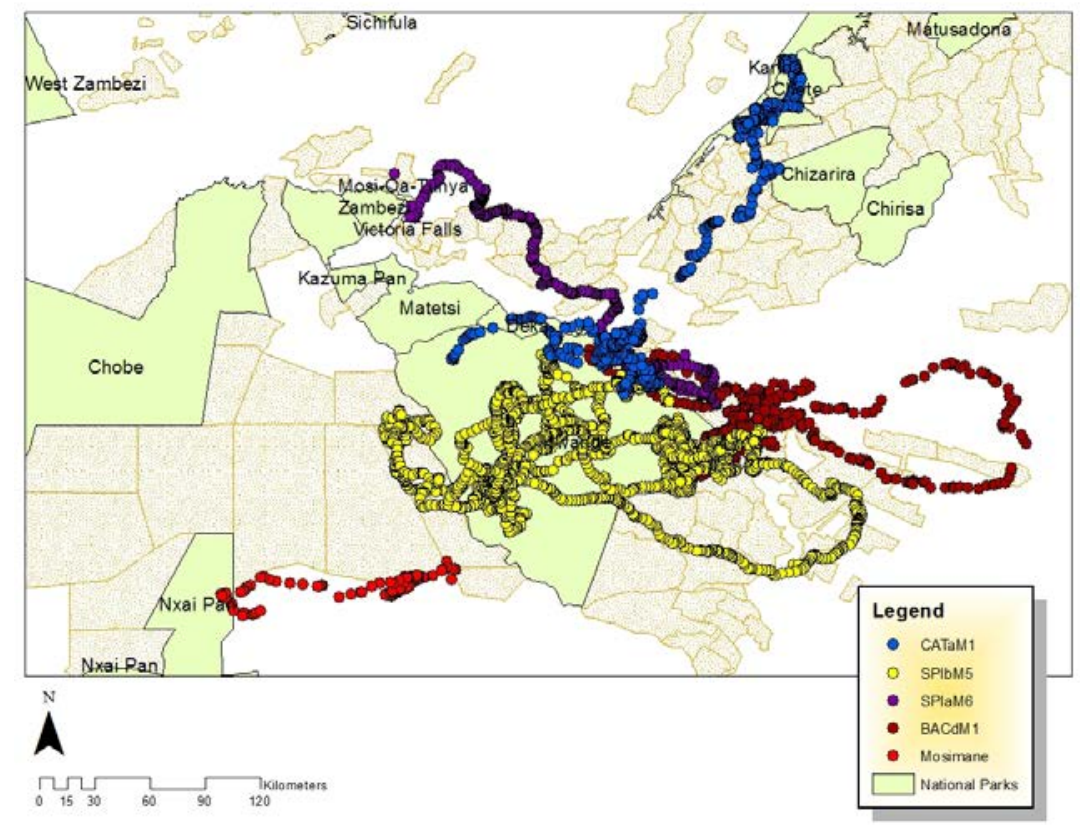

Figure 70 Long range movements of GPS collared male Lions in the region surrounding Hwange NP between 2009 and 2013 (MacDonald and Loveridge 2015) 
Wageningen Environmental Research

\section{P.O. Box 47}

6700 AA Wageningen

The Netherlands

T +31 (0)317480700

www.wur.nl/environmental-research

Wageningen Environmental Research

Report 2813

ISSN 1566-7197
The mission of Wageningen University and Research is "To explore the potential of nature to improve the quality of life". Under the banner Wageningen University \& Research, Wageningen University and the specialised research institutes of the Wageningen Research Foundation have joined forces in contributing to finding solutions to important questions in the domain of healthy food and living environment. With its roughly 30 branches, 5,000 employees and 10,000 students, Wageningen University \& Research is one of the leading organisations in its domain. The unique Wageningen approach lies in its integrated approach to issues and the collaboration between different disciplines.

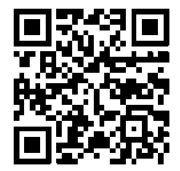




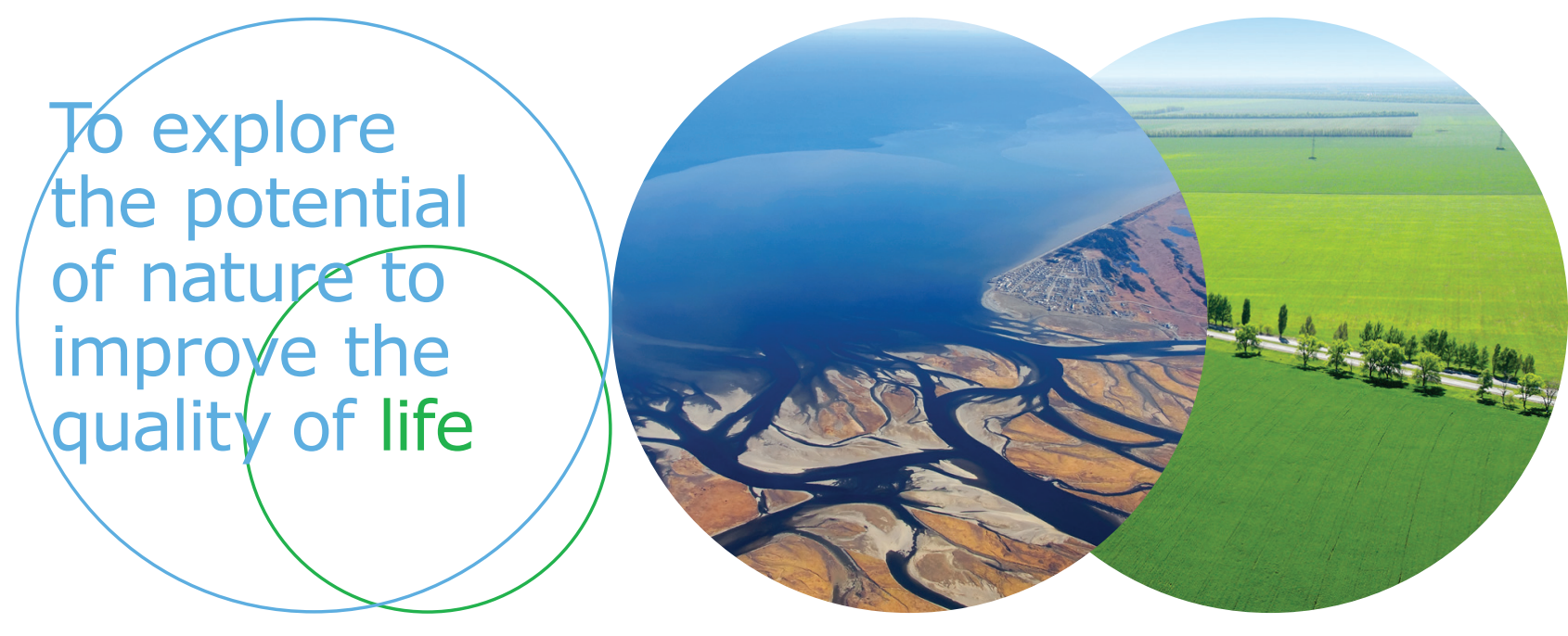

Wageningen Environmental Research P.O. Box 47

$6700 \mathrm{AB}$ Wageningen

The Netherlands

$T+31(0) 317480700$

www.wur.eu/environmental-research

Report 2813

ISSN 1566-7197
The mission of Wageningen University and Research is "To explore the potential of nature to improve the quality of life". Under the banner Wageningen University \& Research, Wageningen University and the specialised research institutes of the Wageningen Research Foundation have joined forces in contributing to inding solutions to important questions in the domain of healthy food and living environment. With its roughly 30 branches, 5,000 employees and 10,000 students, Wageningen University \& Research is one of the leading organisations in its domain. The unique Wageningen approach lies in its integrated approach to issues and the collaboration between different disciplines. 